\title{
A HANDBOOK OF PLANT TISSUE CUITURE
}

PHILIP R. WHITE 


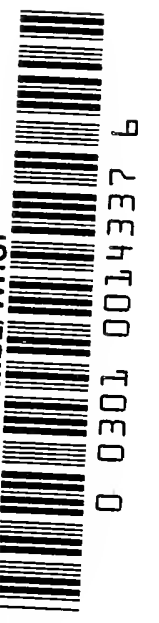




\section{A HANDBOOK OF PLANT TISSUE CULTURE}

BY

PHILIP R. WHITE, A.B., Ph.D. 
Copyright, 1943, by

The Jaques Cattell Press

PRINTED IN D. S. A.

THE SCIENCE PRESS PRINTING COMPANY LANCASTER, PENNSYLVANIA 
D E D I C A T I O N

то Henry K. White, to whom I owe a certain curiosity about the workings of nature and whose first lessons in scientific thinking and procedure are the foundation upon which all of my work has since been built,

то Mary P. White, to whom I owe patience and perseverance and what humility I may claim, to carry through the tasks at hand,

то Caroline D. White, whose inspiration and constant help have supported me at many a diffi- ' cult pass, and

тo little Christopher John and Jonathan Peter for whom, after all, all things in heaven and earth are done,

this little volume is humbly dedicated. 
"Entia non sunt multiplicandi praeter necessitatem,"

Wm. of Occam, 1270-1349. 


\section{PREFACE}

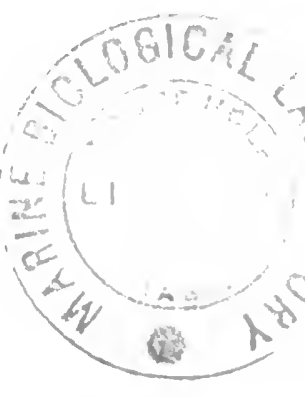

The writing of any book, and particularly one in a new and special field, should, in these days of stress and in the presence of an already staggering plethora of publication, be a matter for very serious consideration. Books are written to be read, and unless one has at least a potential public one should hesitate long and seriously about bringing out a new volume. Yet the history of Science has been from the first a history of methods, either experimental methods or methods of thought. When, therefore, a new method or a new application of older methods is developed, it behooves those who are responsible for its development to consider carefully when it has progressed far enough beyond adolescence to warrant a formal introduction in society.

Tissue Culture as a branch of animal biology has long since passed that stage and has received extended attention in the handbooks of Fischer, Erdmann, Willmer, Ephrussi, Parker, and others. Many of these handbooks carry titles conveying the impression that they treat the subject in its entirety. Yet it is in vain that one searches their pages for any but the briefest possible treatment of the cultivation of plant tissues. One might 
assume that the animal biologists had a strict monopoly on the method. This is, of course, not at all a fair picture. It is with the conviction that Tissue Culture is, in fact, the domain of all biologists and that Plant Tissue Culture has, in the last decade, developed to the point where it deserves and even demands consideration as a separate, valid, useful, and promising, if not yet fully mature, discipline, that I have undertaken the preparation of this little volume.

Having decided that the time is ripe for publication in a new field, an author must then determine the scope of his subject, the type of reader he wishes to reach, and the degree of detail which it is valuable to present. I have plamned this book as an aid to those who may actually make use of the technique-students, investigators in other fields for whom the methods presented may be useful in the solution of their own problems, and perhaps a very few who may approach the subject for its own sake. With this in mind, I have tried to keep the presentation as simple and concise as seemed compatible with completeness and lucidity and have used, wherever possible, photographs and drawings in place of long descriptions. I have not attempted an inclusive survey of the field in all its past and present ramifications but have concentrated on those matters which may suggest to the student new fields of conquest and provide him with the basic information and the techniques 
necessary to an intelligent approach to those fields. Most of the techniques described are those developed and perfected in my own laboratory, but I have tried also to provide a working outline of other techniques and methods of approach.

One does not prepare a book, even a small one, alone. I should like especially to acknowledge the help of Professor Edmund Sinnott of Yale, Professor George Avery and Miss Bethe Anderson of Connecticut College, Dr. Esther Carpenter of Smith College, Dr. and Mrs. Warren Lewis of the Carnegie Institution, Dr. Frank Thone of Science Service, and Harriet Butler Bunker of Dummerston, Vermont, all of whom examined the early plan, read and criticized the preliminary drafts of the manuscript, made many helpful criticisms and suggestions, and gave me their unstinted encouragement throughout the task. I should like also to express my gratitude to Professor Gottlieb Haberlandt, Dr. Ross Harrison, Dr. Alexis Carrel, Dr. and Mrs. Warren Lewis, Dr. Walter Kotte, and Dr. Roger Gautheret for permission to use their portraits. These will, I hope, add greatly to the living quality of the book. Dr. Gautheret in particular deserves my deepest gratitude for the difficulties and perhaps danger which he overcame in sending me his picture and biography out of war-ridden Paris. I sincerely regret that Dr. W. J. Robbins preferred to have his portrait omitted from the series. The illustrations, with 
the exception of these portraits and of figures 1, $2,3,4,14,15,35,39$, and 64 , are all from my own laboratory and were photographed or drawn by Mr. Julian A. Carlile whose competent help has certainly greatly enhanced whatever value the book may have. My sincere thanks are due him and other members of the technical staff of the Rockefeller Institute for their unfailing cooperation. I should like to thank Dr. James Bonner for the photographs used in figure 35 and John Wiley and Sons for permission to republish figure 22 , the original of which I furnished them in 1937. Pictures taken from periodicals and from older books carry their acknowledgments in the text. The bibliography at the end of the book is intended to cover the major contributions in the field of Plant Tissue Cultures and to contain in addition some collateral material from related fields sufficient to suggest to the reader possible interrelations. Corrections, suggestions, and criticisms will, of course, be welcomed.

With this brief introduction, I turn my offspring over to the good graces of a critical and exacting, but I trust understanding, public.

Princeton, New Jersey,

September, 1942. 


\section{TABLE OF CONTENTS}

Chapter I. Introduction ........................................... 1

Chapter II. The History of Plant Tissue Culture 19

Chapter III. The Living Materials ................................ 43

Chapter IV. The Laboratory ................................. 67

Chapter V. Nutrients .................................................... 90

Chapter VI. How Cultures Are Started ........................ 117

Chapter VII. Culture Techniques ..................................... 131

Chapter VIII. Growth Measurements and Their Interpretation ............................................................... 154

Chapter IX. Tissue Culture and the Study of Problems in the Pathology and General Physiology of Plants ........................................................ 183

Chapter X. Morphogenesis .................................................. 209

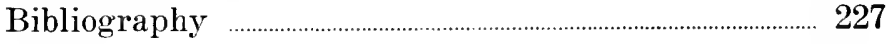

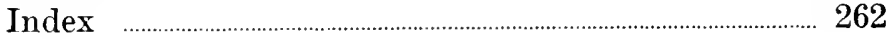





\section{LIST OF ILLUSTRATIONS}

PAGE

Fig. 1. Polarity in regeneration of cut tubers of Corydalis solida

Fig. 2. Retention of specific eharacteristics by grafts of fruits of three varieties of gourds

Fig. 3. Retention of specific characteristics by grafts between two species of tadpoles

Fig. 4. Production of lens by grafted belly epithelium of a toad, under induction from the eye-cup of a frog 15

Fig. 5. Gottlieb Haberlandt .................................................................... 16

Fig. 6. Ross G. Harrison ........................................................................ 23

Fig. 7. Warren H. Lewis ........................................................................... 24

Fig. 8. Margaret R. (Mrs. Warren H.) Lewis ............................ 25

Fig. 9. Alexis Carrel ................................................................................. 26

Fig. 10. W. Kotte ................................................................................................ $\quad 37$

Fig. 11. R. J. Gautheret .............................................................................. 38

Fig. 12. Philip R. White ................................................................. 39

Fig. 13. Roots of tomato, white clover, and red clover ............... 40

Fig. 14. Section of seed of Peperomia hispidula ………............... 46

Fig. 15. Undifferentiated embryo of Peperomia hispidula ..... 47

Fig. 16. Leaves regenerated on root of dandelion ........................... 51

Fig. 17. Cultures of sunflower tissues .................................................... 52

Fig. 18. Cultures of Nicotiana eallus ...................................................... 53

Fig. 19. Cultures of bacteria-free crown-gall tissues of sunflower ...................................................................................................... 53

Fig. 20. Young embryo of Portulaca oleracea ……………............ 54

Fig. 21. Root cap on root of white clover …….................................. 61

Fig. 22. Root-hairs on growing excised tomato root ...................... 62

Fig. 23. Root-liairs on growing excised buckwheat root .............. 63

Fig. 24. Growing excised roots of tomato and buckwheat :........ 64

Fig. 25. Plan of a laboratory suite ........................................................... 68

Fig. 26. Week by week increment rates of excised roots over eight years 
Fig. 27. Diagram of special pierced slide for hanging-drop cultures

Fig. 28. Implements commonly used in plant tissue culture work

Fig. 29. Equipment for preparing and transferring cultures 86

Fig. 30. Procedure of eutting roots within flasks .......................... 87

Fig. 31. Distributing nutrient to flasks ......................................... 87

Fig. 32. Method of obtaining sterile adventitious roots ............. 88

Fig. 33. Exeising adventitious roots from cuttings ...................... 88

Fig. 34. Method of obtaining uniform stocks of root tips ........ 113

Fig. 35. Bean pod segments used in testing wound stimulants 114

Fig. 36. Removing blocks of eambium from large trees ............. 115

Fig. 37. Procedure in making eultures of eambium …………….. 115

Fig. 38. Cambium culture of Salix caproea …................................ 116

Fig. 39. Surface of eambial cultures of Abics pectinata ........... 127

Fig. 40. Measuring a root within the enlture flask ……................. 128

Fig. 41. Sample pages from a book of records ………................. 129

Fig. 42. Equipment used in making langing-drop cultures ..... 130

Fig. 43. Average daily inerement rates of 1000 roots during one week in vitro .................................................................... 141

Fig. 44. Effects of temperature ou growth rates of tomato roots

Fig. 45. Example of a line graph recording daily march of inerements of exeised roots

Fig. 46. Example of a histogram reeording effects of nutrient variables on growth

Fig. 47. Example of an isopleth diagram showing the effects of two simultaneous variables

Fig. 48. Tomato root showing gross effect of indole aectic

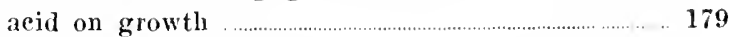

Fig. 49. Effects of iron concentration on root growth ............... 180

Fig. 50. Effects of iron coneentration on root growth ............... 181

Fig. 51. Detail of the effects of indole acetie acid on cells of an excised root

Fig. 52. Graph slowing effects of indole acetie acid on growth rates

Fig. 53. Graph of rates of water seeretion (root pressure) in exeised toniato roots 
Fig. 54. Developmental cycle of plastids in cells of Stellaria media

Fig. 55. Region of maturation of excised tomato root 195

Fig. 56. Manometer for measuring root pressure 196

Fig. 57. Manometer assembly, detail 197

Fig. 58. A battery of manometers with attached pressure equipment

Fig. 59. Titration of distribution of aucuba-mosaic virus in a tomato root

Fig. 60. Tyrosinase distribution in an excised tomato root ..... 205

Fig. 61. Hyperhydric enlargement of cells of seed primordia of Antirrhinum

Fig. 62. Meristematic cells in Nicotiana callus culture

Fig. 63. Scalariform cells in Nicotiana callus eulture... 207

Fig. 64. In vitro grafts of cambium cultures 208

Fig. 65. Cross section of a Nicotiana callus culture 213

Fig. 66. Detail from figure 65 214

Fig. 67. Disorganized vascular tissue from a sunflower tumor tissue culture 216

Fig. 68. Formation of stem growing point on a Nicotiana callus culture

Fig. 69. Section showing Nicotiana callus cultivated in a rabbit's eye

Fig. 70. Detail from figure 69 225

Fig. 71. Effect of aeration on differentiation of a Nicotiana callus culture 
"Man kann sich also folgende zwei Vorstellungen von der Ursache der organischen Erscheinungen, des Wachstum usw. machen: Erstens die Ursache liegt in der Totalität des Organismus. . . Die andere Erklärungsweise ist die: Das Wachstum geschiebt nicht durch eine im ganzen Organismus begrïndete Kraft, sondern jeder einzelne Elementarteil besitzt eine selbständige Kraft, ein selbständiges Leben. . . .

"Wir haben gesehen, dass alle Organismen aus wesentlich gleichen Teilen, nämlich aus Zellen zusammengesetzt sind, dass diese Zellen nach wesentlich denselben Gesetzen sich bilden und wachsen, dass also diese Prozesse überall auch durch dieselben Kräfte hervorgebracht werden müssen. Finden wir nun, dass einzelne dieser Elementarteile, die sich von den übrigen nicht unterscheiden, sich vom Organismus lostrennen und selbständig weiter wachsen können, so können wir daraus schliessen, dass auch jeder der übrigen Elementarteile, jede Zelle für sich schon die Kraft besitzt, neue Moleküle anzuziehen und zu wachsen, dass also jeder Elementarteile eine eigentiimliche Kraft, ein selbständiges Leben besitzt vermöge dessen er selbständig sich zu entwickeln imstande wäre, wenn ihm bloss die äusseren Bedingungen dargeboten würden, unter welchen er im Organismus steht. Solche selbständig, getrennt vom Organismus wachsende Zellen sind z. B. die Eier der Tiere. . . Bei niederen P'flanzen kann sich jede beliebige Zelle von der Pflanze lostrennen und dann selbständig weiter wachsen. Hier bestehen also ganze Pflanzen aus Zellen, deren selbständiges Leben unmittelbar nachweisen lässt. Da nun alle Zellen nach denselben Gesetzen wachsen, also nicht in einem Falle der Grund des Wachstum in der Zelle selbst, im andern Falle im ganzen organismus liegen kamn, da sich ferner nachweisen lässt, dass einzelne, von den übrigen in der Art des Wachstums nicht verschiedene Zellen selbständig sich entwickeln, so müssen wir iberbaupt den Zellen ein selbständiges Leben zuschreiben. . . . Dass nicht wirklich jede einzelne Zelle, wenn sie von einem Organismus getrenut wird, weiter wächst, ist gegen diese Theorie so wenig ein Einwurf, als es ein Einwurf gegen das selbständige Leben einer Biene ist, wenn sie getrennt von ihrem schwarm auf die Dauer nicht fortbestehen kann."

"One can thus construct the following two hypotheses concerning the origin of organic phenomena such as growth: either this origin is a function of the organism as a whole, or growth does not take place by means of any force residing in the entire organism but each elementary part possesses an individual force, a separate life.

"We have seen that all organisms consist of essentially like parts, the cells; that these cells are formed and grow according to essentially the same laws; that these processes are thus everywlere the result of the same forces. If, therefore, we find that some of these elementary parts, which do not differ from others, are capable of being separated from the organism and of continuing to grow independently, we can conclude that each of the other elementary parts, each cell, must possess the capacity to gather new molecules to itself and to grow, that therefore each cell possesses a particular force, an independent life, as a result of which it too wonld be capable of developing independently if ouly there be provided the external conditions under which it exists in the organism. The eggs of animals are in fact such cells, eapable of living separated from the orginism. Among the lower plants any cell call be separated from the plant and continue to grow. Thus, entire plants may consist of fells whose capacity for independent life ean be clearly demonstrated. Now, since all cells grow aceording to the same laws so that it is not possible that in one case the cause of growth lies in the cell itself while in another ease it lies in the entire organism, and since moreover it ean be demonstrated that single cells whose growth does not diffor from that of other cells call develop independently, we must therefore ascribe an indevendent life to the cell as such. That not every cell, when separated from the organism does in faet grow is no more an argument against this theory than is the fact that a bee soon dies when separated from its swarm, a valid argument against the individual life of the bee."

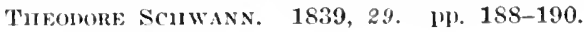




\section{Chapter I}

\section{INTRODUCTION}

In the whole gamut of human thought, there is perhaps no question that crops up more frequently in one form or another than that which asks "By what means do the myriads of different forms and processes which we see in the Universe around us come into being, what controls them within normal metes and bounds, and how does it come about that those 'normal' bounds are occasionally transcended, so often with disastrous results? What is it that brings about and maintains the extraordinary harmony which we usually find in Nature, yet from time to time alters that harmony by what appear to us to be transgressions?" If we knew the full answers to the multitudinous variants of this question, there would be very little left worth inquiring about.

For this question does have a multitude of variants. It is asked at all sorts of different levels of human experience. At the cosmic level it becomes the question of creation itself. The psychologist asks it at the level of human thought 
and behavior. The sociologist asks it at the level of races and nations, tribes, sects, and societies. The chemist asks it at the level of "substances", and the physicist at the level of material bodies great or small, be they galaxies or particles of light. The geneticist and taxonomist ask it concerning the segregation and delimitation of characters of related organisms. With regard to single organisms, we ask "How is it that the size, form, texture, rate of development, function of the various parts are determined and limited? Why does an anterior limb-bud give rise to a hand while a posterior limb-bud gives rise to a foot? Why does a cell of a given type, when chance places it in one region of the body, become an element of the glandular epithelium of the kidney, while in another part of the body the same type of cell appears as a constituent of the iris? Why does the sub-epidermal cell of a foliar leaf become a center of food synthesis, while in a floral leaf it becomes a megaspore-mother-cell with a reproductive function? Why do the cells surrounding a wound in a "normal" individual take part in an orderly granulation, closing the wound, forming well-limited scar tissue, organizing a harmonious replacement of the injured regions, while in an individual carrying a cancer, even at some distant part of the body, cells of the same region may 
be detonated into an explosive, disordered, disharmonious, and ultimately self-destroying overgrowth?" The factors which control these characteristics of size, form, function, and rate of development of living organisms, which maintain at all times the proper balance among their parts, and which, when disturbed, result in creatures of abnormal type, constitute the materials of that important branch of biological science which we call "morphogenesis."

Science progresses in five main steps. First, there is the observation of more or less evident facts, their codification and analysis. Second, there is the formulation of ideas and principles based on these facts and their arrangement into working hypotheses. Third, there is the development of techniques for the testing of these hypotheses. Fourth, there is the acquiring through use of these techniques of pertinent but less evident information, the verification, modification, and refinement of these hypotheses, until they themselves become facts. And fifth, there is the integration of these latterly acquired larger facts into the general picture. In the study of living' or'ganisms, one of the early observed "facts" was the ubiquity of those units which we call cells. Information about cells, acquired by general observation, very early led to the formulation of the 
fundamental hypothesis of the so-called "cell theory," promulgated a century ago in the words which are set at the head of this chapter (Schwann, 1839,29, , that all cells are essentially elementary organisms, theoretically alike and capable of autonomous existence. But there is an alternative hypothesis which also rests upon a considerable mass of observed facts, namely, that somewhere in the developmental history of an organism its constituent cells cease to be totipotent, by segregation and loss of certain functions. No mechanism is known by which such segregation or loss can take place, yet it so often appears to have taken place that this alternative hypothesis has today many adherents.

If all cells of an organism are essentially alike and, within the genetic pattern, totipotent, then the differences in behavior of cells of a given type in different situations in the body must result from the interrelations of these cells with their environments and with other cells in the organism. It should be possible to restore suppressed functions by isolating the cell from those external influences which were responsible for the suppression. If, on the other hand, there has been a true segregation and loss of function so that the cells are, in the mature organism, no longer totipotent,

* Italic numbers refer to bibliography. 
then no modification of a given cell-line's environment could hope to restore the lost functions. It is clear that a decision between these two alternative hypotheses is essential to any valid notion of the origin of form and function. And it is also clear that one of the most promising techniques for arriving at such a decision lies in the segregation of cells, tissues, and organs from the associated members of the body and their maintenance and study as isolated units, under as nearly optimal and as fully controlled conditions as possible. The attempt to reduce an organism to its constituent cells and to study these cells as elementary organisms is thus a project of fundamental importance in the solution of basic biological questions.

Schleiden (1838, 27) and Schwann (1839, 29), who formulated the concept of cellular totipotency, and Virchow $(1858,433)$, who popularized that concept, made no attempt to put it to experimental test. A half century elapsed between its formulation and the first well-organized experimental study of the question. In the 1870's, several workers attacked the problem, no one with more lucidity and patience than Vöchting. Vöchting chose two methods of approach. First, he dissected plants into smaller and smaller fragments, studying the phenomena of polarity in these fragments. He found "polarity" to be a character- 
istic of every fragment, irrespective of size, and hence by implication of the individual cells (1878, $329,1884,329)$. Thus, the distal portion of a stem or piece of stem always produced leaves and the proximal portion roots, but whether a given cell

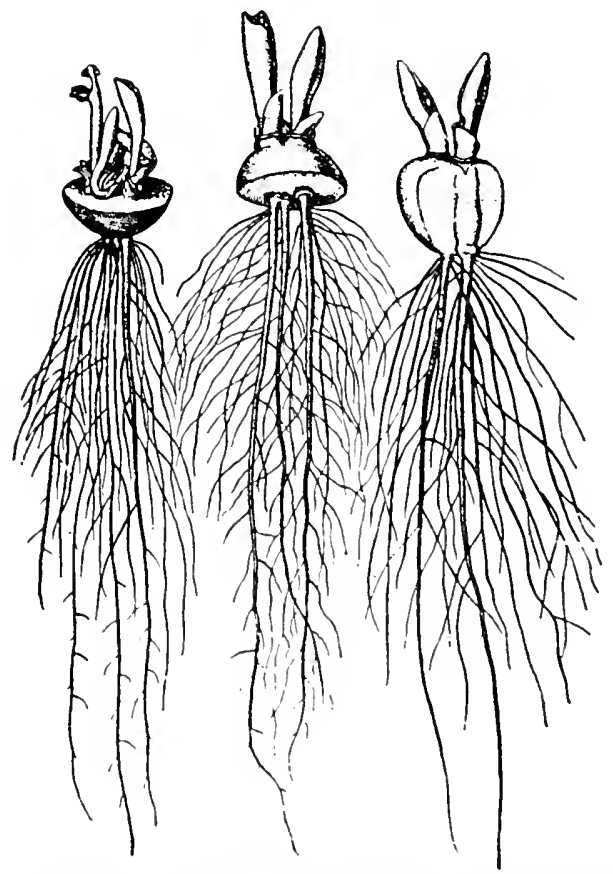

Fia. 1. Tubers of Corydalis solida, cut and allowed to regenerate. The tissues at the eenter of the tuber form leaves (left), roots (center), or merely wound eallus (right), depending on the spatial orientation of the eut, showing the depentence of morphogenetic expression on fortutous external factors. (From Goebel, K. 1908. Winleitung in die experimentelle Morphologie der Pflanzen. 220, fig. 111, 293.) 
produced leaves or roots depended on that cell's fortuitous position, whether distal to or proximal to the nearest cut surface or uninjured growing point. If a three-foot piece of willow was left intact, the distal foot of stem would produce only roots, but if a six-inch piece was isolated from the distal end of such a stem either by removal or merely by severing the bark, the proximal three inches of this piece would produce leaves instead of roots. Later observations by von Goebel (1908, 293) (Fig. 1) Schwanitz (1935, 323) and others led to similar conclusions. Here the morphogenetic pattern was a function of the "organism as a whole" (considering here the autonomous fragment as the organism), of the relationships of cell to cell within the particular tissue continuum. The cell appeared to be totipotent, its actual expressed function being a resultant of the influences coming from outside. Vöchting's second approach involved the age-old method of grafting (Fig. 2) or transplantation (1892, 330, 1894, 331) and merely confirmed what had been known from time immemorial, that no matter what the environment or host into which a scion was transplanted, it always developed in a given pattern which was fixed by the species from which it came. Not only was the developmental pattern fixed, but the physiological behavior was also fixed by the spe- 
cies and could not be altered by contact with or even dependence on the tissues of another species (Vöchting, 1894, 331). The transplantation experiments demonstrated the restrictions which species places on the potencies of a cell. The dissection experiments demonstrated the essential totipotency of the cell within these species limitations. Similar conclusions may be drawn from experiments with animal materials (Figs. 3, 4).

To carry this method of dissection to its logical end, we would have to go to the cells themselves, as we have already said. Implicit in Schleiden and Schwann's concept, subjected to a preliminary pragmatic test by Vöchting, this idea seems nevertheless not to have been explicitly formulated as a basis for planning experiments with either plant or animal materials until much later. In the early years of the present century, Haberlandt (1902, 98) (Fig. 5) set forth the principle frankly and lucidly in the words that I have placed at the head of Chapter II. He then proceeded methodically to fill the gap in our knowledge, the existence of which he had called to our attention. He set out to grow cells and small groups of cells in suitable nutrients and to study their behavior. The discipline which Inaberlandt thus outlined is that which, in the four decades since his paper, has gradually crystallized into what we know today 
as "tissue cultures." (See Harrison, 1928, 18). (See also references 1-41.)

But it is not always given to one individual both to formulate the broad outlines of a new technique and to put that technique into actual practice. Haberlandt was faced at the start with a series of major difficulties inherent in plant anatomy and morphogenesis which it has actually taken workers a third of a century to learn to overcome. These difficulties are chiefly three. In the first place, most cells of a plant are not bathed in any free, complete nutrient medium. The xylem sap lacks many of the organic constituents needed to maintain life. The phloem sap is in direct contact with only a very few specialized cells. Most plant cells must obtain a large part of their nutriment by diffusion through neighboring cells. There is no "natural" nutrient which can be extracted from a plant and used for the cultivation of its cells and for subsequent analysis. In the second place, most plant cells, with rare exceptions, are surrounded by a rigid pellicle. This prevents the cells from seeking and engulfing food, thus greatly restricting the forms of food which they can use. It prevents their adhering satisfactorily to any solid substratum. And, since excision involves rupturing this pellicle and exposing the protoplast naked to the surrounding 
medium in a way that seldom occurs in nature, it greatly increases the shock which any cell must inevitably suffer in the process of removing it from the body. In the third place, "growth," in the plant, is normally restricted to a few specialized regions of the body, leaving all other parts in an essentially inert condition, as far as capacity for continued cell multiplication is concerned, and greatly restricting the experimenter in his choice of materials. As a result of these difficulties, although the problem has been investigated by a considerable number of workers, more than 30 years elapsed between Haberlandt's formulation of the tissue culture concept and the first really successful experiments with plant tissue cultures.

Fortunately for the development of the field as a whole, however, animal tissues present none of the above-named difficulties, at least to anything like a comparable degree. In the first place, animal cells throughout the body are regularly bathed in one or both of two characteristic and essentially complete nutrient fluids, the blood and lymph. These can be easily removed from the body in large quantity. They serve as basic "natural" nutrients for animal cells in which such cells can be immersed without serious shock. They can be analyzed at leisure to determine which of their constituents are truly essential. In the second 
place, animal cells are for the most part surrounded by a tough but mobile pellicle in place of the rigid pellicle of the plant cell. Animal cells can therefore be removed from the body with a minimum of shock. Anyone who has worked with both types will appreciate this difference. Animal cells adhere well to a variety of solid substrata. They are capable of autonomous movement and phagocytosis, so that they can be fed on relatively complex nutrient materials which they themselves transform into constituents which can pass readily into the protoplasts. And finally, "growth" of the animal body regularly takes place in all parts of the body and, in the sense of replacement, throughout the life of the animal. There is thus comparatively little obvious restriction placed on the experimenter in choosing favorable materials for cultivation. These facts have largely affected the progress of tissue cultures in the two living kingdoms and are responsible for the early success in the animal field. Plant tissue cultures have only within the last half decade reached anything like a comparable position.

\section{Summary}

The question of the origin of form and function in our Universe is one of the most fundamental problems to the solution of which man has set his 
intellect. As regards living organisms, this problem embraces everything that we include under the name of "morphogenesis." Since the cell is theoretically the ultimate unit of structure in living organisms, the question of the origin of form and function in living beings may be stated thus: "Are the factors which determine these characteristics external to the individual cell (in which case the cell is totipotent but its particular expression comes about through a potentially reversible suppression of some of its potencies due to its spatial association with other cells), or are they internal, in the individual cell (in which case the cell is obviously not totipotent but has lost some of its potencies at some point in the sequence of events which constitute its temporal association with other cells)?" One method of deciding between these two possibilities lies in the isolation and cultivation of individual cells as separate units or elementary organisms. The technique of isolating and studying cells in this way has, in the last four decades, become established as the technique of "tissue culture.", 


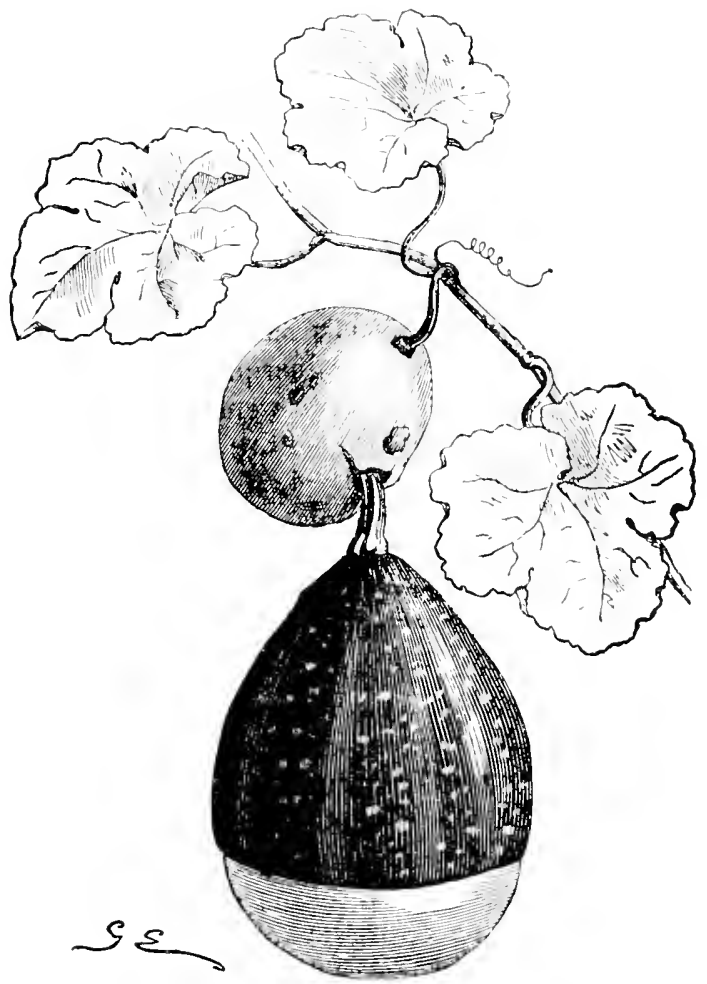

Fig. 2. Ovary segments of thres varioties of gourds (it fruits james, ahove: poire verte, center: à fruits blanes, below) grafted together. Each variety retains its specific characteristies, although in intinate anatomieal and physologieal contalet with the tissues of other varieties. The portion à fruits blanes must oletain all its nutriment through the tissues of two other varieties, yet remains maffected by this fart. The dependence of morphogenetic capactty on strictly leveditary internal tactors is clearly shown. (From Carriere, E. A. 1875. Rev. Horticole 1875: 14-16, 278.) 

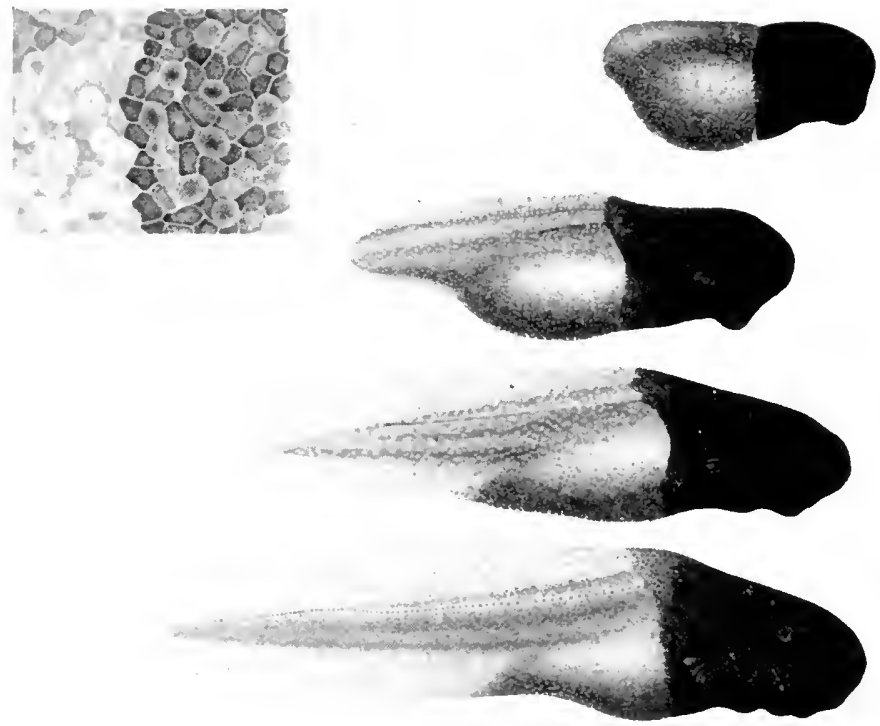

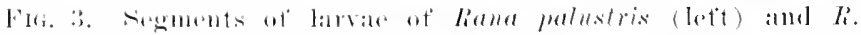
syleation (right) having different pigmentation, eratted togethere

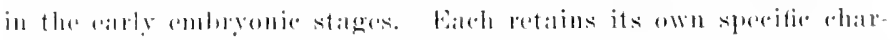

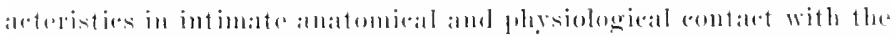

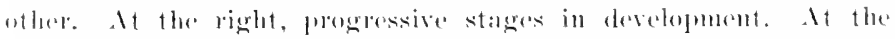

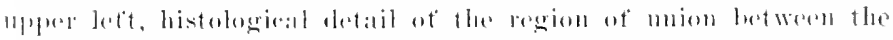

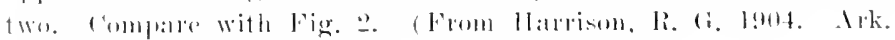

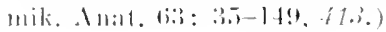




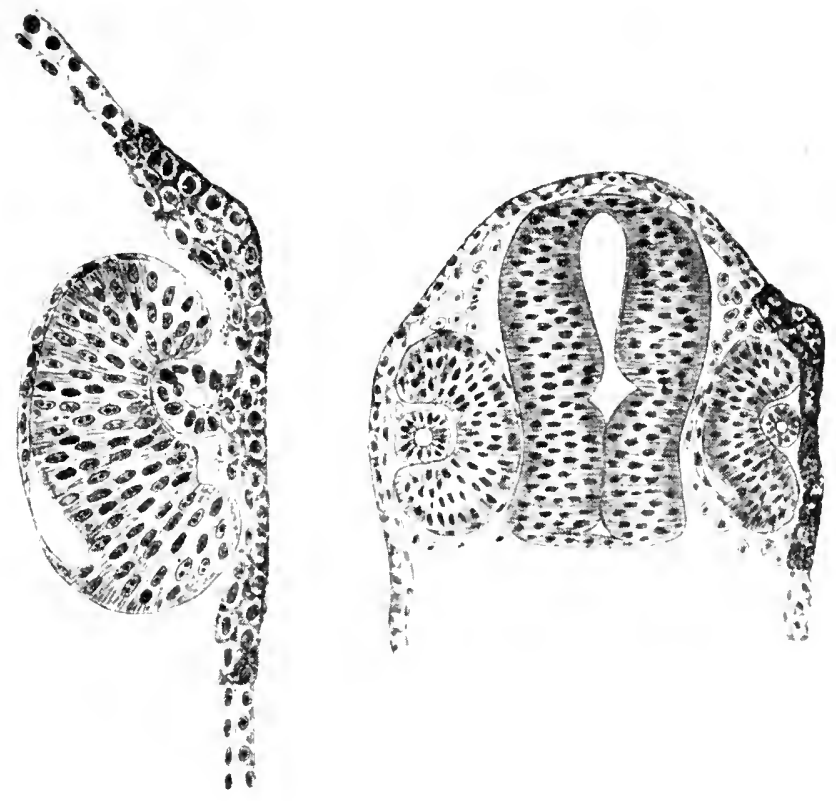

Fig. 4. Results ot grafting belly epithelium from a toin emhero (Bufo rulgaris) onte the eye region of an embryo of a frog

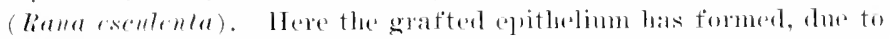

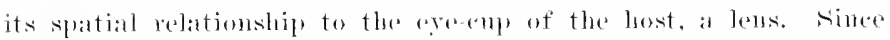

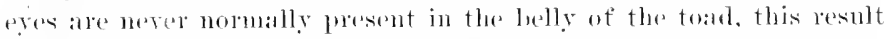
shows that Jully epithelium possesses a poteney (the lems forming potency) which, while nevel nomally expersed, wan he evoked by

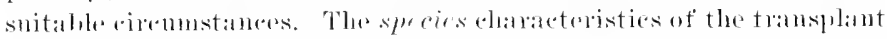
(molanotic figmentation) mmain determined by the somree, lont the morphological chatarteristies have been detomined by the bost. At the right, eross secotion of entire lesal region. At the left, detail of the right hand ege showing the transplant. (Frem Filatow, I).

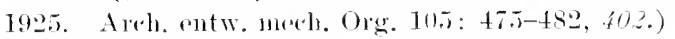



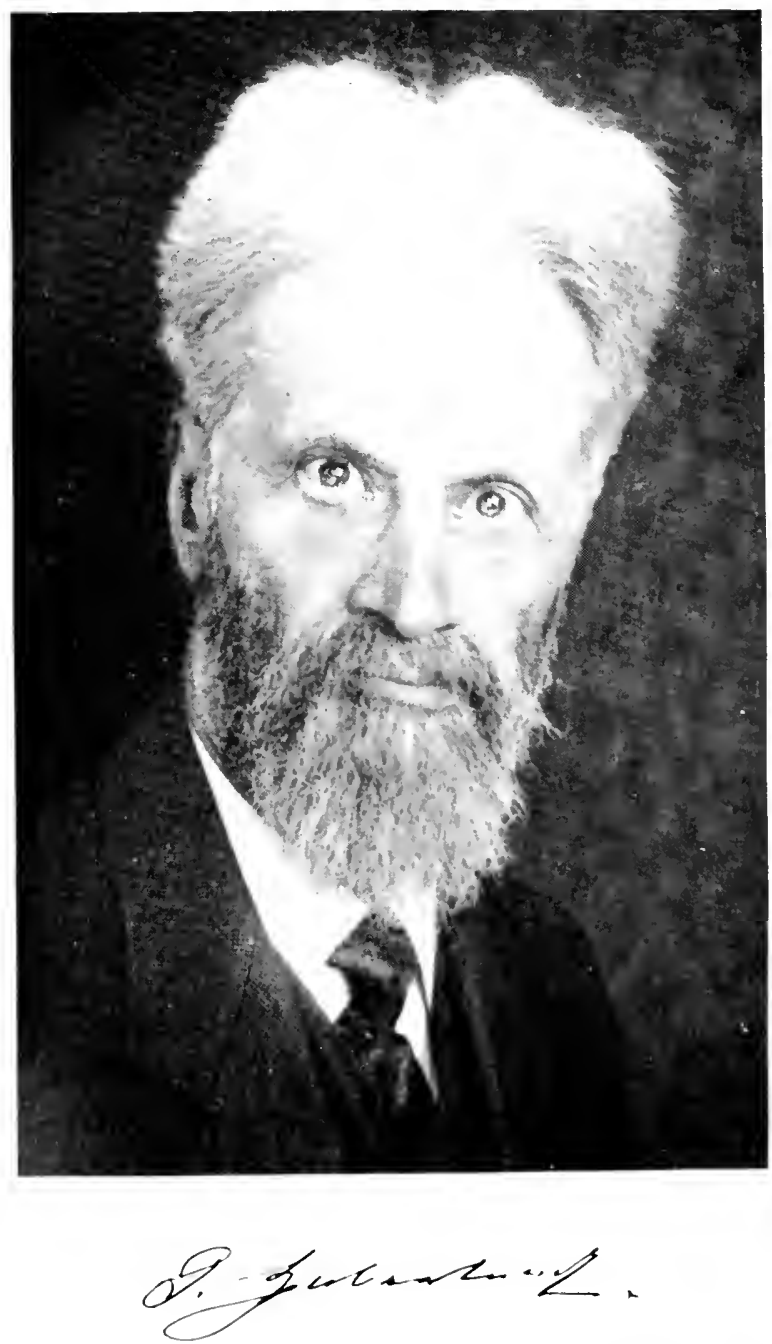

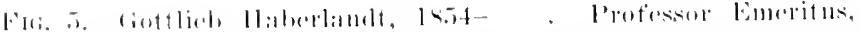

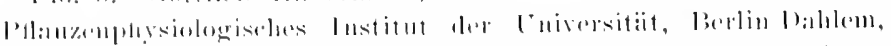

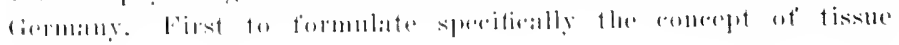
roltures. 
"Ws sind meines Wissens nach bisher noch keine planmässig angelegten Versuche gemacht worden, isolierte vegetative Zellen von höher entwickelten Pflanzen in geeigneten Nährlösungen zu kultivieren. Und doch müssten die Ergebnisse solcher Kulturversuche manches interessante Streiflicht auf die Eigenschaften und Fäligkeiten werfen die die Zelle als Elementarorganismus in sich birgt: sie muissten Aufschliisse bringen iiber die Wechselbeziehungen und gegenseitigen Beeinflussungeu denen die Zellen innerhalb des vielzelligen Gesamtorganismus ausgesetzt sind."

"There has been, so far as I know, up to the present, no planned attempt to cultivate the vegetative cells of higher plants in suitable nutrients. Yet the results of such attempts should cast many interesting sidelights on the peculiarities and capacities which the cell, as an elementary organism, possesses: they should make possible conclusions as to the interrelations and reciprocal influences to which the cell is subjected within the multicellular organism."

G. Haberlandt. 1902, 98 . p. 69. 


\section{Chapter II}

\section{THE HISTORY OF PLANT TISSUE CULTURE}

The science of plant tissue cultures has had a long but tenuous history. It would be difficult to assign an exact date for the "first step" in its development. Certainly, as we have seen, the idea of cultivating fragments of plants was implicit in much that was done in the 19 th century. Rechinger, in 1893, 108, seems to have been the first to investigate experimentally the "minimum limit" of divisibility of plant parts, using isolated buds of Populus nigra, Fraxinus Ornus, roots of Beta vulgaris, Brassica rapa, sections of stems of Pothos celatocaulis, Coleus arifolia, and many other materials. He concluded that pieces less than $20 \mathrm{~mm}$. thick would only rarely regenerate entire plants and that some vascular tissue must be included in the fragments cultivated. But in this work he used no nutrient solutions, "growing", his cultures on sand moistened with tap water. These were scarcely "tissue cultures" in any real sense. 
A decade later, as we have seen, the real problem was clearly formulated for the first time by Haberlandt (1902, 98) (Fig. 5). Where Rechinger had sought to determine the limits of divisibility of plant materials, Haberlandt boldly took his point of departure directly from the cell theory and assumed that down to the cell level there were no limits of divisibility. He, therefore, chose to work with single cells, an aim which we now look upon as an elusive and as yet unattained ideal. Further, Haberlandt fully appreciated the importance of the photosynthetic process to all living material and consequently conceived the idea that, since most plants contain green cells, by cultivating these particular cells the necessity for providing carbohydrate in the nutrient would be eliminated and the problem of technique simplified. In this he apparently lost sight of the fact that green cells are, for the most part, relatively mature and highly differentiated cells which have, to a great extent, lost their meristematic functions. This "simplification" led him to work with palisade cells of Lamium, pith cells from the petioles of Eichhornia crassipes, glandular hairs of Pulmonaria, stamen hairs of Tradescantia, stinging hairs of Urtica, stomatal guard cells of Ornithogalum, and many other similar materials. The results were, without exception, disappointing 
and the attempt to attack the problem directly was regretfully abandoned for another decade with the remark that

"Jedenfalls dürfte die Methode der Züchtung isolierter Pflanzenzellen in Nährlösungen verschiedene wichtige Probleme von einer neuen Seite her der experimentellen Bearbeitung zugänglich machen."'
"At any rate, the method of eultivating isolated plant cells in nutrient solution should make possible the experimental study of many important problems from a new point of view." (1902, 98)

Haberlandt turned to an indirect approach, that of the study of wound healing (1913, 294, 1914, 295, 1919, 245, 296, 1920, 297, 1921, 354, 1922, 355), and has never returned to the original problem.

It was during this unfruitful first decade of the 20 th century that the sister science of animal tissue cultures saw its initiation and greatest development. Harrison (Fig. 6) in 1907 succeeded in settling an old controversy by just the methods suggested by Haberlandt, when he cultivated the neuroblast of the frog in clotted lymph (1907, 131, 1908, 132, 1910, 414). He followed the presentation of his experimental results with a brilliant exposé of the possibilities of this method of approach. Two years later Burrows studied with Harrison, subsequently joined Carrel, and together these two established the present-day method of cultivating excised animal tissues in a nutrient made up of blood plasma and embryo 
juice or their equivalents (Burrows, 1910, 117, 118, 1911, 119; Carrel, 1911, 120, 1912, 121-125, 1913, 190; Carrel and Burrows, 1910, 128). The method outlined in 1913 by Carrel (Fig. 9) has changed only in minor details since that date.

Carrel and Burrows' method of cultivating animal cells in a blood-plasma embryo-juice nutrient, while relatively simple and easily duplicable, has not led to any exact knowledge of the nutrient requirements of such cells and tissues. Blood plasma and embryo juice are organic complexes of unknown constitution, and such attempts as have been made to elucidate their makeup have not been especially successful (Baker, 1929, 233, 1933, 183 ; Baker and Carrel, 1925, 195, 1926, 184, 185, 1927, 186, 1928, 187-189; Carrel and Baker, 1926, 191 ; Ebeling, 1921, 192 ; Fischer and Demuth, 1928, 19.4). Nor have the attempts at a synthesis of a nutrient, led by Dr. and Mrs. Warren H. Lewis (Figs. 7, 8) in this country and Dr. A. H. Drew in England been much more successful in eliminating the unknowns (Baker, 1936, 23.4; Drew, 1922, 1.45, 1923, 146 ; M. R. Lewis, 1916, 148 ; M. R. and W. H. Lewis, 1911, 149-151, 1912, 152, 153 ; W. H. Lewis, 1921, 15.4, 1923, 155, 1929, 156; Vogelaar and Erlichmam, 1933, 162, 1934, 163, 164, 1936, 235, $1937,236,1939,165)$. The cultivation of animal tissues is still an empirical science. 
The II istory of I'lant Tissue Culture
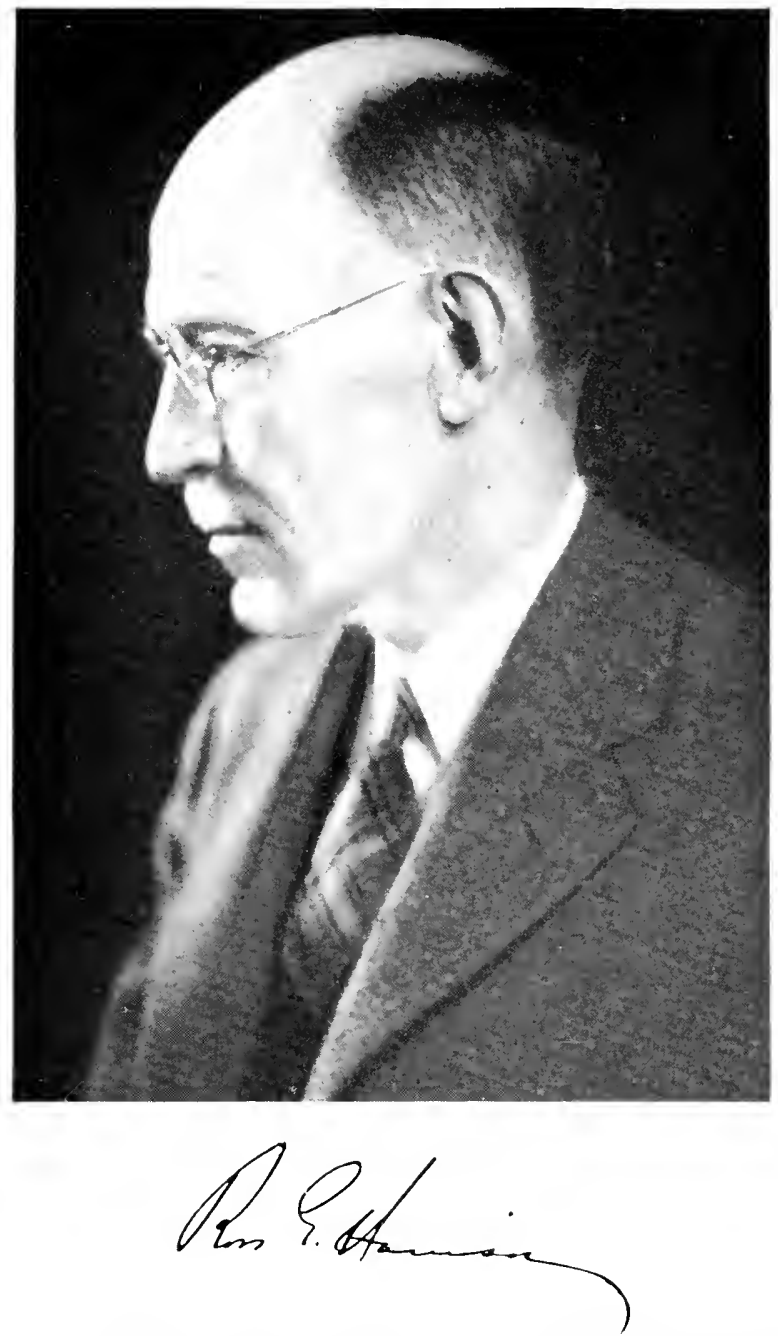

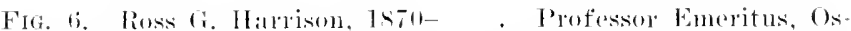

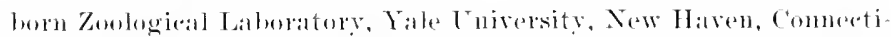
rut. First to carry out suceessful cenlt ures ot excised animal tissmes. 


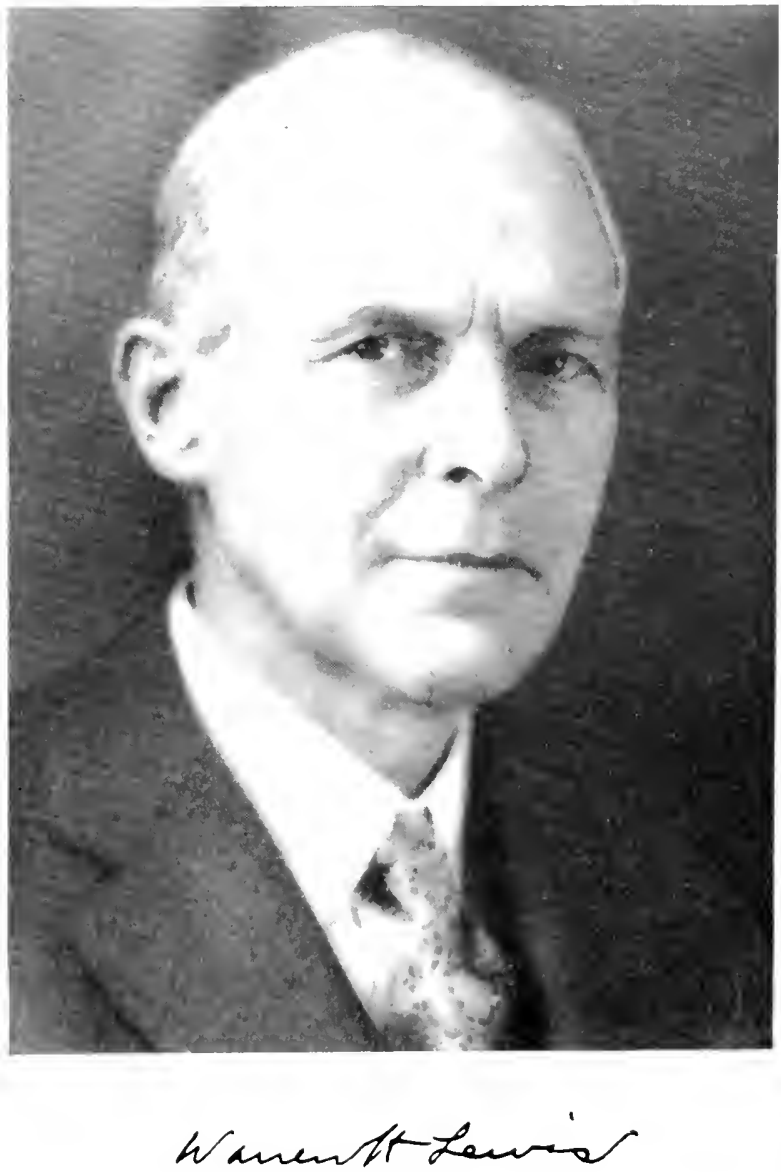

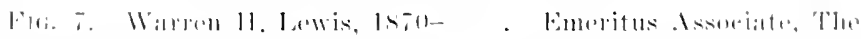

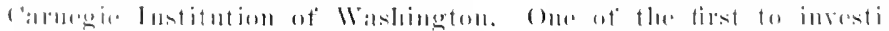

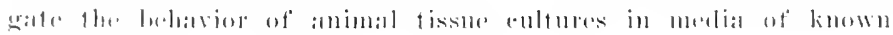
anstitutions. 


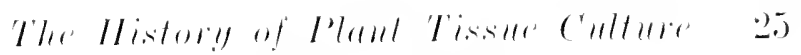
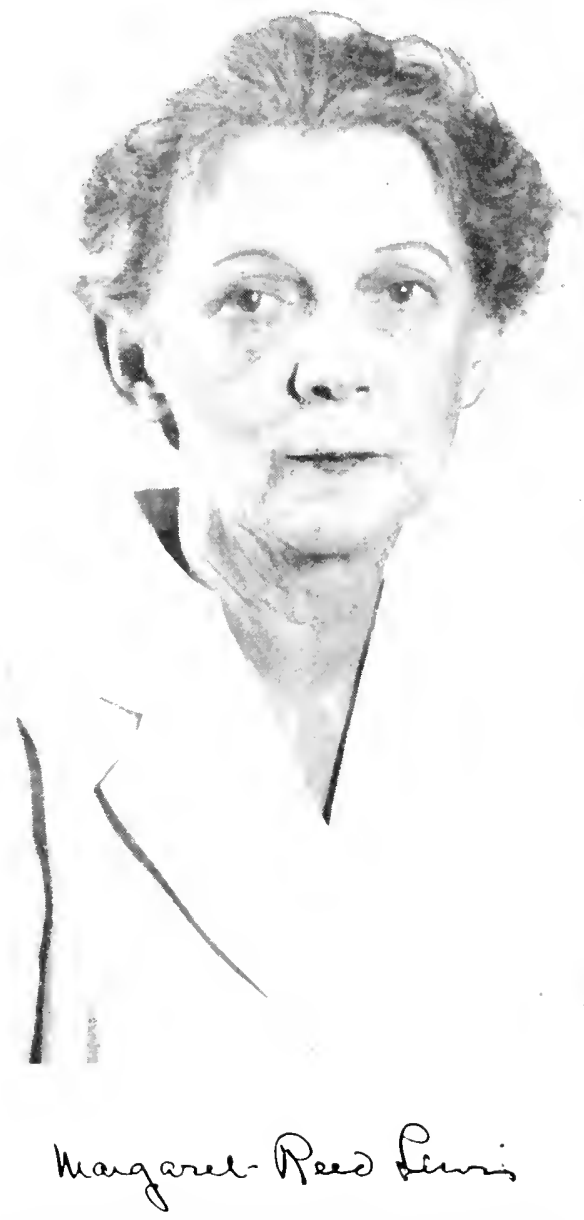

Fiti. 8. Marganet R. (Mrs. Wiaren 11.) Lewis, 1s81- Researeh Assomiate, The Carmegie Institution of Washington. Investigator of ammal tisste cultures, particularly of malignant tissues. 

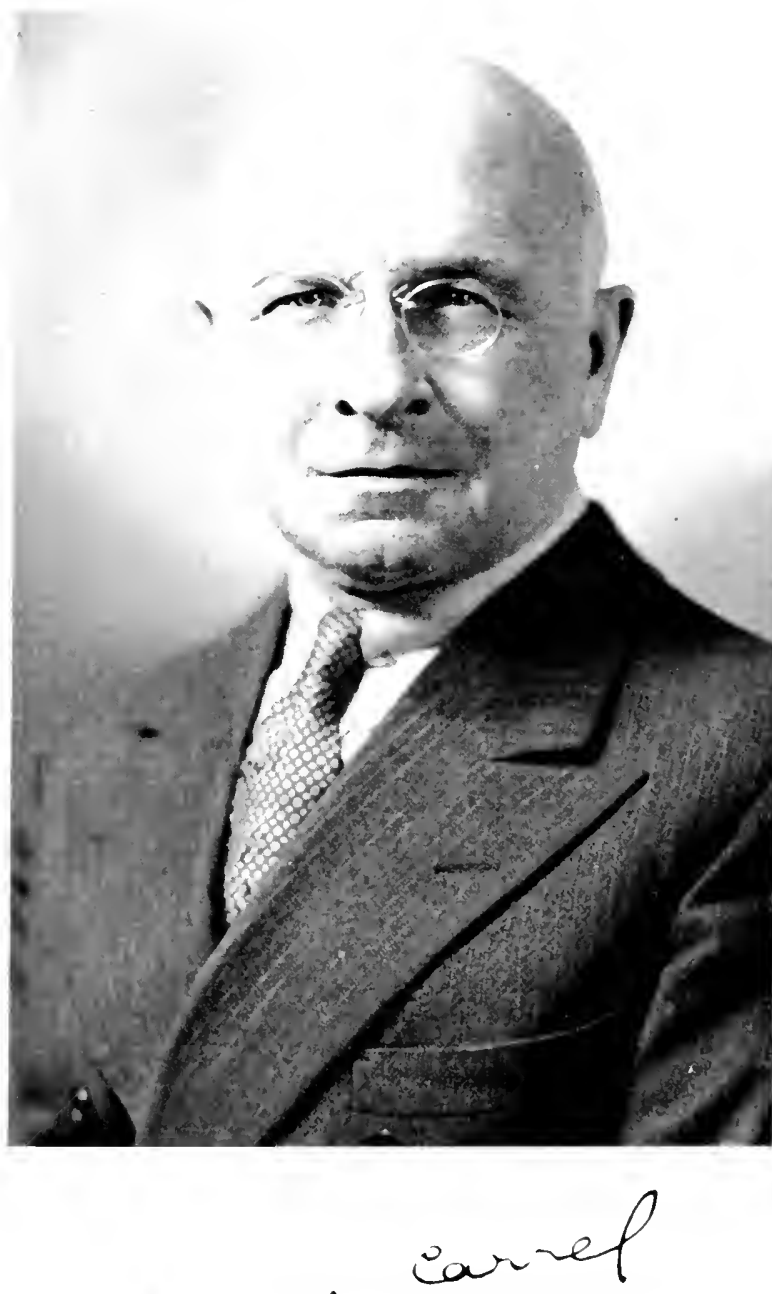

\section{alesers}

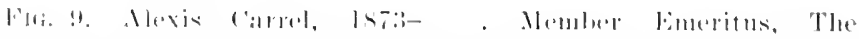

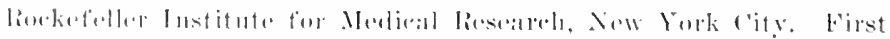

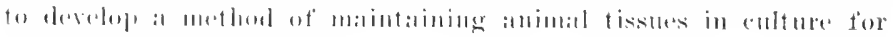
mulimited perionls. 
Attempts were, of course, made to duplicate Carrel's and Lewis' brilliant results, with plant tissues, by use of some "natural" nutrient comparable to embryo juice. All such attempts, with one possible exception, have consistently failed. Schmucker, in 1929, 110, reported that he had successfully g'rown individual leaf-mesophyll cells of Bocconia in a fluid prepared from a filtered extract of Bocconia leaves. Details were apparently never published, the work has not been verified by any later worker, and the result is so at variance with all other recorded experiments that its correctness is to be doubted. In the hands of other workers, all preparations of tissue juices, xylem sap, phloem exudate, liquid endosperm, etc., have given evidence of toxicity (Prát, 1927, 451; Robbins, 1922, 17 ; Robbins and V. B. White, 1937, 178*). This has, of course, forced workers in the plant tissue culture field to resort to the much more tedious, difficult, and uncertain, but at the same time when successful more satisfying method of developing step by step an essentially synthetic medium.

The profound influence of Haberlandt's wide reputation determined the subsequent orientation

* van Overbeek, Conklin and Blakeslee have reported successful use of coconut milk as a nutrient for Datura embryos, too late for the reference to be included in the bibliography of this volume. (Science $94: 350-351,1941$ ). 
of the majority of investigations concerned with the cultivation of plant tissues for a quarter of a century and, while animal tissue culture studies were making rapid strides, plant studies were for the most part wandering in what we now look upon as blind alleys. Smith in 1907, 325, BobilioffPreisser in 1917, 90, Lamprecht in 1918, 102, 103, Thielman in 1924, 111, and 1925, 112, 113, Börger, 92, and Czech, 93, in 1926, Kunkel, 101, and Prát, 451, in 1927, Úlehla, 115, and Kemmer, 99, in 1928, Pfeiffer, 107, and Scheitterer, 109, in 1931, five of them students of Haberlandt, all attempted to grow cells of mature type. The materials studied included leaf fragments of Peperomia, Bryophyllum, Kalanchoё, Crassula, Sempervivum, Allium, Polypodium, Aspidium, Dicranum, Begonia, Triticum, Pisum, Tradescantia, etc., epidermis of Viola, Thunbergia, Rhoeo, stem tissues of Solanum, Brassica, Saintpaulia, Coleus, Daucus, young ovaries of Cucurbita, pith cells of Symphoricarpus, and a variety of other plant parts. All gave equally unsatisfactory results. Küster, in 1928, 20, considered the problem hopeless ("aussichtslos") and asked if perhaps the assumption that cells are totipotent might not itself be false. There was, indeed, much evidence from a variety of sources which appeared to be contrary to this assumption. Not the least indicative of these evidences came 
from the field of animal tissue cultures. Fibroblasts, when grown in culture, not only always maintained their characters as fibroblasts, but retained growth rates which were characteristic of the particular tissues or organs from which they had been excised (Parker, 1931, 421, 1932, $422-424,1933,425,426)$. Epithelial cells also continued true to type (Ebeling, 1924, 389, 1925, 390; Ebeling and Fischer, 1922, 391; Fischer, 1922, 403, $404,1929,408)$. These results conveyed the impression that somewhere in the ontogeny of the individual animal the potential capacities of the cells had been segregated, only "fibroblast characters" being retained by fibroblasts and "epithelium characters' by epithelium. This impression has been so emphasized by much recent biological work that the older concept of the cell as an "elementary organism" and the plant or animal as a "society of cells" has fallen into disrepute and has, to a considerable extent, given way to the modern concept of the "organism as a whole." The cell has come to be looked upon as a more or less fortuitous structural element without any fundamental importance except as one means out of several by which the integrations of the whole may be attained.

There nevertheless remains much indisputable evidence which seems to point to the importance 
of the cell as a physiological entity and to its fundamental totipotency. The whole gene mechanism, as exemplified in somatic cells, seems to lose its meaning without this concept. The regeneration of leaves and roots from tissues which are neither leaf nor root points to the existence of capacities which are called forth only by exeeptional circumstances. Vöchting's dissection experiments suggest a similar explanation. Spemann and his followers have obtained in their transplantation experiments striking support of this concept, for, while a piece of epithelium of a melanotic amphibian is always melanotic (species specific) in whatever host it may be grown (Fig. 3 ), it may form tail, or mouth, or eyelid, depending on the position in the body in which it is placed (Fig. 4) (Harrison, 1904, 413; Filatow, 1925, 402 ; Spemann, 1936, 431; Schotté, 1932, 430). Some transformations such as, for example, that from fibroblast to macrophage are also known to take place in animal tissue cultures (Ebeling and Fischer, 1922, 391 ; Fischer, 1925, 406, 1926, 40\%). There thus still seems to be much evidence to support Haberlandt's original concept and to lend support to the hope that, while excised plant cells have not yet been grown in vitro with the facility which IIaberlandt appears to have anticipated, they will eventually be so grown. Such is the 
basis for the continued study of the subject of "plant tissue cultures.",

Haberlandt's influence, while tending to orient the subject in a fundamentally unfruitful direction, nevertheless did keep interest in the field alive. Moreover, Haberlandt was a sound enough scientist to see that there were other possible orientations and to encourage them even though he did not recognize their full value. In 1922 one of his students, Kotte, 51, 52, (Fig. 10) made the first important experimental contribution to the subject. Kotte chose to work not with single, green, mature cells, but with colorless meristems, excised root tips. His motivation in this choice, although not very clearly formulated, appears to have been similar to that which oriented the present writer's choice of material a decade later (White, 1931, 32, 1932, 89), namely, their meristematic character, their ease of excision and consequent relative freedom from trauma, and the considerable variety of their normal physiological responses. Kotte succeeded in cultivating excised root tips of pea and maize in a variety of nutrients. These all contained the salts of a dilute Knop solution. To these were added various combinations of glucose, peptone, asparagin, alanine, glycine, Liebig's meat extract, a pepsin-diastase digest of pea seeds, etc. The most satisfactory results, in 
which normal development and response were maintained for considerable periods, were obtained in a solution containing, besides the salts, 1 per cent dextrose plus 5 g. Liebig's meat extract per liter. The work was well planned, excellently carried out, and, as we can now see, of considerable promise, but no subcultures were attempted, Haberlandt apparently overlooked its importance, and no attempt seems to have been made to follow it up. By one of those coincidences which often crop up in science, Robbins in the United States, following the leadership of Jacques Loeb (Robbins, 1939, 220; Loeb, 1915, 302, 1916, 23, 303, 1917, 304, 305, 1918, 306, 1924, 24) and Louis Knudson (Knudson, 1916, 168, 1919, 100; Knudson and Smith, 1919, 169), simultaneously and independently carried out similar work with comparable results (Robbins, 1922, 57). His method differed from Kotte's chiefly in the use of yeast extract in place of Liebig's meat extract. Robbins (1922, 1ry) and his colleague, Maneval (Robbins and Maneval, 1923, 59, 1924, 258) carried their work somewhat further than did Kotte and, by using subcultures, succeeded in maintaining cultures for some 20 weeks. But in every series, there set in a gradual diminution in growth rate and all cultures were ultimately lost. The results seened to suggest that some unknown material 
not present in the nutrient night be essential for continued growth. The work was dropped and was not resumed by Robbins for another decade. Somewhat analogous studies were made by Chamber's in 1923, 43, 44, Mayer in 1929, 138, Heidt in 1931, 50, and Malyschev in 1932, 53, 54 .

The ideas originally outlined by Haberlandt and given their first really encouraging investigation by Kotte and Robbius, passed then to other hands and have seen considerable fruition since 1930 . Progress since that date has been largely under the leadership of two workers, in France and in the United States. Gautheret (Fig. 11), a student of Guilliermond and disciple of Molliard, carried out a great many investigations in the field of "plant tissue cultures" in the years 1930-1940. Studies similar to those of Kotte with excised root tips were without marked success (Gautheret, 1932, 48, 1933, 49, 95, 96, 1935, 15, 1937, 242, 1939, 97). But simultaneous studies using cambium from large trees were much more promising. $\mathrm{He}$ succeded in growing cambium tissues for considerable periods (Gautheret, 1934, 67, 1935, 15, $1937,68,1938,69,70,1939,71,72,1940,73)$, in producing in vitro grafts $(1935,15,1937,16)$, and in learning a great deal about the nutrient requirements of such tissues. With the work of his compatriot Nobécourt (Nobécourt, 1937, 74, 1938, 75, 
76, 1939, rr; Nobécourt and Dusseau, 1938, 311), and with White's (Fig. 12) independent work in America, these studies have led to the first really successful prolonged cultivation of undifferentiated plant tissues (White, 1939, 78,333 ). At about the same time that Gautheret's work was initiated, the author of this volume, under the influence of $\mathrm{Dr}$. and Mrs. Warren H. Lewis and of the late Professor Duncan S. Johnson, began at the Johns Hopkins University an intensive study of the whole problem of plant tissue cultures. The methods of approach finally adopted as most promising, although developed independently, came to resemble superficially those of Kotte and Robbins on the one hand and of Gautheret on the other (White, 1931, 32, 1932, 63, 89, 1933, 64, 116, 141, 142). These studies led in 1934 to the first prolonged cultivation of excised roots (White, 1934, 65), to the development of satisfactory synthetic culture media in 1937 (White, 1937, 141, 143, 144, 180, 181, $231,1939,182,1940,172,173,232)$, and to the prolonged cultivation of undifferentiated plant tissues in 1939 (White, 1939, rs). The work of Bonner (Bommer, 1937, 198, 1938, 199, 1940, 201; Bonner and Addicott, 1937, 42), Fiedler (1936, 45), Galligar (1934, 46, 1936, 166, 1938, 16r, 1939, 4r), Marotto (1935, 55, 1936, 56), Loo and Loo (1935, $216,1936,217)$, and others, and recent studies of 
Robbins and his coworkers on excised roots (Robbins and Bartley, 1937, 170, 222, 223; Robbins, Bartley, and V. B. White, 1936, 58; Robbins and Schmidt, 1938, 60, 1939, 61, 224, 225; Robbins and V. B. White, 1936, 62) stem largely from these studies of $1930-1934$. It is this work since 1930 which forms the basis for the present volume. The field is still too new to be frozen into definite patterns. This account merely attempts to bring it as nearly up to date as possible and to make the present techniques available to students of the field.

\section{Summary}

The history of plant tissue culture has been a long and tenuous one. It may be conveniently divided into four periods: 1834-1900-The concept of cellular totipotency and its demonstration by cultivation of single cells was implicit in the fundamentals of the "cell theory" but was neither clearly expressed as a distinct concept nor subjected to experimental test during this period. 1900-1922_The idea of tissue cultures was outlined for the first time in its broad aspects by Haberlandt in 1902 and was first put into practice, with animal tissues, by Harrison in 1907 and by Burrows and Carrel in 1910. Efforts aimed at the establishment of similar cultures of plant tissues were fruitless until 1922 when Kotte and Rob- 
bins independently cultivated excised root tips for brief periods. 1922-1934-The method as outlined by Kotte and Robbins was still far from fully successful, and the period from 1922 to 1934 was again one of largely unsuccessful attempts in a great many different directions. 1934-1939In 1934 White and Gautheret gave a new impetus and orientation to the subject, White by demonstrating the possibility of growing isolated roots for unlimited periods in vitro, Gautheret by demonstrating the possibility of obtaining in vitro growth of fragments of cambium. The period 1934 to 1939 was one of rapid expansion of the field, of perfecting the nutrients and culture conditions, and of gradual establishment of the technique on a firm basis. This was capped in 1939 by White's, Nobécourt's, and Gautheret's independent demonstration of the possibility of growing undifferentiated tissues for unlimited periods and by White's demonstration of experimental control of differentiation in such cultures.

* William J. Robbins, 1890 Director, The New York Botanical Garden, Bronx l'ark, New York City. Simultaneously and independently from Kotte, cultivated excised root tips for the first time for limited periods in artificial media. Student of the vitamin requirements of plants. The author regrets thit Dr. Kobbins has requested that his portrait be omitted from this serles. 


\section{The Ilistory of I'lant Tissure C'ulture :}

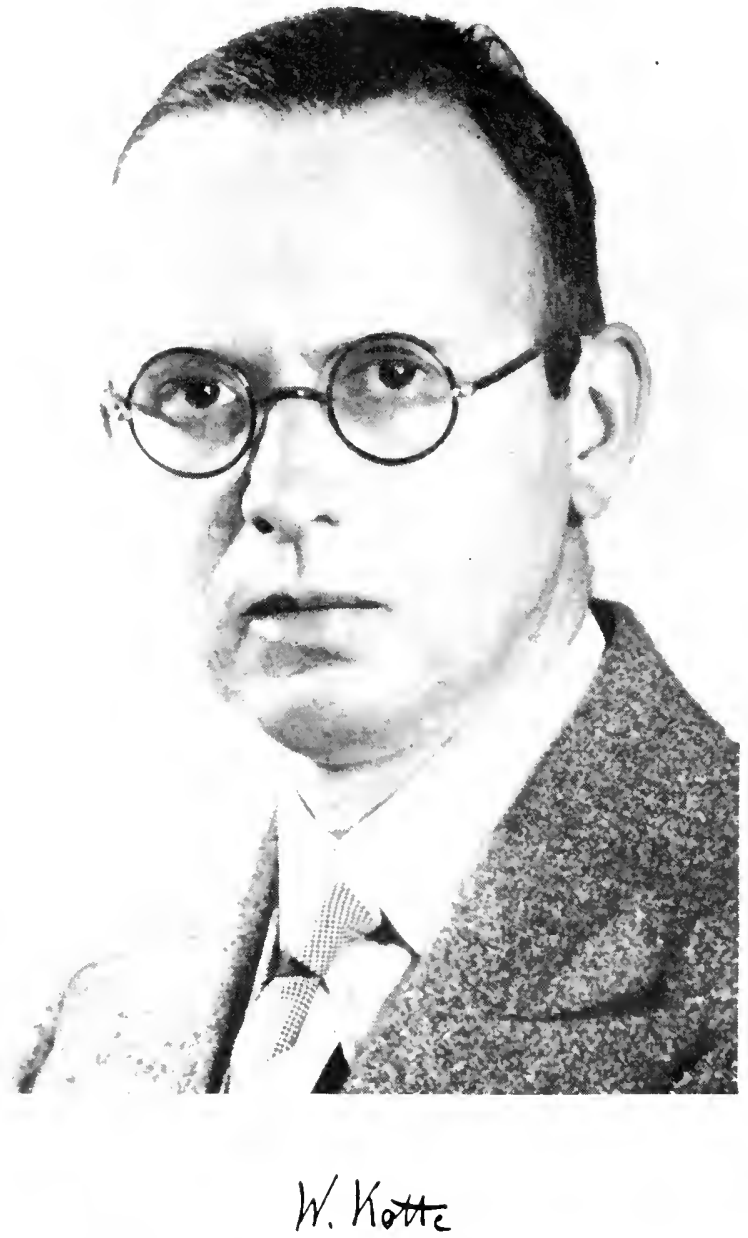

Fif. 16. Walter Kotte, - . Reg. Bot., Hauptstelle fürr P'llanzenschutz, Augustenleerg, Post Grotzingen, Badon, Gemany. simultaneously and independently firom Roldhins cultivated exejsed ront tips for the first time for limited periods in artificial media. 
:3
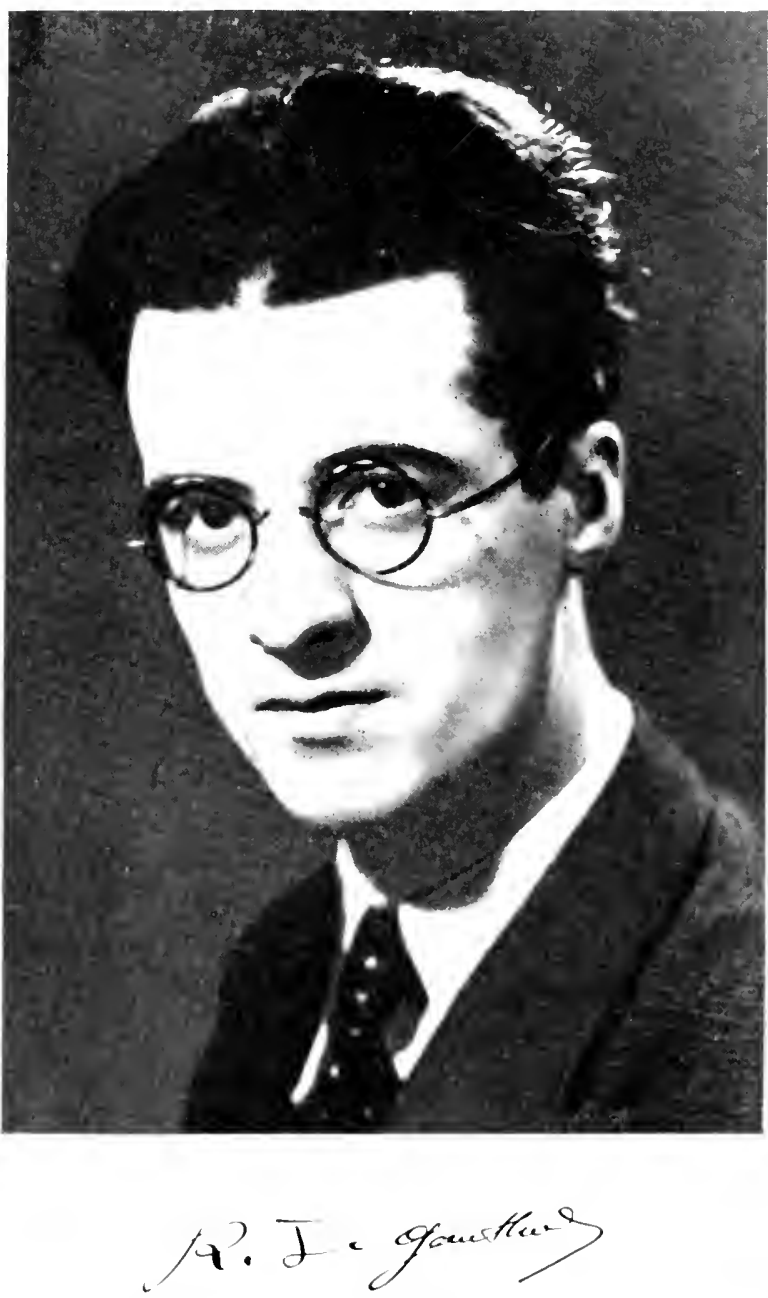

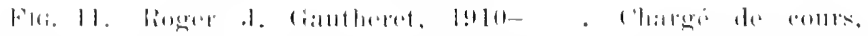

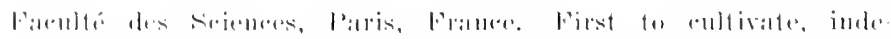

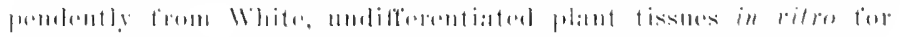

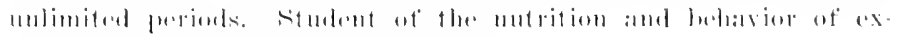

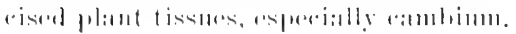


The Ilistor!l of Plant Tissue C'ulture 39
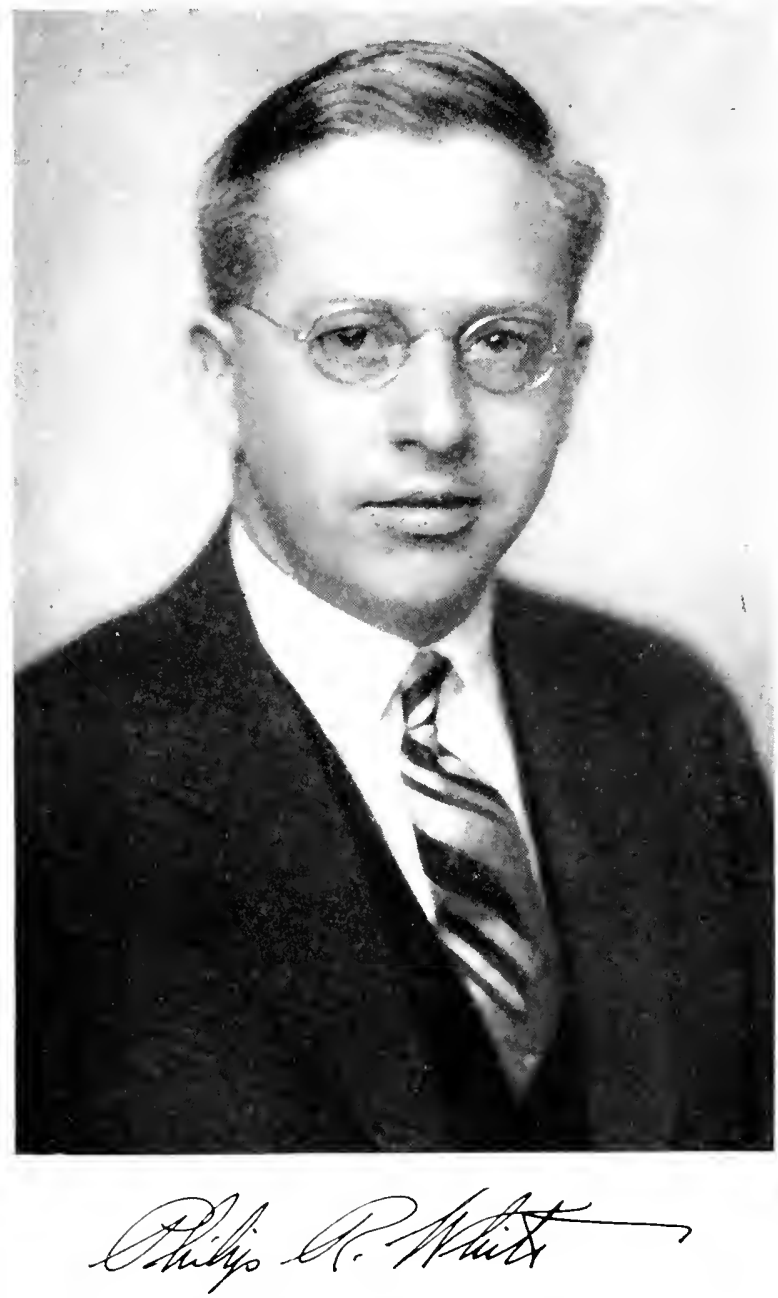

FIf. 12. Philip R. White, 1901- . Associate, The Rockefeller Institute for Medieal Researeh, Princetom, X. J. First to cultivate reot tips and, independently from cauthere undiffercoltiated plant tissues in ridro for molimited perionds. Student of the mutrition and morphogenesis of excised plant tissues. 


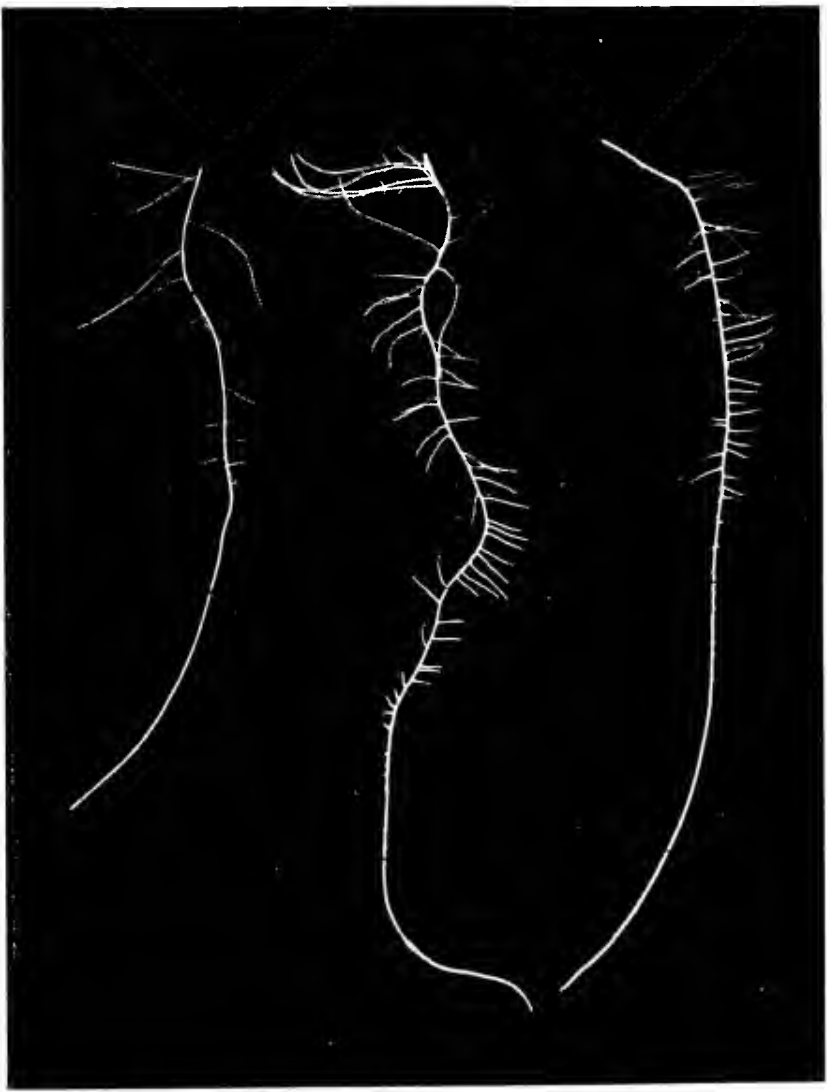

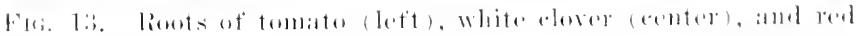

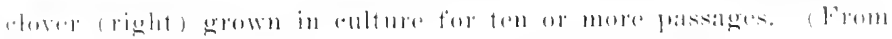

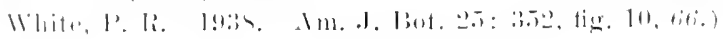





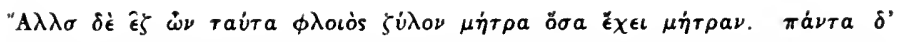

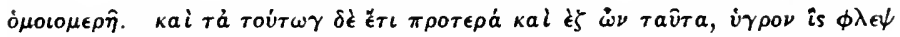

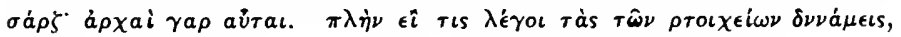

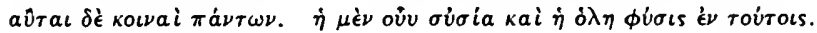

"Again there are the things of which such parts (root, stem, leaf) are composed, namely, bark, wood, and core (in the case of those plants which have it), and these are all 'composed of like parts.' Further, there are the things which are even prior to these, from which they are derived-sap, fibre, veins, flesh ; for these are elementary substancesunless one should prefer to call them the actire principles of the elements; and they are common to all parts of the plant. Thus, the essence and entire material of plants consists in these."

Theophrastus. Enquiry into plants. I. II. I.

Translation by Sir Arthur Hort. Loeb Classical

Library. G. P. Putnam's Sons. 1916, $\$ 53$. 


\section{Chapter III}

\section{THE LIVING MATERIALS}

In the chapter on the history of plant tissue culture, data were presented on a long series of attempts to grow excised plant tissues. Most of these attempts failed; a few were successful. If plant tissues are classified according to their observed usefulness as culture material, it becomes immediately obvious that all of the tissues which have given promise of being grown satisfactorily, with the single exception of Schnucker's uncorroborated report $(1929,110)$ on leaf-mesophyll cells, have been meristematic tissues. With this single exception, all "mature" tissues have failed. This is not to say that they are all incapable of growth. But available evidence seems to indicate that, when a meristematic function is resumed by cells at any point in the plant body, as in the case of healing internal wounds, these cells are for the most part not truly mature (Schilling, 1915, 321, 1923, 322; Jaeger, 1928, 298). The medullary ray parenchyma, phloem parenchyma, pith cells in general, pericycle and endodermis, and cortical parenchyma are known to retain their meriste- 
matic eapacity throughout most of the life of the plant (Úlehla, 1928, 115; MacDougal, 1926, 307; MacDougal and Shreve, 1924, 445; Sinnott and Bloch, 1941, 324). Epidermal tissue does so ordinarily for somewhat shorter periods (Naylor, 1931, 308; Naylor and Johnson, 1937, 309 ; Naylor and Sperry, 1938, 310), while such cells as trichomes, guard cells, xylem fibers, etc., retain this capacity for only very brief periods (Haberlandt, 1913, 294, 1914, 295, 1919, 245, 296, 1920, 29r, 1921, 354 ), because of mechanical modifications if for no other reason. It is probable that means may ultimately be found for obtaining cultures from most living, nucleated cells. But the initial work in any discipline is quite properly concentrated on the easier materials available and the less promising ones may well await the establishment of more adequate techniques. Recent work in this field has, therefore, been concentrated on the meristems.

Plant meristems can, for the most part, be classified in three main groups, leaving a rather large residue of those more difficult to classify.

The fertilized egg is, of course, the meristematic cell par excellence, since there can be no question about its fundamental totipoteney. It is, however, an extremely delicate "organism," (Fig. 20) normally hedged around by all sorts of protec- 
tions against mechanical and chemical shocks, provided with very special and obscure nutrition, and requiring considerable manipulation for its excision. Hannig (1904, 81), Stingl (1907, 85), Dietrich (1924, 79), Essenbeck u. Suessenguth (1925, 80), White (1932, 89), Tukey (1933, 86, 1934, 87, 1938, 328), Werckmeister (1934, 88), LaRue (1936, 82), LaRue and Avery (1938, 83), Razdorskii (1938, 84), and others have grown excised embryos of more or less advanced stages of development, but egg cells have apparently not yet been cultured. It is probable that the difficulties involved can be overcome. Indeed, Tukey's results with older embryos of stone-fruits indicate considerable progress. However, since the cultivation of such embryos, as practiced, results in entire plants which differ in no wise from plants obtained from viable seed by the more usual methods, such cultures are likely to prove of value only in special cases. Noteworthy among these are the fairly numerous cases where viable embryos are initiated but where, for one reason or another, endosperm is not developed so that the embryos die of starvation. Such was the case with Tukey's hybrid peaches $(1933,86)$ and with the Musa seminifera studied by White $(1928,332)$. Similar "physiologically sterile" plants have been reported in the literature on numerous occasions. 
The embryo itself, even up to a fairly late stage of development, is largely or entirely made up of undifferentiated cells. Indeed, in the orchids, Peperomias, and many other plants there is little or no morphological differentiation evident in the

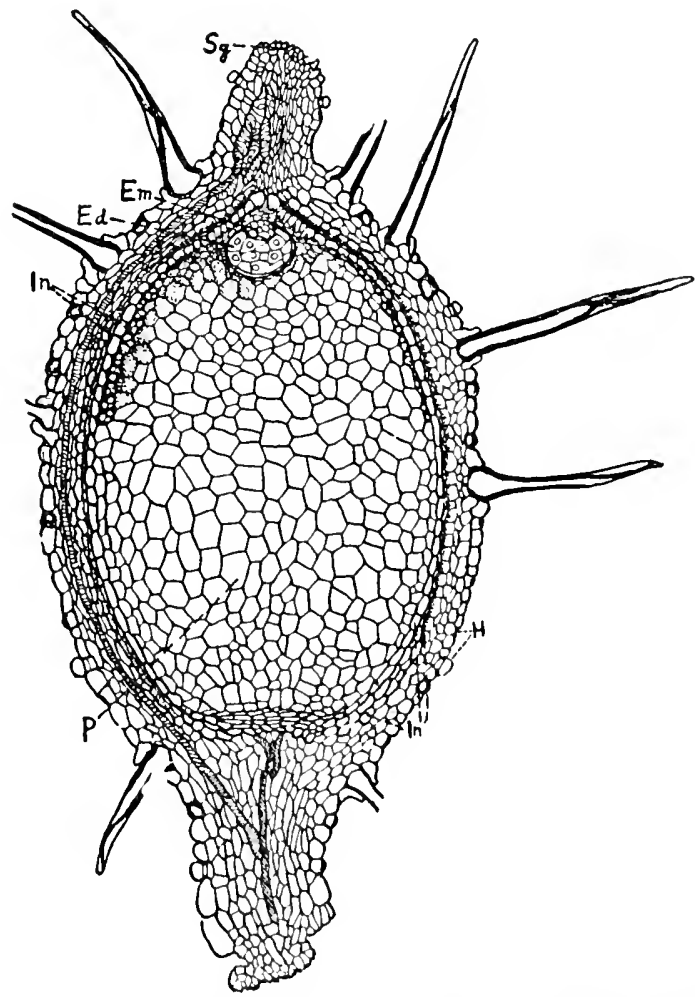

FIG. 14. Longitudinal section of seed of Peperomia hispidula showing the mature but completely undifferentiated, few-elled embryo. (From Johnson, D. S. 1914. Am. J. Bot. 1: 396, fig. 100, 41.4.) 
embryo at the time the seeds are "ripe"' (Johnson, 1912, 444). (Figs. 14, 15.) It is, therefore, possible to cut an embryo into bits and grow any one of these fragments. But, as Smith (1907, 325), Molliard (1921, 106), LaRue (1936, 82, 104), Dauphiné $(1929,94)$, and others have shown, even in the embryo there are some regions having a greater proliferative capacity than others, an observation which agrees with that established in animal embryology. Cotyledons will usually regenerate easily (Molliard, 1921, 106 ; Behre, 1929, 275). Roots can be counted on to grow as roots, but means of inducing them to develop leaves have, with rare exceptions (especially among the Compositae) (Fig. 16), not yet been found. Hypocotyl is in general still more refractory,

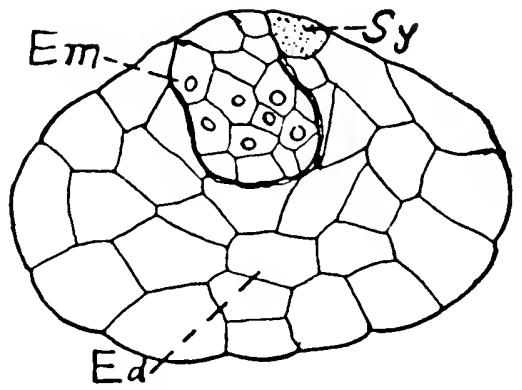

FIG. 15. Detail of endosperm and embryo of Peperomia hispidula. This is an ideal type of material for the study of embryo differentiation after germination. (From Johnson, D. S. 1914. Am. J. Bot. 1: 396, fig. 110, 444.) 
while the epicotyl and plumule tend to form roots and develop into normal plants without serious difficulty. Thus, even in the embryo there is the begimning of an apparent loss of totipotency, a segregation of function which is marked in the root, somewhat less in hypocotyl and cotyledon, and lacking in epicotyl and plumule.

As the embryo grows into a plant, there is a progressive maturation of some tissues so that, except for "juvenile", cells like the medullary ray parenchyma seattered through the plant body, there are segregated certain meristematic regions which earry on the function of proliferative growth (Priestley, 1928, 314; Priestley and Swingle, 1929, 316 ; Jaeger, 1928, 298). These regions are: the terminal growing points of roots and stems, the lateral meristems designated as cambiums and phellogens, and interealary meristems in the procambial region, at the base of the internodes in grasses and lianes and at the base of some leaves or, as in Camptosorus, near the tips of leaves.

The intercalary meristems require considerable manipulation for their excision and therefore suffer rather severe injury. Scheitterer $(1931,109)$ had slight success with the intercalary meristem of grasses, and none of those of lianes have been cultivated although they should be fairly easy to 
work with. The only intercalary meristem which has been successfully grown is that from the procambial region of tobacco (White, 1939, 78 ). If the procambial tissues of fairly succulent plants such as tobacco or squash are carefully excised under aseptic conditions (see later) and placed on a nutrient substratum, proliferation will occur, the newly formed callus tissue can be removed from adherent non-proliferating medullary elements, and a rapidly growing "pure-line" callus culture will result which can be propagated in series indefinitely. This is one of the most important types of culture obtained to date and will be discussed in more detail later (Fig. 18).

If, moreover, the cambium is taken from perennial plants having secondary thickening, and for this purpose trees of fairly good size offer fewer mechanical difficulties than do smaller plants, and is placed on a nutrient, a similar proliferation occurs, the product of which can be treated in the same manner (Gautheret, 1934, 6r, 1935, 15, 1937, $68,1938,69,70,1939, r 1,72,1940,73)$. When established in culture, it behaves much as do cultures derived from procambium. Gautheret has been especially successful with this type of culture and has made a number of very interesting experiments therewith (Figs. 38, 64). The cultures of callus from carrot root, carried out by 
Gautheret and Nobécourt (Nobécourt, 1937, 74, $1938,75,76,1939,7 \%$ ), may be considered as "cambiun," cultures although grown from root cambium rather than from stem cambium.

Terminal meristems are of two types-stem tips and root tips. The plumule taken from the embryo is a stem tip and cultures of this region, taken from no matter what age of plant, behave in much the same way. They differentiate into normal organs; if they become successfully established, they develop roots and subsequently behave as entire plants. As grown to date, they thus offer little or no advantage for physiological studies over seedlings derived in the usual way. Hence, although excised stem tips have been grown with some success by Robbins (1922, 5\%), White (1933, 116), Avery and LaRue (1938, 23\%), Behre (1929, 275), and others, such cultures have not proved of great value to the tissue culture field and have not been pushed very far.

Root tips, on the other hand, represent one of the most important types of material for tissue or organ cultures. If the tips of very young roots of any sort, from ungerminated embryos, seedlings, old root systems, or adventitious roots produced on euttings, are obtained in an aseptic condition and are exeised and placed in nutrient solntion or on a nutrient substratum, they will, if con- 


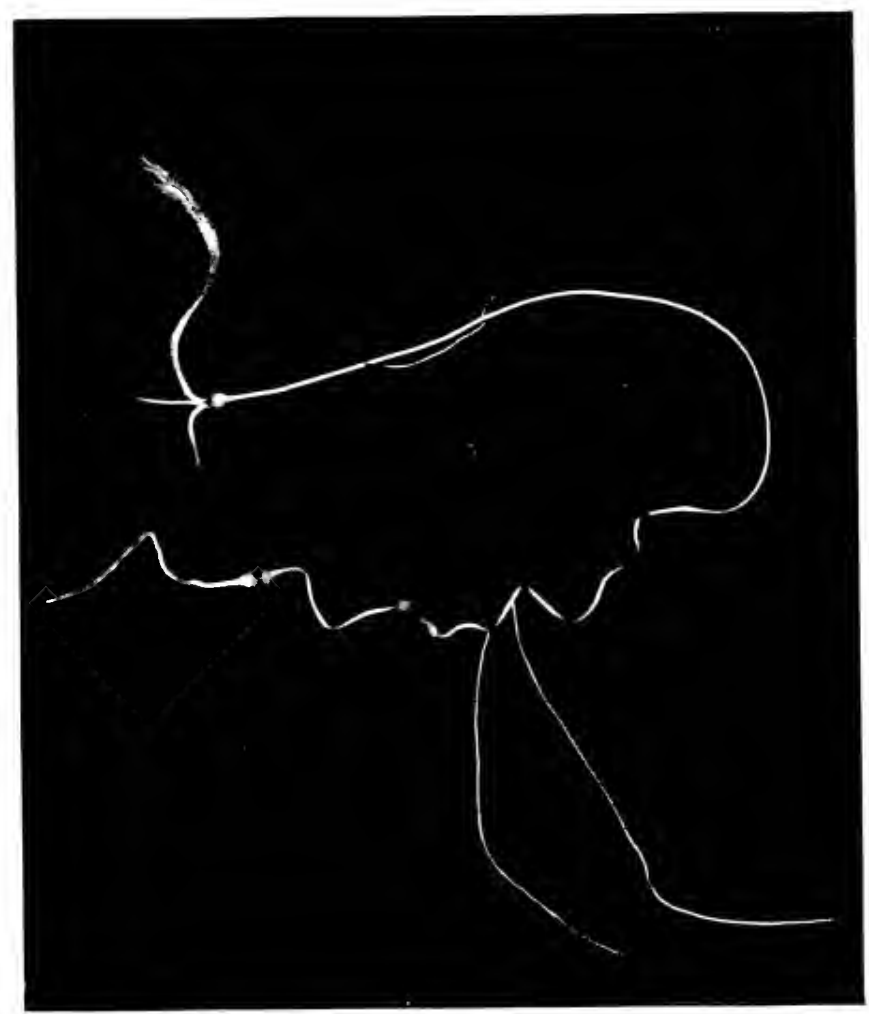

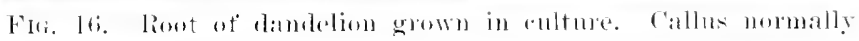
forms on lowts of many complosites on both distal ambl pouximal

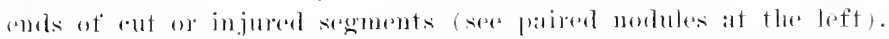

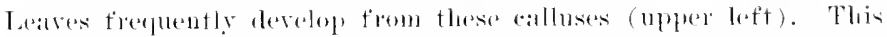
is in shalle contuast to the lehavion of allos on plants which proliterate only at the distal omols of segments. 


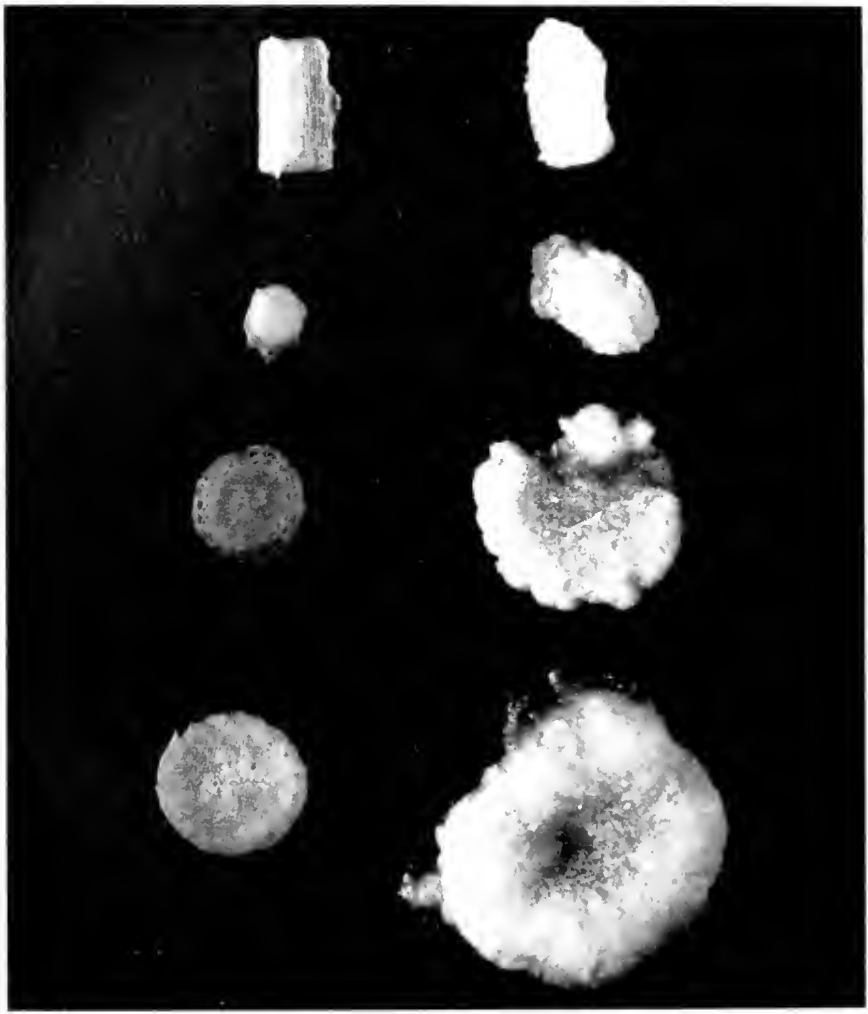

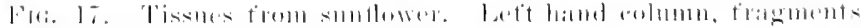

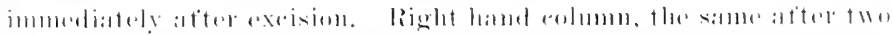

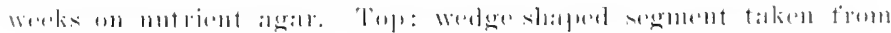

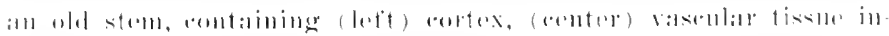

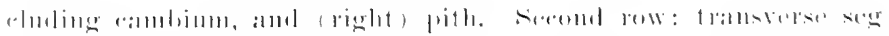

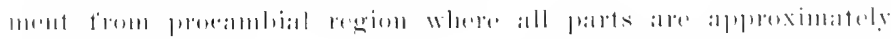

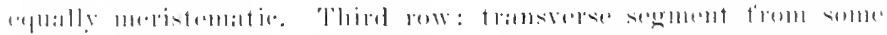

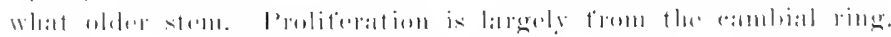

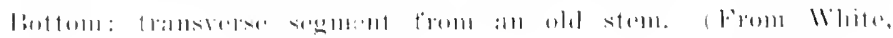

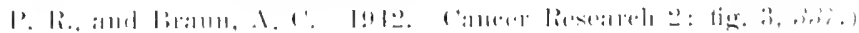




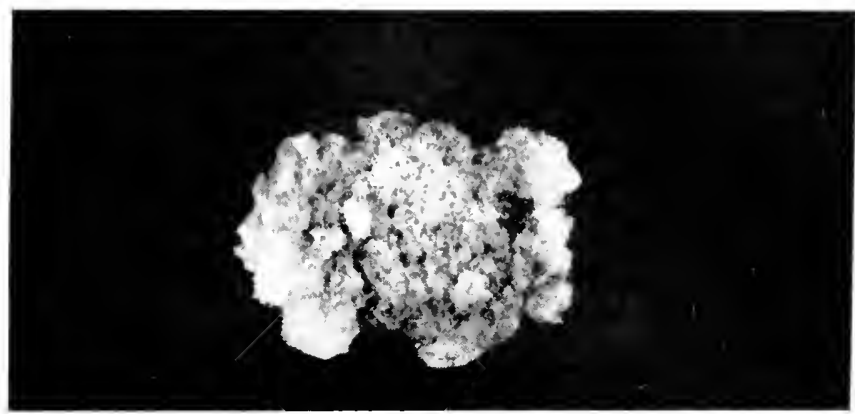

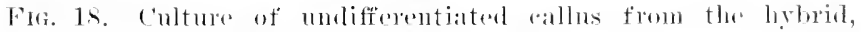

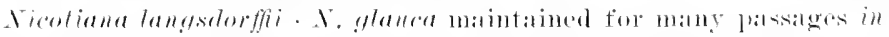

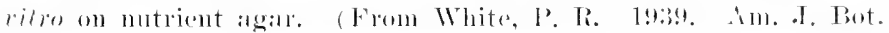
$26:(10$, fig. $2,7$.

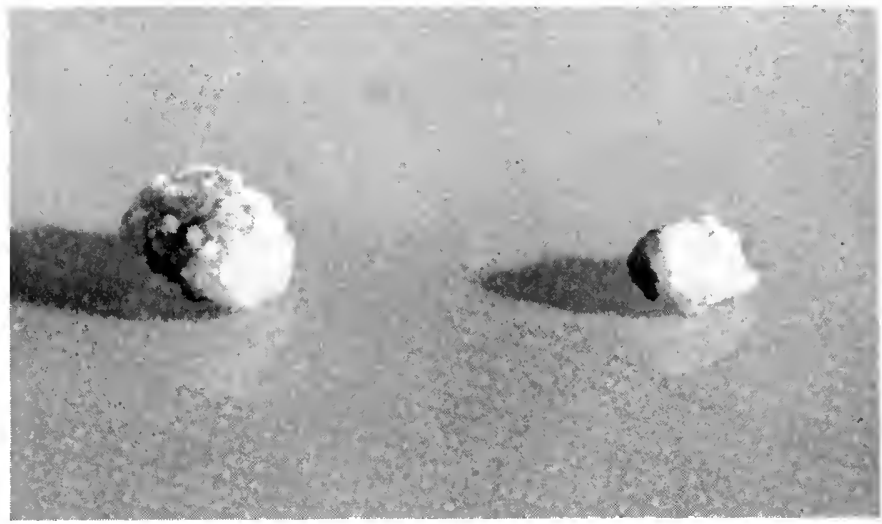

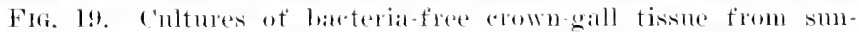
flower, grown in vilro on nutrient agar. 


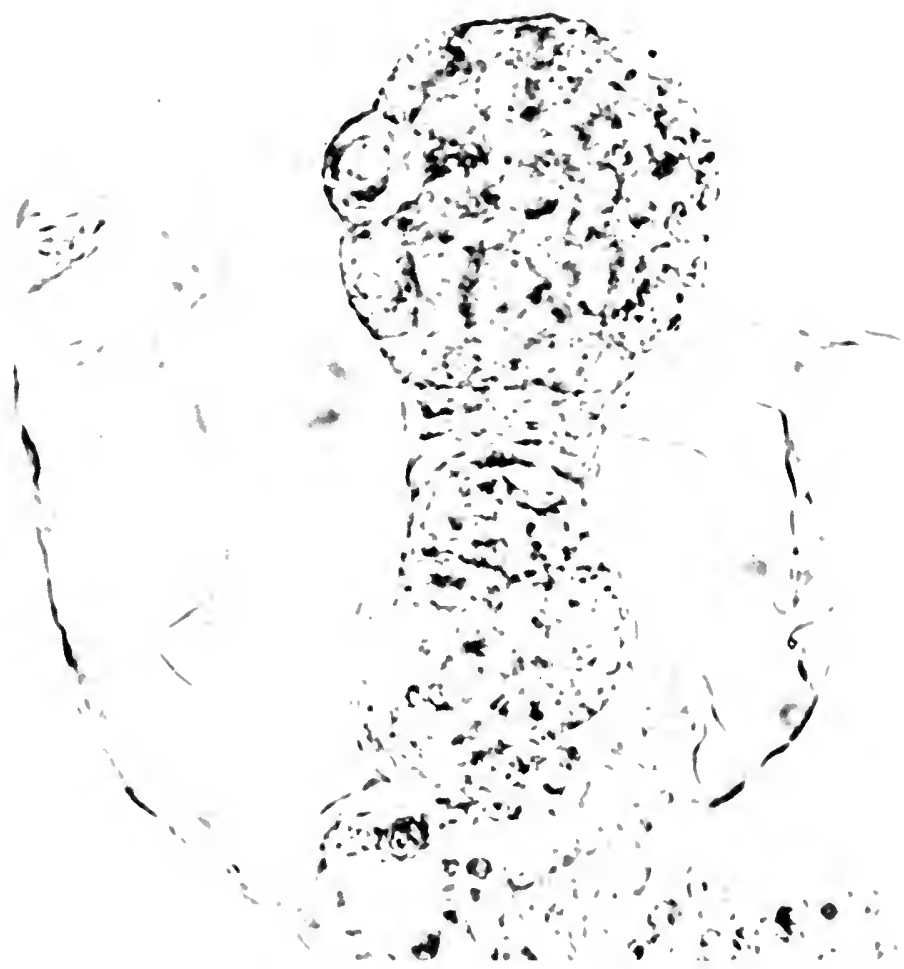

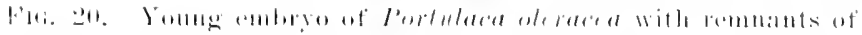

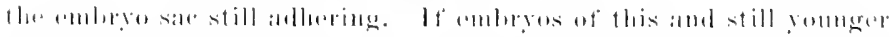

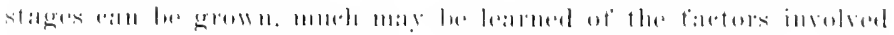

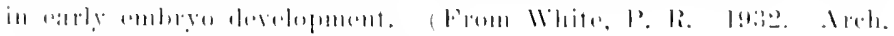

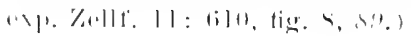


ditions are right, grow normally. They maintain for the most part their normal morphology, branching and extending in a regular way. The details of this morphology are characteristic for different species (Figs. 13, 21-24). There is, for example, a very marked and wide difference in degree of apical dominance (White, 1938, 66). In the mustard, Brassica nigra, apical dominance is extremely weak; as fast as branches are laid down, they grow with a vigor equal to that of the parent root so that an open network of rootlets is formed without definite outlines. Roots of clover, Trifolium repens (Fig. 13), on the other hand have a very marked apical dominance so that, even though many branches may be laid down, their increment is greatly retarded as compared with that of the original root and the growth habit is that of a well defined and very attenuate cone. The habits are thus roughly comparable to those of the white oak (Quercus alba), on the one hand, and the white fir (Abies lasiocarpa), on the other.

Such roots can be excised with a minimum of injury since the cross sectional area is small in proportion to the volume of even a comparatively short piece. They are meristematic for a considerable length and consequently can be counted on to grow with fair rapidity. They are naturally 
immersed in a nutrient substratum (the soil solution), the essential feature of which is a mobile liquid solution so that placing them in a liquid nutrient does not involve any marked change in their environment, provided the nutrient is suffciently aerated in some way (Cannon, 1932, 240; Zimmerman, 1930, 270; Steward, Berry, and Broyer, 1936, 262; Hoagland and Broyer, 1936, 246 ). This substratum is, in nature, a fairly complex solution of salts, humic acids, and other simple organic compounds. The major problem in duplicating the environment of a root is in providing the equivalent of the organic materials ordinarily supplied by the parent plant, and a glance at the anatomy of a rapidly growing root shows that these materials, coming from the phloem, must travel for considerable distances by diffusion through other cells before they can reach the dividing cells themselves. It might, therefore, be anticipated that these organic materials would prove to be relatively simple substances, as indeed they have (see later). The problem of growing excised roots should, therefore, both from a mechanical and a plyysiological point of view, be relatively simple. Kotte's (1922, 51, 52) and Robbins' $(1922,5 \%)$ early work supported this supposition. Excised root tips have, in fact, served as the experimental material par excellence for the pre- 
liminary work in developing a tissue and organ culture technique, and practically all of the fundamental steps in that development have been made first with root tips and only later applied to other tissues. Such roots are, in fact, very sensitive to differences in cultural conditions such as temperature, $\mathrm{pH}$ (White, 1932, 63), osmotic value (Bonmer and Addicott, 1937, 42), concentration and proportion of nutrient salts (White, 1933, 141, 1937, 143; Bonner and Addicott, 1937, 42), carbohydrate supply (White, 1932, 63, 1940, 172, 173), etc.; this sensitivity manifests itself either in change of growth habit (qualitative) or change in growth rate (quantitative). Growth rate can be measured quite accurately by any of a number of methods (see later), so that it is possible to follow the effects of relatively small differences in environmental conditions and to establish optimal ranges for these conditions.

There remains a variety of meristematic regions which are more difficult to classify. The entire young flower, and particularly the ovary, is at first meristematic. This function is retained in some tissues for a long time. Wehnelt (1927, 230) and subsequently Bonner and English (1938, 342) have taken advantage of this fact in using the inner surface of bean pods as test-pieces for a study of the growth stimulating properties of 
certain plant extracts (Fig. 35). White (1932, $89)$ and Moebius $(1922,105)$ have attempted to grow immature ovules and Tukey $(1937,114)$ and Börger (1926, 92) attempted to grow excised placental tissue without marked suceess. There are, in additon to these meristematic regions, cells scattered throughout the plant body, such as the medullary ray cells, the "xylem parenchyma" cells, the phloem companion cells, which retain a characteristic meristematic appearance long after the neighboring cells have "matured," and are capable of resuming growth when freed from the inhibitory effects of the neighboring tissues. Cells of the pith, of the cortex, of the epidermis, and other tissues may also, under speeial and at present little understood conditions, resume a meristematic function (Reiche, 1924, 369; Okado, 1920, 312; Wilhelm, 1930, 338; Winkler, 1902, 339 ; Sinnott and Bloeh, 1941, 32.4; Stingl, 1909, 326), but until a great deal more is known about them than at present they eamnot be looked upon as satisfactory material for plant tissue cultures. 


\section{Summary}

Examination of the history of plant tissue cultures shows that only those tissues have so far been successfully cultivated which possess a fundamentally meristematic character and do not have to undergo any major degree of de-differentiation. Plant meristems are, for the most part, of three main types. Apical meristems, particularly root tips, have been cultivated extensively and most of the details of technique have been developed through their study. Intercalary meristems such as cambium have also been successfully grown, as undifferentiated masses or with their differentiation experimentally controlled. Eggcells and embryos, insofar as they have been grown in culture, have given rise to complete plants. Such cultures can be of importance in the study of the origin of form and function only insofar as the degree and direction of their differentiation can be controlled. Other tissues, such as young ovaries, placental tissues, etc., have been studied to a lesser degree and have in some cases proved useful for special purposes. 



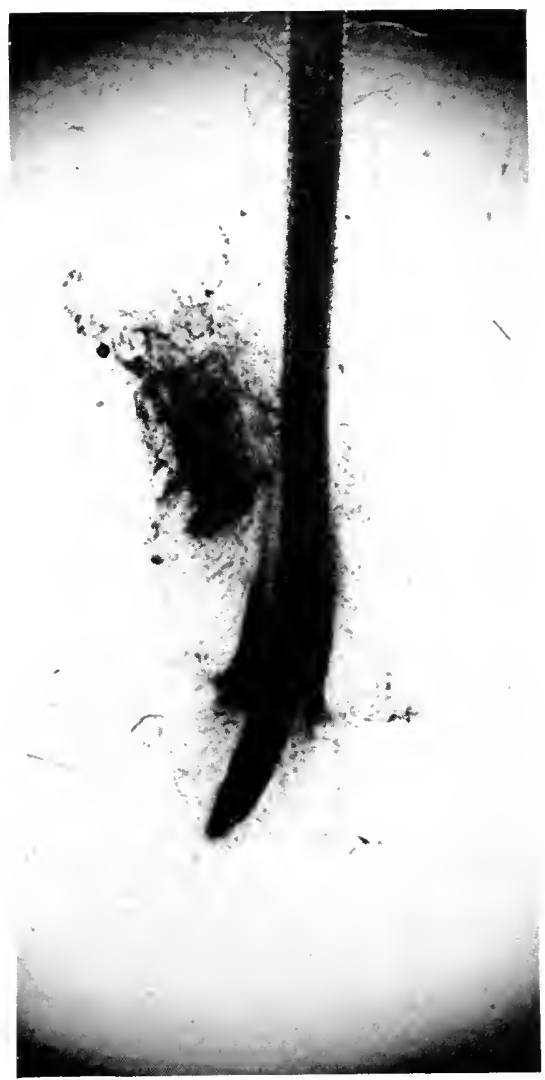

Fir. 21. White-rover root grown in rilro, showing the massive root-cap commonly formed on the roots of legumes. (From White, P. R. 1938. Am. J. Bot. 25: 352, fig. 11a, 66.) 
(i)

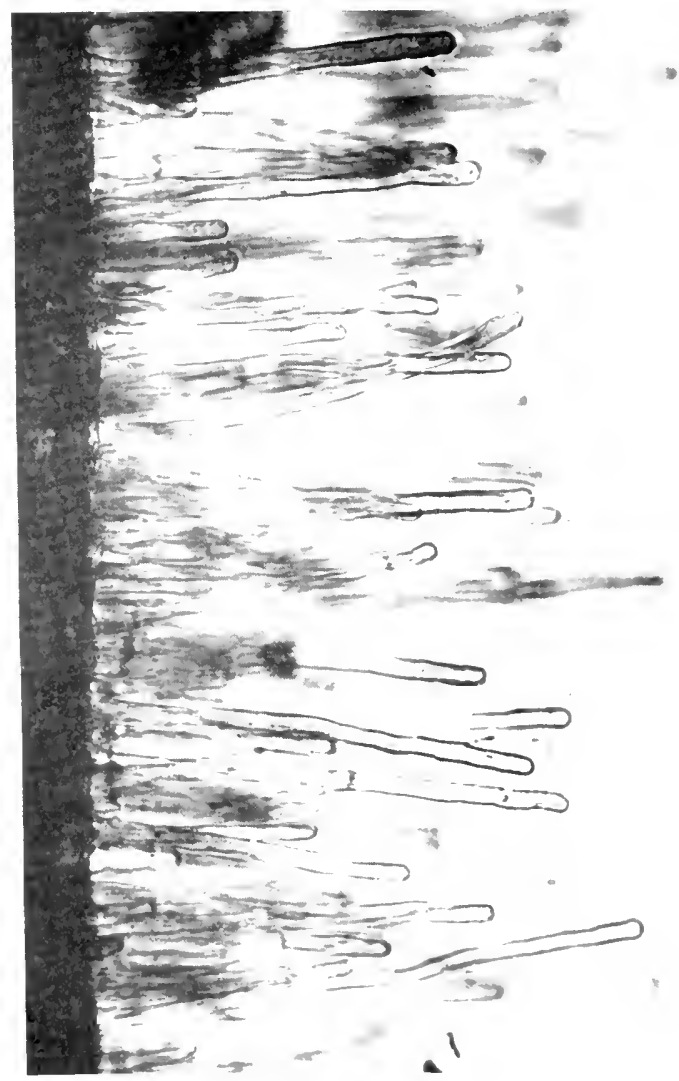

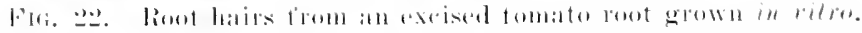

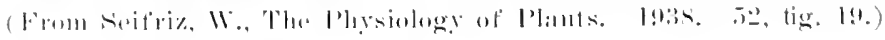




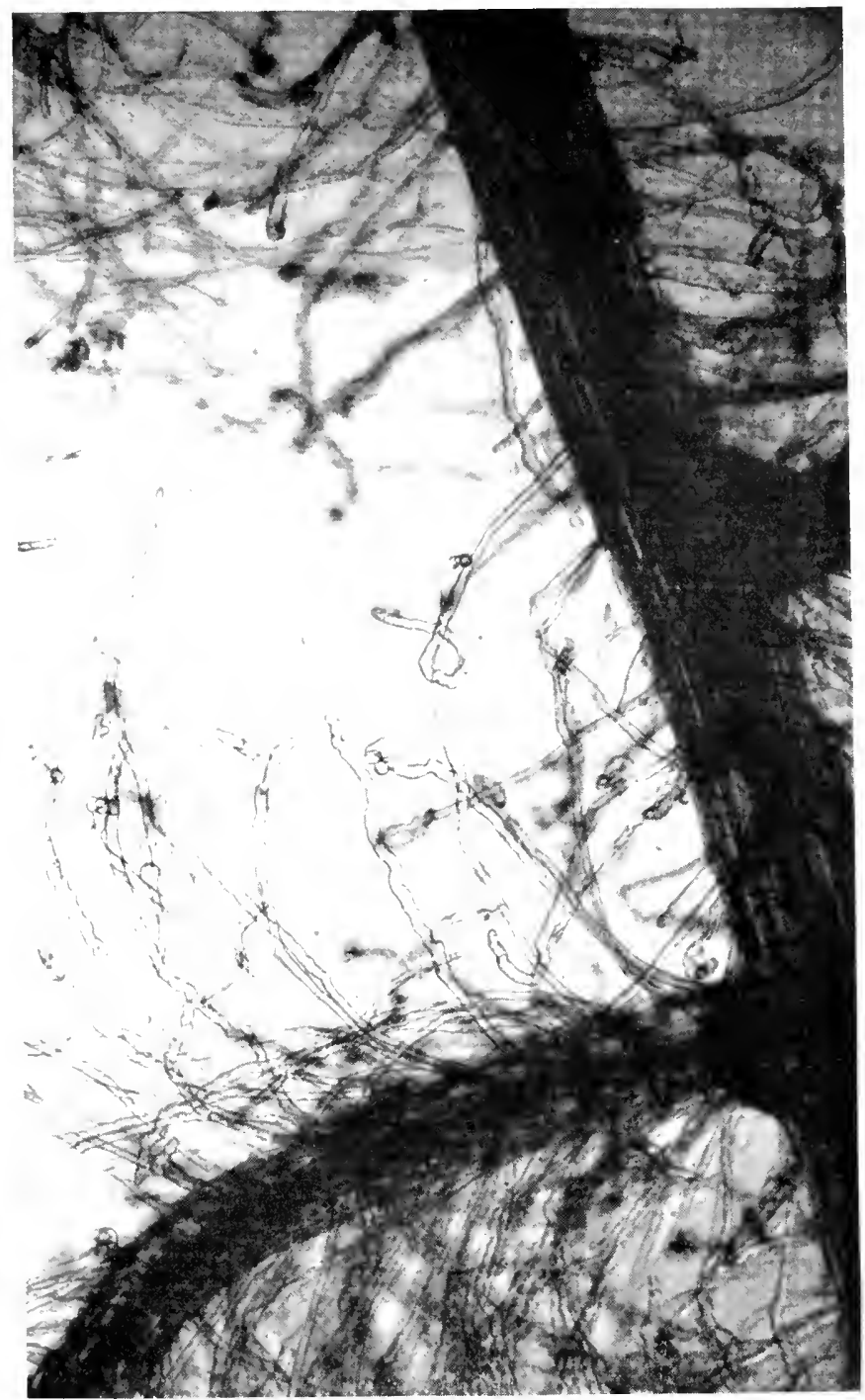

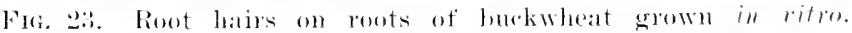
(From Whitn, P. R. 193s. An. .T. Bot. 25: 349, fig. 4, 66.) 


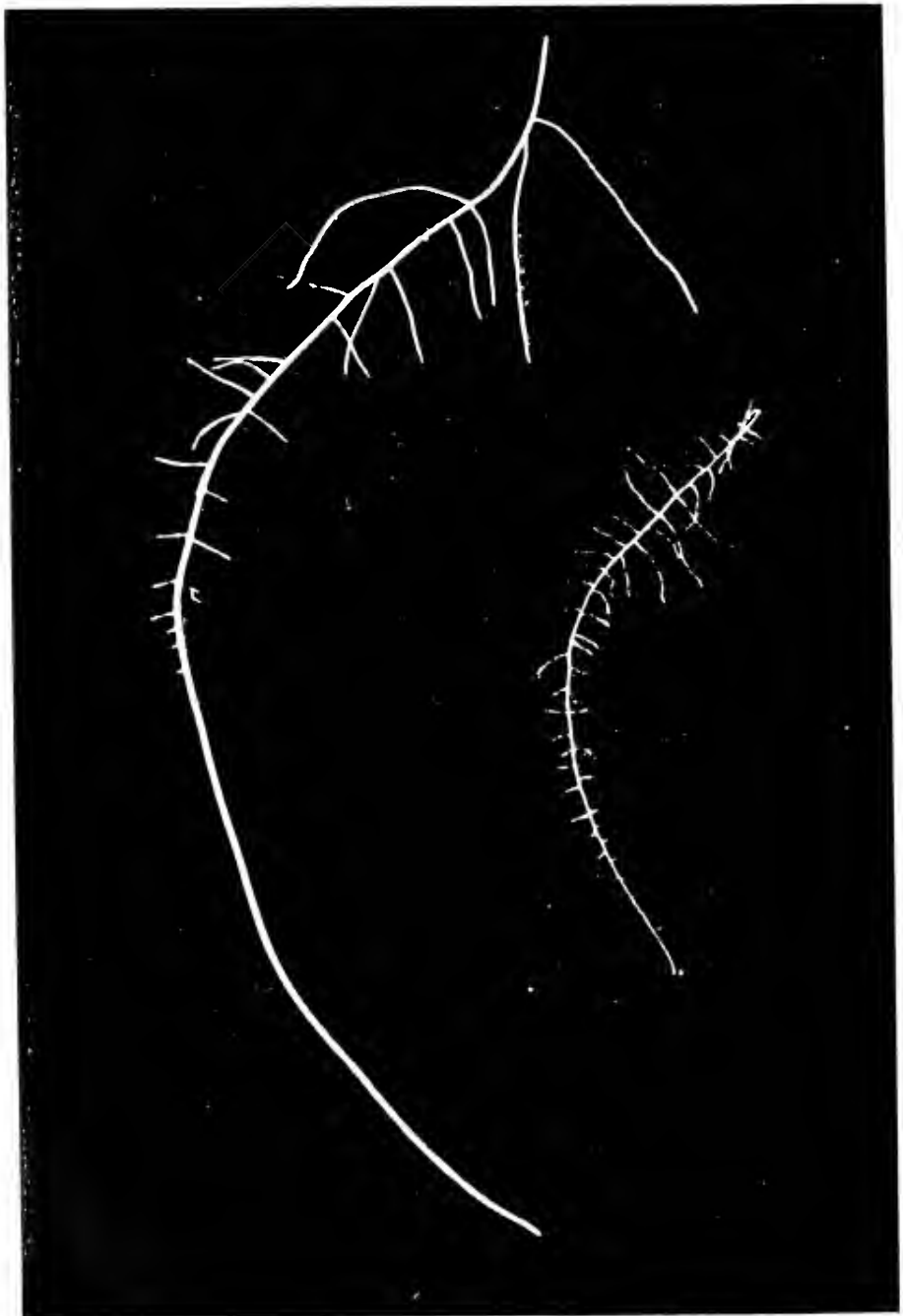

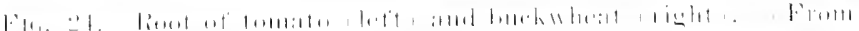

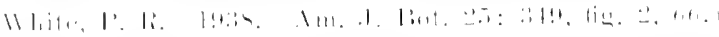



"(My) room was generally hung round with Guts, stomachs, bladders, preparations of parts and drawings. I had sand furnaces, Calots, Glasses and all sorts of Chymical Implements. . . Here I and my Associates of ten dined upon the same table as our dogs lay upon. I often prepared the pulvis fulminans and sometimes surprized the whole College with a sudden explosion. I cur'd a lad once of an ague with it, by fright. In my own Elaboratory I made large quantitys of sal volatile oleosum. Tinctura Metallorum, Elixir Proprietatis and such matters as would serve to put into our Drink."

Diary of Mr. Wm. Stukeley, 1707, describing his rooms at Cambridge wlere he and his fellow student, Mr. Stephen Hales, planned and carried out some of the first real experiments in plant and animal physiology. $4 \$ 3$. 


\section{Chapter IV \\ THE LABORATORY}

The description of a laboratory given above is presented as an example, not an ideal! The general requirements for a plant tissue culture laboratory are the same as those for any detailed micro-culture work: 1 , facilities for the preparation, sterilization, and storage of nutrients and for the cleansing of used equipment; 2, a place for the aseptic manipulation of tissue masses; 3 , facilities for the maintenance of cultures under carefully controlled conditions; 4, facilities for examination and study of cultures in whatever ways may be desired, and 5, a place for the assemblage and filing of records. It will seldom be possible to carry on all these procedures in a single room with any degree of effectiveness, but the degree of complexity introduced into the organization of the laboratory will depend on the particular needs and the facilities available for any given work. The ideal organization would allow a separate room for each of the above procedures-a media room, a transfer room, one or more culture rooms, a laboratory, and an office. (Compare Parker, 1938, 26.) (Fig. 25.) 
The media room. The media room will ordinarily be used for preparing and sterilizing of nutrients and equipment and probably also for the storage of extra supplies. If possible, it should be reserved for the preparation of nutrients and equipment for tissue cultures only, since sharing it with bacteriologists, mycologists, etc., involves definite risks of contaminations, both biological and chemical. There will be required: a good stove, an autoclave, a dry-sterilization oven, a refrigerator, a sink, a water still, tables and cup-

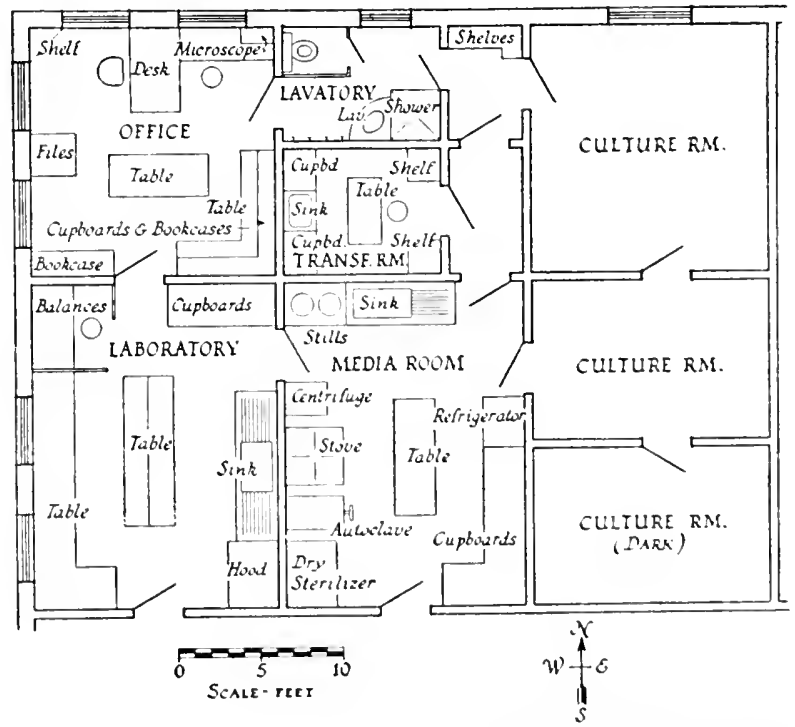

FIG. 25. Plan for a suite of rooms designed particularly for use in the study of plant tissue cultures. 
boards, and possibly an Arnold sterilizer. Gas, vacuum for use in filtering, compressed air for use in drying pipettes, etc., and extra water connections and electric outlets should be provided. The stove, autoclave, and oven require no special comment. The sink should be of acid-proof vitreous material with vitreous piping, or should be kept thoroughly paraffined since a great deal of washing in chromic acid cleaning solution will have to be done therein. It should be fairly large, with the faucets placed high enough to escape possible splashing from the sink. It has been found convenient to place a broad shelf above the sink wide enough to take two 20-liter Pyrex carboys, one for single-distilled water, the other for double-distilled water, and to drain graduates from a rack below the shelf. There should also be a draining rack for flasks and miscellaneous glassware. If distilled water is available as a laboratory service, it can be piped above the sink and replace the carboy of single-distilled water. Such a supply should not, however, be relied upon for water for making up solutions or for the final rinsing of glassware. For these purposes, water should always be re-distilled in a special still installed in the media room. Where a laboratory supply of distilled water is not available, it will be necessary to have two stills, either separate or built in tan- 
dem. The best procedure appears to be to start with "tap water" from a spring or well (city water frequently contains chlorine which may pass over in the still and reappear in the product unless the condenser is properly vented). This should be treated with a softener and filter to remove the greater amount of dissolved salts, oil from pumps, particulate matter, and other products which might interfere with the efficiency of the first distillation. It should then be distilled with an ordinary well-vented still and should finally be passed into a second still, re-distilled, and the final product collected in Pyrex containers. A block tin still of the "Precision" type, if properly handled, is quite satisfactory for the final distillation for all ordinary purposes. A Pyrex still can also be used. Distillation in quartz, silica, silver, or other special types of stills will seldom be necessary. Special precautions to insure removal of traces of particular elements may have to be taken in special cases-thus, Pyrex can, of course, not be used for storage of water to be used in any critical experiments on the behavior of tissues towards boron, rubber tubing or stoppers should not be used in experiments with zinc or sulfur, and so on (A rnon, 1938, 13.3; Arnon and Stout, 1939, 13.4, 135; Stout and Arnon, 1939, 140; Hoagland and Arnon, 1941, 
137). With these points in mind, a satisfactory supply of water can be prepared.

Salts must be accurately weighed. With the exception of the sugar (see later) which can be weighed on a coarse torsion balance in the media room, all weighings should be carried out in the laboratory room on high grade quantitative balances.

The actual preparation of media will be discussed in a separate chapter and the glassware required will be listed there.

Glassware must be kept scrupulously clean (Richards, 1936, 452). Carrel (see Parker, 1938, 26) boils his flasks in soap solution, rinses thoroughly with water and then with 95 per cent alcohol, and allows them to dry, after which they are dry-sterilized. Vogelaar and Erlichmann (1939, 457) recommend washing in a sodium pyro-phosphate solution. In this laboratory, it has been customary to wash all glassware after use in a sulfuric acid-potassium dichromate solution, made up without added water. The cleaning solution is kept in 3-gallon glazed crocks, such a crock being placed in one corner of the vitreous or wellparaffined sink. The flasks to be washed are first emptied and, if they contain any solid matter, this is rinsed out (Step 1 in the cleaning routine). They are then placed in the acid and allowed to 
stand for a few minutes (Step 2). For ordinary routine washing of flasks used only for liquid nutrients, the time required to transfer 50 flasks from the draining table to the rinsing container (Step 4 in the washing routine) is usually long enough for flasks to stand in the acid. Flasks which have contained solid residues likely to stick to the walls should be left in acid over night. After standing the requisite time, the flasks are removed from the acid, using linemen's rubber gloves, are drained thoroughly into the crock, and are then placed on $18^{\prime \prime} \times 24^{\prime \prime}$ enamel trays for further draining (Step 3). While they are draining, a second batch of flasks can be immersed in the crock of acid. After thorough draining on the trays, the flasks are placed under rumning warm water for a few minutes (Step 4). It is important that all traces of bichromate be removed (Richards, 1936, 452). They are then rinsed thoroughly at least five times in rumning tap water, twice in single-distilled water, and finally once in double-distilled water, after which they are inverted in paper-lined metal trays and set aside to dry. Excess cleaning solution from the draining trays can be poured back into the crock at intervals. The acid should be replaced by fresh whenever it turns green and ceases to remove pencil markings on flasks without rub- 
bing. Do not pour exhausted solution down the sink! It can be emptied in some waste place where it will do no serious damage.

Nutrients will generally be made up in 4-liter, 10-liter, or 20-liter serum bottles (see later). A supply of graduates of various sizes, 125, 250, 500, and $1000 \mathrm{ml}$. Erlenmeyer flasks, 500, 1000, and $3000 \mathrm{ml}$. balloon flasks, test tubes, pipettes, etc., will be required for the preparation of different nutrients and should be kept in the media room. Both absorbent and non-absorbent cotton, a good grade of cheesecloth, heavy paper for wrapping glassware for dry-sterilization, cord, stones for sharpening instruments, etc., should also be provided.

Cotton plugs for flasks should be of non-absorbent cotton and should be wrapped in cheesecloth. This reduces the danger of plugs sticking to the mouths of the flasks, prevents loose fibers from falling into the flasks, and helps to preserve the form of the plugs. Plugs prepared in this way can be used repeatedly. It has been found best to cover each plugged flask with an inverted $50 \mathrm{ml}$. beaker to keep out dust and water of condensation, else molds are likely to grow in the plugs and ultimately penetrate to the nutrient (Figs. 29-31). (See Tukey, 1934, 87). Metal trays $13^{\prime \prime} \times 21^{\prime \prime} \times 3 \frac{1}{2}$ " (Fig. 31) are of the proper dimen- 
sions to hold forty $125 \mathrm{ml}$. Erlenmeyer flasks, and three such trays of flasks can be placed simultaneously in a 20-inch autoclave. Shelves should be provided of proper depth to hold these trays where nutrient can be stored after sterilization.

The transfer room. This is perhaps the most important room in the laboratory. A good transfer room is absolutely essential for satisfactory tissue culture work. For very simple manipulations, a low bacteriologist's hood may suffice, but for any extensive work a special room is essential, and, since the conditions required differ somewhat from those in a pathological laboratory, it should, if possible, be reserved for this work alone. Robbins, and Lewis use plywood chambers about $4^{\prime} 6^{\prime \prime} \times 5^{\prime} 6^{\prime \prime} \times 7^{\prime} 6^{\prime \prime}$, provided with air filters, electricity, and gas. The ideal transfer room should be an inside room, without windows. Windows always leak, no matter how well built, so that a marked increase in contaminations in a room provided with them always occurs in windy weather. Light from windows is also very irregular. The temperature drop across a window, moreover, sets up convection currents within the room. These amnoyances are eliminated by using an inside room. It should have no special heating unit, since such a mit is also a source of convection eurrents. A well designed air-conditioning outfit 
with proper filters and correctly placed outlets will provide adequate aeration and temperature control. A room about $8 \times 10 \mathrm{ft}$. with $8 \mathrm{ft}$. ceiling is an excellent size. The lighting should be diffuse, preferably through a broad skylight supplemented by properly placed indirect lamps. Cupboards with tight, sliding doors may be built into the walls, but there should be no fixed furniture in the room and all wall surfaces, doors, etc., should be designed so as to reduce to a minimum the possibility of dust accumulating. Outlets for electricity, compressed air, vacuum, and water should be provided. There should be a sink built into a flush hood at one end of the room. A movable table and stools should be provided. The walls and ceiling should be of washable tile or enamel and, as Carrel (see Parker, 1938, 26) has pointed out, a dark gray color is best since it reduces reflections and the mental distractions which lighter-colored surfaces always impose. Provision should be made for washing the air of the room with a series of water sprays or steam jets so as to remove any spores which may get in when the room is opened.

A transfer room for plant tissue cultures should not contain gas outlets. Gas is extremely toxic to plant materials and unburned gas may easily be occluded in the culture flasks if the mouths are 
flamed (Saeger, 1933, 261). Cotton plugs char, and bits of charred cotton falling into flasks of nutrient may vitiate the results of nutrition experiments. Cotton itself contains significant quantities of thiamin (Schopfer et Rytz, 1937, 226). With rare exceptions, the custom of flaming the mouths of tubes and plugs is a pernicious hocus-pocus. Flasks which are properly handled and plugged and are capped to keep out dust and water of condensation will remain sterile for months without flaming. Instruments can be adequately sterilized in boiling water. If needles for bacteriological studies must be flamed, this can be done quite satisfactorily in a small alcohol flame without the hazards involved in the use of gas. The use of gas around a plant tissue culture laboratory should be reduced to a minimum.

The culture rooms. The details of culture rooms, laboratory, and office will, of course, be modified to meet the needs and facilities of individual workers. Facilities for accurate control of temperature, illumination, and humidity, and experimental comparison of different levels of these factors are desirable. Since plant tissue cultures are extremely sensitive to temperature fluctuations (White, 1932, 63, 1937, 265, 266) and have an optimum temperature only slightly above room temperature (about $27^{\circ}-30^{\circ} \mathrm{C}$.), it is impor- 
tant that even the room used for routine stock cultures be air-conditioned, with faciilties for cooling in extremely hot weather. Cultures maintained in an ordinary laboratory room without such control show a marked seasonal variation in growth rate (Fig. 26) (White, 1937, 265) and may, in extreme weather, suffer serious injury. The experimental culture room should be provided with plenty of table space or, alternatively, with table-height wall benches, since most experimental cultures must be examined at frequent intervals and must be easily accessible. Stock cultures can be kept on shelves, since they do not need to be handled.

The laboratory. Like the culture room, the laboratory must be adapted for the particular type of problem in view. A complete laboratory should contain facilities for chemical analyses, a good hood, balances, drying ovens, equipment for preparation of sections and slides and their examination, equipment for special types of experiments such as respiration apparatus, facilities for glass-blowing, etc. Gas outlets for use in connection with plant tissue culture work should, where possible, be restricted to this room and the media room. There should, of course, be adequate cupboard space for chemicals.

The office. Every man has his own ideas of 


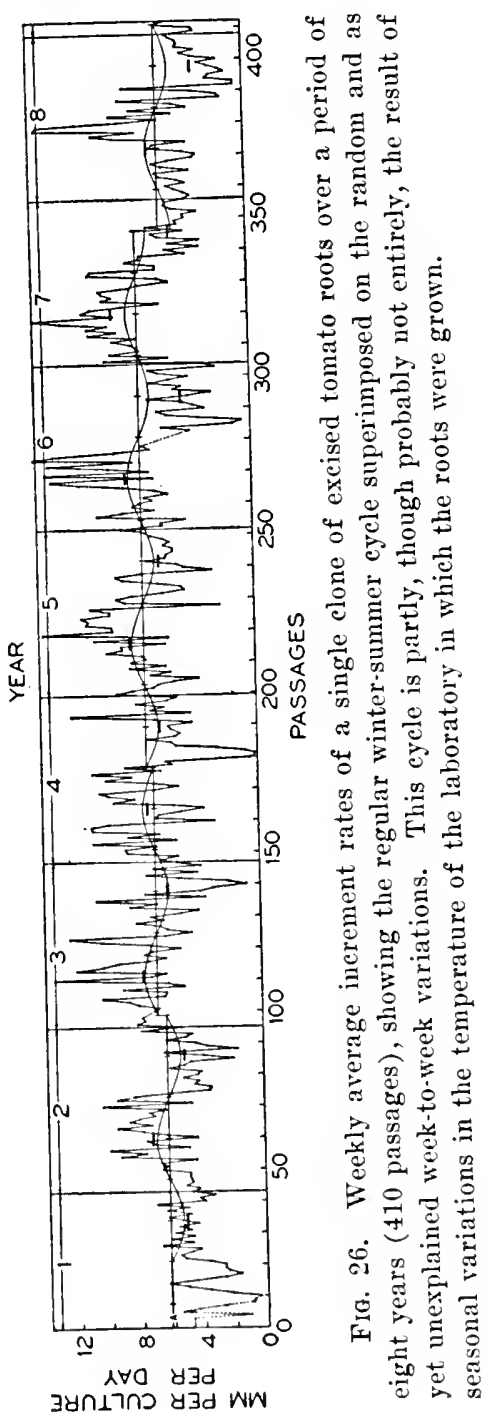


how an office should be arranged, so that that need not be treated in detail here.

What has been outlined above is approximately an ideal suite. Most setups will, of course, fall short of this ideal, but that need not detract from the quality of the work done so long as the problems attacked are restricted to those for which the available equipment is adequate. Good work has been done in many a garret. But it must be remembered that the garret is usually the birthplace of sciences, not their adult milieu. Jacques Loeb's tumblers and finger bowls would hardly have sufficed for the determination of particle shape of virus molecules.

Most of the equipment used in preparing and maintaining plant tissue cultures-glassware, implements, etc.-are the same as those available in any good microbiological laboratory, so that they need only be enumerated. There are, however, a few items not so likely to be found in the average laboratory.

Glassware. Graduates, pipettes, Erlenmeyer flasks, balloon flasks, beakers, Stender dishes, watch glasses, test tubes, hollow ground slides, cover slips of various sizes and shapes, burettes, etc., are, of course, stock necessities. Most cultures of both roots and callus can best be maintained in $125 \mathrm{ml}$. Erlenmeyer flasks. These can 
be handled far more easily than test tubes (which require special sloped racks), they present a larger space in which to work when dissections are to be performed on the cultures, they will stand on an ordinary table without rolling, and they are easily cleaned. They do occupy considerable space. Special flasks such as Carrel flasks
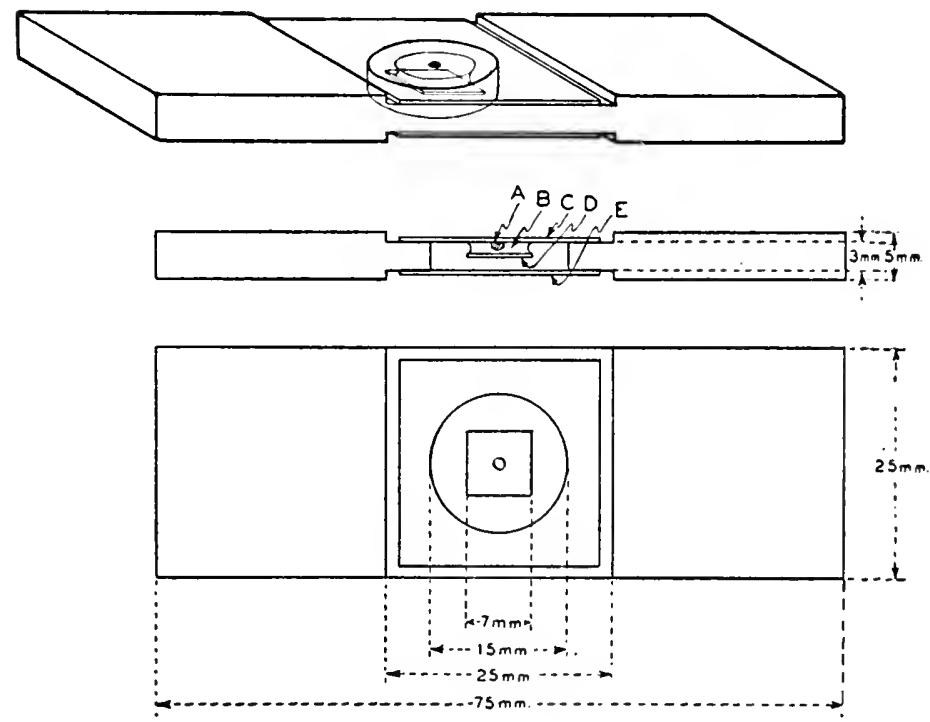

FIG. 27. Diagram of a special, piereed slide found particularly satisfactory for hanging-drop cultures of plant tissues. A, tissue fragment. B, drop of nutrient. C, square $22 \times 22 \mathrm{~mm}$. No. 1 cover glass on which culture is made. D, small $7 \times 7 \mathrm{~mm}$. No. 0 cover (square or round) held on lower surface of nutrient by capillarity providing a flat lower as well as upper surface to the drop. E, square $22 \times 22 \mathrm{~mm}$. No. 2 cover glass elosing the bottom of the chamber. 
appear not to have any considerable advantages for plant tissue cultures. If test tubes are to be used-as may be desirable in some experimentsthe $1^{\prime \prime} \times 6^{\prime \prime}$ size is the most useful (Fig. 29).

Two special pieces of glassware have been found extremely useful. The first is the Maximow embryological watch glass (Maximow, 1925, 420). This has a cemented plate-glass bottom which offers an optically flat surface far superior to the pressed type in common use, especially for fine dissections under the binocular. Those with the beveled wall to the cavity are more easily cleaned than those with a straight up-and-down wall. This same property of optical flatness is often likewise important in the slides used for hangingdrop cultures. This requirement may be met in several ways. The glass Van Tiegham cell can be used. Dr. Warren Lewis places low brass rings dipped in paraffin on ordinary slides and cements the inverted cover slips to these. A still better method is to use special $3 \mathrm{~mm}$. thick slides, each of which is pierced with a 10-12 mm. hole. Short pieces of thin $(1 \mathrm{~mm}$.) slides are cemented to both top and bottom of these, at both ends, leaving a space $25 \mathrm{~mm}$. long in the center, surrounding the hole, free. A $22 \mathrm{~mm}$. square No. 2 cover slip is fastened with vaseline to the bottom of the slide in this space, forming a circular chamber with a 
thin flat bottom. The cover slip carrying the culture is then inverted over the chamber. This chamber is optically flat. It can be opened either by removal of the culture or, if access to the culture is desired without disturbing it, as for micromanipulation, the chamber can be opened from below by sliding out the first cover glass. Because of the cemented-on strips at the ends of the slides, they can be stacked one on top of another or used freely on the microscope platform without danger of deranging the cultures. Pierced slides for this purpose can be obtained for about 30 cents apiece (Fig. 27).

A special burette for filling flasks has been found useful. This will be discussed in the chapter on the preparation of nutrients.

Implements. Scalpels, scissors, needles, forceps, platinum loops, etc., are standard equipment. For severing roots in the flasks, Robbins uses a long-handled scalpel made by spot-welding a chip of razor blade to a wire held in a transfer loop handle. A surgeon's nasal scissors of the Gruenewald or Heymann type is, for many types of dissection, still more satisfactory. It is of just the right length to reach to the bottom of a $125 \mathrm{ml}$. Erlenmeyer flask, does not require a wide space for manipulation as do iridectomy scissors, will cut cleanly even against considerable resis- 
tance (a point of importance in operating on woody cultures), and is generally very efficient. For working in very large flasks, cystoscopic scissors may be desirable, but will be needed only in special cases. Scalpels have, in general, been found not very satisfactory (Fig. 28).

As has been pointed out elsewhere, it is not desirable to have gas in the transfer room. Most implements are best sterilized by boiling. This may be done in a surgeon's sterilizing pan or on an ordinary hot plate. A very satisfactory method is to place a one-liter stainless steel beaker of distilled water, heated with a Westinghouse immersion heater such as is sold to traveling salesmen for heating shaving water, on the operating table. The instruments may be kept immersed in this when not in actual use. In making transfers usually two needles or loops are employed, one being kept in the boiling water at all times. With this precaution, bacterial or fungus contaminations are almost never carried from one flask to another (Figs. 29, 30).

For flaming flasks, tubes, or needles in special cases as, for example, when it is necessary to pour nutrient from one flask to another, an alcohol lamp may be provided. 


\section{SumMary}

Ideal facilities for plant tissue culture work should include a media room for the preparation of nutrients and equipment, an operating and transfer room for the preparation of cultures, one or more culture rooms for the maintenance of cultures under accurately controlled and systematically manipulated environmental conditions, a laboratory for the study and analysis of nutrients and cultures and for chemical and physical tests, and an office for the study and filing of experimental records.

Little special equipment is required other than that to be found in any good microbiological laboratory. 


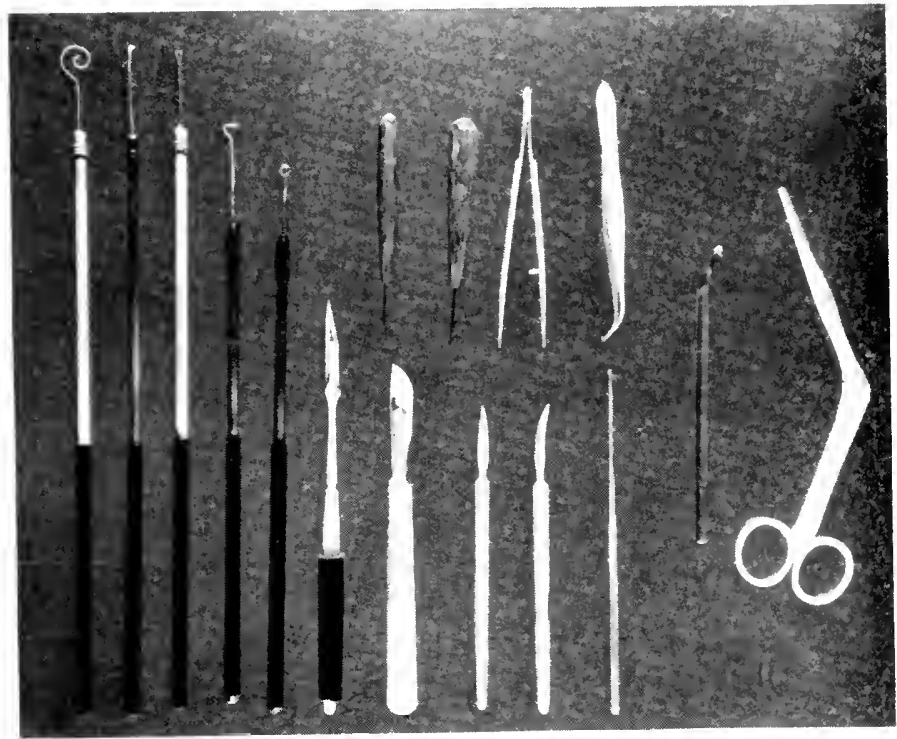

Fig. as. Implements commonly usen in plant tissme enlture work. From left to right: spiral loop used for transferring large eallus rultures intalet platinum spatula tor transferring small ant tures; loop for transforring small roots, eallus coltures, and sus pensions of hacteria, yeasts, ete.; hooked wire used by Rohbins to

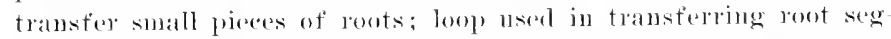
ments a centimeter or more in length; two tyges of sealpels with replaceable blades, suitable for dissesting callus vultures in situ and twe smaller sealpels with fixed lolates: a surgeon's ear-eurette used for making initial isolations of forcanbial and other meristematic tissues from stems, galls, ote : glass spatula used for grimbling tissues and making inoculations to beaves in the study of viruses in

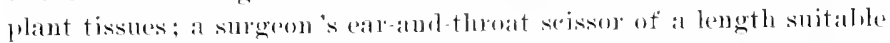

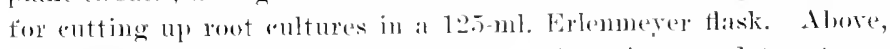
two disserting needles suitable for fine disseretions, and two types of forcenss. 

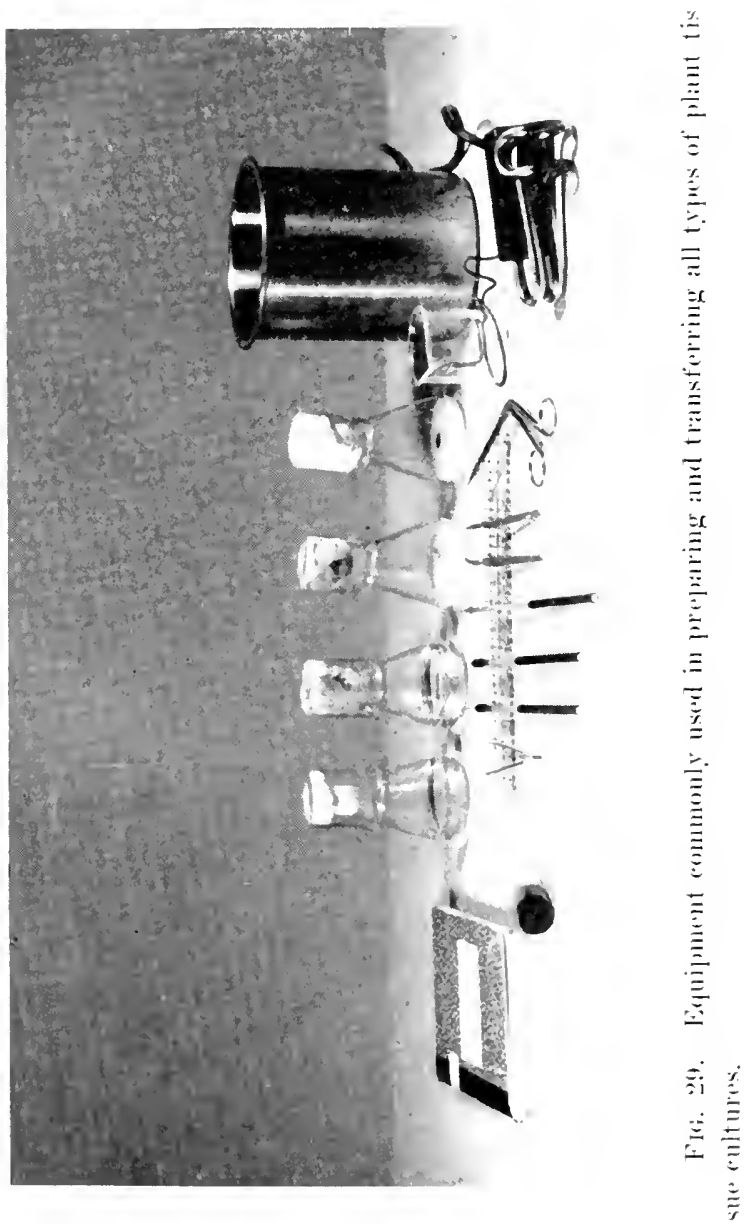


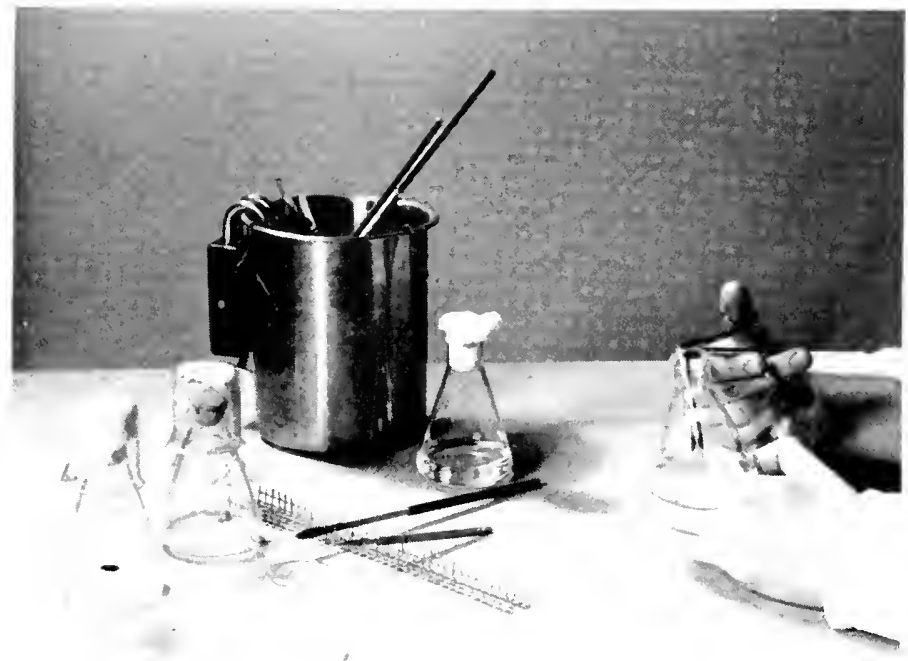

Fic. 30. J'ueedure emplosed in catting roots within their flasks, prelaratory to transferoing them to foeste motrient.

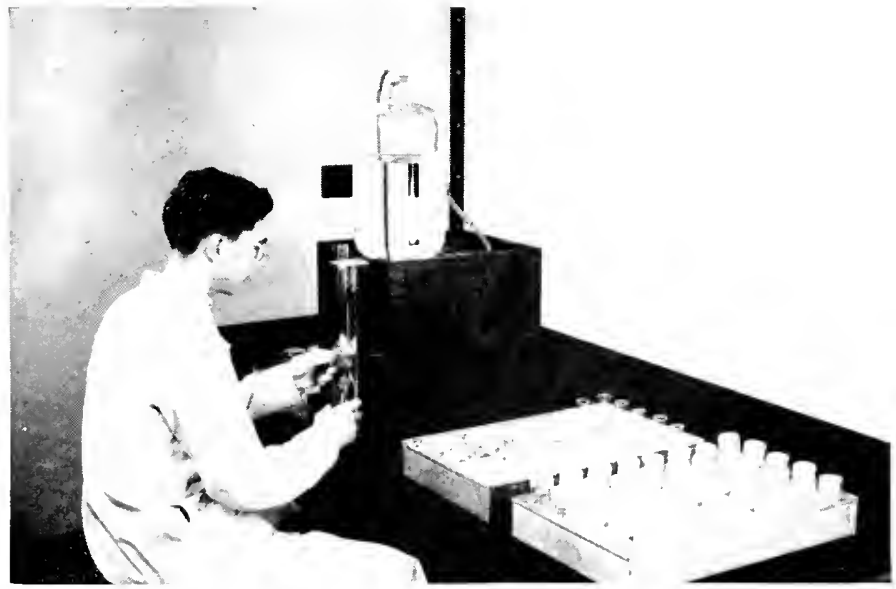

Fif. 31. Distributing untrient to tasks. The tray to the operator's left contains empty flasks which are filled from a semi-antomatic burette and transfered to the tray to the right, to lwe plugged, capled, and sterilized. 
तi

$$
\text { P'lant Tissure C'ulture }
$$

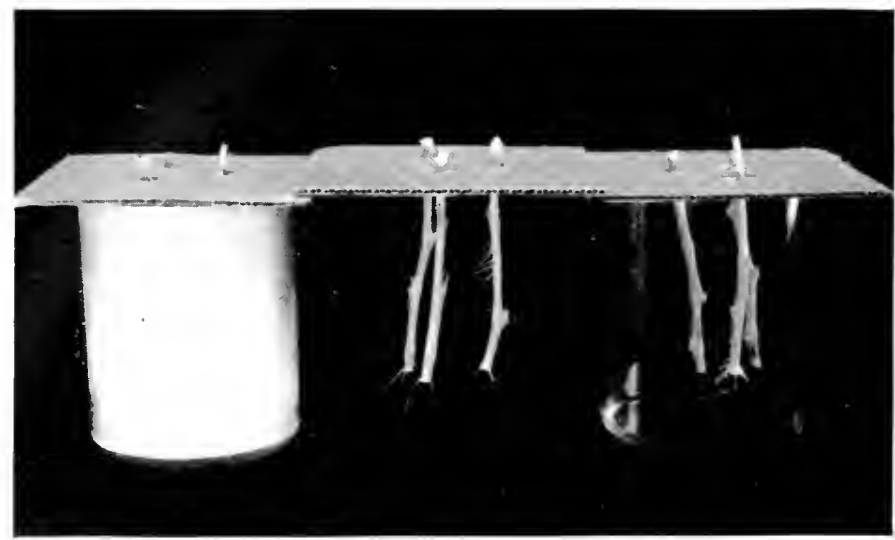

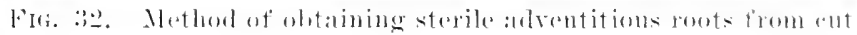
tings of tomato. Conttings alre shspended inside al ghlass eylinder

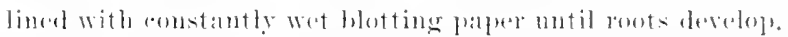

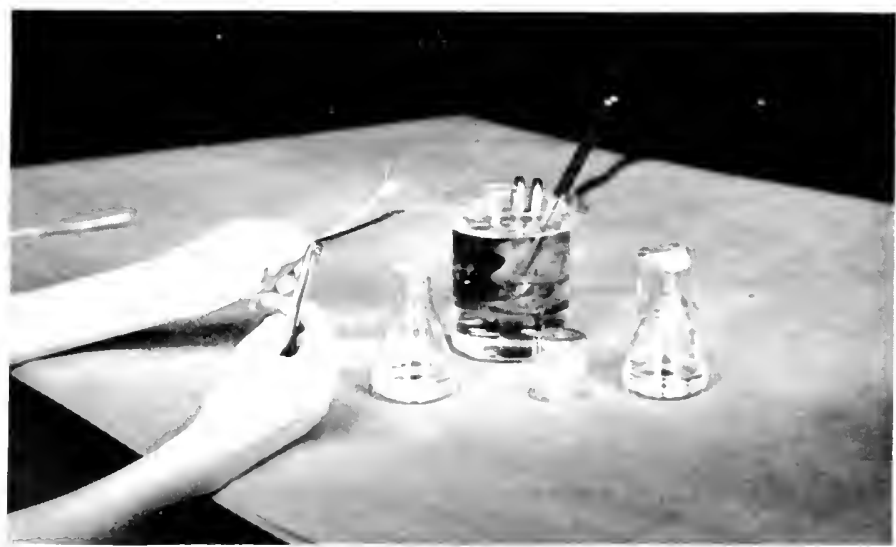

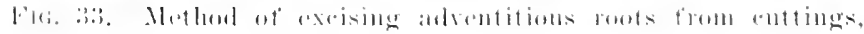
for inorolation into sterile mutrient. 



\section{Chapter V \\ NUTRIENTS}

Unlike animal tissue cultures, plant tissue cultures have from the beginning been carried out in nutrients which are wholly or in major part synthetic. This is, of course, of great practical as well as theoretical importance. Nevertheless, it has come about as a matter of necessity rather than by deliberate intent. Animal tissue culture nutrients are for the most part made up of complex organic materials-embryo extract (Carrel, 1913, 190), blood plasma or serum (Harrison, 1907, 131; Erlichman, 1935, 147), peptic digests of fibrin (Baker, 1933, 183; Baker and Carrel, 1926, 184, 185, 1928, 18\%-189; Carrel and Baker, 1926, 191; Ebeling, 1921, 192, 1924, 193; Fischer and Demuth, 1928, 194), tissue broth and the like with, it is true, salt mixtures such as Ringer's (1886, 160), Tyrode's (1910, 161), Locke's (1895, 15\%-159), or other solutions (Drew, 1922, 145, 1924, 146 ; Lewis, M. R., 1916, 148 ; Lewis, M. R., and Lewis, W. H., 1911, 149-151, 1912, 152, 153; Lewis, W. H., 1921, 154, 1923, 155, 1929, 156 ; Vogelatar and Erlichman, 1933, 162, 1934, 163, 164, 
1936, 235, 1939, 165), added, but in which these synthetic adjuncts play only a secondary and illdefined role. Little is really known about the exact constitution of such nutrients and, although they are quite satisfactory for their primary purpose of sustaining growth of isolated members, their preparation is largely a matter of rule-ofthumb. The successful use of such complexes by the animal tissue culturists antedated by many years the development of satisfactory plant tissue culture media. Attempts were, of course, made to utilize similar media for plant tissues but, as we have already seen, these attempts all failed, with the exception of the single unconfirmed piece of work by Schmucker $(1929,110)$. This failure has had as one consequence the forcing of investigation into a different channel and the slow, tedious building up of a mass of information sufficient to permit the designing of nutrients made up of welldefined products of synthetic origin in place of the ill-defined organic broths and juices.

Plant tissue culture nutrients contain four categories of materials. These are, first, water; second, inorganic salts; third, organic constituents; and sometimes, fourth, coagulating agents.

Water. Since water makes up approximately 97 per cent of the mass of all nutrients, while some other ingredients are required in amounts repre- 
sented by ten-thousandths of a per cent, the purity of the water used is of prime importance and cannot be overemphasized (White, 1932, 63, 1933, 141). "Tap water"' is, of course, worse than useless in any critical studies on nutrition. Many laboratory supplies of "distilled water" are likewise worthless, because of significant amounts of impurities of many sorts. These may range from traces of lead from improperly soldered joints in faucets to distillable petroleum-oil fractions coming from the pumps used in wells or pumping plants from which the "tap water"' is derived. In order to insure a truly pure supply, water should be first run through a softener and filter (see Chapter III), then distilled at least twice, and finally stored in vessels of hard glass or Pyrex. Carboys can be covered with inverted beakers to keep out dust or can be plugged with wads of clean cotton enclosed in well-boiled and rinsed cheesecloth. Rubber stoppers should not be used, and care must be taken that water does not come in contact with cotton plugs.

Salts. Plant tissues require for satisfactory growth at least eleven elements besides oxygen, hydrogen, and carbon. These are calcium, potassium, magnesium, nitrogen, sulfur, phosphorus, iron, manganese, zine, boron, and iodine. While not essential, sodium and chlorine are to be con- 
sidered as not undesirable additions. These elements are supplied in the form of inorganic salts (White, 1933, 141, 1937, 142, 143, 1938, 144 ; Berthelot, 1934, 136; Robbins, V. B. White, et al., 1936, 139 ; Bonner and Addicott, 1937, 42). Because of the extremely minute quantities of some of these elements which are required and because of the toxic effects which very small traces of other elements may exert, it is essential that the salts used be of the greatest possible purity. For stock nutrients, the "C.P. Grade" products of most reliable manufacturers are satisfactory, but for critical studies it may be necessary to prepare specially purified salts. Methods of purification for particular purposes, by recrystallization or by other means, have been developed and are to be found in the literature of plant nutrition (see Arnon, 1938, 133; Arnon and Stout, 1939, 134, 135; Stout and Arnon, 1939, 140). Detailed procedures for any given problem will have to be chosen with the particular exigencies of that special problen in mind. Procedures used in the preparation of nutrients will be considered later.

Organic materials. The organic materials required for the nutrition of plant tissue cultures fall into four main groups: carbohydrates, vitamins and hormones, amino-acids and other simple nitrogenous substances, and organic complexes of the tissue broth type. 
Carbohydrates. Carbohydrates make up from 0.5 per cent to 10 per cent of the mass of nutrients. They serve two main purposes: as sources of energy for the maintenance of the various living processes in the growing tissues, and as osmotic agents. Apparently the first of these, as energy source, is their major role, for nutrient solutions which have proved satisfactory for plant tissues, in marked contrast to animal tissue culture nutrients, are seldom isotonic with the tissues themselves. The osmotic value of the nutrient seldom exceeds 2 atmospheres for a tissue having an "osmotic value" of 5 to 10 atmospheres (Thielman u. Bérzin, 1927, 263). This discrepancy may be more apparent than real, since the "osmotic value" usually given for plant tissues is the plasmolytic value and may be greatly in excess of the true osnotic value of the protoplasm itself (Bennet-Clark, Greenwood and Barker, 1936, 23s; Mason and Phillis, 1939, 446). That the major role of the carbohydrate is nutritional rather than osmotic is further indicated by the fact that specific carbohydrates, not carbohydrate per se, are required. Glucose and fructose have been employed in some media, particularly those used for the eultivation of tissues of monocotyledonous plants, but with results which have not been entirely satisfactory (Kotte, 1922, 51, 52; Robbins, 
1922, 57; Robbins and Maneval, 1923, 59 ; Robbins and V. B. White, 1937, 178; Malyschev, 1933, 53, 54; White, 1932, 63, 1940, 172, 173). Mannose, galactose, etc., have also been tested. There is some evidence that galactose may be quite toxic (White, 1940, 173). This unsatisfactory behavior of the monosaccharides may be due in part to the difficulty in purifying them adequately (Robbins and Bartley, 1937, 170; Robbins and Schmidt, 1939, 61). All commercial preparations of monosaccharides, even the best "C.P. Grade," contain varying amounts of impurities which may be injurious. They are also relatively unstable to heat and cannot be autoclaved with impunity (Thielman, 1938, 171). Fortunately, the much more easily purified and more stable disaccharide, sucrose, is a completely satisfactory carbohydrate for all plant tissues which have so far been grown successfully (White, 1934, et seq., 65, 66, 78, 172, 173; Fiedler, 1936, 45; Robbins and Bartley, 1937, 222; Robbins and Schmidt, 1938, 60; Thielman, 1938, 171). Although maltose, brown sugar (Robbins and Schmidt, 1938, 60, 1939, 224), and even dextrin (White, 1940, 173) have given excellent results in some experiments, their beneficial effects above those of sucrose are to be attributed to non-carbohydrate impurities. There is to date no evidence that any sugar other than sucrose needs 
to be employed. Sucrose crystallizes easily so that even the commercial sugar to be bought in every grocery store is usually as pure or purer than most "C.P. Grade" chemicals, though perhaps less reliable. The use of "C.P. Grade" is to be recommended for all critical studies, as a precaution. "C.P. Grade" sucrose usually contains some calcium and magnesium, but the quantities of these two elements required for normal growth of plant tissues are so high that the traces likely to come from the sugar are too small to be of probable significance. Its content of copper and zine may possibly be significant. It does not appear to contain significant quantities of any of the vitamins known to be important for the activity of plant tissues. (Compare Ebeling, 1914, 271, 1936, 174 ; Lewis, 1922, 175.)

Vitamins and hormones. Four oligodynamic organic substances have been reported to be important for the growth of excised plant tissues. Fortunately, all four of these substances are available as synthetic products of high purity.

The only universally necessary member of this group seens to be thiamin (vitamin $B_{1}$ ) (Bonner, 1937, 198, 199; Robbins and Bartley, 1937, 222, 223 ; White, 1937, 231 ; Gautheret, 1938, 69 ; Nobécourt, 1938, r5). Thiamin or its precursors have been shown to be essential for, or at least highly beneficial to, the growth of a great variety of plant 
parts. In some cases apparently either the thiazole portion of the thiamin (Robbins and Bartley, 1937,223 ) or both thiazole and pyrimidine (Bonner, 1938, 199, 1940, 201; Bonner and Buckman, 1938, 239) may be substituted for thiamin itself, and there appears to be some evidence that the thiazole can be replaced by certain complex substituted pyridines, but no plant tissues appear to be able to maintain themselves for long without some source of thiamin activity. In many types of tissues, this requirement becomes evident in complete failure of the cultures if thiamin or thiazole is not included in the nutrient (Bonner, 1937, 198, 1938, 199; Robbins and Bartley, 1937, 222, 223; White, 1937, 231, 1939, 182 ; Bonner and Devirian, 1939, 205). Here the tissues are clearly unable to synthesize thiamin. In other cases, no growth failure may occur in the absence of an external source of thiamin, but thiamin may be recovered in increasing quantities from cultures grown for long periods, showing that the vitamin has been synthesized by the tissues in quantities sufficient to supply their growth requirements (Bonner and Devirian, 1939, 205; Nobécourt, 1940, 252; McClary, 1940, 248).

Nicotinic acid appears to be equally important for a somewhat smaller number of plants such as legumes (Bonner, 1938, 200; Addicott and Bonner, 
1938, 197 ; Bonner and Axtman, 1937, 203 ; Bonner and Devirian, 1939, 205). These show a marked failure in the absence of a significant external source of nicotinie acid. Since no means of estimating nicotinic acid concentrations in small quantities of plant tissues is yet available, it is not yet possible to determine if those plant members which do not require an external source of nicotinic acid may synthesize it in quantities sufficient to satisfy their needs. It is, therefore, not possible as yet to say if all plant tissues require nicotinic acid or not. It is only elear that most tissues do not require an external source and that a few tissues de require such a source.

Pyridoxine (vitamin $B_{6}$ ) is also clearly beneficial to many plant tissues. It lias been reported to be necessary for satisfactory growth of roots of tomato (Robbins and Schmidt, 1939, 61, 224, 225; Robbins, 1940, 202; Day 1941, 208 ; Bonner, 1940, 201). The evidence in support of this report is not conclusive and has been opposed by other evidence (White, 1940, 232). Certainly many plant tissues ean dispense with all external sources of this vitamin. As with nicotinic acid, there is no evidence either for or against its synthesis by plant tissues.

Indole acetic acid has been reported to benefit the growth of roots of maize (Geiger-Huber, 1936, 
214; Geiger-Huber u. Burlet, 1936, 215 ; Thielman u. Peléce, 1940, 227; Duhamet, 1939, 209), callus cultures from poplar and carrot (Gautheret, 1937, 211, 1939, 212, 1940, 213 ; Nobécourt, 1937, 74, 1938, $75,1939,77)$, and some other types of plant issue cultures (Fiedler, 1938, 45; Thimann and Skoog, $1940,454)$. It has also been shown to be produced by some roots (Thimann, 1936, 228; Nagao, 1936, 249, 1937, 250, 1938, 251; van Overbeek, 1939, 253 254 ; van Overbeek and Bonner, 1938, 255). There is no evidence that it is necessary for such growth and considerable evidence to show that it may be highly injurious. Ascorbic acid, biotin, and other vitamins may likewise play an as yet undetermined role in the development of plant tissues. (Kögl u. Haagen-Smit, 1936, 358; Bonner and Bonner, 1938, 204; Duhamet, 1939, 209$)$.

Organic nitrogen. Amino-acids. Many plant tissues require, in addition to water, salts, carbohydrate, and thiamin or other vitamin, some source of organic nitrogen. This may be supplied in a variety of ways. Many plant tissues will thrive on a nutrient in which this need is met by the single amino-acid glycine (glycocoll) (White, $1939,182)$. This is obtainable as a synthetic product of high purity and is to be recommended wherever its use will give satisfactory results. In other cases, it may be necessary to supply a more 
complex source in the form of a mixture of a number of amino-acids (White, 1935, 179, 1937, 181; Bonner and Addicott, 1937, 42). In that case, the synthetic acids should be used wherever possible, or where they are not available amino-acids of the highest possible purity should be obtained. This must be emphasized because amino-acids of "natural" origin are likely to be themselves mixtures. Thus, even the best commercial samples of leucine are known to contain considerable and highly significant amounts of methionine (Mueller, 1935, 447).

Organic complexes. All tissue culture media contain accessory organic (non-carbohydrate) material of some sort. The early nutrients included yeast extract (Robbins, 1922, 17r; White, 1932, 63, 1934, 65, 1937, 180 ; Fiedler, 1936, 45), Liebig's beef extract (Kotte, 1922, 51, 52; White, 1932, 89), peptones (Robbins, 1922, 17r), fibrin digests (White, 1932, 89), etc. (See also Haberlandt, 1902, 98; Loo and Loo, 1935, 216, 1936, 217). The use of thiamin, nicotinic acid, pyridoxime, the aminoacids, etc., is the outcome of a long and painstaking study of these complexes and in most cases permits us to dispense with the more complex materials entirely. This has not always proved true, however, and it is frequently desirable, when a new tissue or a member taken from a previously 
unstudied species of plant is under investigation, to employ a complex source of organic adjuncts and only gradually to approach the simpler media. While peptone or fibrin proteose preparations (Fischer and Demuth, 1928, 194; Baker, 1933, 183) may sometimes be used with success, the complex of most uniform usefulness is yeast extract. Brewer's yeast is apparently superior to baker's yeast and the well known "Brewer's Yeast-Harris" has proved very satisfactory for this purpose. The standard procedure has been to weigh out 10 grams of dry "Brewer's Yeast-Harris", into a liter of distilled water, boil for one-half hour, then centrifuge, decant the supernatant, make up to one liter, divide into $50 \mathrm{ml}$. aliquots in Pyrex test tubes, and freeze at $-15^{\circ} \mathrm{C}$. Ten $\mathrm{ml}$. of this concentrate is sufficient to make one liter of complete nutrient (White, 1937, 180) (see later). In the frozen state this will keep indefinitely without deterioration. Fibrin digest may be prepared in a similarly concentrated form by use of pepsin or by bacterial digestion (Fischer and Demuth, 1928, 194).

Coagulants. While most tissues grow satisfactorily in liquid media, there are some circumstances under which it is useful to provide a semisolid substratum (see Robbins, 1922, 57; Kotte, 1922, 51, 52; Úlehla, 1928, 115; White, 1933, 64, 
1939, 78, 333; Fiedler, 1936, 45; Gautheret, 1935, $15,1937,68)$. It is, of course, desirable to keep the medium as nearly as possible of the same chemical constitution as are the liquid media. Two common coagulants are available. Gelatin has been used by some workers. This requires a concentration of $10-20$ per cent to maintain a satisfactory consistency, which introduces not only a considerable risk of chemical contamination but also a marked adsorption factor. Agar, on the other hand, will give satisfactory consistency at 0.75 per cent. Commercial agar is seldom free of soluble contaminants and must be thoroughly leached. Take $60 \mathrm{~g}$. of finely shredded agar (the powdered forms are likely to contain a contaminating "filler"), add 2 to 3 liter's of distilled water, and set aside in a cool room. Change the water 3 times daily for a week. After thorough leaching, make up to the required volume with mutrient solution, melt, filter through cotton, and distribute to flasks or test tubes. These can then be autoclaved and set aside to cool.

The preparation of mutrients. While there is already a considerable number of nutrients in use having slightly different constitutions, the procedures used in their preparation will scarcely vary greatly in any important details. A stock example can, therefore, be given which can be con- 
sidered typical. The nutrient used in this laboratory for all routine cultures at present (1942) has the following constitution:

\begin{tabular}{lcl}
\multicolumn{1}{c}{ Salts } & Mg./liter & Mols. \\
$\mathrm{MgSO}_{4}$ & 360.0 & $3 \times 10^{-3}$ \\
$\mathrm{Ca}\left(\mathrm{NO}_{3}\right)_{2}$ & 200.0 & $1.2 \times 10^{-3}$ \\
$\mathrm{Na}_{2} \mathrm{SO}_{4}$ & 200.0 & $1.4 \times 10^{-3}$ \\
$\mathrm{KNO}_{3}$ & 80.0 & $8 \times 10^{-4}$ \\
$\mathrm{KCl}$ & 65.0 & $9 \times 10^{-4}$ \\
$\mathrm{NaH}_{2} \mathrm{PO}_{4} \cdot \mathrm{H}_{2} \mathrm{O}$ & 16.5 & $9 \times 10^{-5}$ \\
$\mathrm{Fe}_{2}\left(\mathrm{SO}_{4}\right)_{3}$ & 2.5 & $6 \times 10^{-8}$ \\
$\mathrm{MnSO}_{4}$ & 4.5 & $3.7 \times 10^{-8}$ \\
$\mathrm{ZnSO}_{4}$ & 1.5 & $9.4 \times 10^{-8}$ \\
$\mathrm{H}_{3} \mathrm{BO}_{3}$ & 1.5 & $1.2 \times 10^{-8}$ \\
$\mathrm{KI}$ & 0.75 & $4.5 \times 10^{-7}$ \\
Sucrose & 2000.0 & $6 \times 10^{-3}$ \\
Glycine & 3.0 & $4 \times 10^{-5}$ \\
Nicotinic acid & 0.5 & $4 \times 10^{-8}$ \\
Pyridoxine & 0.1 & $4.9 \times 10^{-7}$ \\
Thiamin & 0.1 & $2.3 \times 10^{-7}$
\end{tabular}

Osmotic value $\pi=1.8 \mathrm{~atm}$.

Since this nutrient is used in great quantity and must be made up at frequent intervals, it is not efficient to weigh out the separate constituents for each new set of nutrient. In practice only the sucrose and the iron are weighed each time, the first because any stock solution containing sucrose would ferment unless sterilized and kept sterile, the second because in solution $\mathrm{Fe}_{2}\left(\mathrm{SO}_{4}\right)_{3}$ rapidly oxidizes and precipitates. All the other constituents are taken from concentrated stock solutions which will keep indefinitely.

The inorganic stock solution is made up as fol- 
lows: 20 g. $\mathrm{Ca}\left(\mathrm{NO}_{3}\right)_{2}, 20$ g. $\mathrm{Na}_{2} \mathrm{SO}_{4}, 6.5$ g. KCl, 8 g. $\mathrm{KNO}_{3}, 1.65$ g. $\mathrm{NaH}_{2} \mathrm{PO}_{4}, 0.45 \mathrm{~g}$. $\mathrm{MnSO}_{4}, 0.15 \mathrm{~g}$. $\mathrm{ZnSO}_{4}, 0.15 \mathrm{~g} . \mathrm{H}_{3} \mathrm{BO}_{3}$, and $0.075 \mathrm{~g}$. KI are dissolved together in 8 liters of distilled water. 36 g. of $\mathrm{MgSO}_{4}$ are dissolved in 2 liters of distilled water. The two solutions are then mixed slowly, stirring constantly. Some insoluble precipitate may form in the bottom of the bottle. The resulting solution is stored in a dark bottle to prevent growth of algae. Ten liters of this solution are sufficient to make 100 liters of nutrient, taking 100 $\mathrm{ml}$. for each liter of nutrient required.

The stock solution of accessory organic materials is made up as follows: Three grams of glycine, $500 \mathrm{mg}$. of nicotinic acid, $100 \mathrm{mg}$. of pyridoxine, and $100 \mathrm{mg}$. of thiamin are dissolved together in 1 liter of distilled water. This is pipetted into Pyrex test tubes in $10 \mathrm{ml}$. aliquots and stored in the icebox at $-5^{\circ} \mathrm{C}$. A liter of this stock will make 1000 liters of nutrient, taking 1

\footnotetext{
* For callus only.

** "Gelose" - presumably means agar, but is not so speeified, $15,7 \mathscr{2}$.

† Extract of $100 \mathrm{mg}$. dried brewer's yeast (Harris).

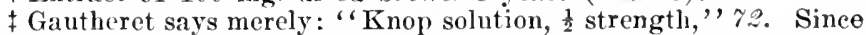
there are many different formulae in use for " Knop solution," this is indefinite. The concentrations given above correspond to a " $\frac{1}{2}$ strength solution" of the "dilute formula" given by Palladin, 449, for use with young plants. The solution for mature plants is given with a concentration 5 times that of the "dilute" solution and 10 times the concentration given in this table.

$\delta$ Gautheret says: "Take 10 drops of Berthelot's solution to each liter of nutrient,"' 7 . A Assuming 20 drops $=1 \mathrm{ml}$., Berthelot's, 186 , formula would give approximately the concentrations shown in this table.
} 
Nutrients

TABLE 1

Nutrients commonly used for cultivation of plant tissues

\begin{tabular}{|c|c|c|c|c|c|c|c|c|c|}
\hline \multirow[b]{2}{*}{ 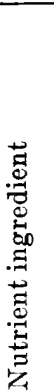 } & \multicolumn{2}{|c|}{ White } & $\begin{array}{l}\text { Rob- } \\
\text { bins }\end{array}$ & \multicolumn{3}{|c|}{ Bonner } & \multicolumn{3}{|c|}{ Gautheret } \\
\hline & 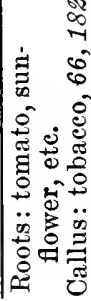 & 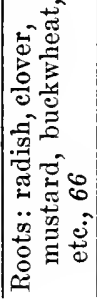 & 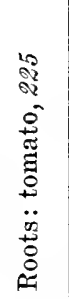 & 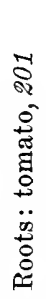 & 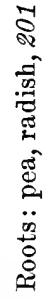 & 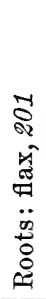 & 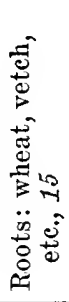 & 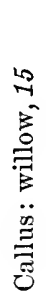 & 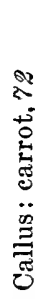 \\
\hline
\end{tabular}

Grams per liter

\begin{tabular}{|c|c|c|c|c|c|c|c|c|c|}
\hline 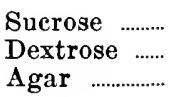 & $\begin{array}{l}20 \\
\ldots \ldots \ldots . \\
7.5^{*}\end{array}$ & $\begin{array}{l}20 \\
\ldots \ldots \ldots . . . \\
\ldots \ldots \ldots . . .\end{array}$ & $\begin{array}{l}20 \\
\ldots \ldots \ldots . . . \\
\ldots \ldots \ldots . . .\end{array}$ & $\begin{array}{l}20 \\
\ldots \ldots \ldots . . . \\
\ldots \ldots \ldots . . .\end{array}$ & $\begin{array}{l}20 \\
\ldots \ldots \ldots \ldots . . \\
\ldots \ldots \ldots . . .\end{array}$ & $\begin{array}{l}20 \\
\ldots \ldots \ldots . . . \\
\ldots \ldots \ldots . . .\end{array}$ & $\begin{array}{l}\ldots \ldots \ldots \\
20 \\
15^{* *}\end{array}$ & $\begin{array}{l}20 \ldots \\
15^{* *}\end{array}$ & $\begin{array}{l}20 \\
13^{*}\end{array}$ \\
\hline
\end{tabular}

Milligrams per liter

\begin{tabular}{|c|c|c|c|c|c|c|c|c|c|}
\hline e $\quad \ldots . . . . . . .$. & 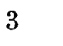 & & & $\cdots$ & $\cdots$ & $\cdots$ & $\cdots \cdots \cdots$ & …….. & . \\
\hline$\ldots$ & & $00 \nmid$ & & & & & $\ldots \ldots \ldots$ & & \\
\hline & 0.1 & & 0.2 & 0.1 & 0.1 & 0.1 & ............. & $\begin{array}{l}1 \\
10\end{array}$ & $\begin{array}{l}1 \\
10\end{array}$ \\
\hline & & $\cdots \cdots \cdots$ & $\ldots \ldots \ldots$ & $\ldots \ldots \ldots$ & $\ldots \ldots \ldots$ & 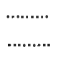 & $\begin{array}{l}10 \\
\ldots \ldots \ldots . . .\end{array}$ & $\begin{array}{l}10 \\
0.01\end{array}$ & $\begin{array}{l}10 \\
0.01\end{array}$ \\
\hline $1 \ldots \ldots .$. & 5 & $\ldots . \cdots \cdots$ & & 0.5 & 0.5 & .......... & $\ldots \ldots \ldots$ & $\ldots \ldots \ldots$ & $\ldots \ldots \ldots \ldots . .$. \\
\hline$\ldots$ & & & 0.2 & 0.1 & & & & & \\
\hline$\left.b_{3}\right)_{2}$ & 200 & 100 & 333 & 170 & 170 & 170 & $285 \ddagger$ & $285 \ddagger$ & $\begin{array}{l}285 \ddagger \\
0.2\end{array}$ \\
\hline .................... & 360 & 3 & 40 & 21 & 21 & 21 & $72 \ddagger$ & $72 \ddagger$ & \\
\hline & 80 & 80 & & & & 85 & & 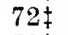 & \\
\hline & 65 & & 43 & 61 & 61 & 61 & $72 \ddagger$ & $72 \ddagger$ & 72 \\
\hline ............. & & . & 60 & 20 & 20 & 20 & $72 \ddagger$ & $72 \ddagger$ & $72 \ddagger$ \\
\hline & 200 & & $\ldots \ldots \ldots$ & $\ldots \ldots \ldots$ & $\ldots \ldots \ldots$ & $\ldots \ldots \ldots$ & $\ldots \ldots \ldots$ & $\ldots \ldots \ldots$ & ....... \\
\hline $\mathrm{O}_{4} \ldots \ldots$ & 16.5 & 16.5 & ........... & $\ldots \ldots \ldots$ & ........... & 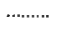 & $\ldots \ldots \ldots$ & $\cdots \cdots \cdots$ & $\ldots$ \\
\hline & & & & ........... & ........ & $\ldots \ldots \ldots .$. & & & \\
\hline & 2.5 & 2.5 & 2.5 & 15 & 5 & 15 & $20 \ddagger$ & $20 \ddagger$ & $20 \ddagger$ \\
\hline & & & .... & & & $\begin{array}{l}1.5 \\
\ldots . . . \cdots\end{array}$ & 0.46 & 0.45 & \\
\hline & & & 0.1 & ............... & ........... & .............. & ........... & ........... & \\
\hline & 1.5 & 1.5 & 0.1 & $\ldots \ldots \ldots$ & .......... & $\ldots \ldots \ldots \ldots$ & ............ & ............ & $0.02 \S$ \\
\hline$\ldots \ldots$ & $\ldots \ldots \ldots$ & $\ldots \ldots \ldots$ & $\ldots . . . . .$. & $\ldots \ldots \ldots . .$. & ........... & .......... & .......... & $\ldots \ldots \ldots$ & \\
\hline & & & & $\ldots \ldots \ldots$ & ........... & $\ldots \ldots \ldots$ & $\ldots \ldots \ldots$ & $\ldots \ldots \ldots \ldots$ & $0.01 \S$ \\
\hline & $\ldots . . . . . . .$. & $\ldots \ldots \ldots . .$. & $\ldots \ldots \ldots$ & $\ldots \ldots \ldots . .$. & .......... & .......... & $\ldots . \cdots \cdots$ & .......... & \\
\hline & & & & $\ldots \ldots \ldots$ & $\ldots \ldots \ldots$ & $\ldots \ldots \ldots$ & $\ldots \ldots \ldots$ & $\ldots \ldots \ldots$ & \\
\hline & $\ldots . .$. & ........... & .......... & ........... & ........... & ........... & $\ldots . \cdots \cdots$ & $\ldots . \cdots \cdots$ & \\
\hline & & ........... & .......... & $\ldots \ldots \ldots .$. & ......... & .......... & $\ldots \ldots \ldots$ & $\ldots \ldots \ldots$ & 0.0004 \\
\hline
\end{tabular}


ml. for each liter of nutrient required. A comparison of this nutrient with a number of others in common use is given in the accompanying table.

A convenient experimental series includes 200 cultures requiring 10 liters of nutrient. Each culture receives $50 \mathrm{ml}$. of solution. To prepare nutrient for such a series, $200 \mathrm{~g}$. of sucrose are dissolved in 2 liters of double-distilled water. In 1 liter of water are dissolved $25 \mathrm{mg}$. of $\mathrm{Fe}_{2}\left(\mathrm{SO}_{4}\right)_{3}$. These are mixed, 1 liter of stock salt solution and $10 \mathrm{ml}$. of glyeine-thiamin solution are added, and the whole is made up to 10 liters. This is then distributed to the eulture flasks in $50 \mathrm{ml}$. aliquots, using a special semi-automatic measuring burette (Fig. 31) which greatly facilitates rapid manipulation. For experimental nutrients (as distinct from stock nutrients) where each liter differs from each other one in constitution, it is best to use graduates instead of burettes for this distribution. After all the flasks are correctly charged with nutrient, they are plugged with cheeseelothcovered non-absorbent cotton plugs, capped with inverted $50 \mathrm{ml}$. beakers, and sterilized.

Sterilization. Most nutrients used for plant tissue cultures contain suerose and are unaffected by autoclaving. The usual routine is to sterilize for 20 minutes at $18-20 \mathrm{lbs}$. pressure. It has been found convenient to place flasks of nutrient as soon as filled in galvanized iron trays $13^{\prime \prime} \times 21^{\prime \prime} \times 32^{\prime \prime}$. 
Each tray holds forty $125 \mathrm{ml}$. Erlenmeyer flasks and three trays (120 flasks) can be sterilized at once in a 20 -inch autoclave. They can then be conveniently handled and stored without removing from the trays. While autoclaving is satisfactory for most nutrients likely to be used in plant tissue culture work, those containing dextrose are somewhat thermolabile and are better sterilized either in the Arnold type of sterilizer or by filtration through Seitz filters or Berkefeld candles. These methods are all so thoroughly standardized in general microbiological practice that they need not be described here.

Storage. Once sterilized, the stock nutrients will keep indefinitely aside from the gradual concentration which results from evaporation. Because of this last factor, it is best not to use nutrients that are more than a month old unless they have been stored in a moist room.

Special mutrients. The details presented above apply specifically to the standard nutrient used for the maintenance of all stock cultures in this laboratory. This standard nutrient is employed in most nutrition experiments as a basis of comparison designated as the control. Experiments involving the stimulatory or depressant effects of increased concentrations of standard ingredients or of materials not present in this nutrient can be set up merely by adding the required materials 


\section{Example 1}

To study effects of various concentrations and combinations of thiamin and vitamin $B_{8}$

November, 1939

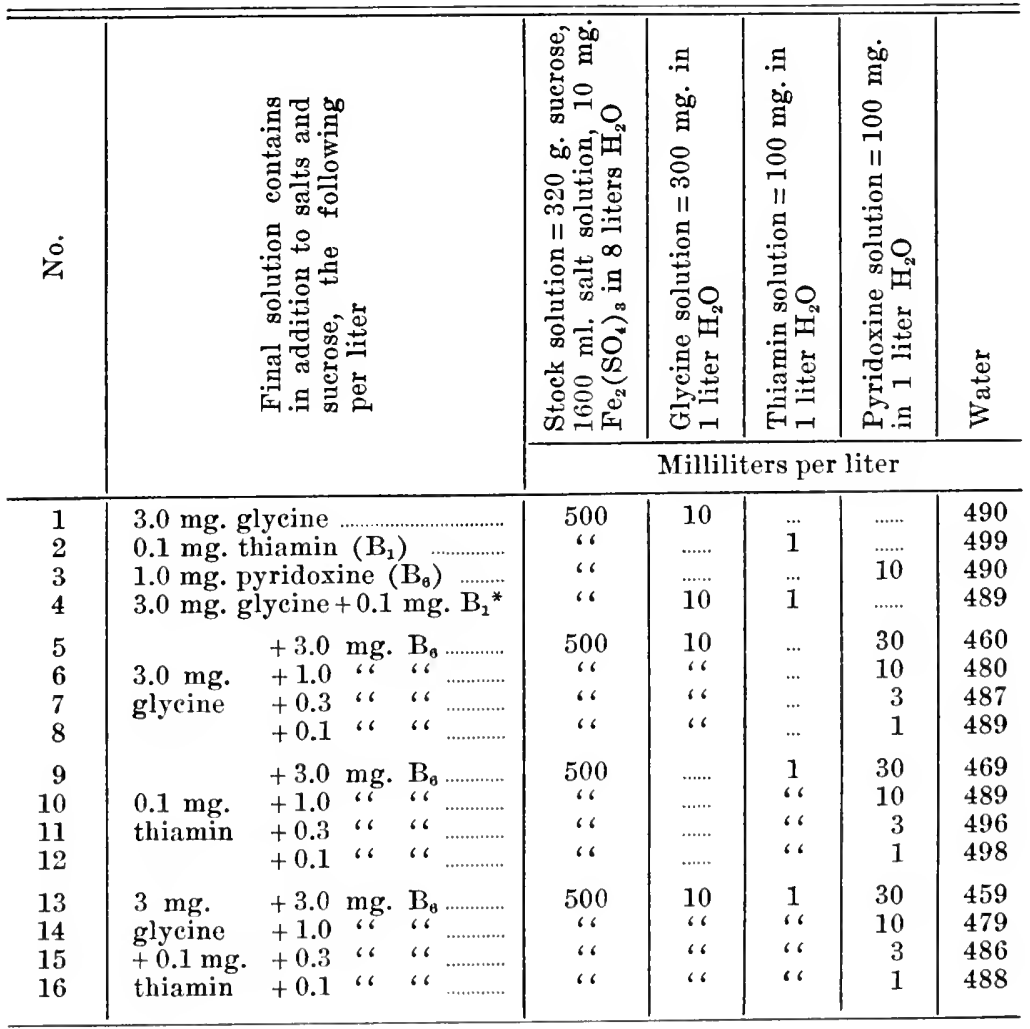

* Control. 


\section{EXAMPLE 2}

To study effects of various concentrations of three iron salts

May, 1940

\begin{tabular}{|c|c|c|c|c|c|c|c|}
\hline \multirow[t]{2}{*}{$\dot{0}$} & & \multirow[t]{2}{*}{ 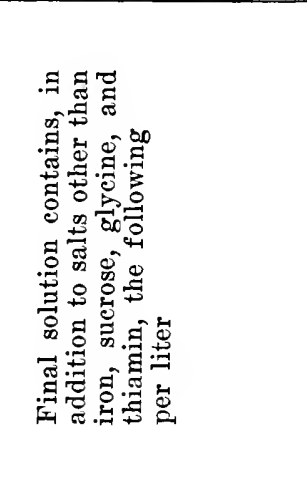 } & 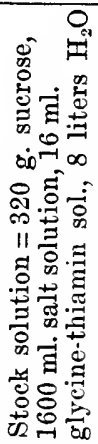 & 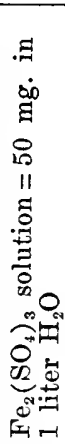 & 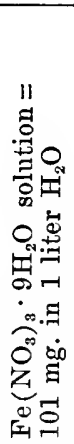 & 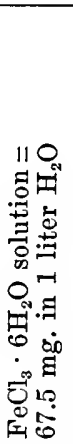 & $\underset{B}{\stackrel{ \pm}{ \pm}}$ \\
\hline & & & \multicolumn{5}{|c|}{ Milliliters per liter } \\
\hline 1 & & & 500 & & $\ldots$ & ............ & 500 \\
\hline 2 & 0.6 & $10^{-\mathrm{a}} \mathrm{M} \mathrm{Fe}_{2}\left(\mathrm{SO}_{4}\right)_{3}$ & 6 & 5 & (n............... & (n............ & 495 \\
\hline 3 & 3.6 & 6263 & 6 & 17 & .................. & ............ & 483 \\
\hline 4 & 6.0 & "، & 6 & 50 & ................. & .............. & 450 \\
\hline 5 & 36.0 & 6 & 6 & 167 & .............. & ............ & 333 \\
\hline 6 & 60.0 & 646 & 66 & 500 & ............... & ............... & ……... \\
\hline 7 & 0.6 & $\mathrm{Fe}\left(\mathrm{NO}_{3}\right)_{3} \cdot 9 \mathrm{H}_{2} \mathrm{O}$ & 500 & .......... & 5 & $\ldots \ldots \ldots . . .$. & 495 \\
\hline 8 & 3.0 & 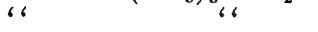 & 6 & ............ & 17 & ............. & 483 \\
\hline 9 & 6.0 & 6 & "6 & ............... & 50 & ........... & 450 \\
\hline 10 & 36.0 & 6 & 6 & ................. & 167 & ............... & 333 \\
\hline 11 & 60.0 & 6 & 66 & & 500 & & \\
\hline 12 & 0.6 & $\mathrm{FeCl}_{3} \cdot 6 \mathrm{H}_{2} \mathrm{O}$ & 500 & ........... & ........... & 5 & 495 \\
\hline 13 & 3.6 & 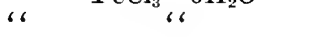 & 66 & & (................. & 17 & 483 \\
\hline 14 & 6.0 & " & 6 & & & 50 & 450 \\
\hline 15 & 36.0 & "6 & 66 & (............... & ................ & 167 & 333 \\
\hline 16 & 60.0 & ، & ↔6 & (............... & ................. & 500 & ........... \\
\hline
\end{tabular}




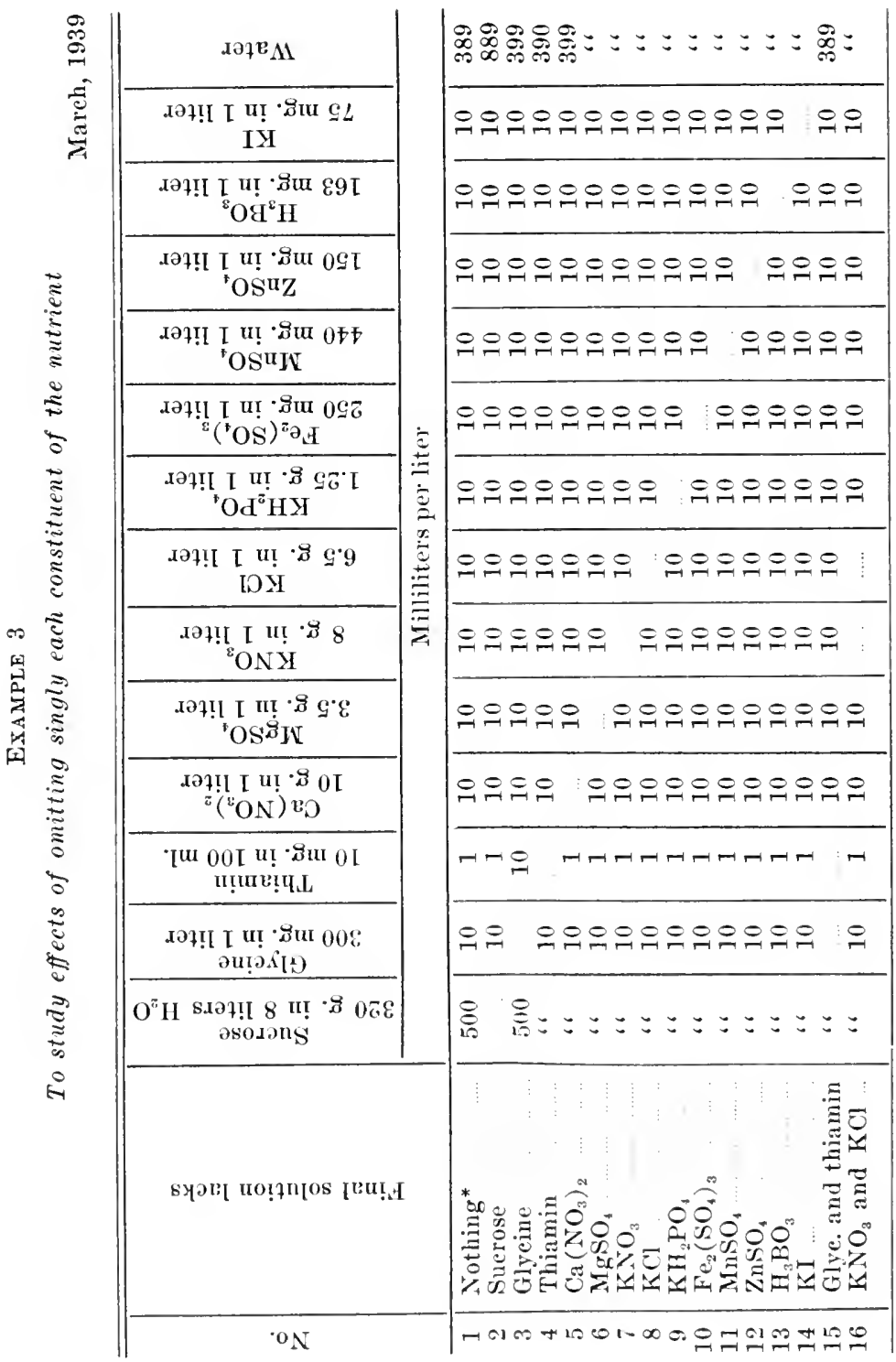


either before or after sterilization. Experiments involving omission or reduction in concentration of the constituents of this nutrient itself (salts, sugar, thiamin, etc.) require the setting up of special nutrients. While this approach is familiar to all physiologists and experienced workers may have their own methods of preparing such nutrients, it seems desirable to outline briefly the simplified procedures developed here. Three examples will be given.

Each of the three sets of experiments outlined above involves a comparison of 16 different solutions, each provided in a quantity of one liter. Since $50 \mathrm{ml}$. of nutrients are used for each culture (see later), this provides 20 replications in each nutrient. By employing condensed records of this sort and simplified procedures, two men working together can easily make up nutrient for 15 or 20 sets of cultures in a half day, which is about the maximum that can be satisfactorily inoculated and measured in a day. Sets of 16 have been found most practical.

Nutrients containing special ingredients not discussed here may require special treatment which the individual worker will have to adapt to his particular needs.

\section{Summary}

Nutrients for plant tissue cultures are for the most part made up of definitely known synthetic 
or highly purified ingredients. These include salts of various kinds (chlorides, nitrates, sulfates, phosphates, and iodides of calcium, magnesium, potassium, sodium, iron, manganese, zinc, and boron); carbohydrate (especially sucrose); organic nitrogenous materials (amino-acids, tissue digest peptides, peptones, etc.) ; hormones and vitamins (thiamin, nicotinic acid, vitamin $B_{6}$, indole acetic acid, etc.); and sometimes coagulating agents (agar-agar, gelatine, etc.).

Standard procedures for the preparation of nutrients are described. 


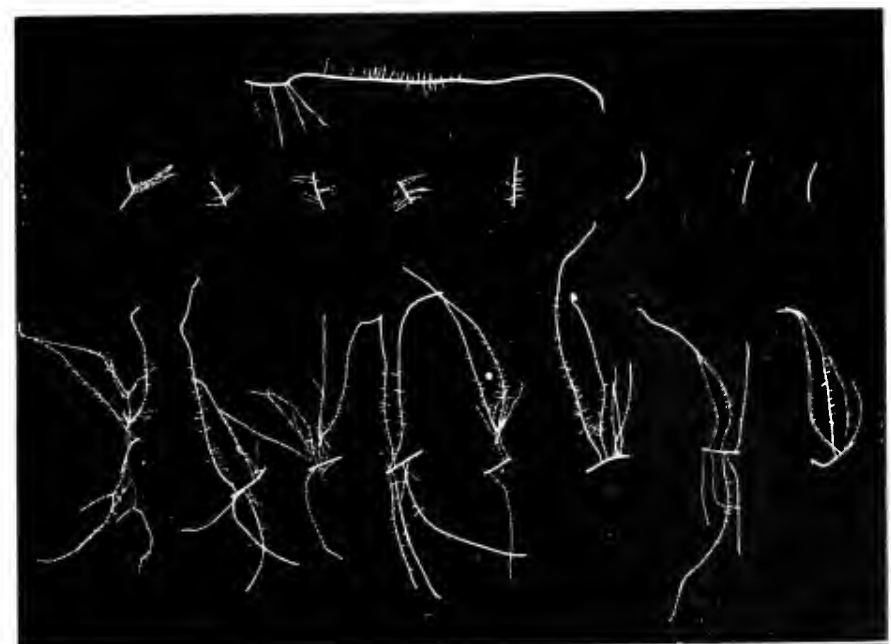

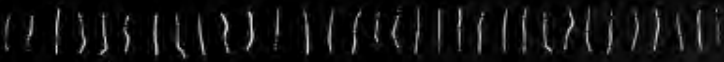

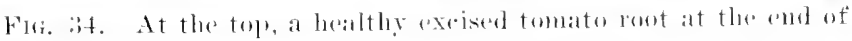

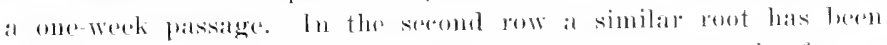
divided into eight pierese to le used in setting up a stock of comb-

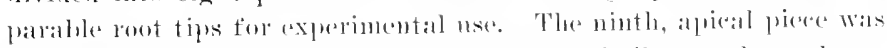
discarded. Thimel row, eight rowt segments similat to those shown ahore after a serond week 's antivation in fresh nutrient. At the

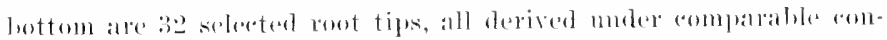

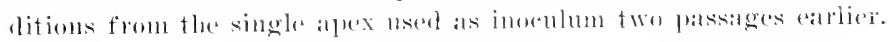




\section{$11+$ Plant Tissure ('ulture}

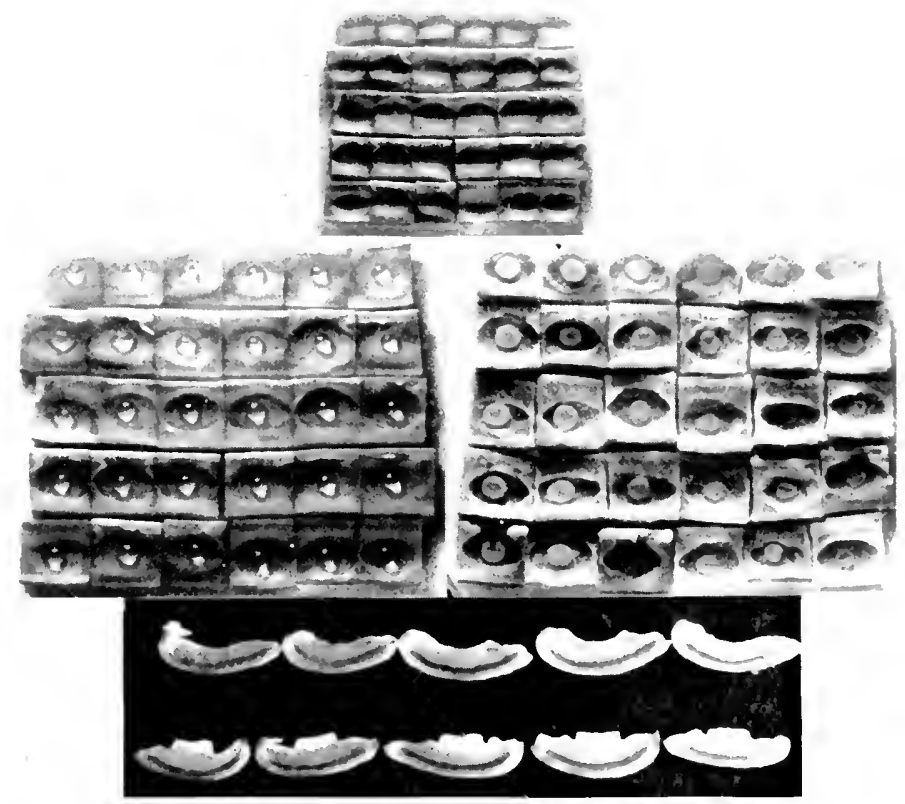

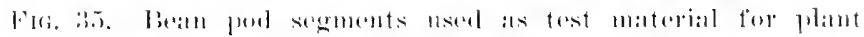
wombl stimulants. Alume: segments form the ronters af fire

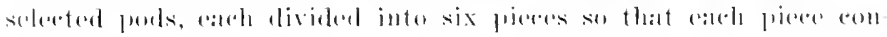

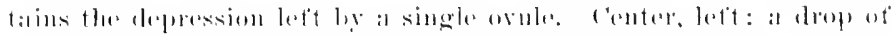

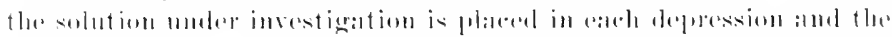

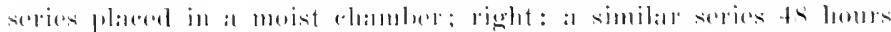

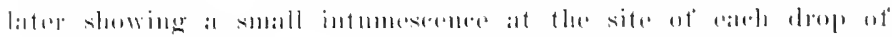

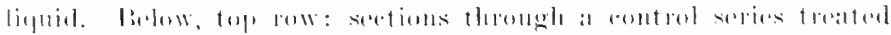
with distilled water: lottom row: a similat series treated with a

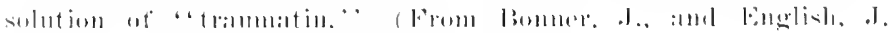

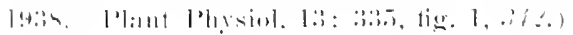




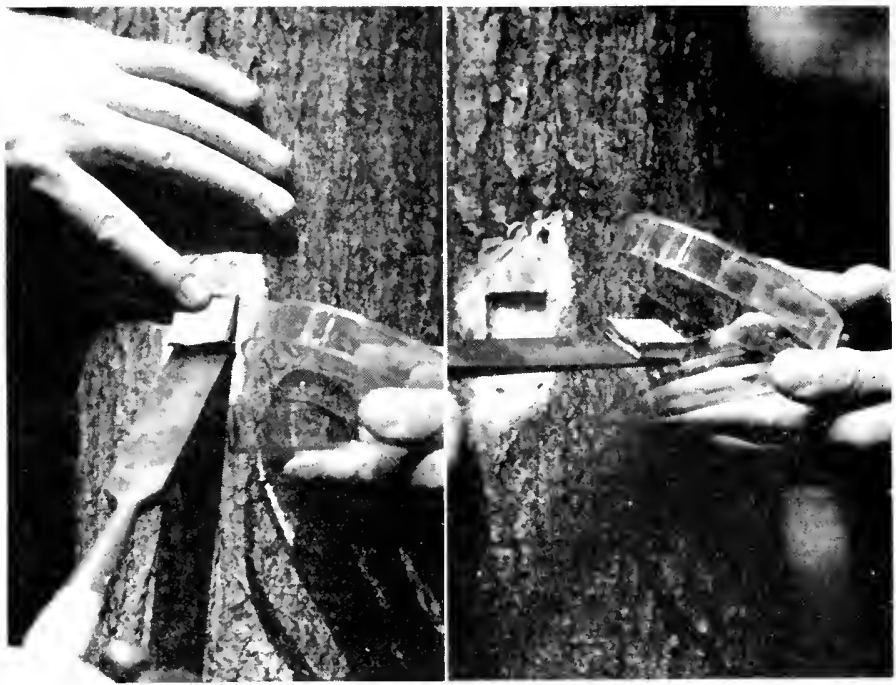

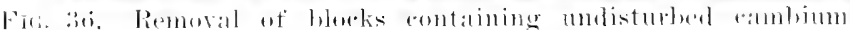

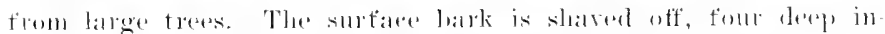

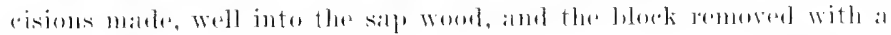

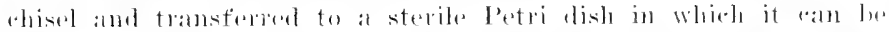
(*arriel to the lalwatery.

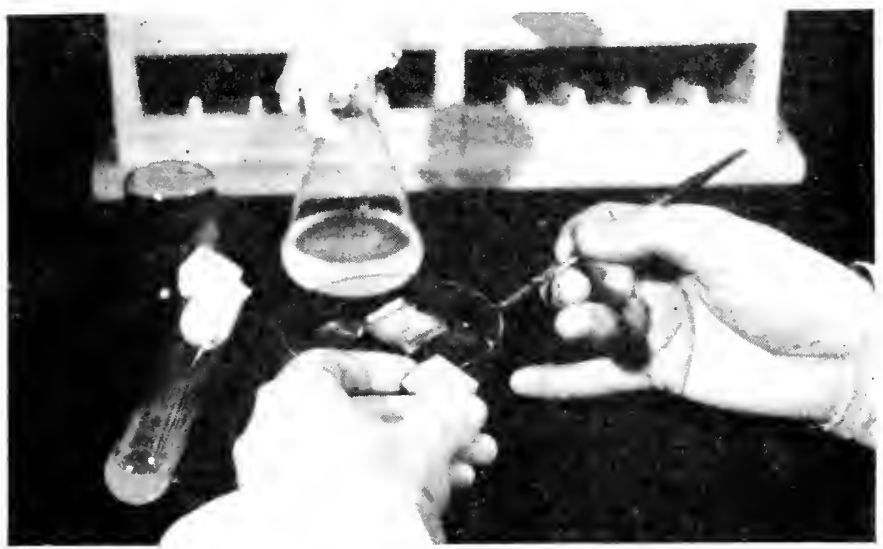

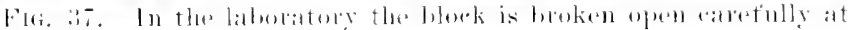

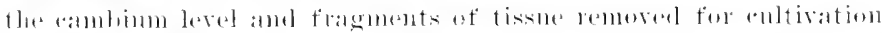
(on mutrient itgar. 


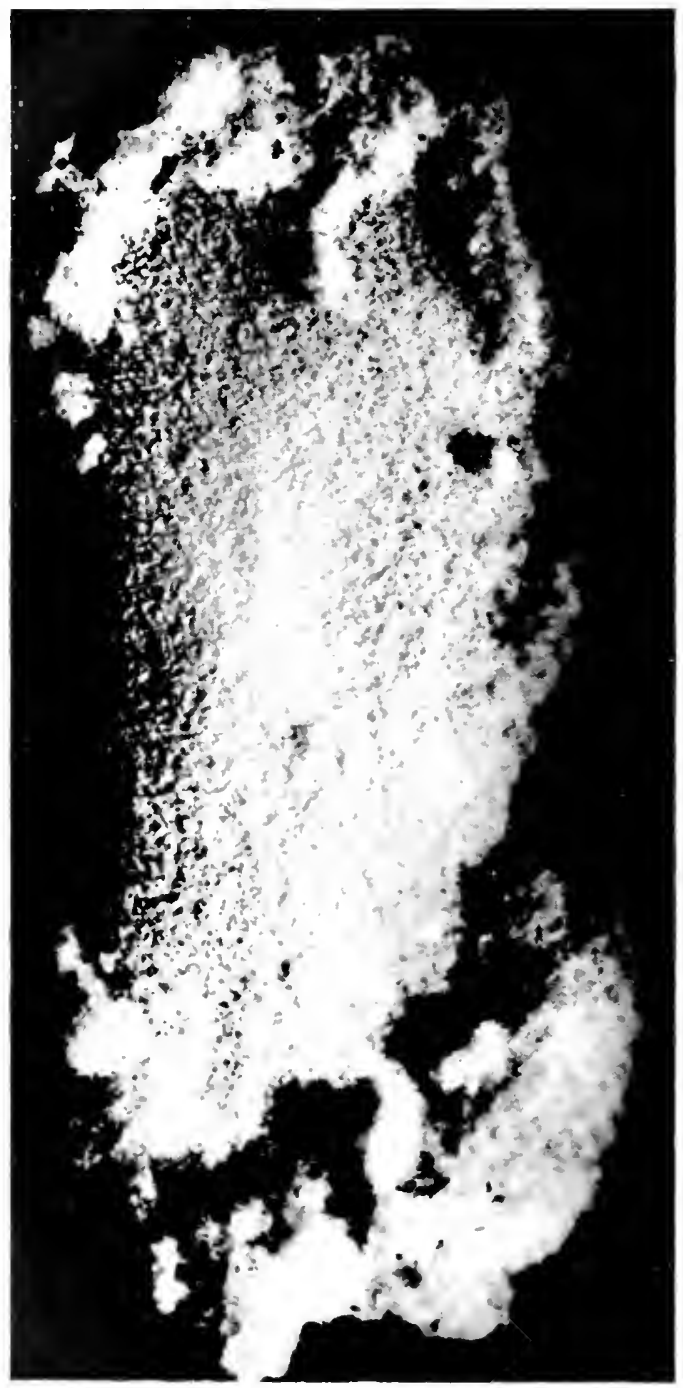

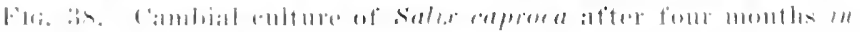

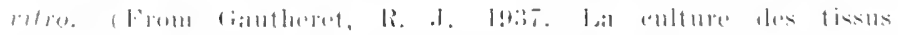

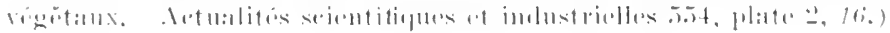




\section{Chapter VI \\ HOW CULTURES ARE STARTED}

As we have already seen, the two types of plant material which have so far proved most useful in plant tissue culture work have been, first, root tips and, second, cambium or procambium. Most of the following discussion will apply to these types.

Seedling roots. Root tips are perhaps subjected in nature to more environmental vicissitudes than are any other types of meristems. They are, therefore, relatively resistant to injury. Nevertheless, once a root is growing either in the soil or in a culture medium, if it is not already aseptic it cannot be rendered so by any but rather drastic means which may well influence its subsequent behavior. It is, therefore, important that roots for culture be obtained wherever possible from sterile seedlings and, moreover, it is highly desirable that the seeds themselves be rendered aseptic with as little chemical interference as possible in order that consideration of potential aftereffects need not enter into the interpretation of results. In many cases, aseptic seeds can be ob- 
tained without any chemical treatment whatever. This is true of all seeds which, when ripe, are enclosed in fleshy, woody, or membranaceous fruits (tomato, apple, squash, bean, tobacco, etc.). Sound, clean fruits of these plants are opened by breaking or tearing in such a way that no instrument penetrates to the seed cavity. The seeds themselves are then lifted out with sterile needles or forceps, placed on slips of sterile paper in Petri dishes, and allowed to dry under conditions which will preclude the entry of contaminants from outside. These seeds can then be used for starting cultures without further treatment (White, 1934, $65)$.

Seeds contained in very small fruits, in drupes or achenes, or the seeds of Gymmosperms cannot be obtained in a uniformly aseptic condition by mechanical manipulation alone. These must therefore be surface-sterilized. Where ultraviolet light is available, this may sometimes serve as a sterilizing agent, but it is rather uncertain since spores may easily become lodged in erevices in the seed surface which are protected from illumination even if the seeds are constantly shaken. The most satisfactory result is to be obtained with bromine gas (Klein u. Kisser, 1924, 299; Burlet, $1936,20 \%)$. Seeds are shaken for 5 to 10 minutes in a bottle containing a few ml. of 1 per cent 
bromine-water. They are then spread out on sterile filter paper in Petri dishes. The bromine quickly penetrates all crevices in the seed coats, killing most if not all contaminants, yet evaporates completely leaving no traces to affect the seedlings. In spite of its obvious advantages, bromine must be handled with great care, under a hood, so that some workers prefer to use other reagents. A solution of calcium hypochlorite containing 1 per cent chlorine will give fairly satisfactory results (Wilson, 1915, 455; White, 1932, 63) if seeds are shaken therein for 15 to 30 minutes, then washed in sterile distilled water and placed in Petri dishes. The time required for complete sterilization will vary considerably with the species of seed, as will the amount of injury to the seedling which usually results. Each species must be studied specially. Dakin solution (Parker, $1938,26)$ is also good. Mercuric chloride, 85 per cent alcohol, "Uspulin," and other disinfectants have been used by particular workers. The methods of using these reagents are standard biological procedures and need not be presented in detail.

Once sterilized, the seeds may be placed for germination either directly in flasks or tubes of nutrient or in Petri dishes on filter paper moistened with sterile water or on agar. If sown on a semi-solid substratum such as agar, several 
seeds can be placed in each receptacle since any contaminant which may be present on one seed will not easily spread to another. If placed directly in a nutrient solution, only a single seed should be put in each container. The flasks, Petri dishes, or test tubes containing the seeds should be set aside in darkness until the seedling roots have attained a length of 10 to $15 \mathrm{~mm}$. The roots are then severed with scissors or scalpel at a length of $3 \mathrm{~mm}$. or more and transferred to the nutrient in which they are to be grown.

Adventitious roots. While most cultures can best be started from seedling roots, conditions occasionally arise which cannot be fulfilled by such materials. This has been notably true of certain virus "cultures" in which no method of inoculating virus into roots growing in vitro has yet been found (White, 1934, 438). It is then necessary to resort to adventitious roots coming from cuttings of infected plants (see later). With plants like tomato which root easily, this presents no great difficulty. Cuttings are made from rapidly growing plants having a lush growth and the leaves are removed, using a sharp clean scalpel. The euttings are then suspended in large flasks or crocks containing a little water in the bottom and lined with moist blotting paper so as to provide a saturated atmosphere (Fig. 32). These are set in 
darkness or in dim light until adventitious roots emerge. The cuttings are removed in a sterile room, the roots carefully severed and placed one by one in flasks of nutrient. (Fig. 33). Using this simple procedure, many roots will, of course, be contaminated with molds or bacteria and must be discarded. Some, however, will regularly remain sterile. These can then be made to serve as the origins for clones of sterile root cultures each carrying the virus of the disease with which the original cutting was infected. With slower-rooting cuttings, greater precautions against contamination will be necessary, and the surfaces will have to be sterilized by some one of the methods described for the sterilization of seeds. Whatever sterilizing agent is used, it must be removed by thorough washing with sterile distilled water. The containers must also be sterile and all manipulations must be carried out aseptically. A high yield of sound aseptic rootlets cannot be expected under these exacting conditions, but they can be obtained with some patience.

Cambium. Theoretically the cambium layer, since it continues to grow throughout the life of the plant, for hundreds and even thousands of years in some cases, should be excellent material for cultivation. Practically, however, it offers of 
all the major meristematic regions except the medullary rays perhaps most difficulties in the way of isolating fragments aseptically without too great injury (White, 1931, 32). Most of the work carried out to date on the cultivation of cambium in vitro has been done by Gautheret (Gautheret, 1934, 67, 1935, 15, 1937, 68, 1938, 69, ro, 1939, r1, г2, 212, 1940, г3; Gioelli, 1937, 291, 1938, 292$).$

To isolate a block of cambium, all six faces of the block must be cut, and this nust be done without carrying contaminating spores from the surface of the plant onto the excised fragment. To perform this operation on the cambium of small woody stems would be almost impossible. It can, however, be successfully carried out on large trees. A piece of bark an inch or more square is cut ont with a sharp knife or chisel, being eareful to cut well into the sap wood (Fig. 36). Gautheret performed this operation with carefully sterilized instruments after surface-sterilizing the tree trunk (Gautheret, 1935, 15), but these precautions are not necessary at this stage. The block is placed in a clean container and transferred to the laboratory. There, under aseptic conditions, it is split at the cambium level in such a way that neither instruments nor possibly contaminated tissue surfaces conce in contact with the center of the exposed surface. Pieces of cambium are then 
carefully eut or torn out of this sterile surface using sterile instruments and are transferred to nutrient solution, preferably to a semi-solid substratum (Fig. 37). Such fragments should be quite sterile. Cultures of this sort have been prepared from willow, poplar, beech, oak, pine, and other trees. Gautheret's most successful cultures were of cambium from Salix capraea (Gautheret, 1935, 15, 1937, 68, 1938,69). The growth obtained is of a loose, fungoid character and in general develops rather slowly (Figs. 38, 39).

Procambial strands. The procedure to be used in isolating procambial strands for cultivation is somewhat similar to that employed with cambium (White, 1939, r8). This tissue can, of course, be most easily removed from stems of succulent individuals. Rapidly growing tips of tobacco, squash, sunflower, and similar plants make excellent material. Terminal pieces about 8 to 10 inches long are severed and the leaves carefully removed with a sharp scalpel or razor, leaving as little stub as possible. Under aseptic conditions, the epidermis of the distal 1 or 2 inches is stripped off, beginning from the proximal end and taking care that the exposed surfaces are not touched by unsterile instruments or epidermis fragments. When the terminal portion is completely exposed, the growing point is grasped with sterile forceps and bent 
sharply sidewise so that the stem breaks. The break will take place in the region of active growth where the cells possess a maximum of turgor with a minimum of cell-wall deposit. Slices about 0.5 $\mathrm{mm}$. thick are made across the stem in or near this region and the pieces transferred to nutrient agar or to very shallow layers of liquid nutrient. Proliferation from very young tissues will take place in all parts, while from older tissues only the region of the provascular strands will proliferate (Fig. 17). Tubereles of white or green callus are formed on the uppermost cut surface. It usually requires 10 days or 2 weeks for these to attain a sufficient size to justify further division. These tubercles can then be separated from the underlying non-proliferative tissue, or the culture can be simply divided into a number of fragments containing both growing and non-proliferative material, and the pieees transferred to fresh nutrient. Cultures from young carrot roots, potato tubers, kohl-rabi, and other fleshy, only partially differentiated members can be made in a similar fashion. A similar technique is used in making cultures from secondary erown-gall tumors (White and Braun, 1941, 335, 1942, 336, 33\%).

Miscellaneous materials. The excision of intercalary meristems such as those of grasses requires much the same technique as that for the procam- 
bial strands. Medullary rays, the multiple pericycle, and certain phelloderm cambiums should in theory be fairly satisfactory experimental material, albeit difficult to isolate. They have apparently not been studied to date. There are in plants, of course, many other regions which show meristematic activity. Very young seed primordia are made up entirely of meristematic cells and are easily removed with little danger of contamination and a minimum of trauma (White, 1932, 89 ; Moebius, 1928, 105 ; Molliard, 1921, 106). All of the tissues of young ovaries are likewise meristematic as are some of those of more mature ovaries (Tukey, 1937, 114). Wehnelt $(1937,230)$ and subsequently Bonner and English $(1938,342)$ have taken advantage of this fact and used tissue from the inner surface of bean pods as material for the study of proliferation. Bonner has had some success with tissue cultures of this material (Bonner, 1936, 91) (Fig. 35). The meristematic centers in the leaves of Begonia, Bryophyllum (Naylor, 1931, 308), Saintpaulia (Naylor and Johnson, 1937, 309), Chlorophytum (Naylor and Sperry, 1938, 310), Camptosorus, etc., and the stipular gemmae of Marattia should theoretically be excellent material with which to work but have not been studied as yet. Many "mature" regions may also be stimulated to renewed activity by proximity to a 
wound (Haberlandt, 1913, 294, 1914, 295, 1919, 245, 296, 1921, 354, 1922, 355; Reiche, 1924, 369; Wehnelt, 1937, 230; Bomner and English, 1938, 342 ; Simnott and Bloch, 1941, 324) or by the injection of such substances as the gall-inducing secretions of certain insects (Küster, 1911, 300). Only the easiest types of materials have, up to the present, been carefully studied. The field open to future investigation is obviously very large.

\section{Summary}

Cultures may be started from seeds, from cuttings, or from excised fragments. In any case, the final result must be a relatively uninjured, aseptic mass of tissue, and the procedures for obtaining such masses, either with or without the intervention of chemical disinfectants, are of the greatest importance. These procedures for obtaining aseptic seeds, adventitious roots, etc., and for dissecting cambium and procambial tissues are described and figured. Procedures for handling other miscellaneous meristematic tissues are also presented. 

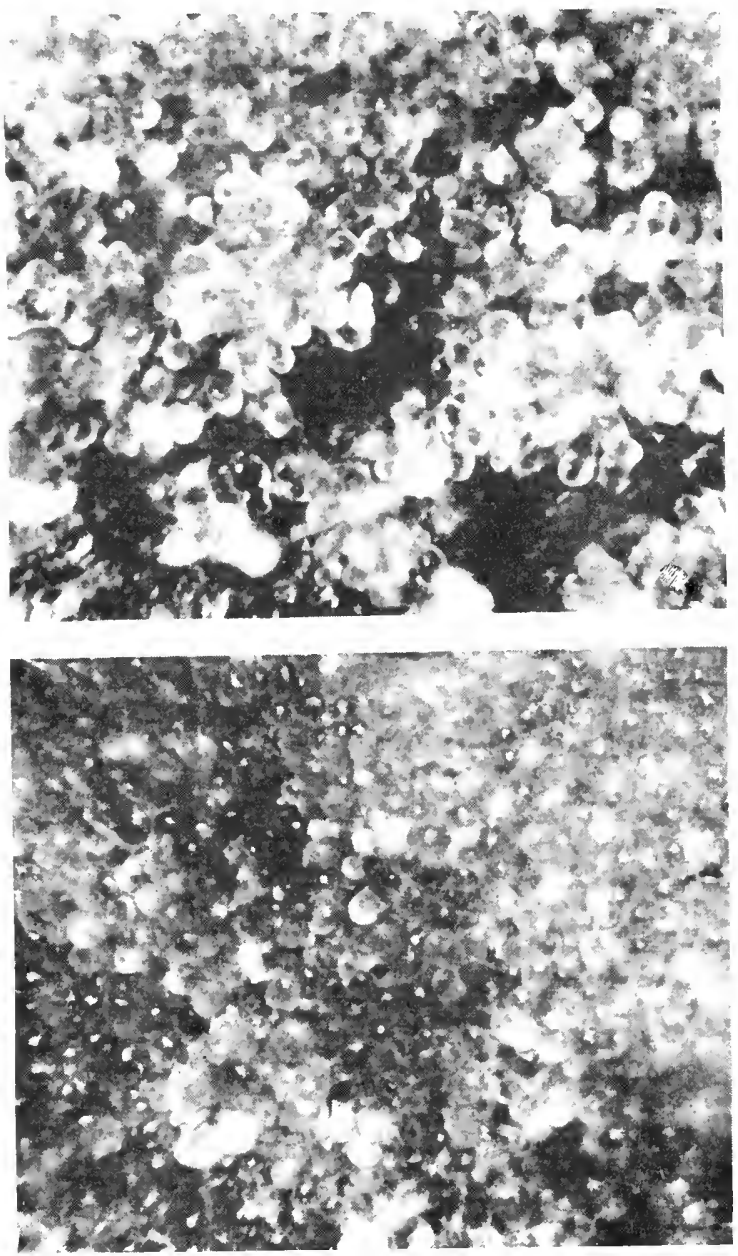

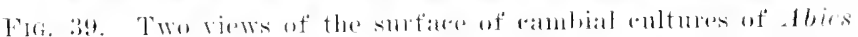
pelinale aftele a days (lelow) and one month (above) in ritro.

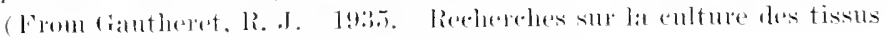

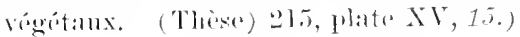




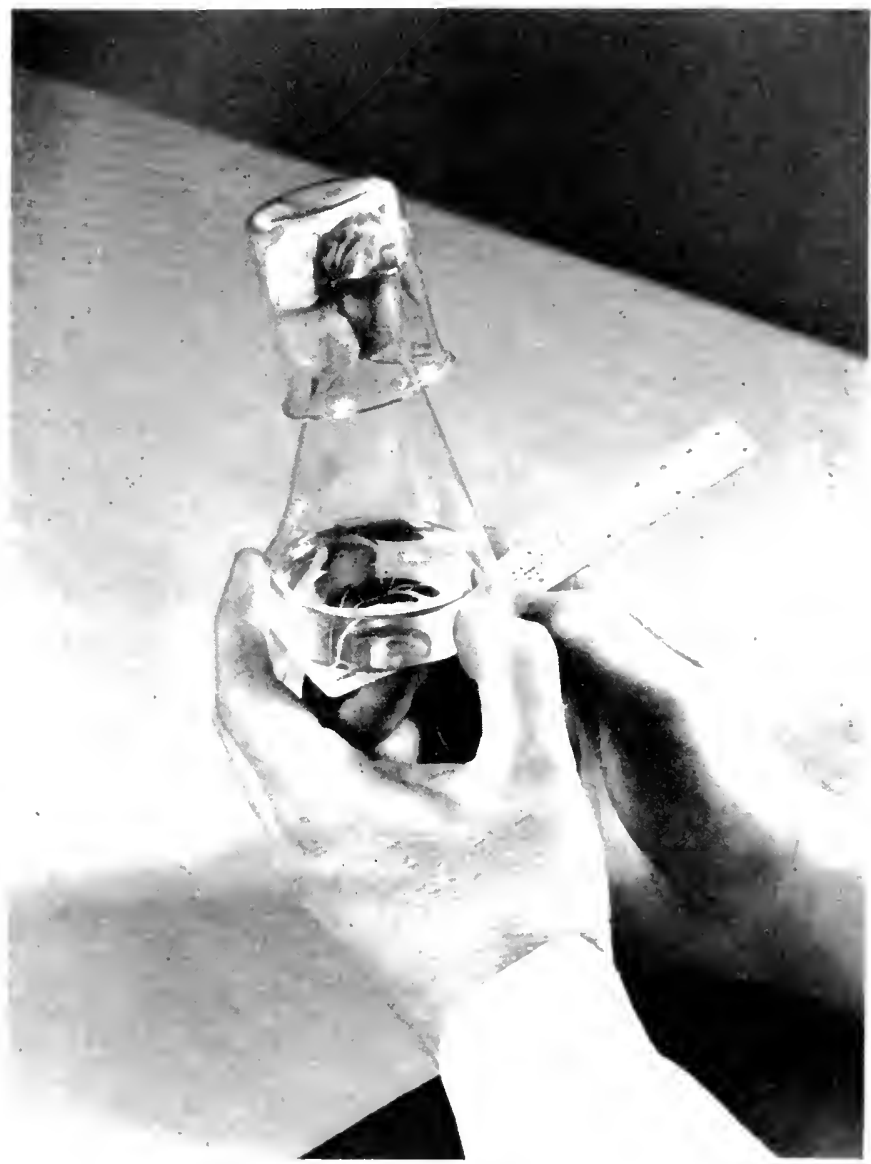

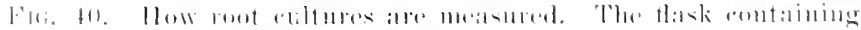

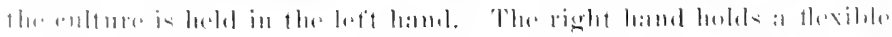

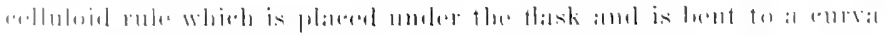

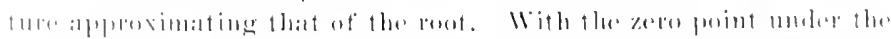

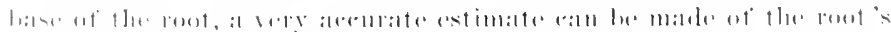

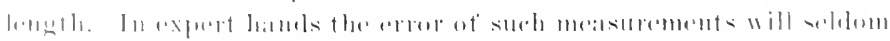

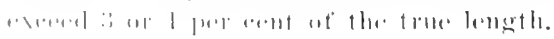




$$
\text { How Cullures Ire started }
$$
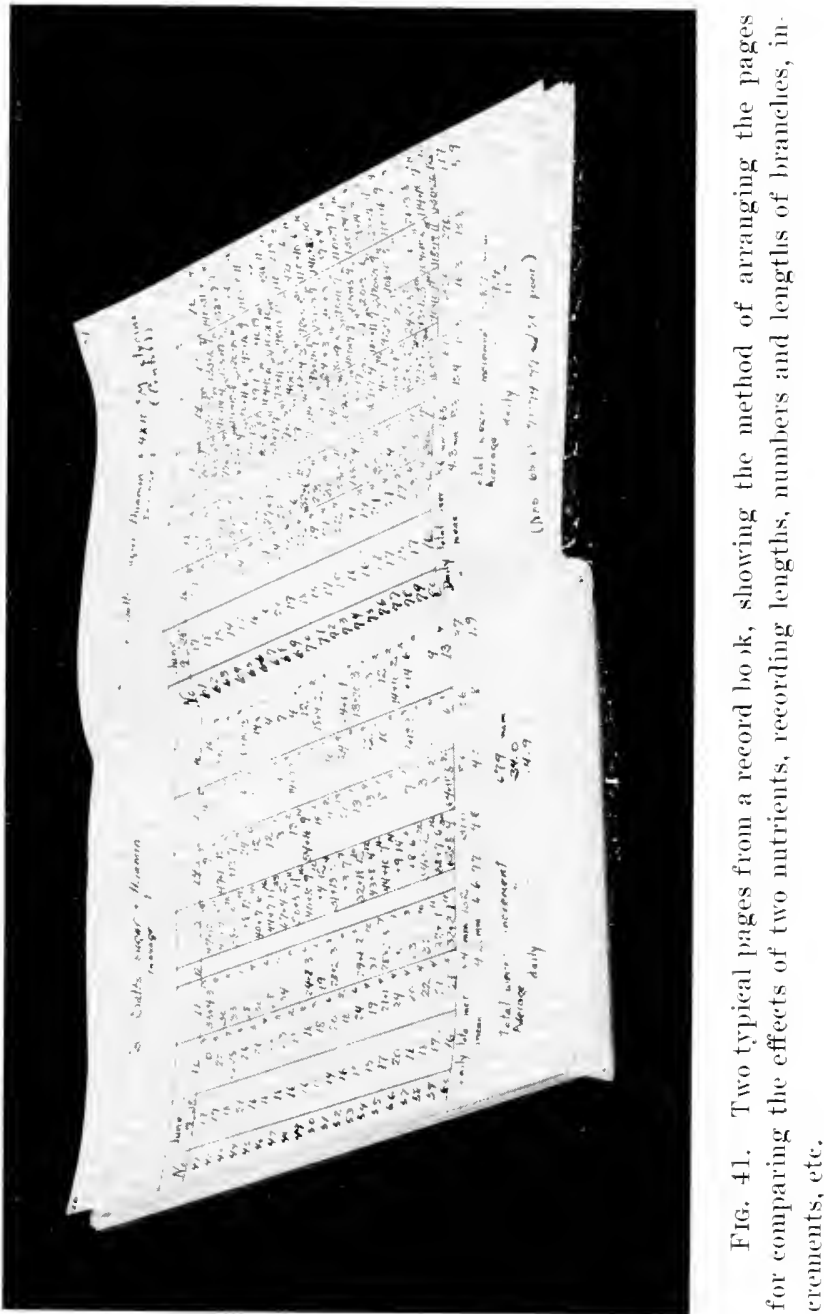


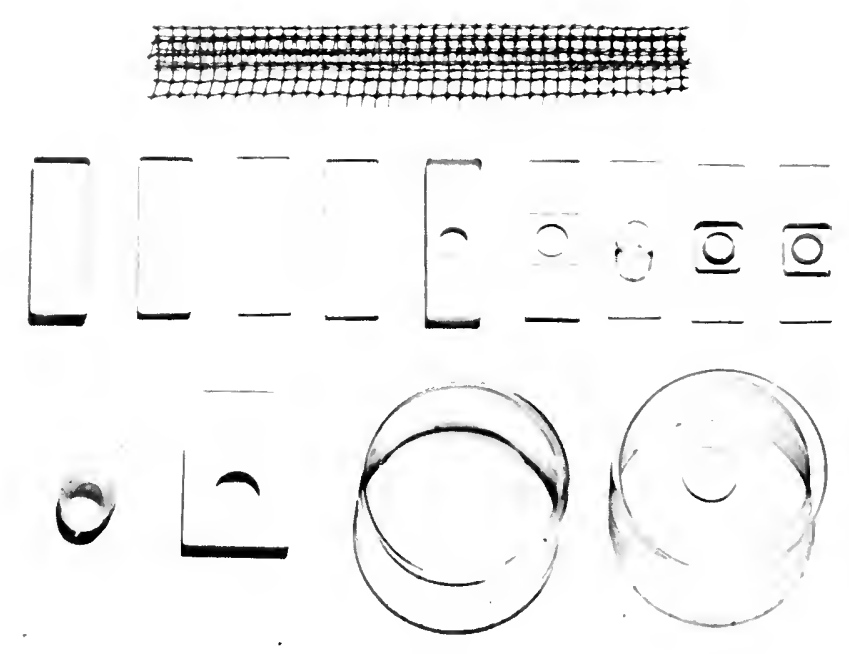

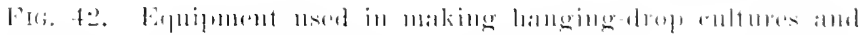

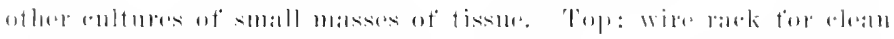
2.2.

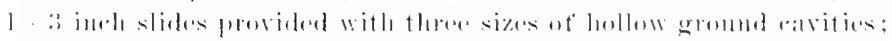

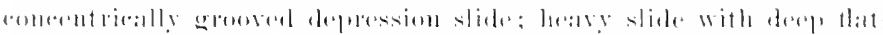

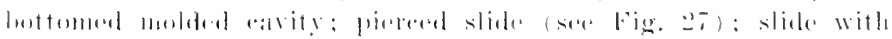

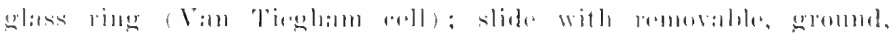

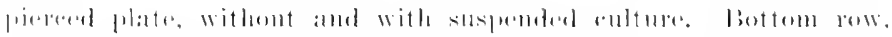

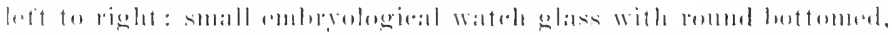

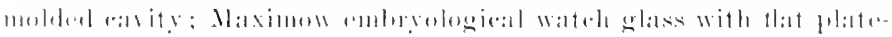

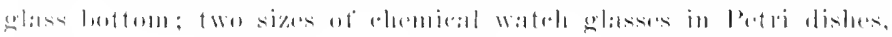

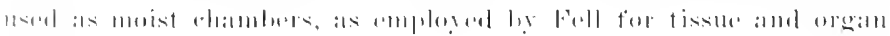
$101111112 \times s$. 


\section{Chapter VII \\ CULTURE TECHNIQUES}

Tissue cultures, whether of plant or animal materials, have for the most part been carried out in three general classes of containers, each class being especially adapted to a particular type of problem. These are, first, cultures in flasks or special vessels of one type or another adapted to the study of relatively large masses of tissue under conditions which involve considerable experimental manipulation (Carrel, 1912, 125, 1923, 126, 127; Maximow, 1925, 420; Fell, 1928, 392 ; Robbins, 1922, 57; White, 1934, 65; Bonner and Addicott, 1937, 42; Parker, 1934, 427, 1936, 428, 429); second, cultures in test tubes, likewise adapted to the study of masses of tissues but in general less suitable to their manipulation (Kotte, 1922, 51, 52 ; Malyschev, 1932, 53, 54; Fiedler, 1936, 45 ; Gey, 1933, 129) ; and, third, hanging-drop cultures adapted to the minute study and observation of very small pieces of tissues (Harrison, 1907, 131; Burrows, 1910, 117 ; Carrel, 1911, 120 ; Lewis and Lewis, 1911, 149; Chambers, 1923, 43, 1924, 44 ; White, 1932, 89). By far the most important 
of these categories in the preliminary attack upon most problems is the first, since for most materials it possesses, of all the methods of approach, the greatest reliability and flexibility.

Bonner $(1940,201)$ carries root cultures in Petri dishes, but these seem to the writer of this volume to offer no significant advantages over flasks. Certainly they must be handled with much greater care to avoid slopping, and would seem much more likely to become contaminated. Fell (1928 et seq., 392401) uses, for animal tissue cultures, shallow vessels of the "salt-cellar" or embryological watch glass type placed in Petri dishes acting as moist chambers. These may have distinct advantages for cultures of small volume such as callus cultures but cannot be used for roots.

The preparation of stocks. In any piece of scientific work, one of the prime requisites if significant results are to be obtained is an adequate supply of uniform, duplicable material with which to work. The tissue culture technique has in this respect one great advantage over most other culture practices-that it permits the building up of vegetatively derived clones, all members derived by division of a single ancestral fragment so that all members have exactly the same genetic constitution. The question of genetic uniformity and stability is entirely eliminated. One might expect 
that under these circumstances all members of such a clone could be counted on to behave exactly alike under a given set of conditions. This is generally true of animal tissue cultures (Ebeling, 1921, 456 ; Parker, 1932, 422, 423, 1938, 26) and cultures of undifferentiated plant materials (White, 1939, 78). It does not, however, appear to be the case with cultures of excised roots (Robbins and Bartley, 1937, 170; Robbins and Schmidt, 1938, 60, 1939, 61; Robbins and V. B. White, 1936, 62; Delarge, 1938, 280, 1939, 281). Sister cultures, placed under supposedly identical conditions, may behave in markedly different manners. This is one of the most disconcerting phenomena encountered in the field of plant tissue cultures. In mycological and bacteriological studies, the inoculation of two fragments of mycelium or two bacterial cells can be counted upon to give rise to colonies of like appearance, aside from the rather infrequent occurrence of saltations. Why is this not equally true of root segments of higher plants?

The difference is probably more apparent than real. When a fragment of fungus mycelium is transplanted, it branches rapidly to form a discoid or spherical colony, the outline of which is delimited by many hundreds of branches, each of which has its own particular increment rate. The colony derived from a bacterial transplant or a frag- 
ment of animal tissue likewise consists of hundreds of cells which behave as individuals. What we observe in measuring such a colony is the integrated behavior of many individuals in which whatever variations exist in the behavior of any one individual disappear in the final average for the colony. It is not at all certain that the individuals in such a colony have behaved alike. In following the behavior of a root culture, on the other hand, one is dealing with a single branch behaving as an individual, so that the full measure of variability is immediately evident. It is only by taking the average of a large number of such individual cultures that one can get a picture truly comparable to that of the single fungus, bacterial or fibroblast colony. Since it is patently impossible to deal with even hundreds of cultures at a time in absolutely uniform conditions of enviromment, the individual variability comes into unavoidable prominence.

Part of this variability doubtless arises as a result of slight and unrecognized differences in the envirommental conditions to which individual flasks are subjected. Anyone who has studied, for example, the differences in atmospheric humidity in different parts of a single greenhonse bench knows how difficult it is to maintain uniform conditions even a few inches apart. Not all variables 
are known. Such sources of error can be reduced by careful study but can never be completely eliminated.

Much of the variability, however, probably arises from differences in age, state of nutrition, degree of established dominance, extent of excision trauma, and similar characteristics of the separate explants. The effects of these differences can be greatly reduced by careful selection of the individual fragments used in each experiment. The importance of adequate uniform stocks from which to make this selection is thus obvious.

It is clear, for example, that, if a rapidly growing root culture containing one terminal growing point and 18 branches none of which has yet acquired an individual dominance is divided into 19 pieces each containing a single apical meristem, these pieces will be far from alike. The terminal meristem will be of much greater diameter than the others and of quite a different past history. It will suffer far less from the shock of excision, since its traumatized surface will be far less in proportion to its volume than for the laterals. It will recover more quickly and will show a much greater growth in the first few days after excision. Experience has shown that this difference can be somewhat reduced by cutting the main root above 
and below each branch instead of severing the branch itself, in such a way that a "heel" of older tissue is left attached to each branch. The difference is still more reduced if only branches which have already acquired their full individuality or "dominance" are used. With tomato this dominance usually develops after the branch has reached a length of about $20 \mathrm{~mm}$. If branches of this sort are severed, they will generally show no more retardation on excision than will apical meristems and can be considered comparable thereto. It is, therefore, advantageous in preparing a stock from which to select root tips, to have as high a proportion of well established branches as possible. Experience has shown that, if a piece of old tissue carrying several branch initials but from which the apex has been removed is cultured for a time, a considerable proportion of these initials will establish themselves with a comparable degree of dominance. Acquaintance with these facts has given rise to a standard experimental procedure.

Experience has shown that, in root cultures in flasks, satisfactorily reliable results cannot be counted on if a given experiment contains less than 20 replications under each experimental condition complex (see later). If, for example, it is desired to compare four sets of conditions among 
one another and with a control, the experiment will require a minimum of 100 cultures. The routine procedure is as follows:

Ten rapidly growing, uniform cultures of clonal ancestry and each about $100 \mathrm{~mm}$. long are selected. The terminal segment of each to a length of $3-4$ $\mathrm{mm}$. is removed and discarded. The remainder is divided into 10 to $15 \mathrm{~mm}$. segments and each segment is placed in a flask of fresh mutrient and allowed to grow for a week. Each will develop from 3 or 4 to a dozen branches, and of these an average of 4 or 5 on each piece will have established comparable growth rates and full dominance. There should thus be available 300 or more uniform, well established root tips. These are carefully severed at a length of $10-15 \mathrm{~mm}$. and from them 100 tips of as uniform character as possible are chosen for use in the actual experiment (Fig. 34). There is thus available a supply of tips which are all root apexes, of uniform size, age, nutrition, and degree of trauma, and which have all come from comparable root pieces of clonal relationship. The individual variability is thus reduced to a minimum. This does not mean that all cultures will behave exactly alike, even under as nearly like conditions as we are able to set upthere still remains a considerable residual variability that is as yet unexplained. But when a 
sufficient number of replications is provided, the results can be counted on to be, under like conditions, similar from one test to another and, after properly correcting for regular seasonal differences (see later), they will give comparable results from year to year and from season to season.

The setting up of stocks for all cultures involves essentially the same procedure. The prime requisites are a considerably greater amount of available material than is at all likely to be needed so that a selection is possible, all material to be of clonal origin. Callus cultures grow much more slowly than do root cultures, so that a greater time, usually about a month, must be allowed between the setting up of stocks and their actual utilization.

Inoculation. The procedure in making inoculations is comparatively simple. The whole procedure is carried out in the transfer room. Stock cultures from which tips or callus fragments are to be taken are placed in a tray to the left of the operator. The instruments are in the sterilizing beaker or pan, in front of him (Fig. 30). Uninoculated flasks of nutrient are placed in trays to his right and a box for discarded caps stands at his left. The glass caps are removed from both sets of flasks. A flask containing a stock culture is grasped in the left hand, tilted to reduce the 
horizontal exposure of the opening, and the cotton plug is removed with the little finger and heel of the right hand and retained. The operating scissors or scalpel is taken out of the boiling water with the right hand, and all satisfactory appearing root tips or callus fragments on the stock culture are severed and a mental note made of their number. The plug is replaced, the scissors returned to the boiling water, and the flask returned to the tray. Root pieces longer than $15 \mathrm{~mm}$. become difficult to pick up. Pieces shorter than $10 \mathrm{~mm}$. are likely to suffer considerable shock from excision and to respond poorly after transfer. While fragments as small as $0.1 \mathrm{~mm}$. in length have been grown successfully (White, 1932, 89), experience has shown that those from 10 to $15 \mathrm{~mm}$. long offer the most satisfactory balance between these various characteristics. The process of excision is repeated until all available tips have been severed. Since a mental note has been made of the total number of root tips severed and the number required for the experiment planned is known, it is then possible to judge how drastically the available pieces can be culled and still leave a sufficient number.

After all tips have been severed, the actual inoculation can be begun. A stock flask is grasped in the left hand and an uninoculated one is placed 
on the table in front of the operator. The plug is removed from the first, and a sound, rapidly growing root tip is selected and picked up on a long. chromel-wire loop. Usually two loops are employed alternately so that one is always in the sterilizing beaker while the other one is in use. The stock flask is plugged and set on the table, the uninoculated flask is taken up in the left hand, its plug removed with the right hand which still holds the transfer loop, and the culture fragment is inserted, the flask plugged and returned to its tray. The loop is returned to the boiling water and a fresh one taken up. The process is then repeated with another flask. In choosing tips for inoculation, it will be noted that occasionally a root which does not visibly differ from the others will nevertheless sink to the bottom of the flask instead of floating at the surface. Such tips should not be used, as experience has shown that they are regularly retarded in their development. Such retarded tips will sometimes recover completely, but they cannot be relied on to do so. What the cause of this condition is is not known, although it appears to be some obscure characteristic of the general "state of health" of the stock culture before excision.

The above description applies to the setting up of root cultures. 'The procedure for callus cul- 
tures is similar except that, for dividing the tissue mass, a small, sharp scalpel gives better results than do the scissors.

Growth. Under ideal conditions, root cultures set up as described above will begin to grow almost immediately and will increase 3 to $4 \mathrm{~mm}$. in length in the first 24 hours. (For methods of measuring growth, see later.) This increment rate accelerates up to about the 5th day when average rates of 10 to $15 \mathrm{~mm}$. per day are common (occasional roots may grow as much as $80 \mathrm{~mm}$. per day for single 24-hour periods), after which the growth rate again decreases rapidly (Fig. 43). This retardation indicates that the 5th or 6th day is the

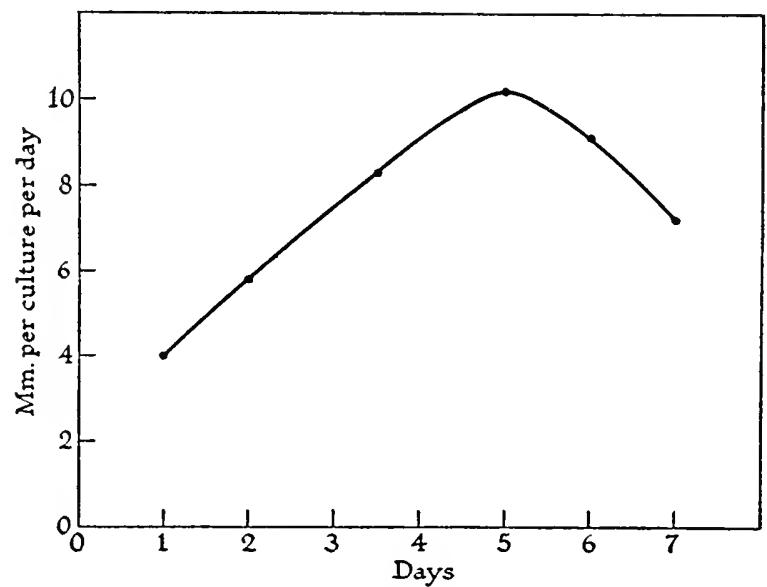

FIG. 43. Typical increment rates of tomato roots (average of 1000 cultures) on each day of a single one-week passage. The maximum increment rate is reached on the fifth day. 
best time for subculturing. A one-week culture period has been ehosen as best for routine work. The average growth rate throughout the year, of cultures grown in the laboratory without special temperature control, is about 7 to $8 \mathrm{~mm}$. per eulture per day, being greater than this in summer and less in winter (Fig. 26). Cultures begin to branch on about the 3rd day and may have as many as 30 branches by the end of a week. Some of the decrease in linear inerement after the 5th day may be due to distribution of material into the branches instead of its concentration in a single axis. However, if, instead of using tips as inocula, non-apical segments bearing branch primordia such as are employed as stock eultures are used, the branches, although at first somewhat retarded, will when established increase at rates characteristic for the particular species and for the nutrient used, but independent of the number of branches developing on the eulture. This behavior makes it clear that the rate of growth of a branch (and presumably of the main axis as well) is not determined by the number of branches present and that the retardation of growth rate after the 5th day is not entirely due to diversion of nutrient materials to newly formed branches.

While this laboratory has found a one-week culture period to be best adapted to the problems 
under consideration here, Robbins and his colleagues have chosen a much longer period, usually from a month to two months. This has certain definite advantages as well as disadvantages. Robbins uses dry-weight as a measure of growth. By this method cultures are examined only at the end of the passage, when they must be sacrificed (see later). A two-month period thus requires only an eighth as much work as do eight one-week periods. The long period permits tissues to mature and might, in theory, give time for morphological changes to become evident that would never appear in cultures maintained for repeated short periods. (Compare Parker, 1936, 428, 429; Fischer u. Parker, 1929, 411.) It permits the accumulation of large masses of tissue so that the percentage differential between the final size in two different nutrients may be much greater than after a shorter period. These appear to be advantages. On the other hand, the long period permits the study of far fewer cultures in a given space of time, tying up both laboratory space and glassware. Contrary to expectation, morphological changes which might be anticipated have not actually appeared. Moreover, the large masses of tissue accumulated in a long period may be largely inert carbohydrate-cell-wall materials, starch, etc. There is some evidence that such cul- 
tures may be built up by a recurrent cyclic reutilization of materials leached out of the older inactive or even dead tissues. The increment figures obtained at the end of a long period may thus give no true measure of the level of metabolic activity of the tissue involved. It is doubtful whether the advantages of a long culture period are not greatly outweighed by its disadvantages.

Culture conditions required. The requisite characteristics of the nutrient have been discussed elsewhere. Cultures are apparently for the most part relatively insensitive to light and can be placed either in darkness or in diffuse light (Robbins and Maneval, 1924, 25s; White, 1932, 63, 1937, 265; Malyschev, 1932, 53, 54; Gautheret, 1935, 15). They should never be exposed for long periods to direct light as they are extremely sensitive to high temperature and to temperature changes and could easily become overheated (White, 1932, 63, 1937, 265). It is highly desirable to have the temperature of the culture chamber and transfer room rather accurately controlled. Root tips of wheat have an optimum temperature of about $27^{\circ}$ (White, 1932,63 ), tomato nearer $30^{\circ}$ (White, 1937, 265). The range between optimum and maximum is, however, very narrow and a $5^{\circ}$ rise above these temperatures, if maintained for 
very long, will kill the cultures (Fig. 44). It is because of this extreme sensitivity to high temperatures that cultures, when maintained at "room temperature," fluctuate so much more widely in growth rate in summer than in winter. Cultures will, on the other hand, endure low temperatures-down to $+5^{\circ}$ C.-for long periods

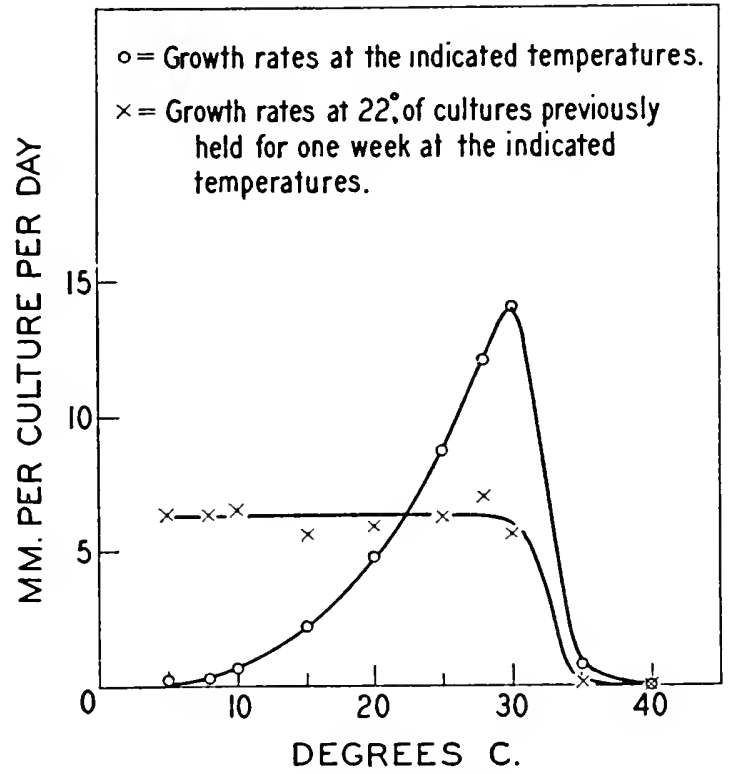

FIG. 44. Average inerement rates of isolated tomato roots maintained for one week at a series of controlled temperatures ranging from $5^{\circ}$ to $40^{\circ} \mathrm{C}$. (open circles) and then all transferred for a second week (crosses) to a temperature of about $22^{\circ} \mathrm{C}$. All except those maintained at $35^{\circ}$ and $40^{\circ}$ show an immediate reversion to the growth rate typical for $22^{\circ}$. (From White, P. R. 1937. Plant Physiol. 12: 773, fig. 1, 266.) 
without apparent injury and, while growing very slowly at such temperatures, will resume a normal growth rate within a few days when removed to higher temperatures (White, 1937, 266). Aside from these two requirements, of maintained temperature level and protection from direct insolation, together with protection from traces of gases or volatile materials, the environmental requirements of plant tissue cultures are not especially exacting.

Flask cultures of the type described above have great flexibility and permit considerable freedom of manipulation. They can be handled easily and do not readily become contaminated. They do, however, occupy a good deal of space, the nutrient evaporates rapidly with consequent alteration in its solute concentration so that the cultures must be transferred at frequent intervals, and they require large volumes of nutrient. Conditions may sometimes arise under which these objectionable factors outweigh the difficulties of manipulation in small space so that it is desirable to grow eultures in test tubes, either on agar or in liquid nutrient. The size of the tube to be used will depend on the requirements of the particular experiment. Gey uses a special $15 \times 100 \mathrm{~mm}$. tube for "roller tube", cultivation of animal tissue cultures (Gey, 1933, 129; Gey and Gey, 1936, 130). This method has 
not been tried with plant tissue cultures but deserves attention. Lewis uses ordinary $15 \times 150$ mm. test tubes for the same purpose (Lewis, 1935, 419). Callus cultures have sometimes been grown in $2 \mathrm{ml}$. of nutrient in $12 \times 100 \mathrm{~mm}$. serum tubes, but such cultures must, of course, be removed from the tubes for any kind of manipulation, even for division in order to make transfers. Tubes 25 $\times 150 \mathrm{~mm}$. without lip and charged with $10 \mathrm{ml}$. of nutrient, have proved to be a fairly satisfactory compromise between the advantages and disadvantages of the test tube and the Erlenmeyer flask. They are shallow enough and have wide enough mouths that considerable dissection and other manipulation can be practiced on the cultures without removing them from the tube. The liquid surface is still small enough in proportion to the volume to reduce evaporation to a considerable extent, yet the depth of liquid is small enough to permit some degree of aeration without special precautions. Such tubes are especially well adapted for routine callus cultures on agar. Root cultures in tubes must be watched to see that the tips do not turn upward when the culture reaches a length greater than the diameter of the tube. Otherwise, with continued growth the tip may be forced out into the air where it will no longer grow satisfactorily. 
Flask cultures and tube cultures are suitable for experiments in which gross increase and habit of growth are the features of chief interest and in which, when further details are required, they can be obtained by removing the cultures from the original containers where, for example, they are to be fixed and sectioned. These are, in general, characteristics of the initial phases in the development of any field of investigation. But these methods do not permit the observer to follow the behavior of individual cells except under conditions which entail a more or less serious disruption of the continuity of growth. Plant tissue cells do not migrate along a solid substratum (Chambers, 1923, 43 ; Pfeiffer, 1933, 450; Scheitterer, 1931, 109 , and Gautheret, 1937, 282, notwithstanding), since the cellulose pellicle interferes with the adhesive qualities of the cells. It is, therefore, not possible to use flasks of the Carrel-flask type for microscopic examination under growing conditions. For this purpose, hanging-drop cultures (see Parker, 1938, 26), in spite of numerous objectionable characteristics, appear to be best. This type of culture is second only to the flask type in importance in carrying out plant tissue cultures.

In the typical hanging-drop culture a drop of nutrient, either liquid or semi-solid, is placed on a cover glass, the cover is inverted over some form 
of depression slide so as to seal the drop into a chamber which will reduce evaporation from the drop, and the culture is then incubated. This technique permits many modifications which have been described in more or less detail in other manuals of microbiological methods.

Slides. A variety of slides have been developed for use with hanging drops (Fig. 42). The simplest of these are the hollow ground slides used by the protozoölogists. The curvature of these depressions provides only a very poor optical medium through which to illuminate cultures for observation by transmitted light. Slides with a deep hot-pressed well with "flat" bottom instead of the ground depression are somewhat better in this respect. Low "Van Tiegham" rings of glass, or the brass rings used by Dr. and Mrs. Warren Lewis (Parker, 1938, 26), cemented to ordinary flat slides, provide still better optical properties but are somewhat clumsy to handle. The pierced slide described in Chapter IV (Fig. 27), in spite of its fragility, offers the best, most easily handled, most widely useful type of slide for hanging-drop cultures. While the optical properties of this slide are excellent, the curvature of the surface of the drop may cause some trouble. This can be obviated by floating a $5 \times 5 \mathrm{~mm}$. sq. piece of No. 0 cover on the surface of the drop over the culture. 
Capillary forces will hold this piece firmly in place while the $2.5 \mathrm{~mm}$. distance from center to margin will still permit a free interchange of gases between the liquid and the air in the chamber.

Cover glasses. Standard No. 1 cover glasses are usually used for hanging-drop cultures. These should be thoroughly cleaned, preferably in eleaning solution, rinsed, dipped in a 50-50 etherabsolute alcohol mixture which is then burned off, and stacked for use in a wire rack. Covers of mica are frequently employed, but their optical properties are seldom satisfactory and they sometimes contain soluble impurities which may be injurious. All covers now available have objectionable features. Cover glasses are usually made of "soft" glass, are quite soluble, and tend to rapidly alkalinize the nutrient drop. In animal tissue cultures, where the optimal $\mathrm{pH}$ is about 7.6 and where the tendency of the tissue metabolism is to render the solution more acid, this alkalinizing tendency of soft glass is not objectionableespecially as animal tissue culture media are mostly lighly buffered. But with plant cultures which are made in umbuffered solutions having an optimal pH of about 5.4, and in which a reaction above 6.0 may be very injurious, this tendeney may be quite serious in its effects. Pyrex covers, if available, would olsviate this difficulty, but these 
have not yet been successfully manufactured. Quartz covers are much too expensive for routine work. Some progress has been made towards solving this problem by dipping glass covers in chemically and physiologically inert plastics such as ethyl-methacrylate (du Pont), "Clarite," etc. This method has given considerable promise, but a reliable technique for obtaining duplicable results has not yet been perfected. At present, this seems, however, to be the best lead.

Methods. Hanging-drop cultures, of course, require very minute amounts of both tissues and nutrients. Methods for their preparation are described in great detail in Parker's $(1938,26)$ recent handbook. The nutrients can be sterilized in either small flasks or test tubes. Sterile pipettes with sterile rubber bulbs must be provided. The material to be cultured is cut up into pieces of the required size-root tips $0.5 \mathrm{~mm}$. or less in length (Chambers, 1923, 43, 1924, 44; White, $1932,89)$, bits of callus, intercalary meristems (Scheitterer, 1931, 109), seed primordia (White, 1932, 89), small bud centers (White, 1933, 116), etc.-and is placed in sterile nutrient in watch glasses which will be set at the operator's left. Instruments, covers, and slides are placed in front. The slides are first prepared with a small drop of vaseline on each side of the depression 
or hole. A clean cover is grasped between the thumb and middle finger of the left hand (the form of the rack used facilitates this) and, while it is held horizontal, a drop of nutrient solution is placed on the middle of the cover. This is spread around in a uniform thin layer about $8 \mathrm{~mm}$. in diameter. The fragment of tissue is then placed in the center of the drop, the cover is inverted with a quick, smooth motion so as not to throw off the drop of liquid, and is pressed down over the depression of a slide. The slide is set to the operator's right and the process repeated. After a sufficient series is completed, the covers are ringed with hot paraffin or vaseline, using a small brush, so as to seal them. They are then ready for observation or incubation.

Hanging-drop cultures should be transferred to fresh nutrient at least every $3 r d$ or 4 th day. If regular depression slides are used, this will necessitate removing the cover carrying the culture, a process which requires great care (Parker, 1938, 26). If special pierced slides are used, it is only necessary to slip out the lower cover, draw off the nutrient with a clean pipette, replace it with a fresh drop, and insert a clean cover in place of the one removed. 


\section{Summary}

Cultures are maintained either in flasks, tubes, or hanging drops. Most of the preliminary studies, particularly on problems of nutrition, have been carried out in Erlenmeyer flasks. These are large enough to permit a good deal of manipulation of cultures and to provide a large volume of nutrient which is only slowly altered by the metabolism of the tissues. Test tubes require much less space and nutrient but permit only a very limited amount of manipulation. Neither method permits microscopic examination of cultures. A technique for such examination is provided in the various sorts of hanging-drop cultures which are important for this reason, although they require much more work and do not provide the stable nutrient conditions necessary for satisfactory study of nutritional problems. Since each of these three techniques has its own special advantages for particular types of problem, the best technique for any given problem will have to be chosen with these characteristics in mind. 


\section{Chapter VIII}

\section{GROWTH MEASUREMENTS AND THEIR INTERPRETATION}

The chief aims of plant tissue cultures are, of course, first, the setting up of a group of conditions which shall adequately duplicate those under which the organ, tissue, or cell lives in nature, in such a manner that its behavior therein is quantitatively and qualitatively "normal," that is similar to what it would have been in its native environment; and, second, the study of the quantitative and qualitative changes which take place in its behavior when single elements of these conditions are altered. This gives us a measure of the inportance and function of each characteristic of the environment in the economy of the organ, tissue, or cell under investigation, permits us to sort ont the significant from the merely fortuitous elements of behavior, thus simplifying our picture of the real organism, and should lead to a better understanding of behavior itself.

Qualitative differences camnot easily be represented except by descriptive-lience subjectivemeans. These must inevitably fall short of the 
ideal requirements of scientific presentation. True science rests upon quantitative representations. And quantitative changes can be precisely represented in terms of measurements. It is thus natural that measurement should play a dominant role in tissue culture studies and that the accuracy and reliability of measurement should be a major concern of the student of this subject.

Living organisms, particularly those which, like most plant materials, are incapable of autonomous movement, give evidence of their reactions to changes in environment chiefly by changes in character or velocity of growth. And growth comes into evidence chiefly through increase either in mass or in complexity of some one or more parts of the living material or its products. Increase can be measured in a variety of ways, depending on the nature of the material to be measured.

Methods. We are, of course, primarily interested in tissue cultures because they are living materials. Increase of living material, as distinct from non-living secretions, is therefore of the greatest importance. These living materials are chiefly proteins. The carbohydrates and fats and the nitrogenous materials of non-protein character are largely constituents which can be removed without destroying the organism's capacity to live. This is also true of some of the 
proteins themselves, but, if we set aside all constituents of an organism except protein and follow the increase or decrease in this one constituent, we have about as good a measure of the increase or decrease in living substance under a given set of conditions as is at present available. This can be done by aliquot determinations of nonsoluble amino-nitrogen. Mueller recognized this when he chose this criterion as the only acceptable one in the measurement of growth of diphtheria bacilli under the influence of different nutrient complexes (Mueller, 1935, 176).

The actual measurement of amino-nitrogen, while slow and tedious, is not especially difficult. It could be applied to tissue culture practice as a routine procedure, if desired. It has, however, one very serious drawback which, together with its tediousness, has prevented its coming into common practice. This is the fact that it requires the destruction of the material measured. In studying living, growing organisms, this is a serious drawback, since it prevents the making of subcultures from examples which prove to be especially favorable. The best that can be done is to make such measurements on a series of aliquots, using sufficient numbers so that the results will truly represent the characteristies of the whole series. This method easily becomes cumbersome or unreliable, or both. 
Increase in protein nitrogen is the best measure of increase in living material available. Increase in carbohydrate may also give a measure of the activity of the protoplasm. It is, however, a cumulative or catalytic process, since any given unit of protoplasm may produce 1 or 10 or 100 units of carbohydrate without itself necessarily either increasing or decreasing in amount. Estimation of dry weight has been frequently used as a measure of increase of the total material in a culture. If samples for such determination are taken when the cultures are growing actively, this may give a fairly accurate indication of protoplasmic activity. But, if they are taken in what we term the "differentiating", stage in development, there may easily be a rapid increase in dry weight along with an actual decrease in living material. Dry weight determinations are tedious and time-consuming, although less so than amino-nitrogen determinations. They can be made with a fair degree of accuracy, the error in good hands probably amounting to about 5 per cent plus or minus the true value. This method of recording increase has been used in plant tissue culture studies to some extent, especially by Robbins and his colleagues (Robbins, 1922, 57, 17\%; Robbins and Maneval, 1923, 59, 1924, 258; Robbins and Bartley, 1937, 170, 222, 223; Robbins and Schmidt, 1938, 
$60,1939,61,224)$, by Gautheret $(1939,285)$ and by Malysehev $(1932,53,54)$. Like amino-nitrogen determinations, however, it involves destruetion of the specimens studied, discontinuity of observations, and the use of aliquots.

There is, however, a third method which does not involve destruction of the tissue, permits eonsecutive measurements, and in practiced hands is at least as aceurate as is the measurement of dry weights. That is the measurement of area inereases. In studying animal tissne eultures, it has long been the practice to project the image of a eulture on paper at hourly, daily, or weekly intervals, making tracings of the outline, to measure the areas of these traeings with a planimeter, and from the results to construet curves representing the growth increments (Ebeling, 1921, 456; Parker, 1938, 26). It is recognized that this method may err in making no distinction between cell migration and cell increase and in taking no account of ehanges in thickness of the cultures. The first objection does not apply to the use of this method for plant eultures, since no migration takes place from plant tissues. The second objection is valid when the areas of callus cultures are under investigation, since these ordinarily develop as somewhat flattened hemispheres of tissue.

When applied to root cultures, however, a modi- 
fication of this method, using linear rather than area increments as a criterion of growth, has furnished the most generally satisfactory measure of increase yet devised. When grown in culture, roots do not undergo secondary thickening (White, 1934, 65). As a result, they ordinarily take up a diameter characteristic of the species and of the culture medium within a very few millimeters of the growing point and retain this diameter throughout the length of even very old cultures (White, 1932, 63, 1933, 64, 141, 1934, 65). The cross sectional area is thus a constant and ean be ignored in comparing measurements, so that length alone becomes an accurate measure of volume and weight. Fiedler $(1936,45)$ has verfied the fact that the weights and linear increments of root cultures bear a constant relation to one another, by parallel measurements and weighings of a series of cultures of different length. This statement, of course, does not apply to branches at the time of or shortly after their initiation (these always have a smaller diameter than do fully established roots), but it is a well established fact that once a branch has acquired its full individuality or "dominance", (discussed elsewhere) it acquires this characteristic diameter. Measurements which record only the linear increment of the central axis will thus give an accurate record 
of the increase, so long as the culture does not branch. If the branches formed are ignored, this measurement will then be somewhat below the true value as measured by dry-weight or amino-nitrogen methods, but will never, on the average, exceed the true value. It will be in error in proportion to the number and importance of the branches present. Since normally growing roots seldom produce branches in great number or of great length, the error introduced in this way will seldom be great. Thus, for example, one series of 20 cultures studied in June, 1939, in the control nutrient, had a total linear increment of the main axes of 7449 $\mathrm{mm}$. in a week's time. There were 492 branches (an unusually large number) with a total length of $2804 \mathrm{~mm}$. Since the cross sectional area of the branches would average about one-fifth that of the main axes, the ratio volume of branches : volume of main axes would be about $\frac{2804}{5}: 7450=\frac{560}{7450}=$ $1: 13=7.5 \%$. Ignoring the branches thus introduces an error of -7.5 per cent into the record. Similarly, an experimental series in which potassium was omitted from the nutrient (April, 1939) gave a linear axial increment of $1654 \mathrm{~mm}$., an increment in branches of $214 \mathrm{~mm}$., and an error of $\frac{214}{5}: 1654=\frac{43}{1654}=1: 38=2.6 \%$. An error of -2.6 per cent is less than that likely to be intro- 
duced into dry weight measurements by hygroscopic absorption of moisture and is less than errors likely to arise from inaccuracies of measurements (see below), so that it is not important. Moreover, this error is always a negative one, the measurements will (aside from errors of manipulation) always be minimal ones, with the result that every experiment recorded in this way is slightly weighted against the experimenter. This has thus furnished a very satisfactory criterion of growth.

The usefulness of any method depends, of course, largely on its simplicity, accuracy, and degree of reliability. The method used in making measurements is extremely simple (Fig. 40). The flask containing the culture to be measured is held in the left hand. A flexible celluloid rule is used to make the measurement. If the culture is very short (under $30 \mathrm{~mm}$.), it can be caused to float against the glass so that both ends touch and the ruler is laid alongside. For cultures more than $30 \mathrm{~mm}$. long, particularly if they have curved greatly, it is best to place the rule below the flask and bend it to approximate the curve of the root. One must be careful to look through the glass downward (parallel to the straight component of the sides) rather than sidewise (radially to the curved component) so that the curvatures will not 
distort and enlarge the apparent image. By this method, measurements can be made with surprising accuracy. The accuracy of measurement has been determined in two ways. In the first place, a series of 10 roots varying in length from 18 to $110 \mathrm{~mm}$. was measured. The flasks were shuffled so that the order of measurements was changed. The roots were remeasured and the process repeated seven times. The measurements were then subjected to statistical analysis. The results are shown in Table 2. They indicate that measurements made by an observer on a single set of roots will vary from measurement to measurement by somewhat less than 2 per cent but give no indication of the deviation from the true length.

In the second place, a series of 20 cultures was measured in the routine way by two different observers and the results recorded. The roots were then removed from the nutrient, placed in a vessel of water, and stretched out along a ruler in such a way that an accurate measure of the true length could be obtained. These last measurements were then compared with the measurements of the two observers made by the standard method, giving a basis for expressing the average error of the method in the hands of these observers. (Observer $A$ was an experienced worker; observer $B$ 
Growth Measurements

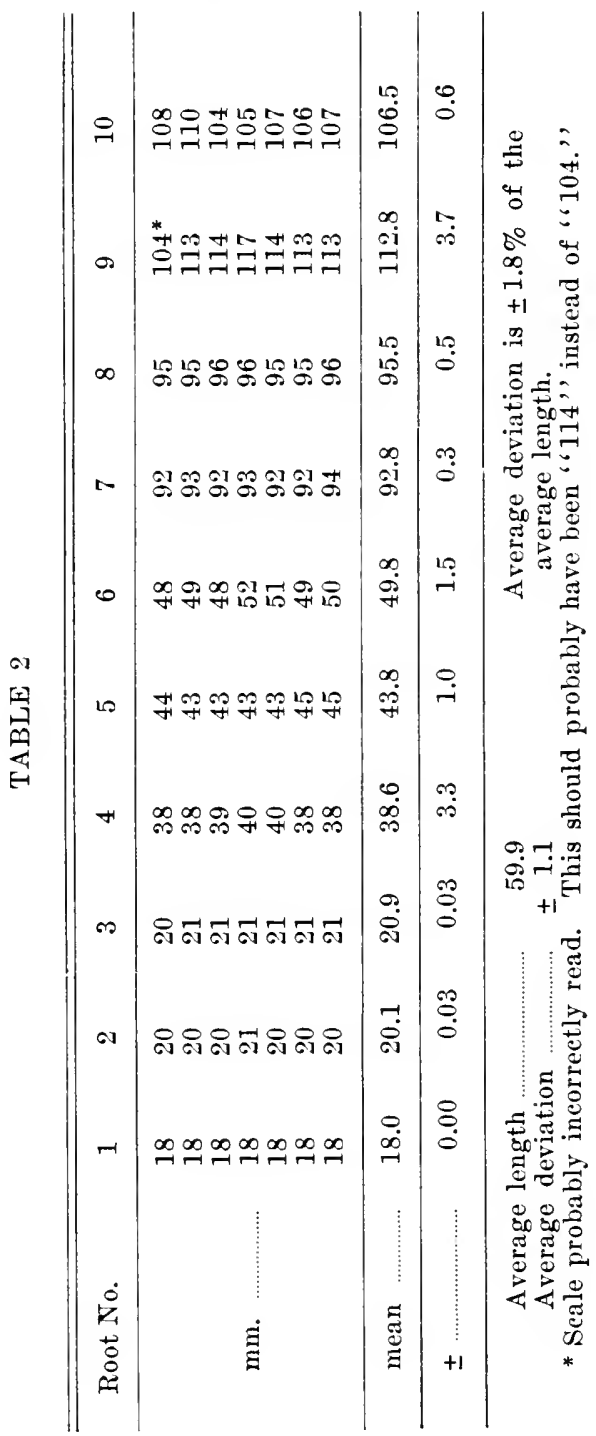


had much less experience with the method.) The results were:

\begin{tabular}{cccccc}
\hline $\begin{array}{c}\text { Root } \\
\text { No. }\end{array}$ & $\begin{array}{c}\text { True } \\
\text { length } \\
\text { mm. }\end{array}$ & $\begin{array}{c}\text { A's } \\
\text { measure- } \\
\text { ments }\end{array}$ & $\begin{array}{c}\text { B's } \\
\text { measure- } \\
\text { ments }\end{array}$ & $\begin{array}{c}\text { A's } \\
\text { error }\end{array}$ & $\begin{array}{c}\text { B's } \\
\text { error }\end{array}$ \\
\hline 1 & 129 & 135 & 115 & +6 & -14 \\
2 & 158 & 165 & 135 & +7 & -23 \\
3 & 37 & 38 & 28 & +1 & -9 \\
4 & 175 & 188 & 150 & +13 & -25 \\
5 & 140 & 144 & 130 & +4 & -10 \\
6 & 58 & 58 & 56 & 0 & -2 \\
7 & 71 & 75 & 68 & +4 & -3 \\
8 & 173 & 182 & 150 & +9 & -23 \\
9 & 178 & 184 & 165 & +6 & -13 \\
10 & 162 & 170 & 135 & +8 & -32 \\
11 & 161 & 172 & 145 & +11 & -16 \\
12 & 162 & 174 & 150 & +12 & -12 \\
13 & 147 & 157 & 130 & +10 & -17 \\
14 & 156 & 167 & 137 & +11 & -19 \\
15 & 154 & 170 & 150 & +16 & -4 \\
16 & 170 & 182 & 160 & +12 & -10 \\
17 & 168 & 180 & 150 & +12 & -18 \\
18 & 66 & 70 & 70 & +4 & -4 \\
19 & 114 & 118 & 115 & +4 & -19 \\
20 & 141 & 148 & 122 & +7 & -19 \\
\hline Average & 131 & 144 & 123 & +7.9 & -13.3 \\
& Error as per cent of true value & +6.0 & -10.2 \\
\hline & & & & +12 & +12 \\
\hline
\end{tabular}

In this series the experienced observer tended to overestimate the length of cultures by about 6 per cent, which is just about enough to compensate for the systematic error of -7.5 per cent due to the presence of ummeasured branches (see above), while the less experienced observer tended to underestimate the lengths by a considerably greater margin. In experienced hands, this method will give results of an accuracy and relia- 
bility very nearly equal to that obtainable in making dry weight determinations and has the great advantage that it can be practiced rapidly and without removing the cultures from their flasks. Repeated measurements can be made on each growing culture at any desired interval, growth curves can be set up, and subcultures can be made from those roots which show, over an extended period, any desired type of behavior.

Replications. As we have already seen, root and callus cultures, since they are biological materials, show a considerable degree of variability. In the series presented in the last table, the lengths at the end of a week in the control nutrient varied between 37 and $178 \mathrm{~mm}$., with an average of 131 $\mathrm{mm}$. This is fairly typical of root cultures. It is obvious that materials of this degree of variability cannot be treated as individuals but must be treated statistically. This being the case, it is important to decide first how many replications are necessary in order that significant results can be obtained and, second, how wide a difference must a given experimental variable produce in a series of the chosen number of cultures before that effect can be considered as being due to this variable and not to chance. Decision on the first point involves a compromise between the ideal of an infinite number on which to base averages and the 
number which can be practicably handled in a laboratory with restricted space and facilities and limited time. This laboratory has chosen 20 as the standard number of cultures used in setting up averages, and each experiment is generally repeated several times. The second point can be settled by a statistical analysis of actual results using this standard number. Some examples are given in Table 3.

In this group of experiments, in each of which 20 cultures grown under one set of conditions are compared with 20 cultures grown either under a different set of conditions or else under the same conditions but on different dates, differences up to 12 per cent between the two series (Nos. 1, 2, 3,4 , and 10 ) are without statistical significance; differences of 24 and 25 per cent (Nos. 5 and 8) are of doubtful significance (odds of less than $20: 1$ against the results being due to chance); while differences of 31 per cent and over (Nos. 6, 7 , and 9) are highly significant (odds of more than 20:1 against the results being due to chance). This analysis indicates that in experiments carried out in this way and using 20 replications in each experimental complex differences of 30 per cent and over can, in generial, be relied on to indicate a true difference in behavior and not merely fortuitous differences due to the variability of the 


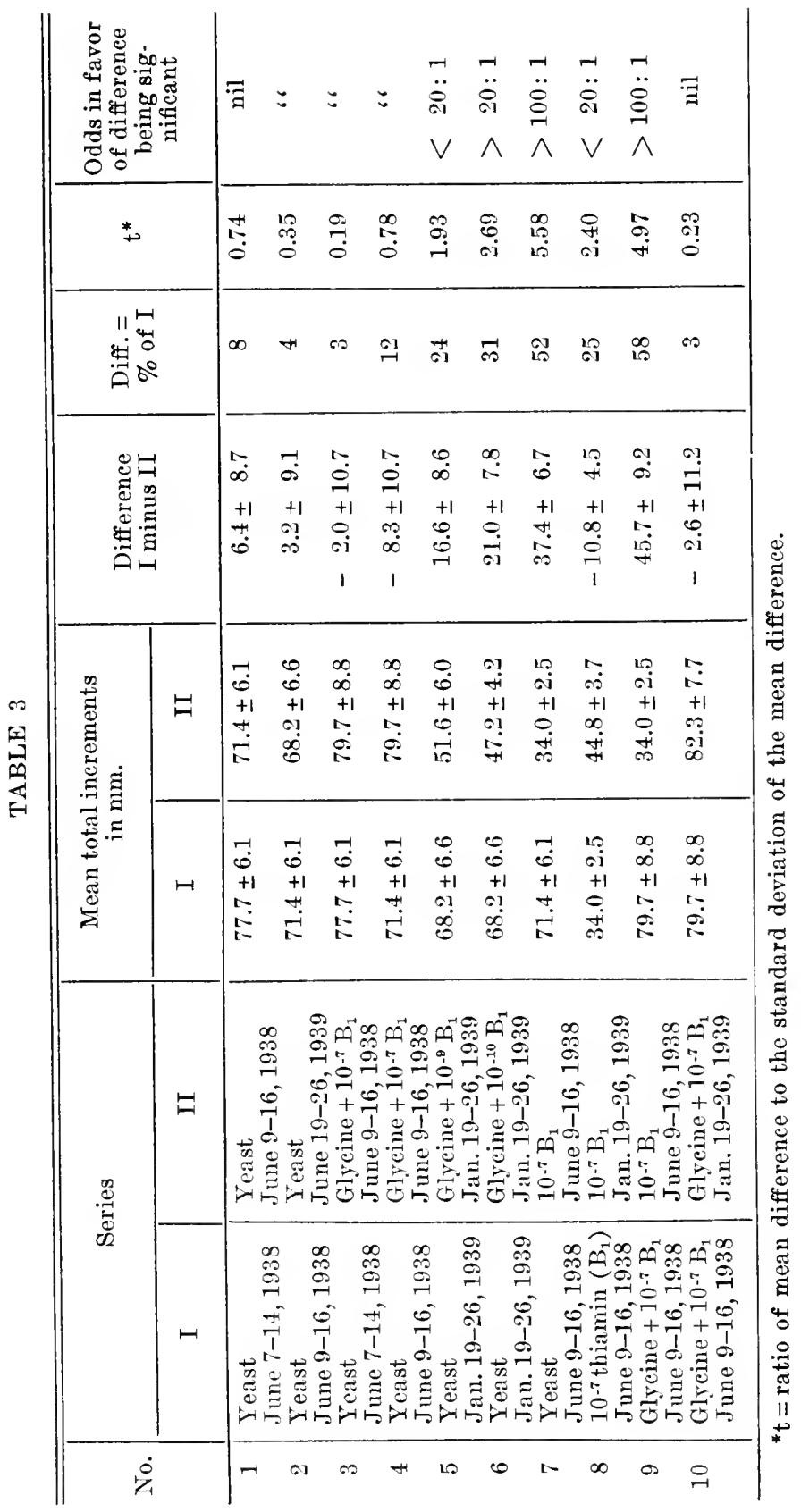


material. This, then, has been used as a basis in interpreting results of experiments of this sort.

Records. Each worker will have his own preferences as to records, which he will adapt to his own particular problems. This laboratory's records, as regards root cultures, may be worth presenting. All records are kept in $5 \times 7 \frac{1}{2}$ " notebooks containing about 120 pages, cross-ruled at $\frac{1}{5}$ " intervals. This book is of a size that will slip into a coat pocket (Fig. 41). The rulings permit the organization of the page into both horizontal and vertical columns and are close enough together so that a great deal of information can be placed on a single page. Three sample pages will suffice to indicate the ways in which such pages can be organized. The three sample pages indicate clearly the way in which routine numerical records are kept. In addition, photographs are taken of typical roots in each important experiment chosen to represent as nearly as possible the average length and growth habit of those grown in each solution or environmental complex. Thus, in Example 2, root No. 136 was set aside for photographing since it most nearly approximated the average of the group. The actual figures were:

Average increment $=24.8 \mathrm{~mm}$.

No. $136=42-18=24 \mathrm{~mm}$. 
Average number of branches $\quad=2.3$

No. $136=2$

Average length of longest branch $=5 \mathrm{~mm}$.

$$
\text { No. } 136=5 \mathrm{~mm} \text {. }
$$

From these records and from any qualitative notes which may be taken, a picture of the effects of any particular experimental variable can be built up.

Presentation of results. It is seldom if ever necessary or desirable to present the numerical data in an experiment in toto. The results can usually be presented better in the form of either histograms where only average results for total passages are desired or curves where temporal trends are to be given. Where a number of simultaneous experiments are to be compared, the results can be presented in absolute units-mm. or mg. or per cent nitrogen. Where experiments carried out on different tissues or at different times, particularly at different times of year, are to be compared, this is not possible, since the effects of varietal differences or of uncontrolled seasonal variables in the environment may have as great or greater effects on growth rates than do the experimental variables. Since all cultures react on the average in approximately the same way and to the same extent to most variables in the environment, this difficulty can be obviated by setting up a control in each series, treating this control always as the norm, and comparing all 
EXAMPLE 1

Passage 326

Stock cultures

1939

Passage 327

\begin{tabular}{|c|c|c|c|c|c|c|c|c|c|}
\hline No. & $\begin{array}{l}\text { Derived } \\
\text { from* }\end{array}$ & $\begin{array}{c}\text { July } \\
25\end{array}$ & A ugust & & No. & $\begin{array}{c}\text { Derived } \\
\text { from }\end{array}$ & Aug. & $\underset{8}{\text { August }}$ & \\
\hline 1 & 1 & $15 \dagger$ & $68+9-13$ & $53 \oint$ & 1 & 1 & 17 & $85+6-18$ & 68 \\
\hline 2 & 2 & 16 & $90+11-6$ & 74 & 2 & 2 & 18 & $83+4-10$ & 65 \\
\hline 3 & 6 & 16 & $53+5$ & 37 & 3 & 4 & 16 & $\mathrm{M}$ & 0 \\
\hline 4 & 4 & 19 & $108+19-30$ & 89 & 4 & "6 & 19 & $90+11-16$ & 71 \\
\hline 5 & 5 & 17 & $134+24-8$ & 117 & 5 & 5 & 17 & $85+10-8$ & 68 \\
\hline 6 & $"$ & 16 & $105+15-9$ & 89 & 6 & 6 & 17 & $105+20-5$ & 88 \\
\hline 7 & 8 & 17 & $25+6-60$ & 60 & 7 & 7 & 16 & $50+6-37$ & 37 \\
\hline 8 & 9 & 18 & $66+8-52$ & 52 & 8 & "6 & 15 & $75+10-18$ & 60 \\
\hline 9 & 10 & 16 & $98+15-8$ & 82 & 9 & "6 & 15 & $52+7-32$ & 37 \\
\hline 10 & " & 19 & $127+20-13$ & 108 & 10 & 6 & 14 & $45+3-10$ & 31 \\
\hline 11 & 11 & 17 & $95+13-23$ & 78 & 11 & 8 & 16 & $115+16-7$ & 99 \\
\hline 12 & 12 & 16 & $85+3-7$ & 69 & 12 & $" 6$ & 17 & $95+2-5$ & 78 \\
\hline 13 & " & 16 & $110+16-12$ & 94 & 13 & $"$ & 16 & $70 \quad M \quad \|$ & 54 \\
\hline 14 & “ & 14 & $85+10-8$ & 71 & 14 & "6 & 16 & $67+6-25$ & 51 \\
\hline 15 & " & 15 & $88+6-3$ & 73 & 15 & 9 & 18 & $51+4-15 \mathrm{M} \|$ & 33 \\
\hline 16 & 14 & 18 & $115+24-11$ & 97 & 16 & 10 & 18 & $136+20-20$ & 118 \\
\hline 17 & 16 & 18 & $108+27-8$ & 90 & 17 & 11 & 15 & $86+20-16$ & 71 \\
\hline 18 & 18 & 17 & $50+7-14$ & 33 & 18 & 12 & 19 & $110+10-5$ & 91 \\
\hline 19 & 19 & 16 & $+5-43$ & 43 & 19 & 13 & 18 & $145+12-20$ & 122 \\
\hline 20 & 20 & 16 & $33+4-7$ & 17 & 20 & 14 & 19 & $129+20-16$ & 110 \\
\hline 21 & “ & 15 & $33+5-10$ & 18 & 21 & 15 & 18 & $132+22-19$ & 114 \\
\hline 22 & 21 & 17 & $87+9-26$ & 70 & 22 & 16 & 17 & $75+15-20$ & 58 \\
\hline 23 & 22 & 17 & $\begin{array}{lll}20 & \mathrm{~S} & 1\end{array}$ & 3 & 23 & 17 & 18 & 65 & 47 \\
\hline 24 & 23 & 17 & $72+10-29$ & 55 & 24 & 19 & 17 & $75+8-22$ & 58 \\
\hline 25 & 24 & 16 & $107+8-6$ & 91 & 25 & 22 & 17 & $87+15-17$ & 20 \\
\hline
\end{tabular}

Total increment $\quad=1663 \mathrm{~mm}$.

Mean iner./eult./lay $=9.5 \mathrm{~mm}$.

$1704 \mathrm{~mm}$.

$9.7 \mathrm{~mm}$.

Notes:

* A record is kept of the genealogy of each eulture. Thus, Nos. 2 and 3 of passage 326 were derived from No. 2 of passage 325 , Nos. 11, 12, 13, and 14 of passage 327 were taken as tips of branches of No. 8 of passage 326 , ete. Thus, the history of any culture can lee traceel at will.

t The length of each eulture is recorded as soon after transfor as possible.

I the end of the passage (one week), the length of the main axis, the number of branehes, and the length of the longest liranch are reeorded. Thus, $68+9-13$ means that the "ulture had attainel a total length of $68 \mathrm{~mm}$. and had formed 9 branehes the longest of which was $13 \mathrm{~mm}$. long. $53+5$ indicates a total length of $53 \mathrm{~mm}$. with only a single branch $5 \mathrm{~mm}$. long. $+5-43$ indieates that the main axis had not grown at all but that there were 5 hranches the longest of whieh was $43 \mathrm{~mm}$. long. In this ease the length of the longest hranch is used in ealenlating ine rements.

\$ 'These figures represent the increase during a week's growth, that is, the difference between 15 mm. initial length and $68 \mathrm{~mm}$. final length.

II "MI" indieates "ontamination with moll, "B", contamination with bacteria, and "S" indieates that the "ulture hat sumk to the hottom of the thask. 


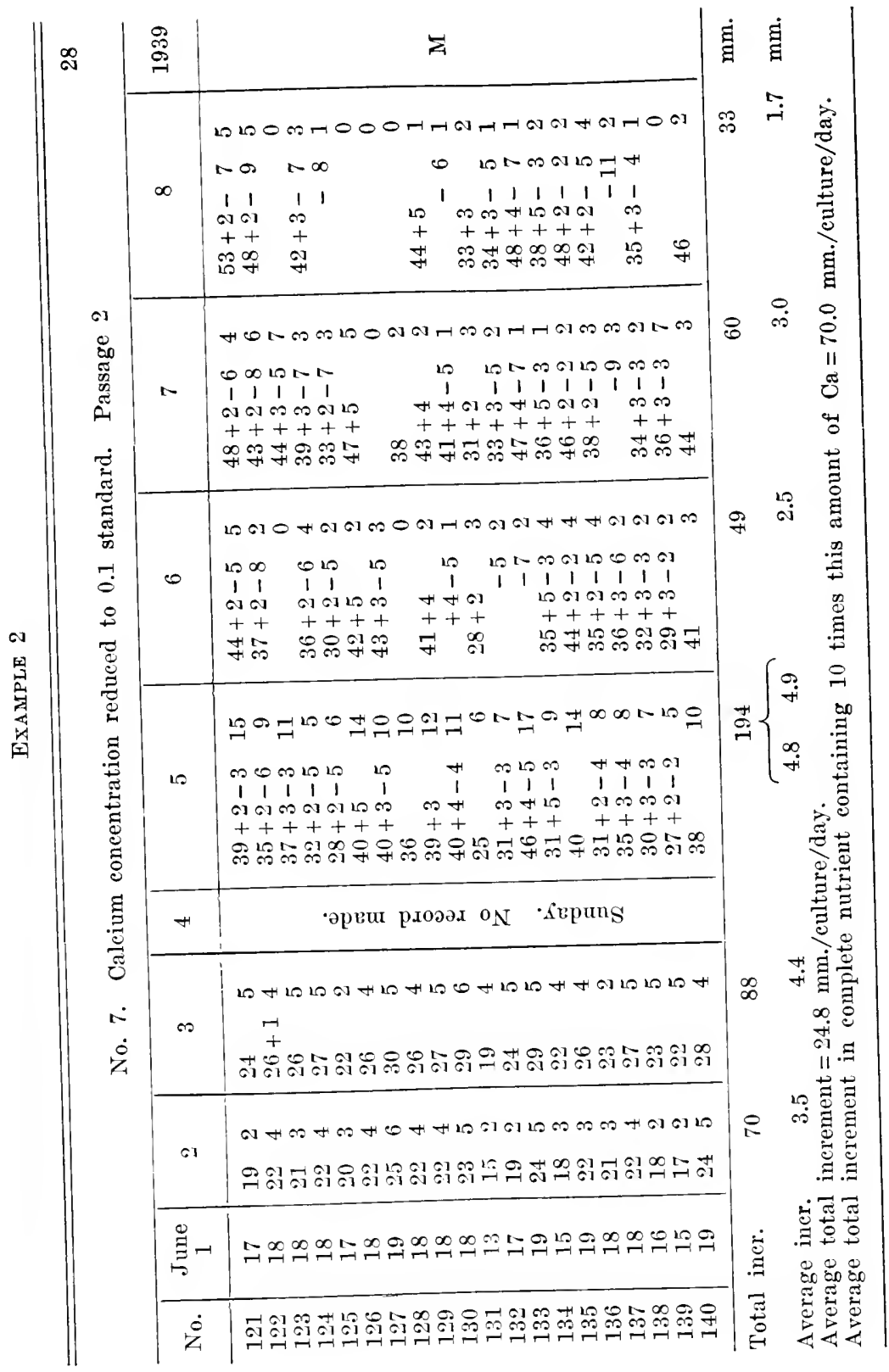


EXAMPLE 3

Root-pressures balanced against compressed air of measured pressure values

Set up June 15, 1937

\begin{tabular}{|c|c|c|c|c|c|}
\hline Date & Days & Time & Hours & Height & Remarks \\
\hline \multirow{3}{*}{$\begin{array}{c}\text { June } \\
15\end{array}$} & \multirow{3}{*}{0} & & & & \\
\hline & & $14: 00$ & 0 & 75 & \\
\hline & & $16: 00$ & $2^{\prime}$ & 75 & \\
\hline \multirow[t]{5}{*}{16} & \multirow[t]{5}{*}{1} & $8: 30$ & $18^{\prime} 30^{\prime \prime}$ & 100 & \\
\hline & & $12: 00$ & $22^{\prime}$ & 106 & \\
\hline & & $16: 00$ & $26^{\prime}$ & 117 & 1 atm. pressure applied \\
\hline & & $16: 10$ & $26^{\prime} 10^{\prime \prime}$ & 120 & 2666 \\
\hline & & $16: 40$ & $26^{\prime} 40^{\prime \prime}$ & 120 & \\
\hline \multirow[t]{6}{*}{17} & \multirow[t]{6}{*}{2} & $8: 30$ & $42^{\prime} 30^{\prime \prime}$ & 148 & 66 \\
\hline & & $11: 00$ & $45^{\prime}$ & 164 & $4 ،$ \\
\hline & & $12: 00$ & $46^{\prime}$ & 164 & \\
\hline & & $13: 30$ & $47^{\prime} 30^{\prime \prime}$ & 176 & 6 \\
\hline & & $15: 30$ & $49^{\prime} 30^{\prime \prime}$ & $172^{*}$ & 66 \\
\hline & & $17: 30$ & $51^{\prime} 30^{\prime \prime}$ & 172 & \\
\hline \multirow[t]{5}{*}{18} & \multirow[t]{5}{*}{3} & $8: 30$ & $66^{\prime} 30^{\prime \prime}$ & 176 & \multirow{9}{*}{$\begin{array}{l}\text { Pressure removed } \\
\text { * Balance between ex- } \\
\text { ternal and internal } \\
\text { pressure (or leakage } \\
\text { point) was reached } \\
\text { in this experiment at } \\
5 \text { atm. or } 75 \text { lbs. per } \\
\text { sq. inch. } \\
\text { Top of manometer } \\
\text { reached }\end{array}$} \\
\hline & & $11: 30$ & $69^{\prime}$ & 197 & \\
\hline & & $12: 00$ & $70^{\prime}$ & 210 & \\
\hline & & $15: 00$ & $73^{\prime}$ & 234 & \\
\hline & & $17: 00$ & $75^{\prime}$ & 244 & \\
\hline \multirow[t]{2}{*}{19} & \multirow[t]{2}{*}{ 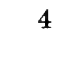 } & $8: 30$ & $90^{\prime} 30^{\prime \prime}$ & 360 & \\
\hline & & $12: 00$ & $94^{\prime}$ & 398 & \\
\hline 20 & 5 & & & $\ldots \ldots .$. & \\
\hline 21 & 6 & $9: 00$ & $139^{\prime}$ & 604 & \\
\hline
\end{tabular}

other cultures within the series with the control, on a percentage basis. The percentage results can then be compared from one experiment to another, which could not be done with the absolute values. Thus, in two series (White, 1940, 23.2) on the effects of vitamin $B_{6}$ on two different strains of roots, one strain in an experiment using 1.0 ppm. vitamin $B_{6}$ as the only organic accessory 
substance and completed on July 13, 1939, gave a numerical index of $58.6 \mathrm{~mm}$., the other strain, in a similar experiment completed on December 7, 1939, gave a numerical index of only $21.8 \mathrm{~mm}$., but the percentage values for the two were 60 and 62 , respectively. While the use of percentages may be objected to on the grounds that it involves a subjective choice of a standard, it is the only way in which non-simultaneous experiments can be compared and has proved very satisfactory as a method of presenting results. Three examples of graphical representations will serve to show the types found most useful (Figs. 45-47).

Interpretation of results. While the results themselves must, wherever possible, be presented in numerical form with a definite idea of the degree of accuracy and significance which can be attached to them, the interpretation of results is the duty of the observer. It is necessary for him to take into account not merely the numerical data but also many qualitative features of the results which cannot be set down in numerical form. Interpretation involves the integration of many sorts of information which only the person who actually handles the cultures can have available. How this is to be done is a matter of personal inclination and cannot be presented in any handbook. Yet it is in this, just as much as in the 


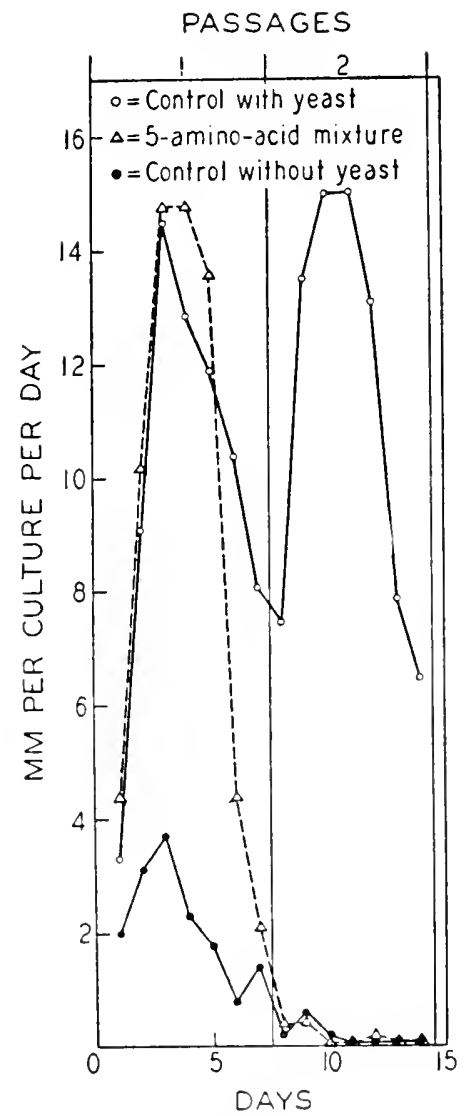

Fig. 45. A line graph reeording the average daily inerement rates of three series of eultures, 20 roots in each series, maintained for 14 days (two passages), eaeh in a different nutrient. 


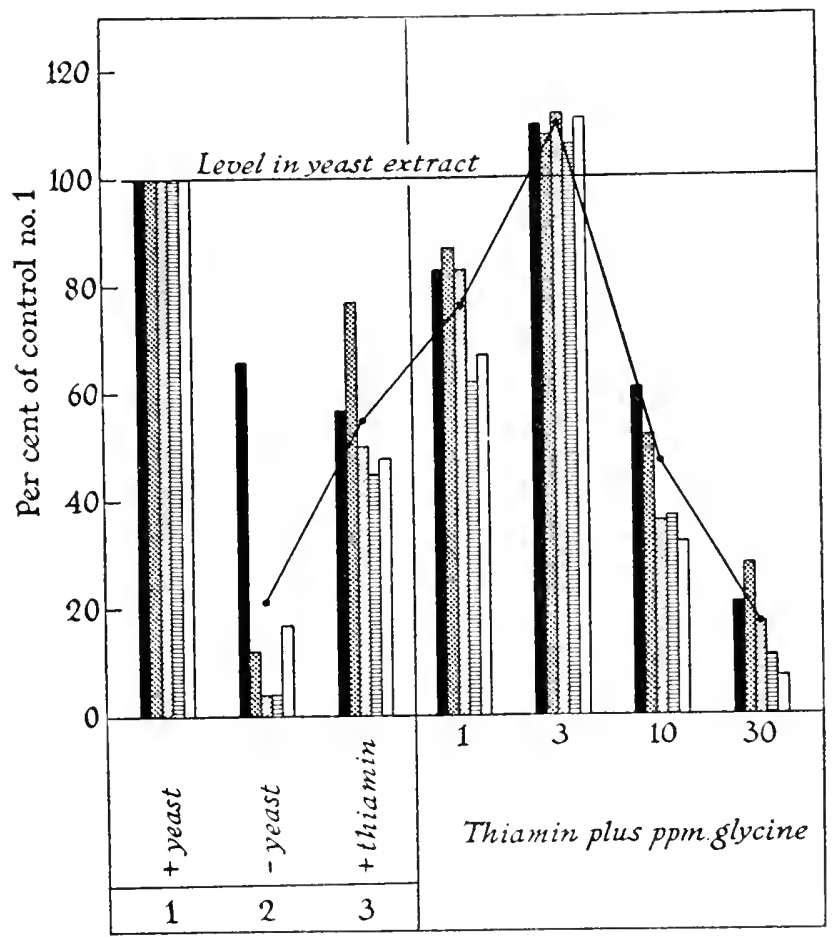

Controls

FIG. 46. A histogram recording the average weekly increment rates of 6 sets of cultures grown in as many different nutrients through 5 successive passages, each of one week's duration. The results are expressed as percentage of the increment rate in the control nutrient containing salts, carbohydrate, and yeast extract. Each vertical column represents the average of 20 cultures for a single week. The solid dots connected by solid lines represent the averages for all five passages ( 5 weeks) in each solution. (From White, P. R. 1939. Plant Physiol. 14: 531, fig. 4, 18.) 


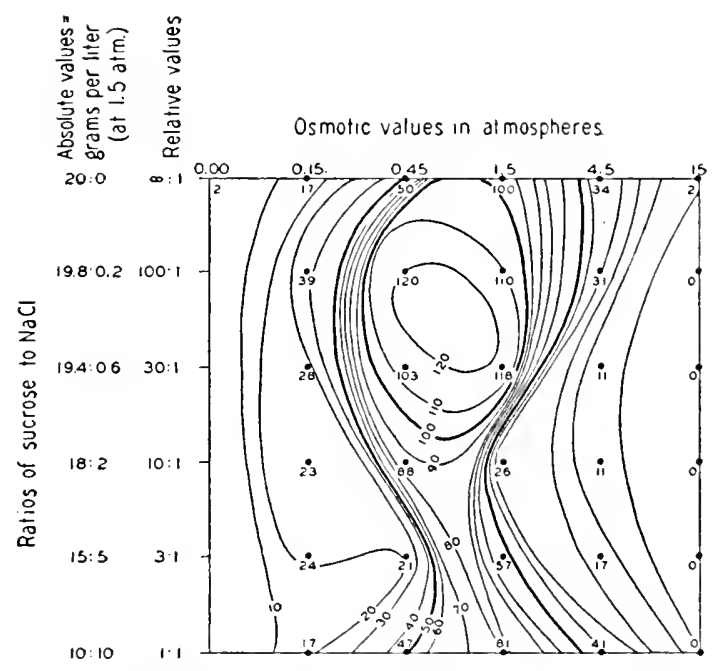

Fig. 47. An isopleth diagram (three-dimensional graph) showing the approximate average inerement rates (indieated by isopleth lines) obtained when tomato roots were grown in solutions in which the concentrations of suerose and of sodium chloride were simultaneously varied in a regular way so as to obtain a graded series of ratios (indieated on the ordinates) and a simultaneous graded series of osmotie values (indicated on the abscissae). This type of diagram, whieh may also be built into the form of a solid graph like a relief map, is extremely useful when it is desired to reeord the effects of the interaetion of two simultaneous variables. (From White, P. R. 1942. Plant Pliysiol. 17: 159, fig. 5, 37.) 
recording of data, that the scientist shows his true calibre. It does not seem amiss, therefore, to emphasize the importance as well as the difficulty of this phase of any experimental project.

\section{Summary}

The significance of any piece of scientific work rests primarily on the ability to express results in quantitative terms and the reliability of these terms themselves. The measurement of cultures and the interpretation and evaluation of such measurements are, thus, matters of prime importance. Plant tissue cultures may be measured by determining protein nitrogen, dry weight, respiration intensity, area, volume, and doubtless other characteristics. The first three methods require the destruction of the tissue studied. With callus cultures none of these methods is fully satisfactory and a subjective criterion can scarcely be avoided. With root cultures linear increment has been found to be a satisfactory criterion of growth which is easily and accurately obtained, yet does not involve destruction of the tissue studied. Measurement of the central axis alone, ignoring all branches, is in error by about 5 to 8 per cent as compared to dry weights. Linear measurements can be made with a mean error of 6 to 8 per cent, an accuracy comparable to that obtainable 
in making dry weight determinations. In order to reduce the random error, each experiment should include at least 20 replications in each environmental complex, and with this number a difference of at least 30 per cent of the control value must be produced by any given variable before that variable can safely be assumed to be responsible for the difference. Records are kept in standard notebooks of a size to be slipped into the coat pocket. Final results may be presented as tables, graphs, histograms, or models. In order that experiments carried out at different times may be compared, it is desirable to express results in terms of percentages of a control maintained under as nearly as possible standardized conditions. 


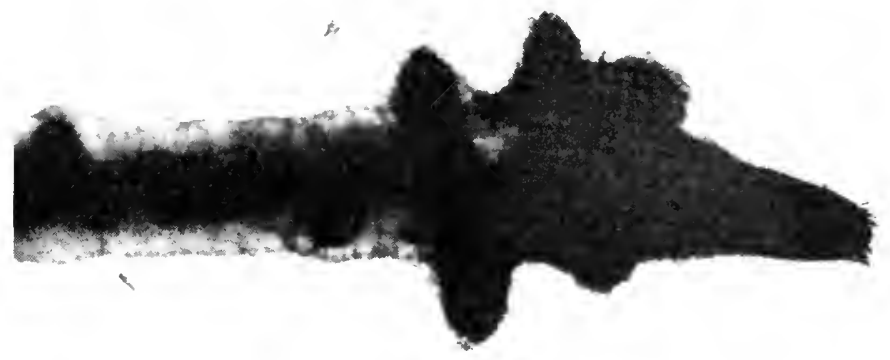

Fig. 48. Tip of excised tomato root grown for one week in a complete nutrient to which were alded $3=10^{-i \mathrm{~g}} \mathrm{~g}$. of indole arectice acid per ml. of nutrient. Failure of the axis to elongate has rowded the litaneh-pimordia which are usually seattered over mauy rentimeters of root into a few millimeters giving the appearance of a "rooting" response. 2.5. 


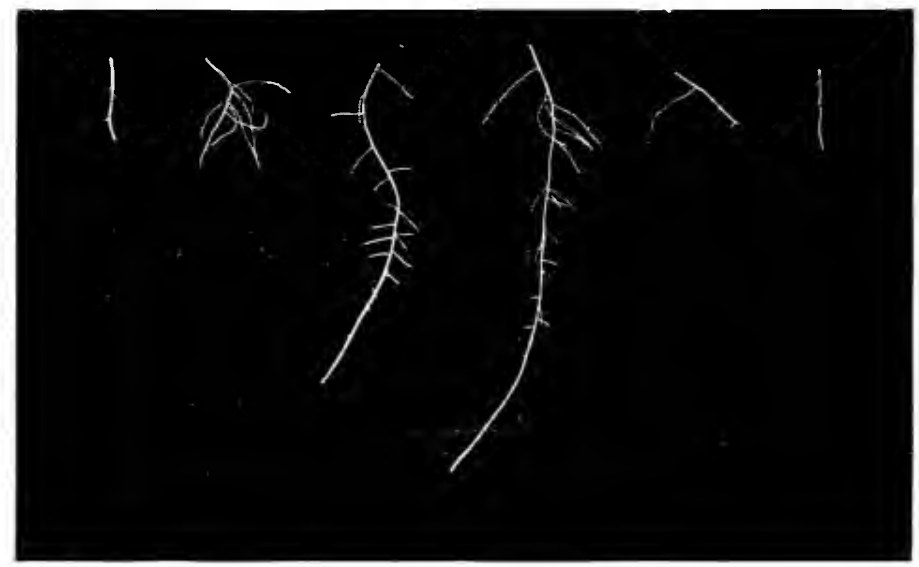

Fis. 4!. Exeised tomato roots grown in solutions eontaining, in addition to other essential comstituents, the following coneentrations

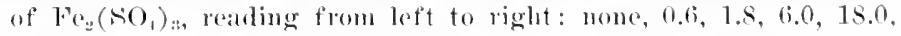
and $80.0 \times 10^{-6} \mathrm{M}$. Photograph was taken after roltivation for one work. (From White, I'. R. 1940. Plant Physiol. 17: 15s, fig. t. $3 \%$.) 


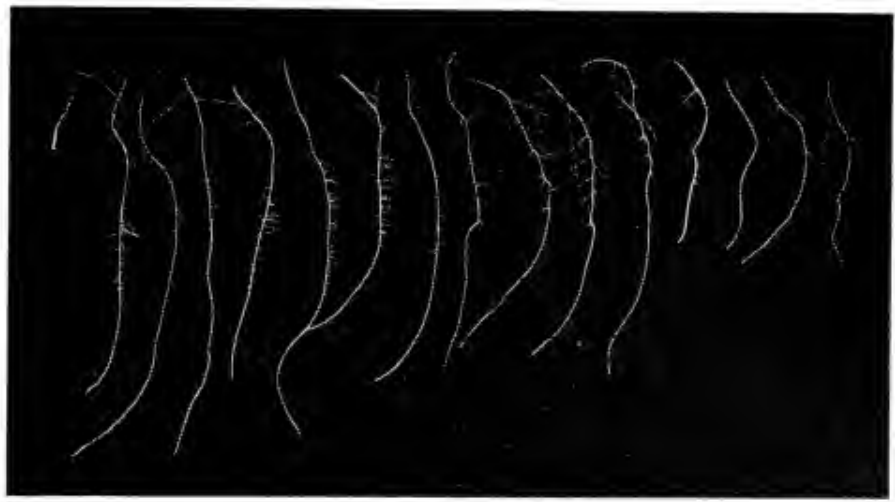

Fig. 50. Excised tomato roots grown in solntions containing, from left to right, the following concentrations of $\mathrm{Fe}_{2}\left(\mathrm{SO}_{4}\right)_{3}$ : none, $0.675,1.35,2.025,2.7,3.375,4.05,4.725,5.4,6.077,6.75,7.425,8.1$, $8.775,9.45$, and $10.125 \times 10^{-6}$ M. The linfar increments of roots grown in iron concentrations from 1.35 to $5.4 \times 10^{-6}$ XI are greater than at higher eoncentrations, but the branches are short and the general halit poor. Experience has shown that roots grow more satisfactorily and for lomger periods if the iron concentration is from 6.0 to $7.0 \times 10^{-6} \mathrm{M}$. The extreme sensitivity of these roots to shight rariations in concentration of ions which are present in as minute amounts as is iron is one of the striking eharacteristies of such cultures. 


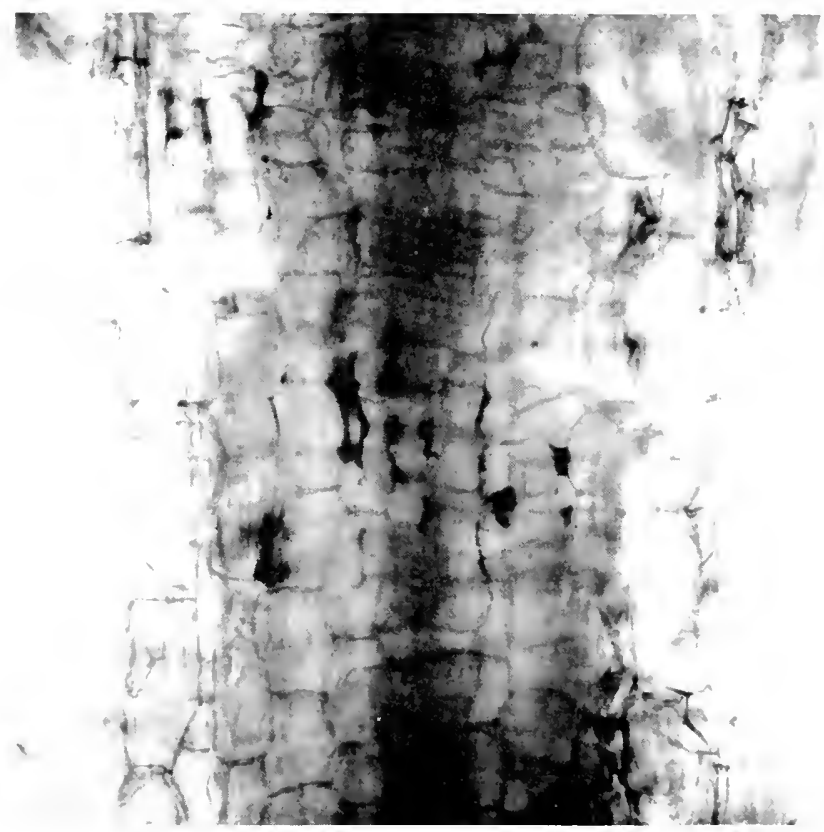

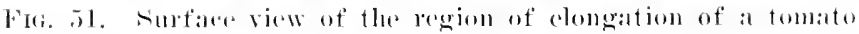
foot grown in a solution eontaining indole aleotic acid, showing the seattered neerotic lesions resulting form plasmoptysis (explosion)

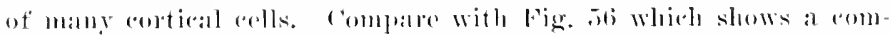

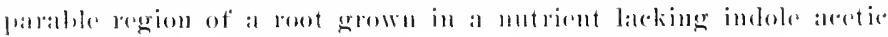
:leil. 150. 


\section{Chapter IX}

\section{TISSUE CULTURE AND THE STUDY OF PROBLEMS IN THE PATHOLOGY AND GENERAL PHYSIOLOGY OF PLANTS}

The history of any biological method covers, in general, three phases which may or may not be simultaneous. These are: the development and perfection of basic techniques; the application of those techniques to already recognized problems; and the formulation of new and unforeseen applications. Harrison $(1907,131)$ began with the second phase in this series, having before him a definite problem, the elucidation of the origin of nerve fibrils, before he devised the tissue culture technique. Having solved that particular problem by relatively simple methods, he found no further incentive to perfect or expand the technique and turned to other problems anienable to other techniques. Carrel (1911 et seq., 120), on the other hand, without a specific problem but with a less formulated concept of a vast field of problems, took this technique and perfected it to a very high degree. The application to new but specific prob- 
lems again passed to a third set of workers, where Fell used it in studying bone-phosphatase activity (Fell, 1928 et seq., 392-401), Warburg in studying tumor metabolism (Warburg, 1923, 272, 1926, 273; Warburg and Kubowitz, 1927, 274), Rivers in growing vaccines (Rivers, Haagen, and Muckenfuss, 1929, 440, 441; Rivers and Ward, 1935, 442), etc.

The plant tissue culture idea began with a theory rather than with a specific problem. Haberlandt's theory $(1902,98)$ gave rise to a technique in the hands of Gautheret (1932 et seq., 48), White (1934 et seq., 65), and others. Being of much more recent development than the animal tissue culture technique, it has no such great literature of applications, yet it has already found a variety of fields of usefulness and will doubtless find many more in the future.

The applications of the tissue culture technique fall for the most part in three fields: in physiology, in pathology, and in morphogenesis.

\section{Physiology}

Gross reactions. As we have seen elsewhere, that aspect of a culture's reaction to its environment which can be most easily recorded in quantitative terms is its increase in mass. Its alterations in form come second, while in the third rank 
in ease of investigation, but by no means third in importance, are its changes in rate of activity as evinced in terms of enzymatic digestion, respiration, photosynthesis (if any), etc.

Mass increase has been used in measuring cultures' behavior towards nutrient variables, vitamins, temperature and light changes, and so on. In this way it has been demonstrated, for example, that, whereas the absolute concentrations of various ions or molecules which give optimal growth rates differ widely for different elements- $0.05 \mathrm{M}$ for sucrose (Robbins, 1922, 57 ; Bonner and Addicott, 1937, 42; White, 1932, 63), $0.02 \mathrm{M}$ for calcium and magnesium (White, 1932, 141), 0.000,002 M for iron (Figs. 49, 50) (White, 1932, 141; Robbins and Schmidt, 1938, 60 ), and $0.000,000,3 \mathrm{M}$ for thiamin (Robbins and Bartley, 1937, 222 ; Bonner, 1937, 198; White, 1937, 231)-the range around these optima which will still permit normal growth is in almost all cases of about the same magnitude, from about 0.5 to 5.0 times the absolute optimal value (White, in press). The capacity of the tissue to adjust its behavior vis a vis these widely different substances appears to be about the same, irrespective of the substance under investigation. These powers of adjustment may be enhanced or reduced according to the existing conditions as regards other variables in the environment with 
which they have no apparent connection. Thus, cultures grown in a glycine-thiamin nutrient give results which, at their best, are superior to the best results obtained in a yeast nutrient, yet in a glycine-thiamin nutrient they appear to be far more sensitive to temperature changes than in a yeast nutrient, so that at suboptimal or supraoptimal temperatures the relations between growth rates in these two nutrients may be just reversed (White, unpublished). The presence of a large number of substances of various character in the yeast extract seems to "buffer" the cultures against a too great sensitivity to other limiting factors as compared to the few substances in the synthetic (glycine-thiamin) solution. Perhaps this is one reason for past failures to obtain satisfactory growth of animal tissues in simple nutrients. Studies of this sort bid fair to give us considerably better insight into the functions and interactions of the various nutrient molecules and ions as well as other environmental variables in the plant's economy.

Qualitative changes. A tissue's or organ's reaction to nutritional variables may, of course, be studied qualitatively as well as quantitatively. The reaction to indole acetic acid and its homologues serves as a striking but by no means isolated example. A graded series of concentrations 
of indole acetic acid added to a basic nutrient will give quantitative results which may be expressed in a fairly uniform curve (Fig. 52) (Fiedler, 1936, 45; Geiger-Huber, 1936, 214; Geiger-Huber u. Burlet, 1936, 215; Duhamet, 1939, 209; Bonner

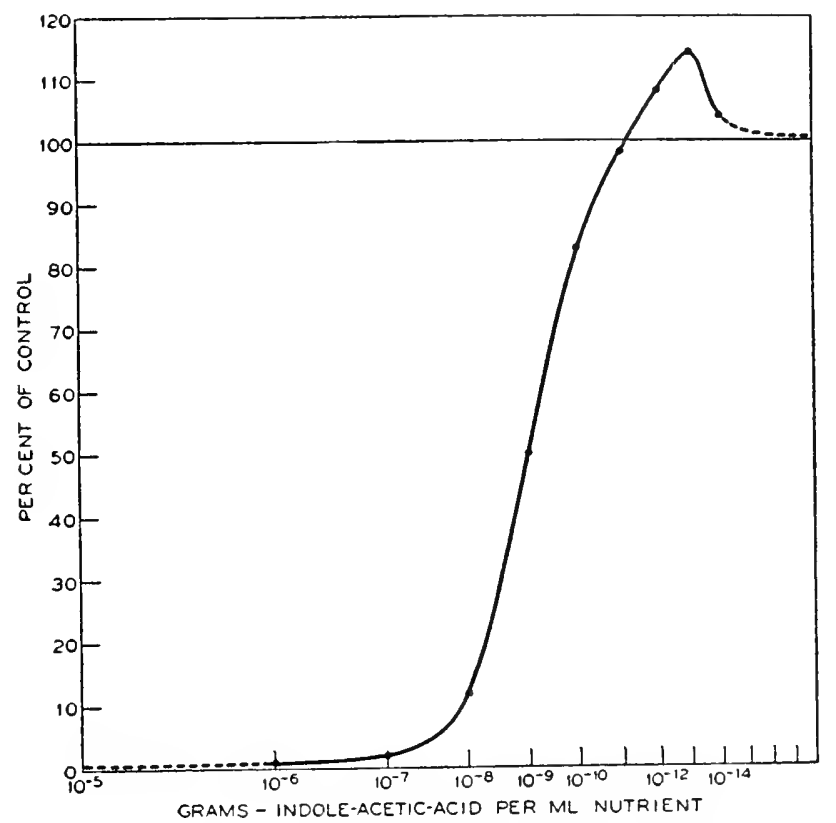

FIG. 52. Graph showing the relative rates of increment of excised tomato roots grown for one week in a complete nutrient to which had been added (from left to right) decreasing concentrations of indole acetic acid. While $10^{-12}$ and $10^{-13} \mathrm{~g}$. of indole acetic acid per ml. of nutrient gave results which might indicate a stimulative effect, the improvement over the control without indole acetic acid was less than the probable error of the experiment and hence of doubtful significance. 
and Koepfli, 1939, 343; White, unpublished). But it is also possible to observe, at concentrations just exceeding the threshold level for growth retardation, a characteristic shortening and thickening of the root axis, resulting in a crowding of the branch primordia into a relatively small space (Fig. 48) (Leonian and Lilly, 1937, 219). This gives an apparent but not real increase in the number of branches and simulates a "rooting" response, although in point of fact a rapidly growing culture of the same age, grown in a nutrient lacking indole acetic acid, would normally form just as many branches but scattered over from 10 to 20 times as great a length of root. Root cultures deprived of potassium continue to grow in length with unimpaired vigor but become progressively more and more slender and fail to branch, as if all the potassium present in the original explant was being retained in the apical meristem so that none was available for the formation of branch primordia. Omission of iodine from the nutrient likewise leaves the culture quantitatively unimpaired but results in a spasmodic growth, the tips dying after 3 or 4 days and a series of new branches developing, giving a picture quite different from that produced by potassium deficiency (White, in press).

Changes in activity. As has already been 
pointed out, changes in mass and in form are only secondary symptoms of the real activity of the tissue and must be interpreted with some caution. The activity of the tissue can be studied in a somewhat more direct fashion by examining its capacities for fermentation or more especially its respiratory activity. This has been done, to date, in only a single piece of work, carried out on callus cultures of Salix capraea by Plantefol (1938, 256, 257) in co-operation with Gautheret. Both callus cultures and root cultures, because of their relatively reduced dimensions which permit a comparatively easy gas interchange between culture and nutrient, because of their freedom from trauma, and because of their high growth rates, should provide ideal material for study of processes of this sort (Warburg, 1923, 272, 1926, 273).

Nothing has been done in the study of photosynthetic activity using plant tissue cultures. Roots normally do not possess such activity and that of callus cultures is probably low so that they do not appear likely to prove very useful in this respect.

While these are some of the obvious tissue activities which suggest themselves as possible subjects of investigation, there certainly exist less obvious but no less important ones. One of these turned up unexpectedly in the form of a glandular 
function in root tissues. Root cultures, although immersed in nutrient fluid, nevertheless form well differentiated vascular strands (Fig. 55). The existence of such strands suggested the possibility that they might be serving some real function, and means were devised which made possible the demonstration of the existence of a unidirectional flow of liquid through these immersed organs (White, 1936, 264). Further study showed that this flow was not continuous but had a diurnal rhythm and that it was maintained even when opposed by very great external pressures (Fig. 53) (White, 1938, 267-269). The existence of a rhythmic secretion was verified by Grossenbacher (1938, 243, 1939, 244), and the unidirectional character of the flow and the magnitude of the force were verified by Rosene (1937, 259, 1941, 260). A correlative diurnal rhythm in respiration rate has likewise been demonstrated in growing excised roots (White, 1942, 37, 38). The techniques required for study of this phenomenon are far from simple, so that investigations thereon have been intensive rather than extensive (Figs. 56-58). The problem is, however, an important one in its bearing on the question of water movement in plants and of glandular activity in general. It serves as an excellent example of the unforeseen applications which a new technique may find. 


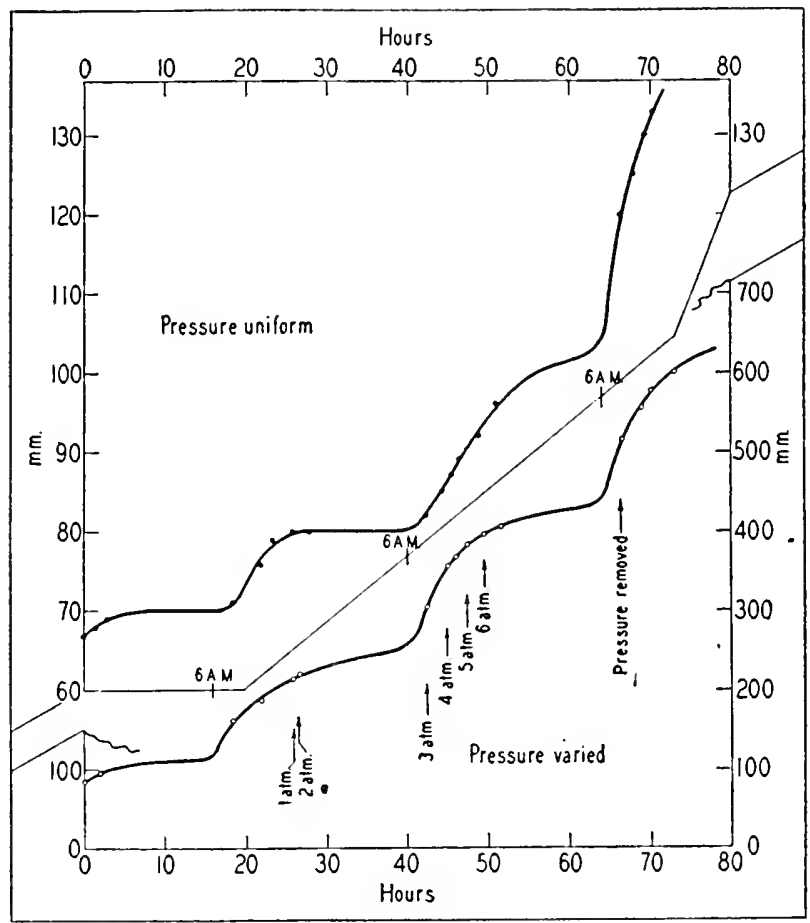

Fig. 53. Graph showing the rates of water secretion of two similar tomato roots over a period of $3 \frac{1}{2}$ days, one (above) against uniform (atmospheric) pressure, the other (below) against imposed pressures up to $90 \mathrm{lbs} . / \mathrm{sq}$. in. The diurnal rhythm with which secretion proceeds is a striking characteristic of the behavior of tissues of this sort. (From White, P. R. 1938. Am. J. Bot. 25: 226 , fig. $6,26 \%$.) 
Tropisms. Kotte $(1922,52)$ and Fiedler (1936, 45) have both made cursory observations on geotropic response of roots grown in an agar substratum and report normal curvature. It has been the experience of this laboratory that roots floated on or near the surface of a liquid substratum show no such response. Two possible explanations of this difference have suggested themselves-either that the positive chemotropic response to the oxygen gradient in a liquid medium is more powerful than the geotropic response and masks the latter (an explanation which should be equally applicable to a semi-solid substratum) or that the absence of a fixed support or fulcrum from which to bend makes it inpossible for a root to retain a unilateral orientation. The positive reaction on agar seems to support the latter explanation, yet, once a root has grown long enough in a liquid nutrient to curve around the flask somewhat, it has built up a bilateral symmetry which should make a reaction to gravity possible. This does not take place. Yet in experiments in which roots were fixed in a constantly aerated medium lacking an oxygen gradient, the response reappeared (White, unpublished). A clear explanation is yet to be obtained. This example should suffice to show that cultures of this sort are capable of serving as excellent material for certain types of tropistic studies. 
Cellular reactions. While the use of hangingdrop cultures adapted to continuous observation of single cells has so far been little developed as applied to plant tissue cultures, there seems to be no a priori reason why questions of the reactions of individual cells should not be followed by means of such a technique. This has, indeed, been done in a number of scattered instances. The gradual resorption of starch from the plastids in hangingdrop cultures of Stellaria media has been studied in this way (Fig. 54) (White, 1933, 116). The localization of tyrosinase in the plastids of roothairs and cortical cells has been demonstrated by

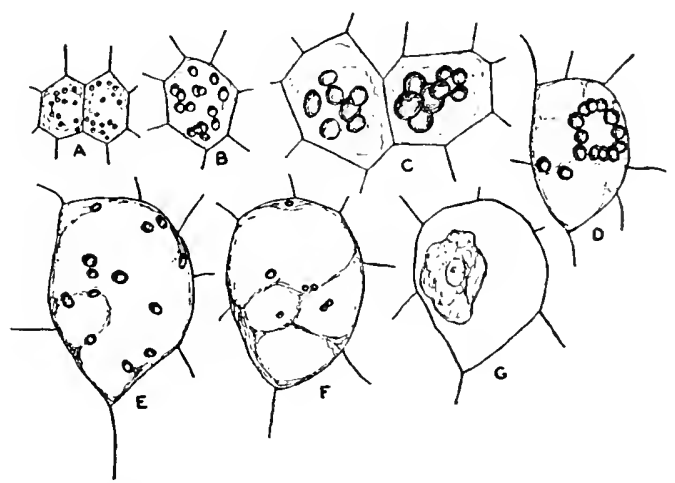

FIG. 54. A typical developmental cycle of individual cells in a culture of the stem tip of Stellaria media maintained for two weeks in a hanging drop of nutrient, showing the progressive increase and then decrease in size of the plastids as the cell grows, reaches maturity, passes into senility, and finally dies. (From White, P. R. 1933. Protoplasma 9: 110, fig. 19, 116.) 
growing root cultures in a nutrient containing 5 ppm. of tyrosine, a concentration which permits normal growth (Fig. 60) (White, unpublished). The behavior of localized root cells towards indole acetic acid with the formation of scattered necrotic lesions produced by the bursting of individual cells (plasmoptysis) has likewise been studied (Fig. 51) (White, unpublished). The tendency towards differentiation of scalariform cells in the interior of callus cultures (White, 1939, 78) may be looked upon as an example of cellular response to a particular environmental complex, in this case one of low available oxygen content (Figs. 62, 63, 65, 66). Cyclosis can be observed very satisfactorily in the large "callus-blasen"' to be found on the surfaces of callus cultures (Fig. 61) (White, 1932, 89), which should facilitate an accurate study of the effects of envirommental variables on this process.

These serve merely to point out some few places at which physiological processes have been or can be approached by means of tissue cultures.

\section{Pathology}

In the field of phytopathology, the most obvious of all applications of a new technique for the cultivation of phanerogamic tissues is in the maintenance of such tissues as substrata for either obligate or facultative pathogens. The method as 


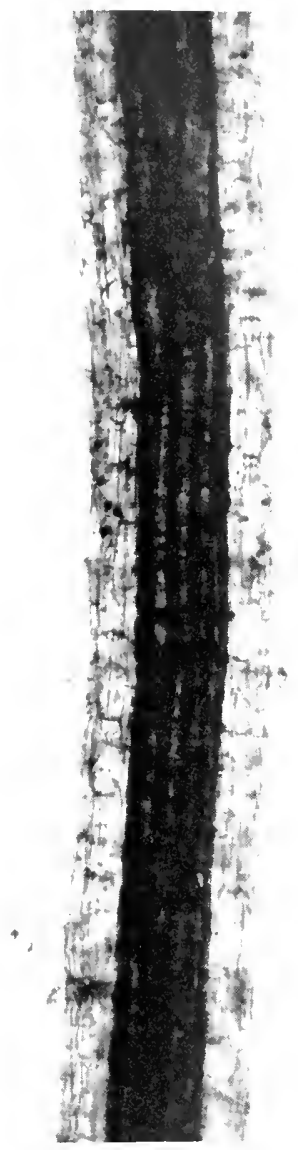

Fig. 55. Optical longitudinal section of the region of maturattion of a growing excised tomate root, showing the well-differenti-

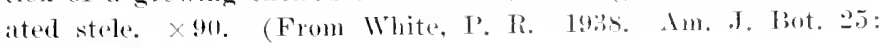
․․․, fig. 1, 26\%.) 


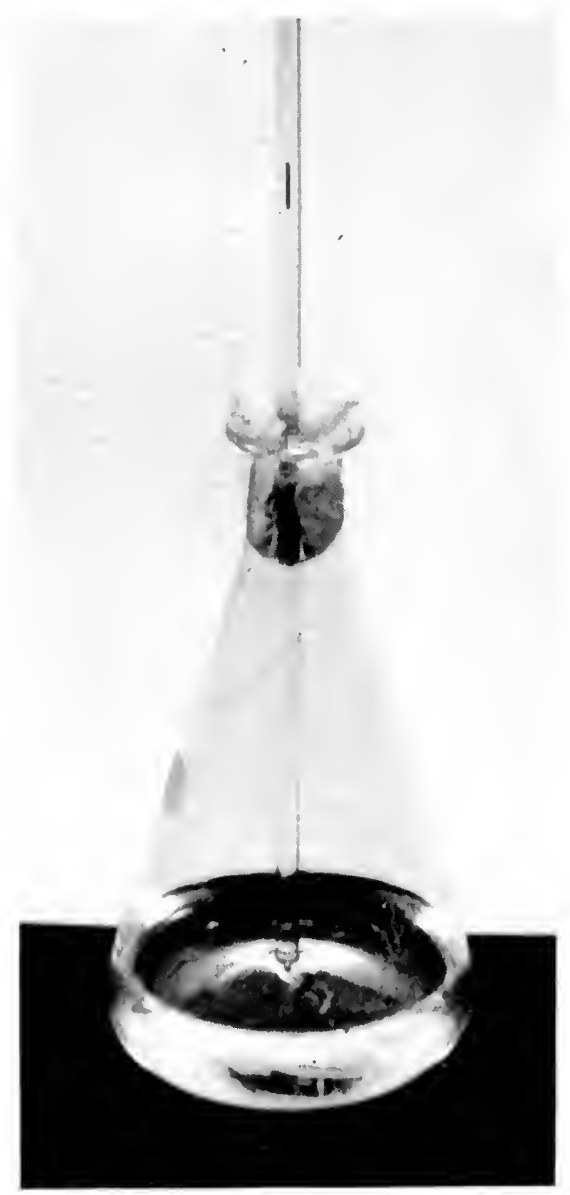

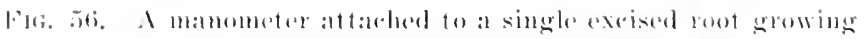
in its aulture tlask. Water is serented into the mamometer, foreing

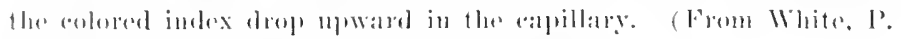

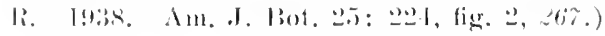




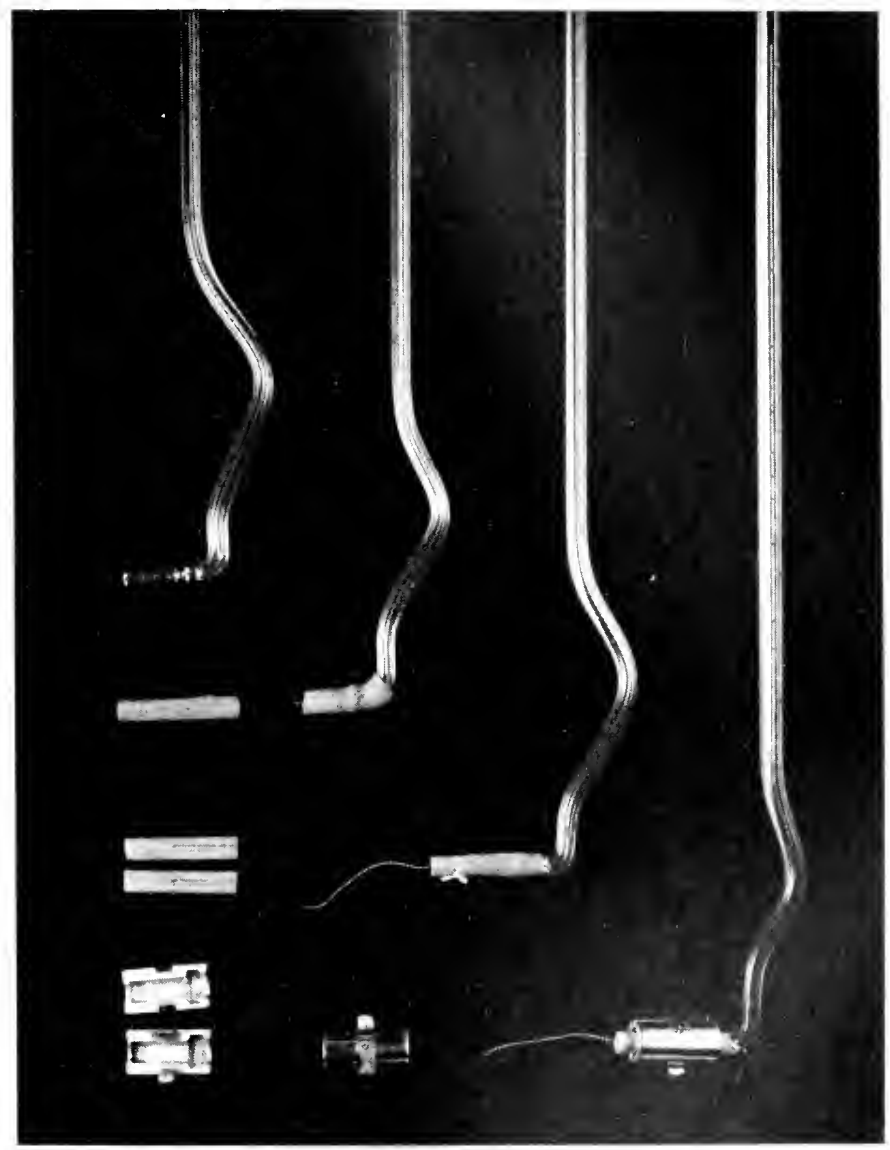

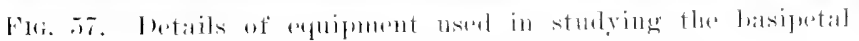

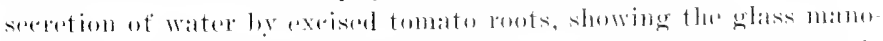

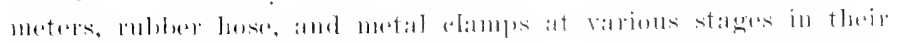

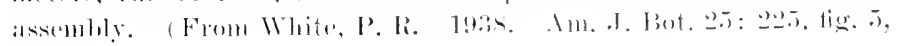
$\therefore$ (6i.) 


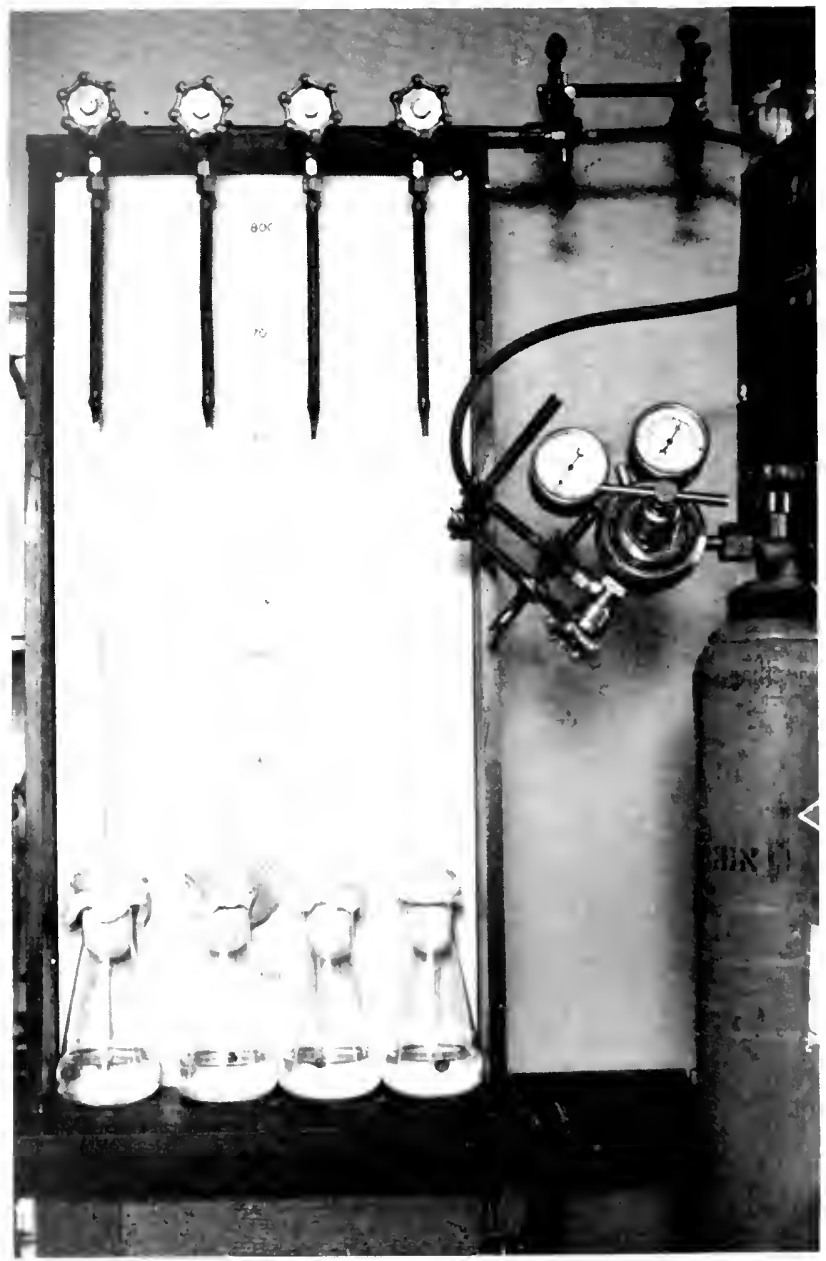

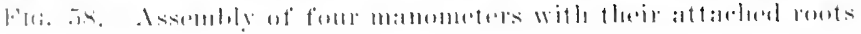

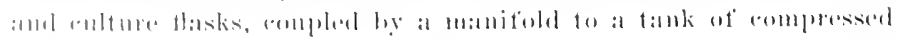

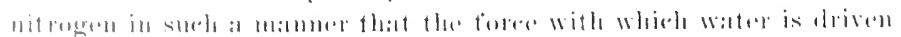

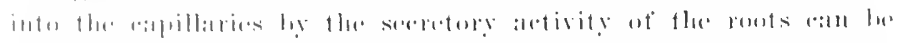

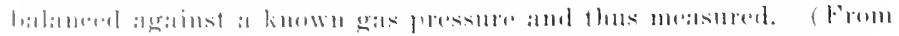

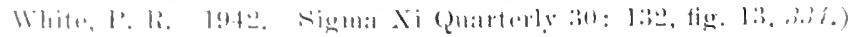


it stands today is hardly usable for the latter, for the obvious reason that the basic nutrient for tissues is also an excellent nutrient for many of these organisms. It may, of course, be possible to modify the nutrient in such a way as to make it suitable for the host tissue but not for the infecting organism. Lewis and McCoy $(1933,301)$ used a primitive sort of organ-culture technique in the study of bacterial nodule formation on the roots of legumes. Although their results were not entirely satisfactory, they suffice to indicate one direction in which the more highly perfected techniques may prove useful. Riker and Berge (1935, 317) foresaw some such possibility in connection with their studies of crown gall organisms, as did Nobécourt and Dusseau $(1938,311)$ and Berthelot and Amoureux (1937, 276). Nothing has been done with fungi except Gioelli's observations on the effects of chance contaminations on his cambium cultures $(1938,292)$. If the roots of cereals can be grown in the same manner as those of dicotyledonous plants, they should serve as interesting substrata for the study of rust infections.

Viruses in tissue culture have been studied to a somewhat greater extent than have bacteria and fungi, though still barely enough to give a suggestion of the possibilities. Viruses of a considerable number of diseases of the mosaic group have 
been cultivated in excised roots of tomato (White, 1934, 438, 1936, 439). (See Chapter VI.) Diseases which cause only moderate local injury and which move rapidly into all parts of the host can be maintained indefinitely in tissue eultures without difficulty and without essential change in the methods. Here they produce no macroscopically visible symptoms. By aliquot titration, it is possible to follow the rate of multiplication of the virus as a function of host-tissue multiplication (Fig. 59) and to show that the two rates are independent of one another. Stanley $(1938,43 \%)$ has used such cultures as a source of virus in order to demonstrate the essential identity of the chemistry of virus protein produced in these chlorophyllfree tissues and of that derived from the usual leaf tissues with their high chlorophyll content and activity. Viruses which eause a high degree of local injury and which have a slow migration rate in the tissue are somewhat more difficult to maintain in culture. A considerable amount of older tissue must be included in every explant along with the usual meristem, since the meristems themselves are often virus-free. Otherwise, the virus may be left behind in the discarded tissue and a strain of healthy tissue segregated for cultivation. Such healthy strains have been segregated from cultures carrying "cucumber mosaic" 


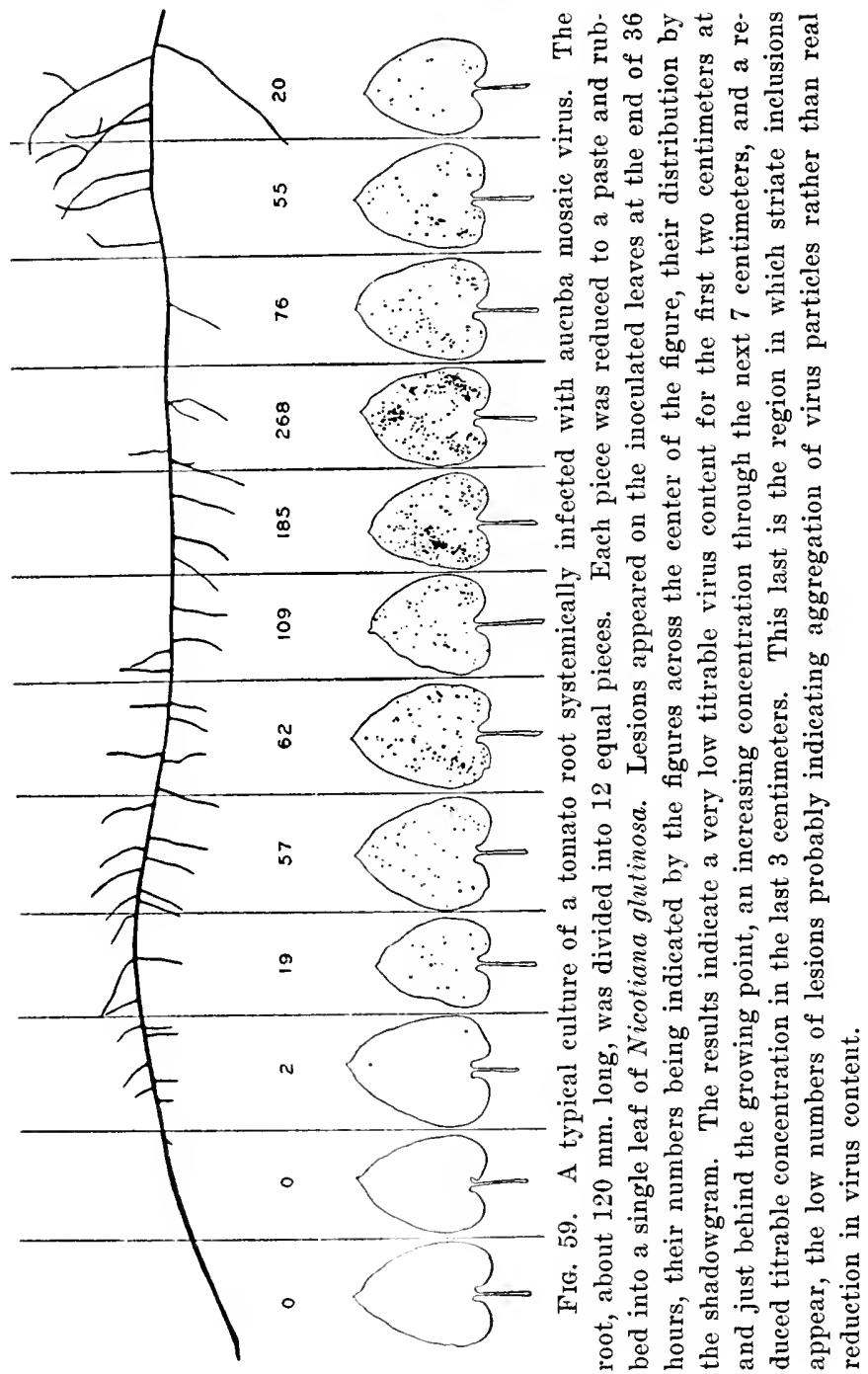


virus, Jensen's No. 16 strain of tobacco mosaic virus, and some other virulent types (White, unpublished). Interestingly enough, no method has yet been found for inoculating such cultures (they must be isolated from systemically infected plants), so that there is no danger of a virus-bearing culture, once established, ever becoming contaminated with another virus (White, 1934, 438).

Tissue cultures have to date not been tested as hosts for phanerogamic parasites such as Cuscuta, Viscum, etc., but should prove useful in the study of phanerogamic host-parasite relations.

One field of investigation in which tissue cultures promise to be extremely useful, which represents essentially an extension of the nutrition studies mentioned above, is that covering the effects of toxic or injurious substances, either of organic or inorganic origin, on the behavior of the tissues of such cultures. The reaction to indole acetic acid mentioned above is an excellent example and serves to show the sorts of observations which are possible in this field using even very simple methods (Figs. 48, 51,52). The reaction of excised carrot tissue to colchicine has also been studied, by Duhamet (1939, 210).

\section{Histology and Cytology}

Tissue and organ cultures furnish unusually clean, uniform, easily handled material for histo- 
logical study. Gautheret (1935, 15, 1937, 282, 1938, 283, 284, 1940, 286-289), Dauphiné (1930, 279), Robbins and his colleagues (Robbins and V. B. White, 1936, 62), and Addicott (1941, 196) have utilized root cultures for some anatomical and histological studies. White $(1939,78)$ Gautheret (1938, 283, 284) and Gioelli $(1937,290)$ have made a few similar studies with callus cultures. There remains, however, much to be done in this direction.

\section{Summary}

The tissue culture technique has been applied to the study of the reactions of tissues, organs, and cells to variations in concentrations of nutrient materials, growth stimulants, toxins, and other environmental variables. These reactions can be measured in terms of mass increase, differentiation, level of respiratory activity, enzyme or water secretion, tropistic bending, and many other sorts of behavior. Bacteria, molds, and viruses have been cultivated on growing isolated plant organs as hosts and the host behavior studied. These represent some of the fields to which the technique has already been applied. Many more obviously remain as yet untouched. 



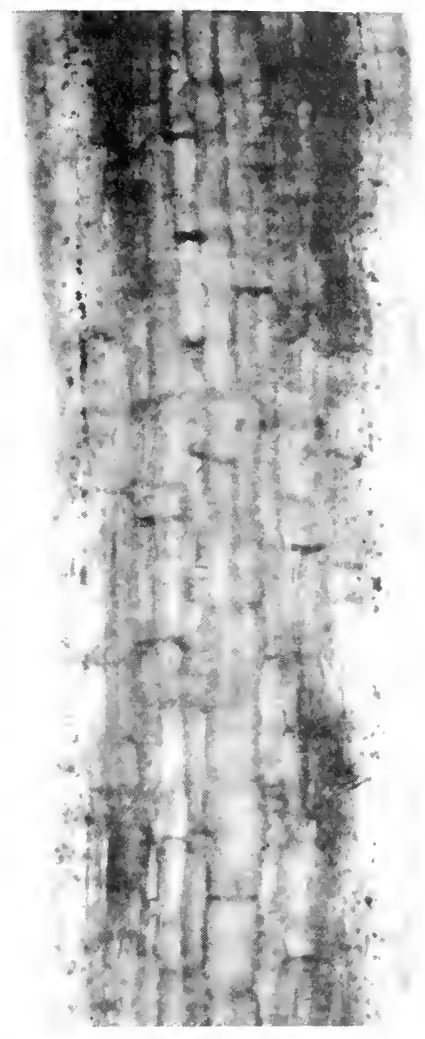

FIg. 60. Optical longitudinal section of an exrised tomato root grown for one weok in a complote nutrient to which was arded 15 mg. of tyrosine per liter of solution, showing the typieal blackening of the plastids indirating the presence of tyrusinass. 150 . 

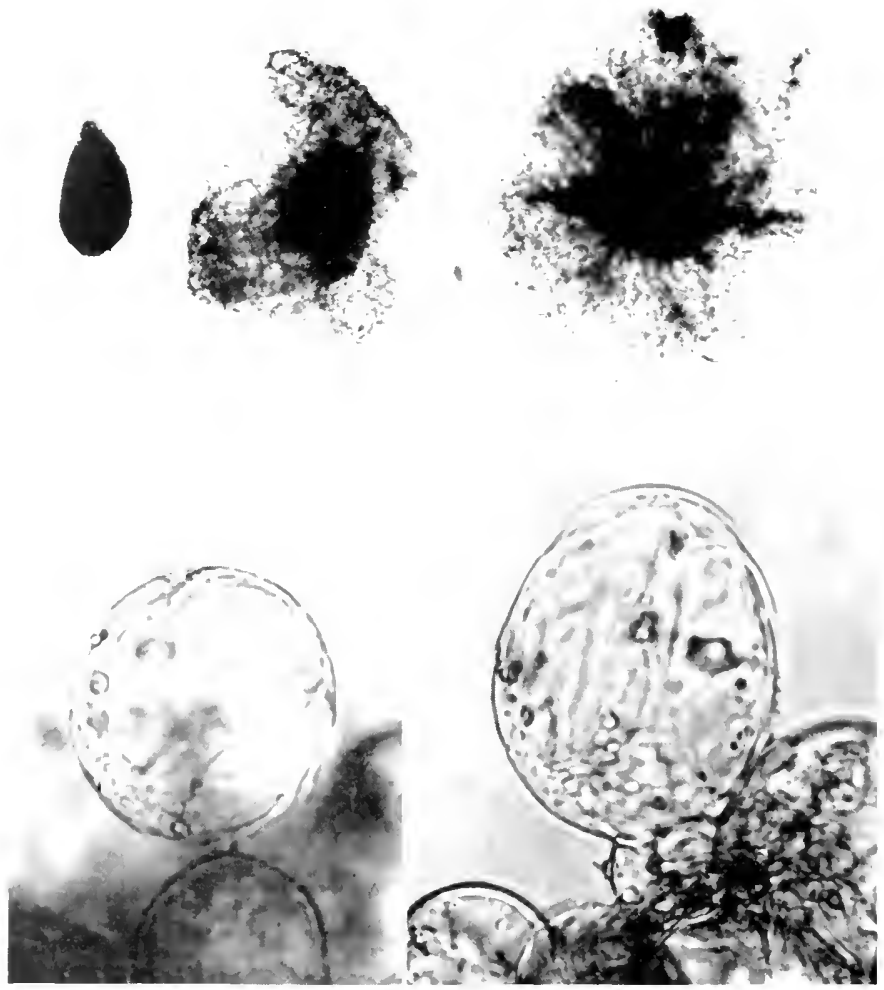

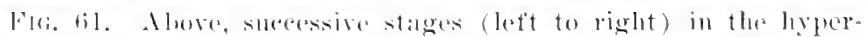

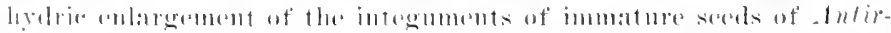

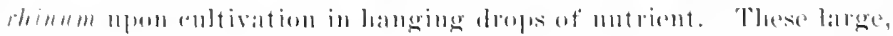

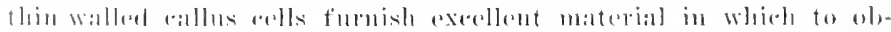

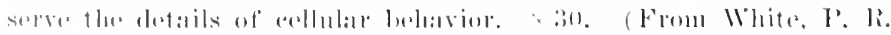

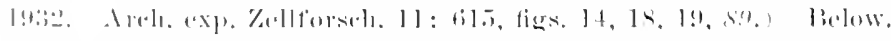

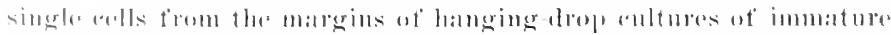

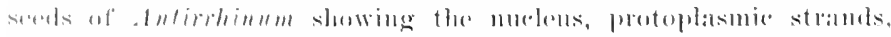

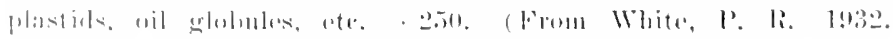

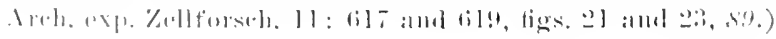




\section{General Pllysiology of Plants 20T}

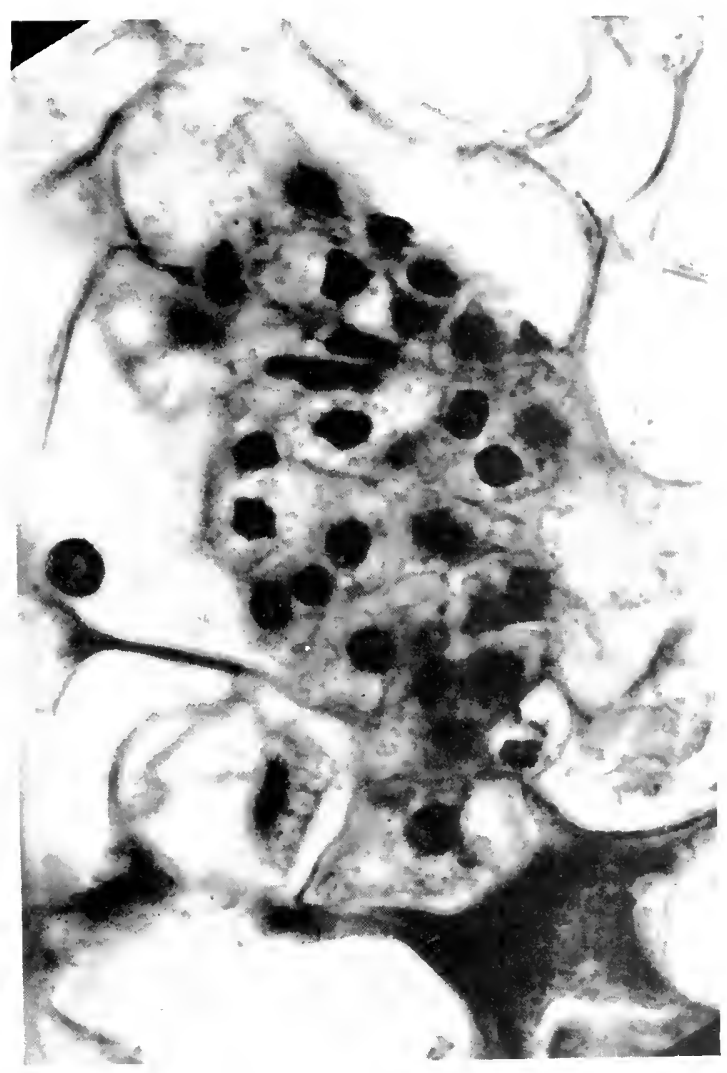

Fig, 62. Detail of a mass of meristematic cells fom the outer region of a culture of undifferentiated callus from a plant of the

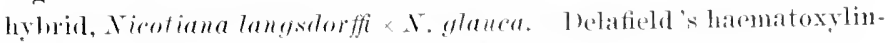
safranin. x 1000. (From White, P. R. 1939. Am. J. Bot. 206: 63 , fig. 11, 7.s.) 


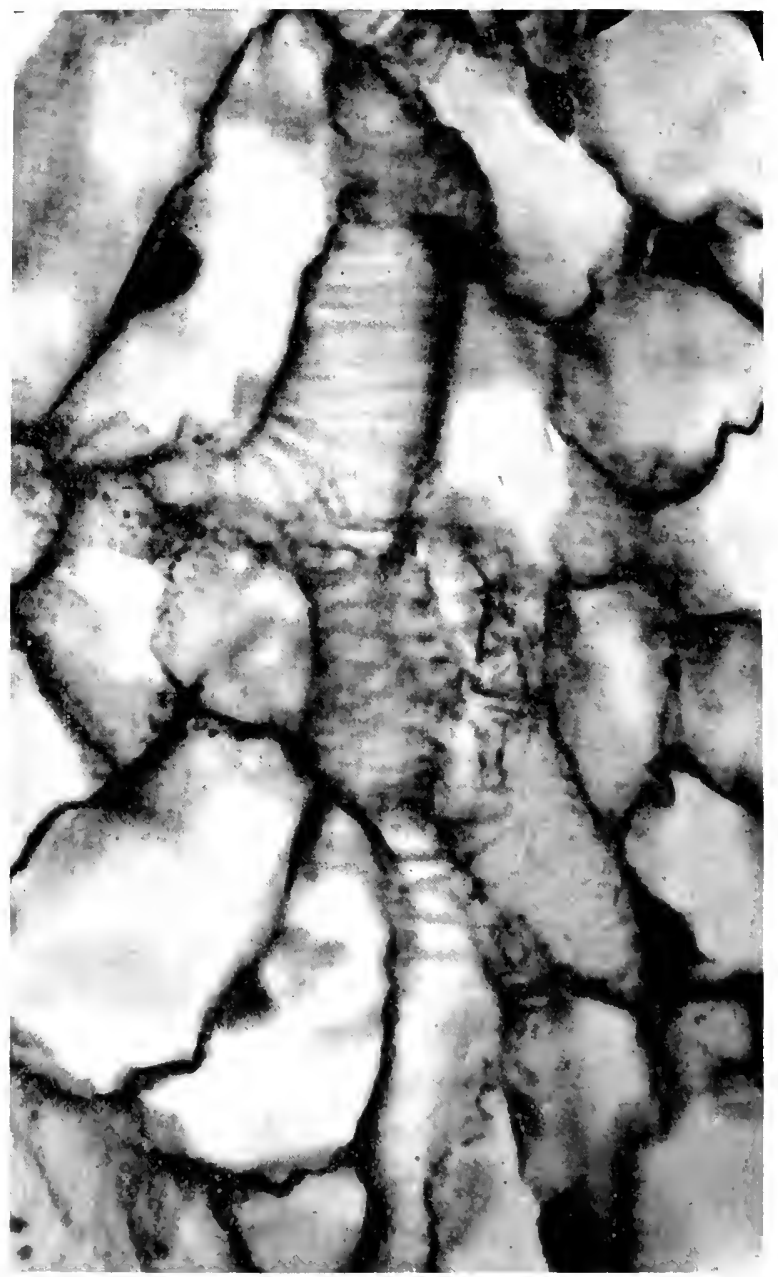

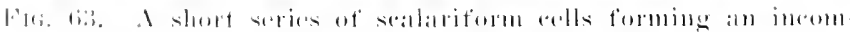

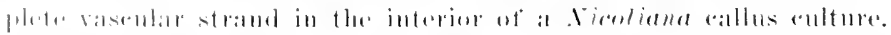

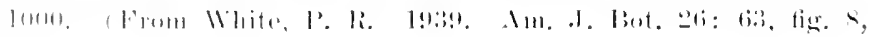
i.i.) 


\section{Chapter X}

\section{MORPHOGENESIS}

It was suggested at the beginning of this volume that the technique of cultivating excised tissues had its chief raison d'etre and gave its greatest promise in the study of the origins of form and function, that is, in problems of morphogenesis. Harrison's original problem which led to the first in vitro cultivation of animal cells-whether the nerve fibrils originate in situ from the innervated cells or their products or whether they originate $a b$ extra, by growth from the distant ganglia-was a morphogenetic problem. So was Robbins' original problem-whether the root was dependent on the leafy portions of the plant for anything more than its basic carbohydrate nutrition. So likewise was the problem-what was the nature of the stimulus by which crown gall organisms or their products induce abnormal proliferation of the host cells-which led the author of this volume to undertake the development of a plant tissue culture technique (White, 1931, 32). The number of problems which have been attacked to date by means of this technique is not large. But the 
number which it should be possible to attack by this means is legion. It seems desirable therefore to outline some of the possibilities. (See Harrison, 1912, 415, 1933, 416 ; Fischer, 1922, 405, 1930, 409, 1931, 410; Fischer u. Parker, 1929, 411; Parker, 1934, 427, 1936, 428, 429).

That the developmental and behavior pattern in higher animals is greatly influenced by metabolic products known as "hormones" is today generally recognized. Of recent years, there has grown up a considerable literature on "plant hormones" as well. The first plant hormone, "auxin," was originally studied as a factor in geotropic and phototropic, hence purely orientation, responses (Paál, 1914, 367, 1919, 368; BoysenJensen, 1910, 344). It has subsequently come to be looked upon as a true morphogenetic hormone, since it seems to induce the differentiation of roots from tissues that ordinarily rarely, if ever, produce roots (Went, 1929, 380; Bouillenne et Went, 1933, 27r; Thimamn and Went, 1934, 229 ; Laibach, 1935, 218; Thimann and Koepfli, 1935, 376; Cooper, 1935, 345, 1936, 346; Zimmerman et al., $1933,384,1935,385,386)$, to control the formation and development of buds (Thimann and Skoog, 1933, 37r, 1934, 3\%8; Snow, 1925, 372; LeFanu, 1936, 359; van Overbeek, 1938, 366), to influence the abscission of leaves and of fruits (Gustafson, 
1936, 350, 1938, 351, 352, 1939, 353; Gardner and Marth, 1937, 348), to initiate the activity of cambium (Snow, 1933, 373, 1935, 374; Avery, Burkholder, and Creighton, 1937, 341), to regulate the specific branching habit of plants (Lehmann, 1936, 360; Delisle, 1937, 347 ; Goodwin, 1937, 349), to mediate between genes and growing tissues in controlling the procumbent vs. erect habit (van Overbeek, 1936, 363, 1938, 365), in producing dwarfness (van Overbeek, 1935, 362, 1938, 364), to take part in the production of bacterial root nodules (Thimann, 1936, 375), and many other responses. (Compare Appleman, 1918, 340; Went, 1928, 379, 1932, 381). All these responses are attributed to the same substance. If this view is correct, then the differences in response must depend on correlative factors resident in, or in the neighborhood of, the responding cells. A growing, undifferentiated mass of cells, such as a callus culture, or a mass characterized by a definite but limited degree of differentiation, such as an excised root, should not only possess fewer of these internal variables but should permit a more rigorous control of the external variables as well. If auxin is truly a specific root-forming hormone (Went, 1929, 380), it should be possible to set up conditions under which its local application to such a callus culture would regularly induce the local fornation of 
roots. If auxin is truly a hormone of tropic response (Boysen-Jensen, 1910, 344), its unilateral application to growing excised roots should regularly induce unilateral curvature. Moreover, there have recently been described a number of other specific "'hormones," a flower-forming hormone (Melchers, 1937, 361; Hamner and Bonner, 1938, 356), a stem-forming hormone, "caulocaline"' (Went, 1938, 382), and a leaf-forming hormone, "phyllocaline" (Went, 1938, 382), in addition to the root-forming hormone, "rhizocaline," which Bouillenne (1938, 206) and Cooper (1935, $345,1936,346)$ believe to be different from the auxin of Went $(1929,380)$ and Kögl, HaagenSmit, and Erxleben (1933, 35\%). If these substances are truly specific for the processes from which they take their names, and if, as we have suggested, the cells of tissue cultures are essentially totipotent, it should be possible to set up cultural conditions for such tissues such that application of a flower-forming hormone would regularly induce the formation of flowers, application of rhizocaline would regularly induce the production of roots, etc. The tissue culture technique seems to offer possibilities for the analysis of these relations, under conditions relatively free of uncontrollable variables.

On the other hand, there is already available 

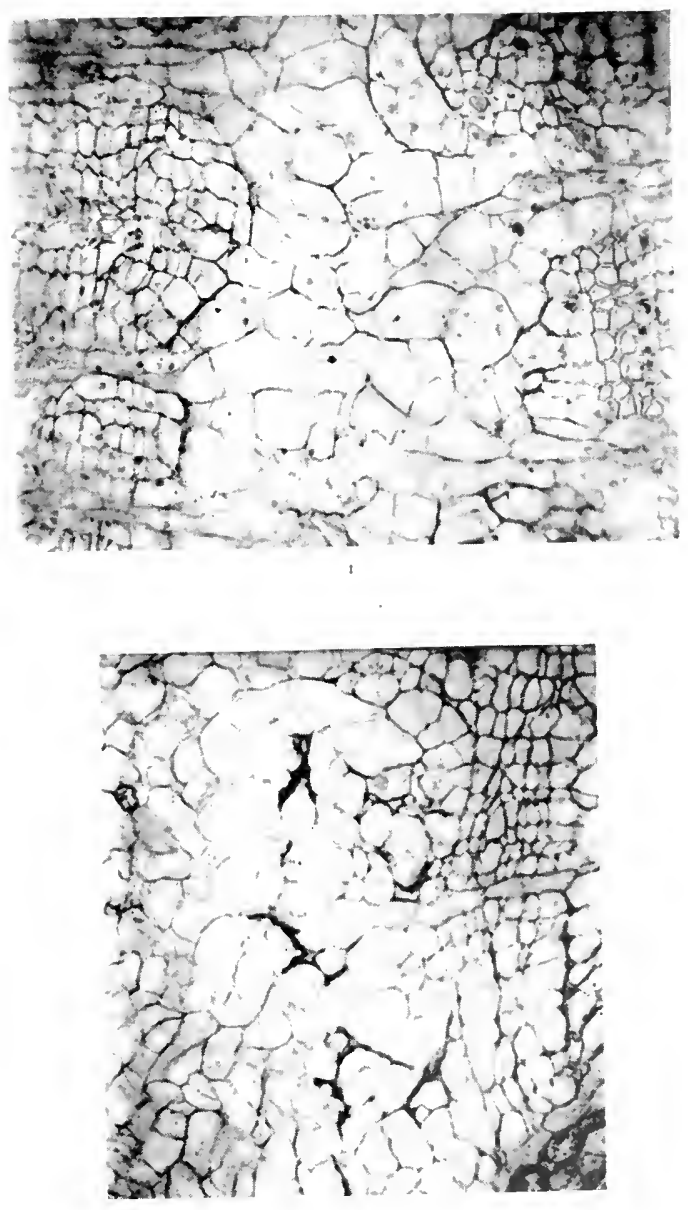

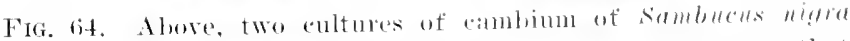
glown side ly side on a semi-solid nutrient in surle a mammer that

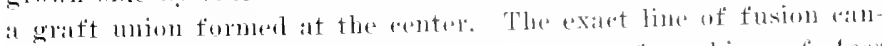

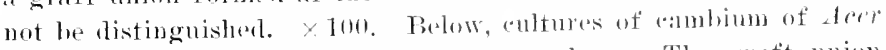

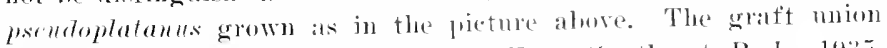
was much less perfect here. . 150. (From (iantheret, R. .J. 1950.

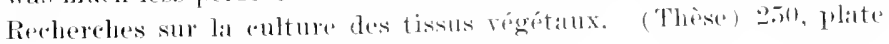
XVIII, 1, 2, 15.) 


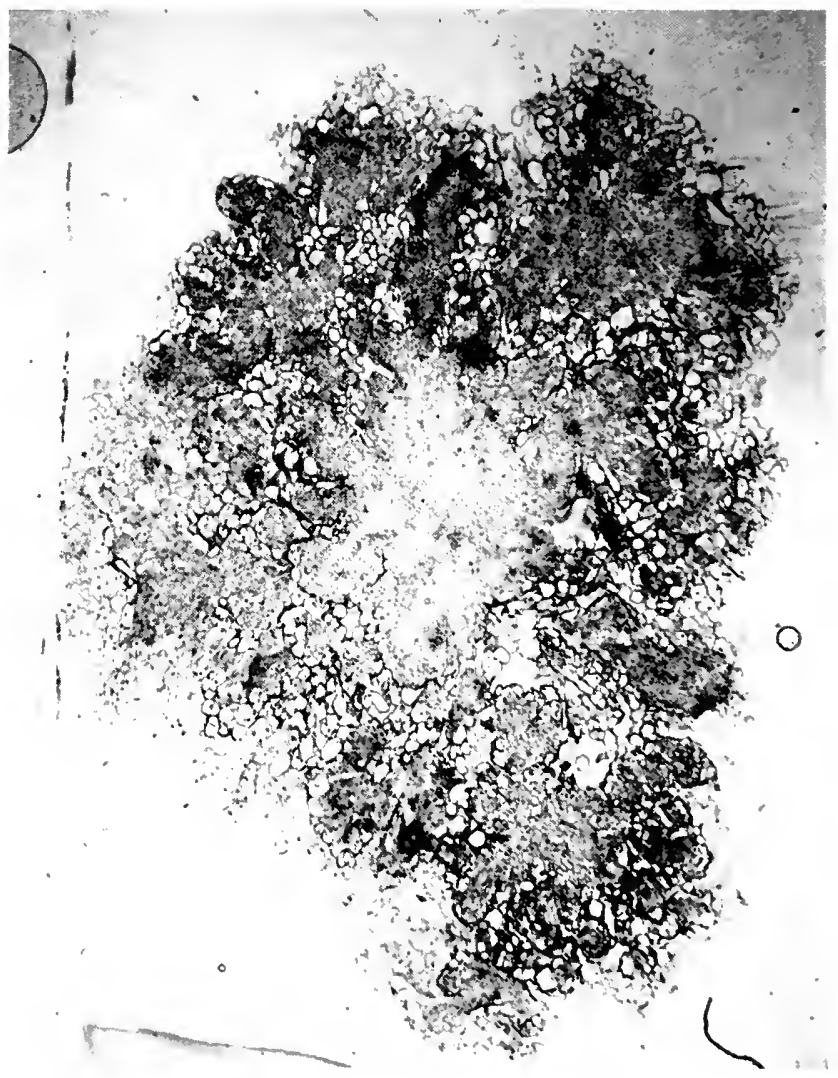

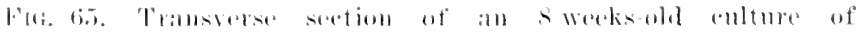

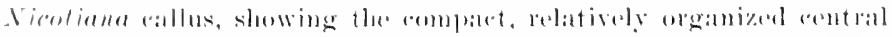

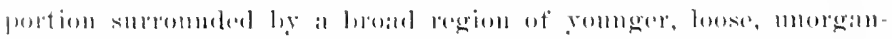

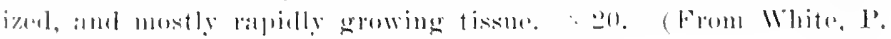

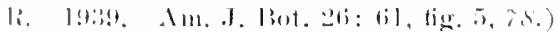

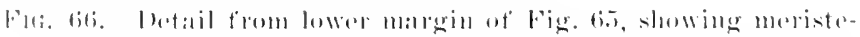

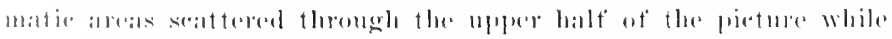

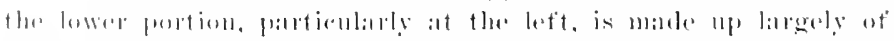

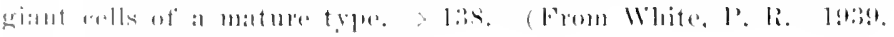

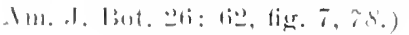




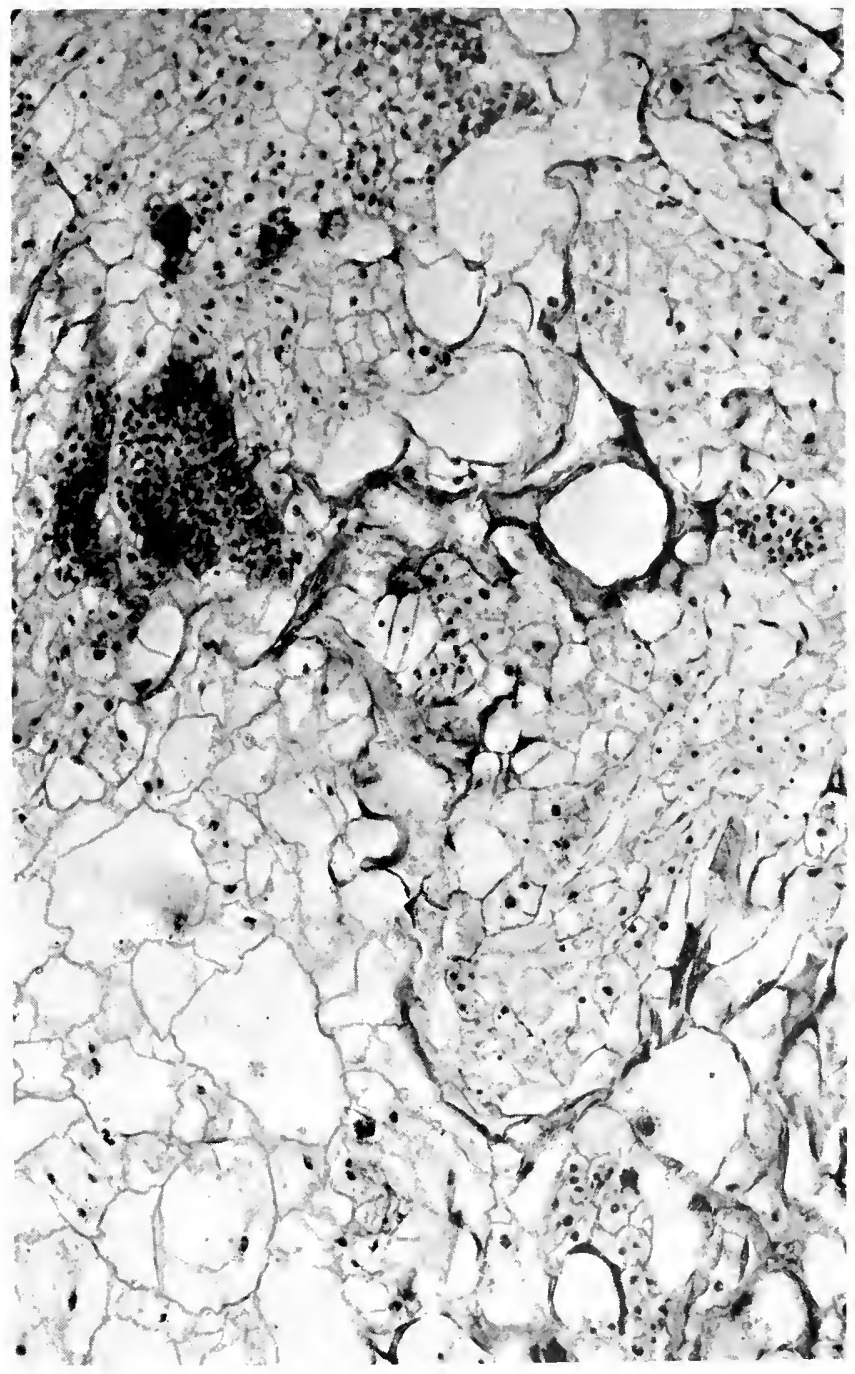

Firg, diti. 


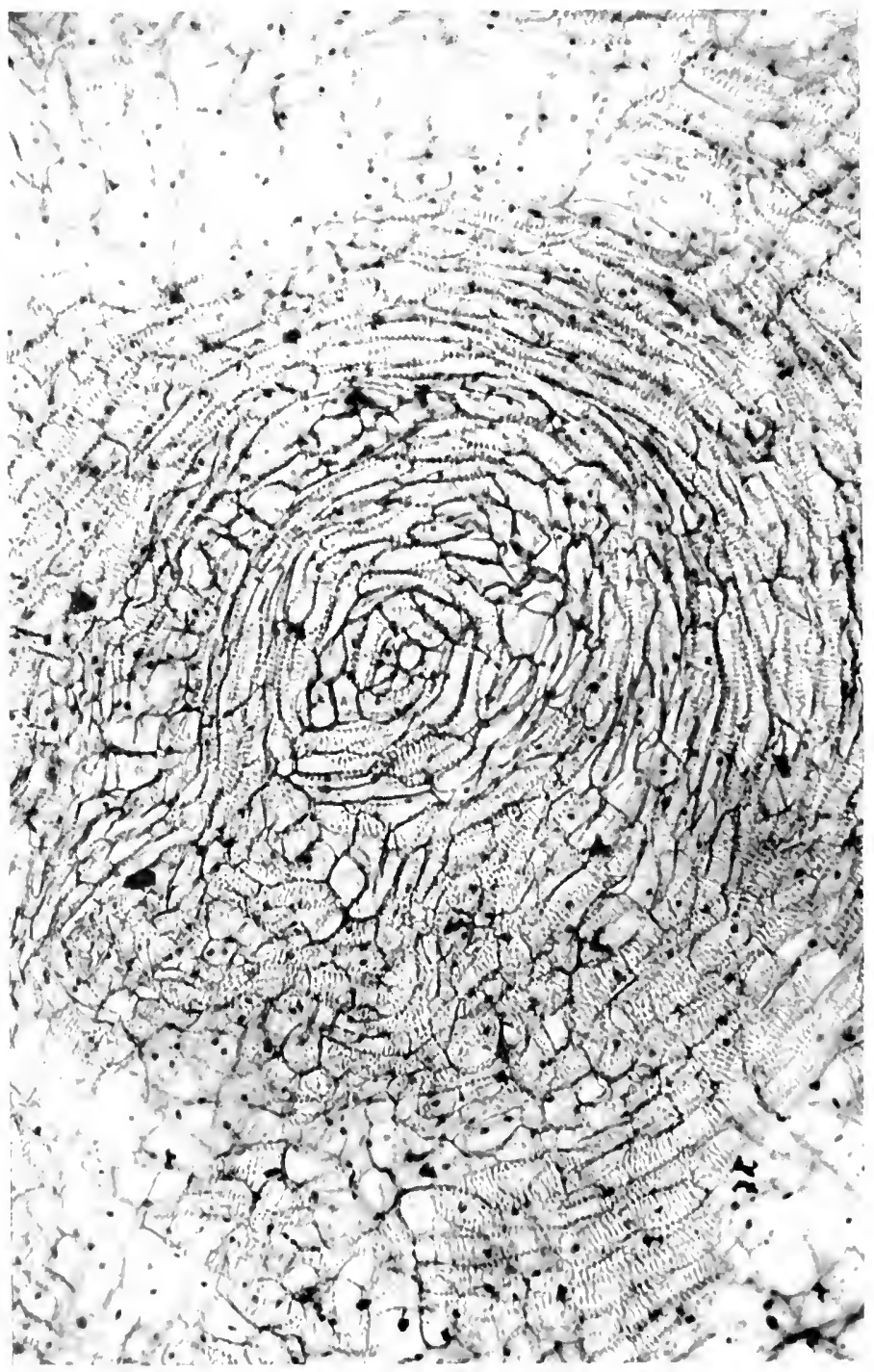

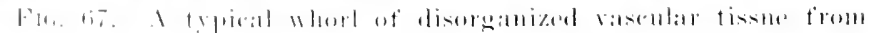

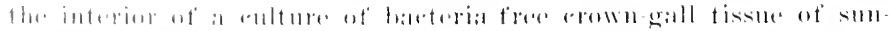


some evidence that the differentiation of specific organs, while it may be influenced by specific substances, may also be controlled to some extent at least by concentration gradients of non-specific substances, hence by polar (physical) as well as chemical relationships. The phenomena of polarity mentioned at the very beginning of this book in connection with the work of Vöchting, Goebel, and others thus offer another field in which the tissue culture technique provides a means of approach not heretofore available. Priestley (1928, 314, 1930, 315, Pearsall and Priestley, 1923, 313) attributes the formation of cambium in radial plant bodies to a radially distributed hydrogen-ion gradient. Lund (1931, 247) and Rosene and Lund $(1935,319)$ have shown that there is a corresponding electropotential gradient which can be modified by imposing artificial oxygen-hydrogen gradients. White $(1939,333)$ has shown that an oxygen gradient may be correlated with the response hy which undifferentiated callus cultures (Figs. $17,18,61,65$ ) are induced to form stems and leaves without the intercession of a caulocaline (Figs. 68, 71). White $(1938,267)$ and Rosene $(1937,259,1941,260)$ have shown that there is a hydrostatic flow correlated with the electrostatic gradient along excised and intact roots. But it is as yet quite unknown which of all these gradients 
- of $\mathrm{pH}$, of redox-potential, of electrostatic potential, of hydrostatic potential, and of tendeney to differentiate-is primary and which secondary. It should be possible in tissue culture to artificially impose or modify any or all of these gradients, except the last, along controlled spatial axes and thus to determine with which other gradients they bear a causal relationship. Brachet has applied this method in animal embryology to the study of effects of imposed oxygen gradients (Brachet, 1937, 387; Brachet and Shapiro, 1938, 38s), and Huxley (1926, 417, 1927, 418), Gilehrist (1928, 412), and Vogt $(1932,434)$ have applied it to the study of temperature gradients. Fife and Frampton $(1936,241)$ have applied it in plant pathology to the study of the causal factors involved in the orientation of a parasitic insect's proboseis in the tissues of the host, with brilliant results. With plant tissue cultures it is a virgin field except for White's preliminary observations on oxygen gradients and differentiation (Figs. 68, 71) (1939, 333, $1942,334)$ and, in a sense, those of Nobécourt (1939, 448 ) and of Gautheret $(1940,286-288)$ on bud formation. Yet these methods of approach should prove effective with exeised organs (roots) and undifferentiated masses (callus) and perhaps even more with young developing embryos, especially if these can be grown from the fertilized egg. 
The forces which, in the egg cell of a vascular Cryptogam, for example, result in the first three mitoses segregating cells which normally develop into stem growing point, cotyledon, root, and suspensor, respectively, are sufficiently clean-cut to offer material capable of clear and definite analysis, once a technique for such studies is available. The tissue culture technique should make possible the development of a true science of plant embryology.

One method of approach to problems of organization which has proved especially effective in animal embryology is, as we have seen, that of transplantation, developed to a high degree by Harrison and by Spemann (1936, 431, 432). With plant material, the Boysen-Jensen-Paál-Went technique of transplanting Avena coleoptile tips, or agar blocks containing extracts from such tips, is essentially a comparable technique, the coleoptile or agar block (Went, 1928, 379) acting in the same way as an organizer in the sense of Spemann. If plant members such as coleoptile tips (Avery and La Rue), root tips (White et al.), stem tips and buds (White), leaf primordia, etc., can be grown in culture, can be subjected to controlled environmental influences, and can then be transplanted into otherwise intact host plants, the question of organ influences at a distance, of correla- 
tions of the type suggested by Sachs (1880, 370, 1882 , 370, 1893, 320,371), could be brought within the scope of experimental analysis (see Went, 1941, 383).

Another field in which this technique might presumably find valuable applications is the study of the physiological aspects of heterosis and incompatibility. Robbins has already studied the growth behavior of excised roots from certain hybrid tomatoes, compared with that of roots from the two inbred parents $(1941,318)$. In cases where the hybrid is "physiologically sterile," due to unsatisfactory endosperm development, as in certain peaches (Tukey, 1933, 327; White, 1928, $332)$, the tissue culture method has proved its value in permitting the propagation of embryos which would otherwise perish. Where adventitious embryos arise aposporously from the nucellar wall, as in many Citrus fruits, Taraxacum, certain Daturas, etc. (Blakeslee and van Overbeek), the technique should prove valuable, not only in propagating these embryos in refractory cases, but also in determining the causes of polyembryony and aposporous embryogony. Moreover, where "incompatibility" is suspected of being physiological rather than anatomical, the cultivation of tissues of the two incompatible members together in vitro might well throw light on 
the nature of this incompatibility. Gautheret $(1935,15)$ has carried out experiments of this type, though for quite a different purpose, in his preliminary study of heterologous and homologous in vitro grafts, which indicate the feasibility of this sort of approach (Fig. 64). (See also Figs. 69, 70.)

The tissue culture technique has recently permitted the transfer of one problem group already mentioned, the "crown gall problem," from the field of pathology to that of experimental morphogenesis with extremely important implications. Tissues isolated from secondary or metastatic crown gall tumors have been grown in tissue culture (Fig. 19). Here they maintained a rapid, disorganized type of growth (Fig. 67) which expressed itself, upon reimplantation into healthy hosts, in the production of new tumors. The tissues were shown to be free of bacteria. The tissue culture technique has thus permitted the experimental manipulation of crown gall tissues free of the original pathogen and the study of the factors involved in the origin of the tumefacient property of the cells themselves. It thus offers a new approach to problems of the origin of malignancy (White and Braun, 1941, 335, 1942, 336, 337; Braun and White, 1942, 436).

The physiological aspects of cellular morpho- 
genesis, the causal factors involved in the differentiation of bast-fibers, stone-cells, medullary ray cells, phloem tube elements, and of true meristems, all from the same parenchymatous elements, are also problems open to attack by tissue culture methods.

These suggestions merely serve to point out some of the as yet essentially untouched fields opened up by the development of this technique. The history of the progress of science is a history of such tools.

\section{Summarx}

In the study of the origin of form and function, that is, of morphogenesis, tissue culture methods provide a means of isolating cells, organs, and tissues from the morphogenetic influences of neighboring cells, organs, and tissues and placing them in controlled environments. Questions of the effects of growth substances or "hormones," of chemical and physical gradients, and of cytogenetic factor's can be approached by this means with considerable hope of success. 


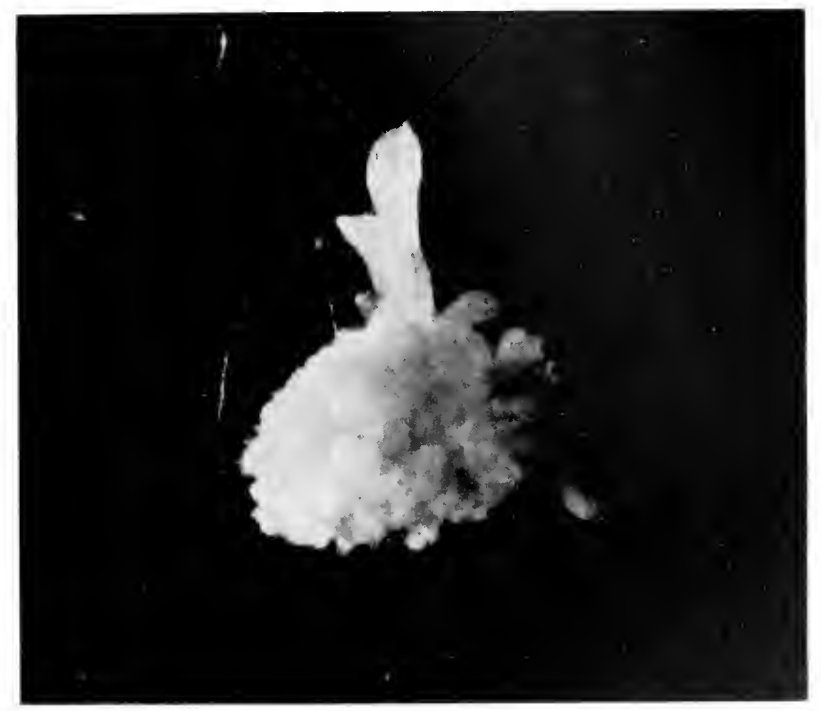

Fir. 68. A culture of Nicotiana callus maintained for s weeks in an undifferentiated state by repeated transfer on a semi-solid nutrient and then placed for 2 weeks in a liquid mutrient. Reduction in available oxygen supply under the latter "onditions has resulted in the formation of differentiated growing points and leaves. × 7.5. (From White, P. R. 1939. Bull. Torrey Bot. Club 66: 509, fig. $2,333$. 


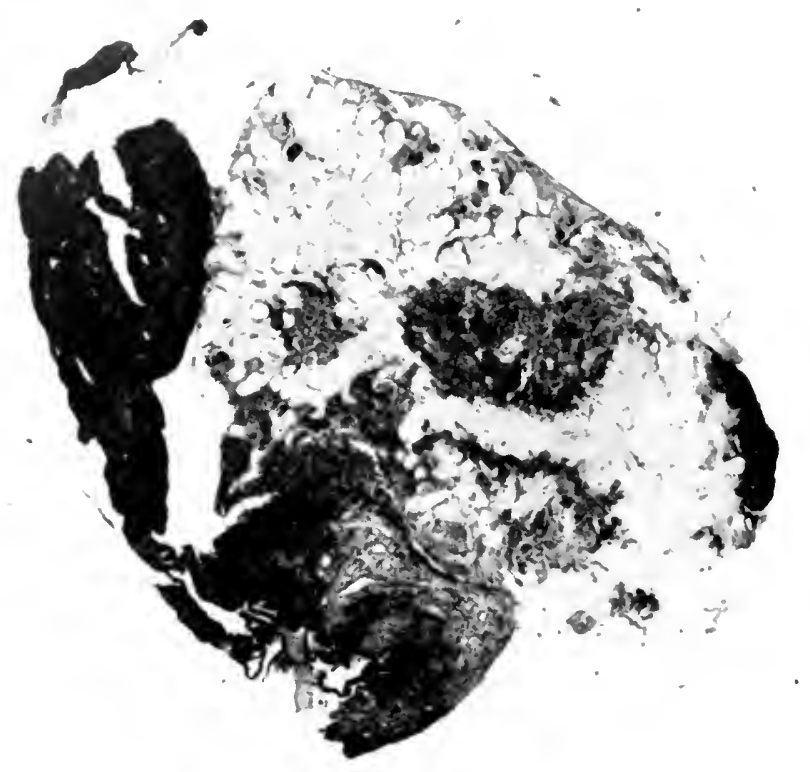

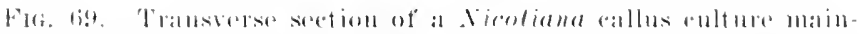

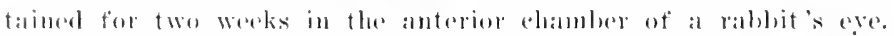

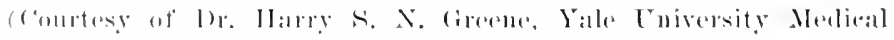

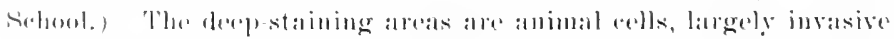

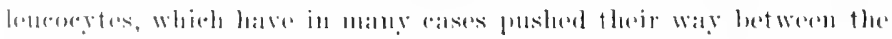

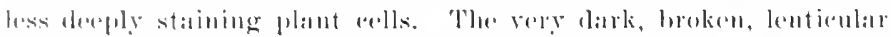
mass at the left is the lens of the ere. The plant tissme routalins

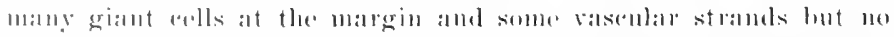

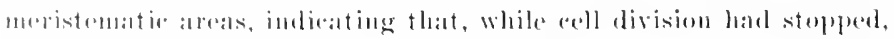

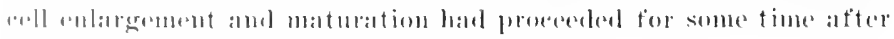
inserfion of the entture in the eyes. 42. 


\section{derphogenesis}

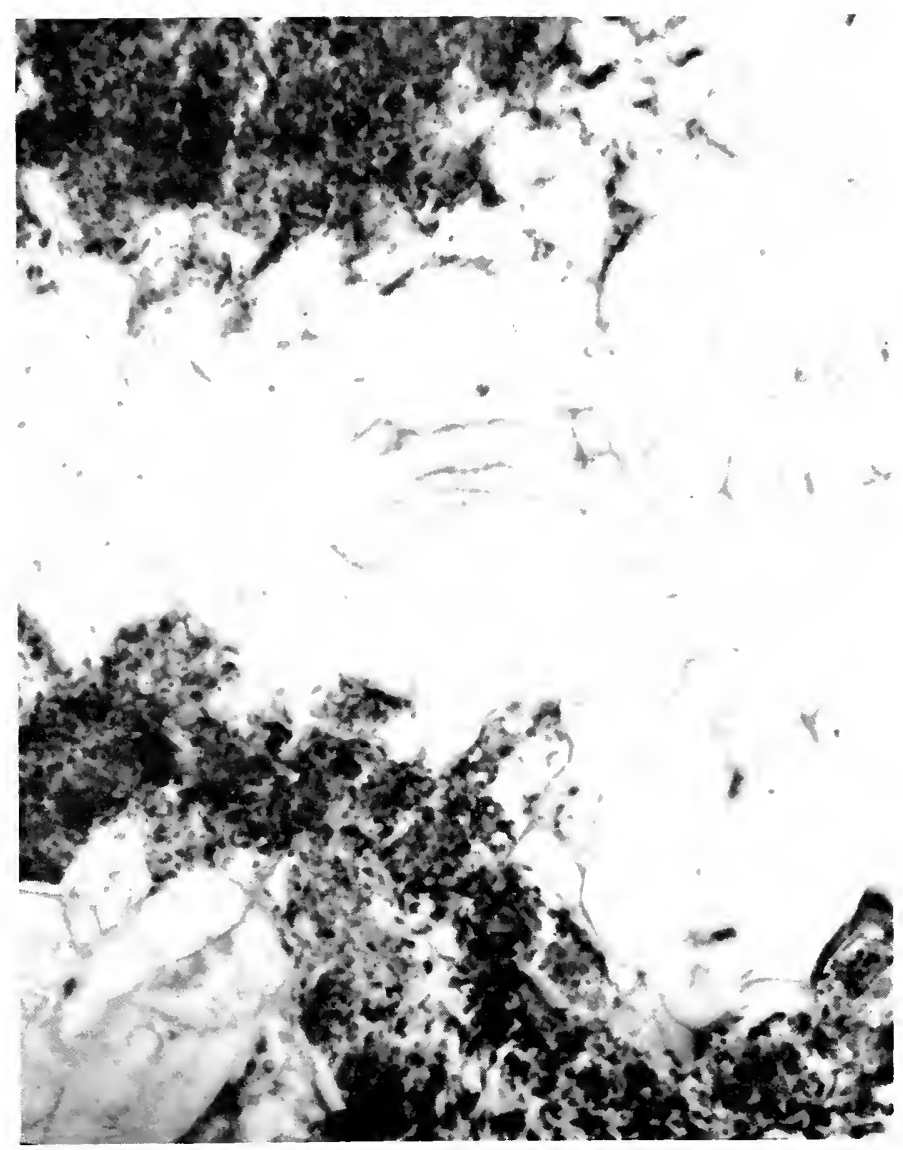

F'tg. 70. Detail from the lower right-hanel portion of Fig. 69, showing plant tissue witle a central rasedalar strand flanked both above and helow by animal eells which have in many cases penetrated into the interecllular spaces. $v 400$. 


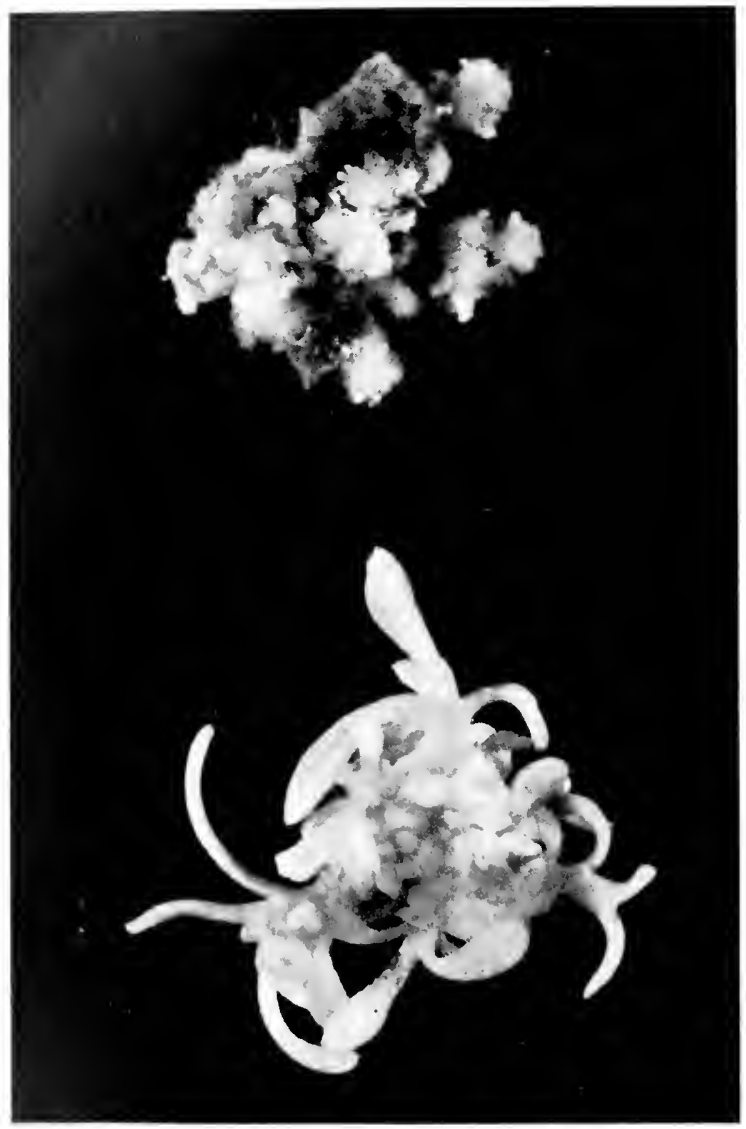

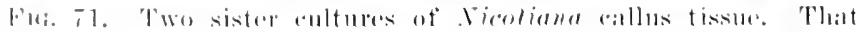

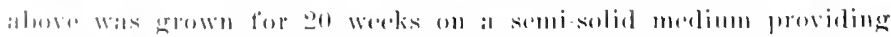

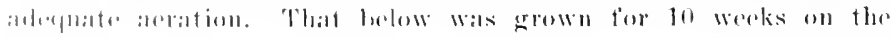
somi solid medium follewed la 10 weeks in a motriont of the simme

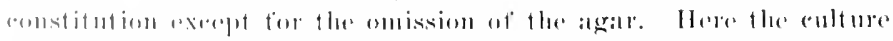

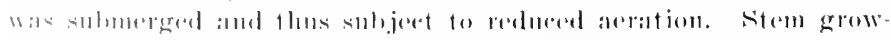

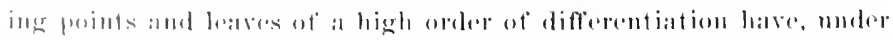

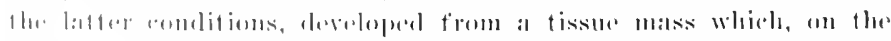

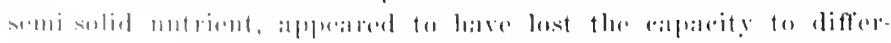

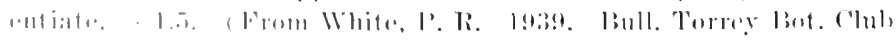
liti: in!! ties. 1. . isis. 


\section{BIBLIOGRAPHY}

Reference has been made in the foregoing text to publications in a variety of fields, some directly bearing on the cultivation of excised plant organs and tissues, some having only an indirect bearing on this subject. The following list of publications eited must obviously be incomplete. It is believed to contain all the major contributions on plant tissue cultures. The references on collateral subjects, such as plant growth substance studies, animal tissue cultures, etc., are intended to be merely suggestive. The citations have been roughly elassified according to subjects to facilitate the reader's search for a given type of material. This classification must obviously appear arbitrary in many cases, but it is hoped may prove useful and suggestive.

I. General treatises …............................................................................. 1-39

II. Cultivation

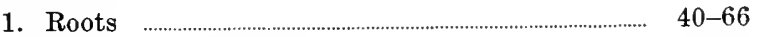

2. Callus and cambium …………………............................ $\quad 67-78$

3. Embryos …...................................................................... $79-89$

4. Tissues other than roots, calluses, and embryos 90-116

5. Animal tissues ................................................................... 117-132

III. Nutrition

1. Inorganic

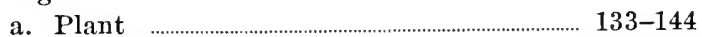

b. Animal ....................................................................... 145-165

2. Carbohydrate

a. Plant ................................................................... 166-173

b. Animal ……........................................................... 174-175

3. Nitrogenous

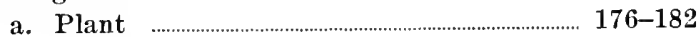

b. Animal .............................................................................. 183-194

4. Fat

a. Plant

b. Animal 195

5. Vitamins and hormones

a. Plant

b. Animal 233-236 
IV. Physiology other than nutrition

1. Plant

2. Animal

V. Morphology and morphogenesis

1. Plant

a. General

275-339

b. Growth substances 340-386

2. Animal $387-435$

VI. Pathology

1. Plant 436-439

2. Animal $440-442$

VII. Miscellaneous

1. Plant $443-455$

2. Animal $456-457$

\section{General Treatises}

1. Bloom, W. 1937. Cellular differentiation and tissue culture. Physiol. Rev. 17: 589-617.

2. Börger, H. 1926. Verfahren pflanzlicher Gewebezüehtung. (Nachtrag zur: Erdmann, Rl. Gewebezüchtung.) Handb. norm. path. Physiol., Band 14, 1.Hälfte: 1000-1002. Springer, Berlin.

3. Burlet, E. 1940. Ueber die pflanzliche Organkultur und ihre Anwendung bei plyssiologischen Untersuchungen. Ber. schweiz. bot. Ges. 50: 519-544.

4. Carrel, A. 1924. The method of tissue culture and its bearing on pathological problems. Brit. Med. Jour. 2: 140145.

5. - 1924. Tissue culture and cell physiology. Physiol. Rev. 4 : 1-20.

6. - 1928. Modern techniques of tissue culture and results. A rch. exp. Zellforsch. 6: 70-81.

7. - 1931. The new eytology. Seience $73: 297-303$.

8. - 1937. Le présent et l'avenir de la cytologie expérimentale. Arch. exp. Zellforseh. 19: 121-128.

9. Ephrussi, B. 1932. La culture des tissus. pp. 233. GauthierVillars, Paris.

10. Erdmann, Rh. 1920. Einige grundlegende Ergebnisse der Gewebezüchtung aus den Jahren 1912-1920. Ergeb. Anat. Entw.-geschichte 23: 420-500. 
11. - 1930. Praktikum der Gewebepflege oder Explantation besonders der Gewebezüchtung. Ed. 2. Springer, Berlin.

12. Fiedler, H. 1938. Die pflanzliche Gewebe- und Organkultur. Ztschr. Bot. 33: 369-416.

13. Fischer, A. 1930. Gewebezüchtung. Handbuch der Biologie der Gewebezellen in vitro. 3. Ausgabe. Miller $u$. Steinicke, Munich.

14. - 1933. Gewebezüchtung und ihre Beziehung zur allgemeinen Biologie. Zool. Anzeig., Suppl. 6: 83-99.

15. Gautheret, R. 1935. Recherches sur la culture des tissus végétaux: Essais de culture de quelques tissus méristématiques. Thèse, Univ. Paris. pp. 279.

16. — 1937. La culture des tissus régétaux. Son état actuel, comparaison avee la culture des tissus animaux. Actualités sci. industrielles. pp. 66. Hermann, Paris.

17. - 1938. La culture des tissus végétaux. Sciences (rev. franç.) $20: 57-71$.

18. Harrison, R. G. 1928. On the status and significance of tissue culture. Arch, exp. Zellforsch. 6: 4-27.

19. Krontowski, A. 1928. Explantation und deren Ergebnisse für die normale und pathologische Physiologie. Ergeb. Physiol. 26: 370-500.

20. Küster, E. 1909. Ueber die experimentelle Erforschung des Zellenlebens. Naturw. Wochenschr. 24: 433-438.

21. 1928. Das Verhalten pflanzlicher Zellen in vitro und in vivo. Arch. exp. Zellforsch. 6: 28-42.

22. Lewis, W. H., and Lewis, M. R. 1924. Behavior of cells in tissue cultures. (In: Cowdry, General cytology, Univ. Chicago Press. pp. 385-447.)

23. Loeb, J. 1916. The organism as a whole. pp. 379. G. P. Putnam's Son, New York.

24. —_. 1924. Regeneration from a physicochemical view point. pp. 143. MeGraw-Hill Book Co., Ine., New York.

25. Nobécourt, P. 1939. État actuel de la question des cultures de tissus végétaux. Soc. Dauphinoise d'études biol. 322 : 54-55.

26. Parker, R. C. 1938. Methods of tissue culture. Paul B. Hoeber, Inc., New York. 
27. Schleiden, M. J. 1838. Beiträge zur Phytogenesis. Arch. Anat., Physiol., wiss. Med. (J. Muller) 1938: 137-176.

28. Schneider. 1926. Gewebekulturen bei Pflanzen. (In: R. Krause, Enzyklopädie der mikroskopischen Technik. 3. Aufl. 2. Band: 160. Urban u. Schwarzenberg, Berlin.) 29. Schwann, Th. 1839. Mikroskopische Untersuchungen über die Übereinstimmung in der Struktur und dem Wachstume der Tiere und Pflanzen. Nr. 176, Oswalds Klassiker der exakten Wissenschaften. W. Engelman, Leipzig. 1910.

30. Strangeways, T. S. P. 1924. Tissue culture in relation to growth and differentiation. Heffer, Cambridge, England.

31. Vogt, W. 1934. Entwicklungsmechanik und Gewebezüchtung. Arch. exp. Zellforsch. 15: 269-280.

32. White, P. R. 1931. Plant tissue cultures. The history and present status of the problem. Arch. exp. Zellforsch. 10: 501-518.

33. —— 1936. Plant tissue eultures. Bot. Rev. 2: 419437.

34. - 1939. Recent contributions from excised plant tissue and organ culture studies to the science of plant physiology. Chron. Bot. 5: 166-167.

35. — 1939. Plant organ and tissue physiology, as exemplified in growing isolated roots. Papers presented before Am. Sci. Teachers Assoc., A.A.A.S., December, 1938. pp. 15-22.

36. - 1941. Plant tissue cultures. Biol. Rev. 16:34-48.

37. - 1942. "Vegetable Dynamicks" and plant tissue cultures. Plant Physiol. 17 : 153-164.

38. — 1942. "Vegetable Dynamicks" and plant tissue eultures. Seience 95: 520-522.

39. - 1942. Plant tissue eulture. Ann. Rev. Biochem. $11: 615-628$.

40. Willmer, E. N. 1928. Tissue culture from the standpoint of general physiology. Biol. Rev. 3: 271-302.

41. - 1935. Tissue eulture. pp. 126. Methuen, London.

\section{Cultivation-Roots}

42. Bonner, J., and Addicott, F. 1937. Cultivation in vitro of excised pea roots. Bot. Gaz. $99: 144-170$. 
43. Chambers, W. H. 1923. Cultures of plant cells. Proc. Soc. Exp. Biol. \& Med. 21 : 71-72.

44. - 1924. Tissue culture of plants. Jour. Mo. State Med. Assoc. 21 : 55-56.

45. Fiedler, H. 1936. Entwicklungs- und reizphysiologische Untersuchungen an Kulturen isolierter Wurzelspitzen. Ztschr. Bot. 30: 385-436.

46. Galligar, G. C. 1934. Growth studies on exeised root tips. Diss., Univ. Illinois.

47. - 1939. Growth behavior of one-millimeter excised root tips. Plant Physiol. 14: 163-169.

48. Gautheret, R. 1932. Sur la culture d'extrémités de racines. C. r. soc. biol., Paris, 109: 1236-1238.

49. - 1933. Cultures de méristèmes de racines de Zea mays. C. r. acad. sci., Paris, $197: 85-87$.

50. Heidt, K. 1931. Ueber das Verhalten von Explantaten der Wurzelspitze in nährstofffreien Kulturen. Arch. exp. Zellforsch. 11: 693-724.

51. Kotte, W. 1922. Wurzelmeristem in Gewebekultur. Ber. d. bot. Ges. 40 : 269-272.

52. 1922. Kulturversuche mit isolierten Wurzelspitzen. Beitr. allg. Bot. 2: 413-434.

53. Malyschev, N. 1932. Das Wachstum des isolierten Wurzelmeristems auf sterilen Nährböden. Biol. Ztrbl. 52: 257265 .

54. 1932. The growth of isolated meristems of roots. Preslia 11: 59-61.

55. Marotto, L. 1935. I resultati di alcune culture " in vitro" di cellule vegetali isolate. Rend. r. acead. naz. Lincei, sci. fis. mat. nat. cl. 21 : 211-215.

56. - 1936. Esperienze esequite con apici radicali isolati ed allevati in cultura. Rend. r. acead. naz. Lincei, sei. fis. mat. nat. el. 23 : 515-517.

57. Robbins, W. J. 1922. Cultivation of excised root tips and stem tips under sterile conditions. Bot. Gaz. 73: 376390 .

58. — Bartley, M. A., and White, V. B. 1936. Growth of fragments of excised root tips. Bot. Gaz. 97: 554579 . 
59. — and Maneval, W. E. 1923. Further experiments on growth of excised root tips under sterile conditions. Bot. Gaz. 76 : 274-287.

60. - and Schmidt, M. B. 1938. Growth of exeised roots of the tomato. Bot. Gaz. $99: 671-728$.

61. — 1939. Further experiments on exeised tomato roots. Am. Jour. Bot. 26: 149-159.

62. ——, and White, V. B. 1936. Limited growth and abnormalities in excised corn root tips. Bot. Gaz. 98: 209-242.

63. White, P. R. 1932. Influence of some environmental conditions on the growth of excised root tips of wheat seedlings in liquid media. Plant Physiol. 7 : 613-628.

64. - 1933. Liquid media as substrata for the culturing of isolated root tips. Biol. Ztrbl. $53: 359-364$.

65. - 1934. Potentially unlimited growth of excised tomato root tips in a liquid medium. Plant Physiol. 9: $585-600$.

66. 1938. Cultivation of excised roots of dicotyledonous plants. Anı. Jour. Bot. 25: 348-356.

\section{Cultivation-Callus and Cambium}

67. Gautheret, R. 1934. Culture du tissu eambial. C. r. acad. sei., Paris, 198: 2195-2196.

68. - 1937. Nouvelles recherches sur la eulture du tissu cambial. C. r. acad. sei., Paris, 205: 572-574.

69. 1938. Sur le repiquage des cultures de tissu cambial de Salix Capraea. C. r. acad. sei., Paris, 206: 125-127.

70. - 1938. Recherehes sur la culture de fraguents de tubercules de carotte. C. r. acad. sci., Paris, 206: 457-459.

71. 1939. Sur le déreloppement de fragments de tubercules de chou-rave. C. r. soe. biol., Paris, 130: 244247.

72. - 1939. Sur la possibilité de réaliser la culture indéfinie des tissus de tubercules de carotte. C. r. acad. sei., Paris, 208: 118-120.

73. - 1940. Sur la culture du tissu cambial de Carotte. C. r. soc. biol., Paris, 134: 398-399. 
74. Nobécourt, P. 1937. Cultures en série de tissus végétaux sur milieu artificiel. C. r. acad. sei., Paris, 205: 521-523.

75. - 1938. Sur les proliférations spontanées de fragments de tubercules de carotte et leur culture sur milieu synthétique. Bull, soc. bot. France 85: 1-7.

76. - 1938. Sur la proliferation in vitro du parenchyme amylifère du tubercule de Solanum tuberosum L. Bull. soe. bot. France 85: 490-493.

77. - 1939. Sur la pérennité et l'augmentation de volume des cultures de tissus végétaux. C. r. soc. biol., Paris, $130: 1270$.

78. White, P. R. 1939. Potentially unlimited growth of exeised plant callus in an artificial nutrient. Am. Jour. Bot. 26: $59-64$.

\section{Cultivation-Embryos}

79. Dietrich, K. 1924. Ueber die Kultur von Embryonen ausserhalb des Samens. Flora 17: 379-417.

80. Essenbeck, E., u. Suessenguth, K. 1925. Über die aseptische Kultur pflanzlicher Embryonen, zugleich ein Beitrag zum Nachweis der Enzymausseheidung. Areh. exp. Zellforsch. 1: $547-590$.

81. Hannig, E. 1904. Zur Physiologie pflanzlicher Embryonen. I. Ueber die Cultur von Cruciferen-Embryonen ausserhalb des Embryosacks. Bot. Ztng. 62: 45-80.

82. La Rue, C. D. 1936. The growth of plant embryos in culture. Bull. Torrey Bot. Club 63: 365-382.

83. — , and Avery, G. S., Jr. 1938. The development of the embryo of Zizania aquatica in the seed and in artificial culture. Bull. Torrey Bot. Club 65: 11-21.

84. Razdorskii, V. 1938. The culture of isolated plant embryos. Priroda akad, nauk. U.S.S.R. 1938: 129-132.

85. Stingl, G. 1907. Experimentelle Studie über die Ernährung von pflanzlichen Embryonen. Flora 97: 308-331.

86. Tukey, H. B. 1933. Artificial culture of sweet eherry embryos. Jour. Hered. 24: 7-12.

87. - 1934. Artificial culture methods for isolated embryos of deciduous fruits. Am. Soe. Hort. Sei. 32: $313-322$. 
88. Werekmeister, P. 1934. Über die künstliche Aufzucht von Embryonen aus Iris-Bastardsamen. Gartenbauwiss. 8: 607-608.

89. White, P. R. 1932. Plant tissue cultures. A preliminary report of results obtained in the culturing of certain plant meristems. Arch. exp. Zellforsch. 12: 602-620.

\section{Cultivation-Tissues Other Than Roots, Calluses AND EMBRYOS}

90. Bobilioff-Preisser, W. 1917. Beobachtungen an isolierten Palisaden- und Schwammparenchymzellen. Beih. bot. Ztrbl. 33: 248-274.

91. Bonner, J. 1936. Plant tissue cultures from a hormone point of view. Proc. Nat. Acad. Sei., Wash., 22: 426-430.

92. Börger, H. 1926. Ueber die Kultur von isolierten Zellen und Gewebsfragmenten. Arch. exp. Zellforsch. 2: 123190.

93. Czech, H. 1926. Kultur von pflanzlichen Gewebszellen. Arch. exp. Zellforseh. 3: 176-200.

94. Dauphiné, A. 1929. Sur le développement d'organes embryonnaires isolés. C. r. soc. biol., Paris, 102: 652-654.

95. Gautheret, R. 1933. Cultures de cellules détachées de la coiffe. C. r. acad. sci., Paris, 196: 638-640.

96. - 1933. Nouvelles recherches sur la culture des cellules de coiffe. C. r. soc. biol., Paris, 112: 861-863.

97. - 1939. Nouvelles expériences sur la eroissance des cellules isolées de coiffe de Lupinus albus. C. r. soc. biol., Paris, 132: 351-352.

98. Haberlandt, G. 1902. Kulturversuche mit isolierten Pflanzenzellen. Sitzungsber. Akad. Wiss. Wien, math.-naturw.Kl. $111: 69-92$.

99. Kemmer, E. 1928. Beobachtungen über die Lebensdauer isolierter Epidermen. Arch. exp. Zellforsch. 7: 1-68.

100. Knudson, L. 1919. Viability of detached root-cap cells. Am. Jour. Bot. 6 : 309-310.

101. Kunkel, W. 1927. Über die Kultur von Perianthgeweben. Areh. exp. Zellforsch. 3: 405-427.

102. Lampreeht, W. 1918. Ueber die Kultur und Transplantation kleiner Blattstüeken. Beitr. allg. Bot. 1: 353-398. 
103. —- 1925. Ueber die Züchtung pflanzlicher Gewebe. Arch. exp. Zellforseh. 1: 412-421.

104. La Rue, C. D. 1936. Tissue cultures of spermatophytes. Proc. Nat. Acad. Sci., Wash., 22: 201-209.

105. Moebius, H. 1922. Kulturversuche an extirpierten unbefruchteten Samenanlagen. Diss., Liepzig.

106. Molliard, M. 1921. Sur le développement des plantules fragmentées. C. r. soc. biol., Paris, 84: 770-772.

107. Pfeiffer, H. 1931. Beobachtungen an Kulturen nackter Zellen aus pflanzlichen Beerenperikarpien. Arch. exp. Zellforsel. 11: 424-434.

108. Rechinger, C. 1893. Untersuchungen über die Grenzen der Teilbarkeit im Pflanzenreich. Abhandl. zoöl.-bot.-Ges., Wien, 43 : 310-334.

109. Scheitterer, H. 1931. Versuche zur Kultur von Pflanzengeweben. Arch. exp. Zellforsch. 12: 141-176.

110. Schmucker, T. 1929. Isolierte Gewebe und Zellen von Blütenpflanzen. Planta 9: 339-340.

111. Thielman, M. 1924. Über Kulturversuche mit Spaltöffnungszellen. Ber. d. bot. Ges. 42: 429-433.

112. - 1925. Über Kulturversuche mit Spaltöffnungszellen. Arch. exp. Zellforsch. 1: 66-108.

113. 1925. Essais de culture des stomates. C. r. soc. biol., Paris, 92 : 888-890.

114. Tukey, H. B. 1937. Plant parts of deciduous fruits which give evidence of being farorable for tissue culture. Proc. Nat. Acad. Sci., Wash., 23: 577-580.

115. Úlehla, V. 1928. Vorversuche zur Kultur des Pflanzengewebe. Arch. exp. Zellforsch. 6: 370-417.

116. White, P. R. 1933. Plant tissue cultures. Results of preliminary experiments on the culturing of isolated stem tips of Stellaria media. Protoplasma 19: 97-116.

\section{Cultivation-Animal Tissues}

117. Burrows, M. T. 1910. The cultivation of tissues of the chick embryo outside the body. Jour. Am. Med. Assoc. 55: 2057-2058.

118. - 1910. Culture des tissus d'embryon de poulet et spécialement cultures de nerfs de poulet en dehors de l'organisme. C. r. soc. biol., Paris, 69: 291-292. 
119.

1911. The growth of tissues of the chick embryo outside the animal body, with special reference to the nervous system. Jour. Exp. Zoöl. 10: 63-84.

120. Carrel, A. 1911. Die Kultur der Gewebe ausserhalb des Organismus. Berlin klin. Wochenschr. 48: 1364-1367.

121. 1912. Neue Fortschritte in der Kultivierung der Gewebe ausserhalb des Organismus. Berlin klin. Wochensclir. $49: 533-536$.

122. - 1912. La vie manifestée des tissus "in vitro", techniques nourelles et leurs resultats. Presse med. 20: $693-694$.

123. 1 1912. Technique for cultivating a large quantity of tissue. Jour. Exp. Med. 15: 393-396.

124. - 1912. On the permanent life of tissues outside of the organism. Jour. Exp. Med. 15: 516-528.

125. - 1912. Pure culture of cells. Jour. Exp. Med. 16: 165-168.

126. 1923. Nouvelle technique pour la culture des tissus. C. r. soc. biol., Paris, 89: 1017-1019.

127. 1923. A method for the plyysiological study of tissues in vitro. Jour. Exp. Med. 38: 407-41s.

128. —, and Burrows, M. T. 1910. La culture de tissus adultes en dehors de l'organisme. C. r. soc. biol., Paris, 69: $293-294$.

129. Gey, G. O. 1933. An improved teclnic for massive tissue culture. Am. Jour. Cancer 17 : 752-756.

130. - and Gey, M. C. 1936. The maintenance of human normal cells and tumor cells in continuous culture. I. Preliminary report. Cultivation of mesoblastic tumors and normal tissue and notes on methods of cultivation. Am. Jour. Cameer $27: 45-76$.

131. Harrison, R. G. 1907. Observations on the living dereloping nerve fiber. Proc. Soc. Exp. Biol. \& Med. 4: 140-143.

132. 1908. Embryonic transplantation and development of the nervous system. Anat. Rec. 2: $385-410$.

\section{Nutrition-INORgaNic-Plant}

133. Arnon, D. I. 1938. Mieroclements in culture-solution experiments with higher plants. Am. Jour. Bot. 25: 322325. 
134. - and Stout, P. R. 1939. The essentiality of certain elements in minute quantity for plants with special reference to copper. Plant Physiol. 14: 371-375.

135. - and - 1939. Molybdenum as an essential element for higher plants. Plant Physiol. 14: 599602 .

136. Berthelot, A. 1934. Nouvelles remarques d'ordre chimique sur le choix des milieux de culture naturels et sur la maniere de formuler les milieux synthétiques. Bull, soe. chim. biol., Paris, 16: 1553-1557.

137. Hoagland, D. R., and Arnon, D. I. 1941. Physiological aspects of availability of nutrients for plant growth. Soil Sci. 51: 431-444.

138. Mayer, G. G. 1929. Der Einfluss verschiedener Nährstoffzuführung auf das Längenwachstum isolierter Wurzeln. Diss., Giessen.

139. Robbins, W. J., White, V. B., MeClary, J. E., and Bartley, M. 1936. The importance of ash elements in the cultivation of excised root tips. Proc. Nat. Acad. Sci., Wash., $22: 636-639$.

140. Stout, P. R., and Arnon, D. I. 1939. Experimental methods for the study of the role of copper, manganese, and zinc in the nutrition of higher plants. Am. Jour. Bot. 26: 144-149.

141. White, P. R. 1933. Concentrations of inorganic ions as related to growth of excised root-tips of wheat seedlings. Plant Physiol. 8: 489-508.

142. - 1933. The. $\mathrm{SH}$ radical and some other sources of sulphur as affecting growth of isolated root tips of wheat seedlings. Protoplasma 19 : 132-135.

143. 1937. Comparison of nutrient salt solutions for the cultivation of excised tomato roots. Growth 1: 182188.

144. - 1938. Accessory salts in the nutrition of excised tomato roots. Plant Physiol. 13: 391-398.

\section{NUTRITION-INORGANIC-ANIMAL}

145. Drew, A. H. 1922. A comparative study of normal and malignant tissues grown in artificial culture. Brit. Jour. Exp. Path. 3: 20-27. 
146. - 1923. Growth and differentiation in tissue cultures. Brit. Jour. Exp. Path. 4: 46-52.

147. Erlichman, E. 1935. Human fibroblasts grown for a year in a medium of sheep plasma and two solutions of known composition. Am. Jour. Caneer 24: 393-396.

148. Lewis, M. R. 1916. Sea water as a medium for tissue cultures. Anat. Rec. 10: 287-299.

149. - and Lewis, W. H. 1911. The cultivation of tissues from ehick embryos in solutions of $\mathrm{NaCl}, \mathrm{CaCl}_{2}, \mathrm{KCl}$, and $\mathrm{NaHCO}_{3}$. Anat. Rec. 5: 277-293.

150. - 1911. The growth of embryonic chicken tissues in artificial media, agar and bouillon. Johns Hopkins Hosp. Bull. 22 : 126-127.

151. — and 1911. The cultivation of tissues in salt solutions. Jour. Am. Med. Assoc. 56: 1795.

152. — and 1912. The cultivation of chicken tissues in media of known chemical constitution. Anat. Rec. 6: 207-211.

153. — $\longrightarrow$, 1912. The cultivation of sympathetic nerves from the intestine of chieken embryos in saline solutions. Anat. Ree. 6: 7-17.

154. Lewis, W. H. 1921. The effect of potassium permanganate on the mesenchyme cells of tissue eultures. Am. Jour. Anat. 28: 431-445.

155. - 1923. Cultivation of heart muscle from chick embryos (four to eleven days old) in Locke-bouillon-dextrose-medium. (Abst.) Anat. Rec. 25: 111.

156. - 1929. The effect of various solutions and salts on the pulsation rate of isolated hearts from young chick embryos. Contrib. Embryol. Carnegie Inst., Wash., Publ. 115: 173-192.

157. Locke, F. S. 1895. Artificial fluids as uninjurious as possible to animal tissues. Boston Med. \& Surg. Jour. 134: 173.

158. - 1895. Towards the ideal artificial eireulating fluid for the isolated frog's heart. Jour. Plysiol. 18: $332-333$.

159. — - 1896. Artificial fluids as uninjurious as possible to animal tissues. Jour. Boston Soe. Med. Sci. 1, No. 1: $2-3$. 


\section{Bibliography}

160. Ringer, S. 1886. Further experiments regarding the influence of lime, potassium and other salts on muscular tissue. Jour. Physiol. 7 : 291-308.

161. Tyrode, M. V. 1910. The mode of action of some purgative salts. Arch. internat. pharmacodyn. 20: 205-223.

162. Vogelaar, J. P. M., and Erlichman, E. 1933. A feeding solution for cultures of human fibroblasts. Am. Jour. Cancer 18: 28-38.

163. — and - 1934. Some remarks on the growth of human fibroblasts in media containing copper. Am. Jour. Cancer 22: 66-75.

164. — , and 1934. The growth of human fibroblasts in media containing silver. Am. Jour. Cancer 22 : $555-560$.

165. - 1939. The interehangeability of the elements ehlorine and iodine in culture media for human thyroid fibroblasts. Am. Jour. Cancer 37: 242251.

\section{NUTRITION-CARBOHYDRATE-PLANT}

166. Galligar, G. C. 1936. Influence of eertain organic substances upon the growth behaviour of excised root tips. Trans. Illinois Acad. Sei. 29: 59-68.

167. - 1938. Correlation between growth of excised root tips and types of food stored in the seed. Plant Physiol. 13: 599-609.

168. Knudson, L. 1916. Influence of certain carbohydrates on green plants. Cornell Univ. Agr. Exp. Sta. Memoir 9. pp. 75.

169. — , and Smith, R. S. 1919. Secretion of amylase by plant roots. Bot. Gaz. 68: 460-466.

170. Robbins, W. J., and Bartley, M. A. 1937. Use of dextrose by excised tomato roots. Seience $86: 290-291$.

171. Thielman, M. (Tauja-Thielman). 1938. Untersuchungen zur Wahl der Kohlehydrate für Explantationsversuche mit Pflanzengeweben. Arch. exp. Zellforsch. 21: 477522.

172. White, P. R. 1940. Does "C.P. grade" suerose contain impurities significant for the nutrition of excised tomato roots Plant Physiol. 15: 349-354. 
173. - 1940. Sucrose vs. dextrose as carbohydrate source for excised tomato roots. Plant Physiol. 15: 355-358.

\section{NUTRITION-CARBOHYDRATE-ANIMAL}

174. Ebeling, A. H. 1936. Effect of high concentrations of glucose on fibroblasts, leucocytes, and epithelial cells. Proc. Soc. Exp. Biol. \& Med. 34: 886-889.

175. Lewis, M. R. 1922. The importance of dextrose in the medium of tissue cultures. Jour. Exp. Med. 35: 317-322.

\section{NUtrition-NitrogenOUS-Plant}

176. Mueller, J. H. 1935. Studies on cultural requirements of bacteria. V. The diphtheria bacillus. Jour. Bact., 29: 515-530.

177. Robbins, W. J. 1922. Effect of autolized yeast and peptone on growth of excised corn root tips in the dark. Bot. Gaz. 74: 59-79.

178. — , and White, V. B. 1937. Effect of extracts from the corn plant on growth of excised root tips. Bot. Gaz. 98: 520-534.

179. White, P. R. 1935. Growth-promoting factors of yeast. The role of amino-acids in the nutrition of excised roottips of tomato. (Abst.) Paper presented before Am. Soc. Plant Physiol., A.A.A.S., December, 1935.

180. - 1937. Separation from yeast of materials essential for growth of excised tomato roots. Plant Physiol. 12: 777-791.

181. - 1937. Amino acids in the nutrition of excised tomato roots. Plant Plysiol. 12: 793-802.

182. - 1939. Glycine in the nutrition of excised tomato roots. Plant Physiol. 14: 527-538.

\section{NUTRITION-NITROGENOUS-ANIMAL}

183. Baker, L. W. 1933. The effect of proteolytic digestion products on multiplication and morphological appearance of monocytes. Jour. Exp. Med. 57: 689-704.

184. - and Carrel, A. 1926. Effect of the amino acids and dialyzable constituents of embryonic tissue juice on the growth of fibroblasts. Jour. Exp. Med. 44 : 397-407. 
185. and - 1926. Action on fibroblasts of the protein fraction of embryonic tissue extracts. Jour. Exp. Med. $44: 387-395$.

186. ——, and — 1927. Effect of age in serum lipoids and proteins. Jour. Exp. Med. 45: 305-318.

187. — and - 1928. The effect of digests of pure proteins on cell proliferation. Jour. Exp. Med. 47: $353-370$.

188. — and - 1928. Effect of liver and pituitary digests on the proliferation of sarcomatous fibroblasts of the rat. Jour. Exp. Med, 47: 371-378.

189. - - 1928. Nitrogen metabolism of normal and sarcomatous fibroblasts in pure culture. Jour. Exp. Med. 48: 533-547.

190. Carrel, A. 1913. Artificial activation of the growth in vitro of connective tissue. Jour. Exp. Med. 17: 14-19.

191. — and Baker, L. E. 1926. The chemical nature of substances required for cell multiplication. Jour. Exp. Med. 44 : 503-521.

192. Ebeling, A. H. 1921. Fibrin and serum as a culture medium. Jour. Exp. Med. 33: 641-646.

193. - 1924. Action des acides aminés sur la croissance des fibroblastes. C. r. soc. biol., Paris, 90: 31-33.

194. Fischer, A., u. Demuth, F. 1928. Eiweissabbauprodukte als wachstumsfördernde Substanzen. Arch. exp. Zellforseh. 5: 131-142.

\section{NUTRITION-FAT-ANIMAL}

195. Baker, L. E., and Carrel, A. 1925. Lipoids as the growthinhibiting factor in serum. Jour. Exp. Med. 42: 143154.

\section{NUTRition-Vitamins AND HoRMONES-Plant}

196. Addicott, F. T. 1941. Effects of root-growth hormones on the meristem of excised pea roots. Bot. Gaz. 102: 576581.

197. — and Bonner, J. 1938. Nicotinic acid and the growth of isolated pea roots. Science 88: 577-578. 
198. Bonner, J. 1937. Vitamin $B_{1}$ a growth factor for higher plants. Seience 85 : 183-184.

199. 1938. Thiamin (vitamin $B_{1}$ ) and the growth of roots: the relation of chemical structure to physiological activity. Am. Jour. Bot. 25: 543-549.

200. 1 1938. Nicotinic acid and the growth of isolated pea embryos. Plant Physiol. 13: 865-868.

201. 1940. On the growth factor requirements of isolated roots. Am. Jour. Bot. $27: 692-701$.

202. 1940. Specifieity of nicotinie acid as a growth factor for isolated pea roots. Plant Physiol. 15: 553557.

203. - - and Axtman, G. 1937. The growth of plant embryos in vitro. Preliminary experiments on the role of accessory substances. Proe. Nat. Acad. Sci., Wash., 23: $453-457$.

204. — and Bonner, D. 1938. Ascorbic acid and the growth of plant embryos. Proe. Nat. Aead. Sei., Wash., $24: 70-75$.

205. - and Devirian, P. S. 1939. Growth factor requirements of four species of isolated roots. Am. Jour. Bot. 26 : $661-665$.

206. Bouillenne, R. et M. 1938. Contribution à l'étude des faeteurs de la neoformation et de la croissance des racines. Rhizocaline, hétéro-auxine, aeides aminés, vitamin $B_{1}$. Bull. soe. roy. bot. belg. $71: 43-67$.

207. Burlet, E. 1936. Zur Methodik der pflanzlichen Organkultur. Verh. schweiz. naturf. Ges. 1936: 312-313.

208. Day, D. 1941. Vitamin $B_{6}$ and growth of exeised tomato roots in agar eulture. Science 94: 468-469.

209. Duhamet, L. 1939. Aetion de l'hétéro-auxine sur la croissance de racines isolées de Lupinus albus. C. r. aead. sei., Paris, 208: 1838-1839.

210. - 1939. Action de la colehicine sur la croissanee de méristemes radieulaires de Lupinus albus. C. r. soc. biol., Paris, 131: 757-758.

211. Gautheret, R. 1937. Action de l'aeide indol- $\beta$-acétique sur le développement de plantules et de fragments de plantules de Phaseolus vulgaris. C. r. soe. biol., Paris, 126: 312314. 
212. 1939. Action de l'acide indol- $\beta$-acétique sur les tissus du tubercule de carotte. C. r. soc. biol., Paris, 130 : 7-9.

213. - 1940. Recherches sur l'action de divers substances sur la croissance des cultures de tissus de carotte. C. r. acad. sci., Paris, 210: 186-188.

214. Geiger-Huber, M. 1936. Der Einfluss des Wuchshormons (Heteroauxin) auf das Wurzelwachstum. Verh. schweiz. naturf. Ges. 1936: 313 .

215. —, u. Burlet, E. 1936. Über den hormonalen Einfluss der $\beta$-indolylessigsäure auf das Wachstum isolierter Wurzeln in keimfreier Organkultur. Jahrb. wiss. Bot. 84: 233-253.

216. Loo, T. L., and Loo, S. W. 1935. Studies on the eulture of isolated root tips under sterile conditions. $I$. 'The effect of leaf extract on the growth of root tips. Sci. rep. nat. eent. univ. Nanking, Ser. B, Biol. 2: 51-79.

217. and 1936. Studies on the culture of isolated root tips under sterile conditions. II. Further experiments on the effects of leaf extract on the growth of root tips. Chinese Jour. Exp. Biol. 1: 189-206.

218. Laibach, F. 1935. Über die Auslösung von Kallus- und Wurzelbildung dureh $\beta$-Indolylessigsäure. Ber. d. bot. Ges. 53 : 359-364.

219. Leonian, L. H., and Lilly, V. G. 1937. Is heteroauxin a growth-promoting substance Am. Jour. Bot. 24: 135139.

220. Robbins, W. J. 1939. Thiamin and plant growth. Science 89 : $303-307$.

221. 1940. Response of excised tomato roots to $\beta$ (-4-methylthiazoly]-5)-alanine. Plant Physiol. 15: 547552 .

222. - and Bartley, M. A. 1937. Vitamin $B_{1}$ and the growth of excised tomato roots. Science 85: 246-247.

223. - $\longrightarrow$, 1937. Thiazole and the growth of excised tomato roots. Proc. Nat. Acad. Sei., Wash., 23 : 385-388.

224. $\longrightarrow$, and Schmidt, M. B. 1939. Vitamin $B_{6}$, a growth substance for excised tomato roots. Proc. Nat. Acad. Sci., Wash., 25: 1-3. 
225. — and 1939. Growth of excised tomato roots in a synthetic solution. Bull. Torrey Bot. Club 66: $193-200$.

226. Schopfer, W. H., et Rytz, W., Jr. 1937. La ouate comme source de facteur de croissance de microörganisme. Arch. Mikrobiol. 8: 244-248.

227. Thielman, M. (Tauja-Thielman), u. Peléce, E. 1940. Wachstum isolierter Wurzelspitzen in Heteroauxin enthaltenden Nährlösungen. Arch. exp. Zellforsch. 24: 1-26. 228. Thimann, K. V. 1936. Auxins and the growth of roots. Am. Jour. Bot. 23: 561-569.

229. - and Went, F. W. 1934. On the chemical nature of the root-forming hormone. Proc. konink. akad. Wetenschappen, Amsterdam, 37: 3-6.

230. Wehnelt, B. 1927. Untersuchungen ïber das Wundhormon der Pflanzen. Jahrb. wiss. Bot. 66: 773-813.

231. White, P. R. 1937. Vitamin $B_{1}$ in the nutrition of excised tomato roots. Plant Physiol. 12: 803-811.

232. - 1940. Vitamin $\mathrm{B}_{6}$, nicotinie acid, pyridine, glycine and thiamin in the nutrition of excised tomato roots. Am. Jour. Bot. 27: 811-821.

\section{NUTRI'TION-VitaMins AND HORMONES-ANimaL}

233. Baker, L. E. 1929. The chemical nature of the substances required for cell multiplication. II. Action of glutathione, hemoglobin, and ash of liver on the growth of fibroblasts. Jour. Exp. Med. 49 : 163-182.

234. 1 1936. Artificial media for the cultivation of fibroblasts, epithelial cells and monocytes. Science 83: 605-606.

235. Vogelaar, J. P. M., and Erlichman, E. 1936. The growth of human fibroblasts in media containing various amounts of thyroxin. Am. Jour. Cancer 26: 358-367.

236. — and 1937. Significance of ascorbic acid (vitamin C) for the growth in vitro of Crocker mouse sarcoma 180. Am. Jour. Cancer 31: 283-289. 


\section{Physiology Other ThaN Nutrition-Plant}

237. Avery, G. S., and La Rue, C. D. 1938. Growth and tropic responses of excised Avena coleoptiles in culture. Bot. Gaz. 100: 186-199.

238. Bennet-Clark, T. A., Greenwood, A. D., and Barker, J. W. 1936. Water relations and osmotic pressures of plant cells. New Phytol. 35: 277-291.

239. Bonner, J., and Buckman, E. R. 1938. Syntheses carried out in vitro by isolated pea roots. I. Proc. Nat. Acad. Sci., Wash., $27: 431-438$.

240. Cannon, W. A. 1932. Absorption of oxygen by roots when the shoot is in darkness or in light. Plant Physiol. 7 : 673-684.

241. Fife, J. M., and Frampton, V. L. 1936. The $\mathrm{pH}$ gradient extending from the phloem into the parenchyma of the sugar beet and its relation to the feeding behavior of Eutettix tenellus. Jour. Agr. Res. 53: 581-593.

242. Gautheret, R. 1937. Action de la racine sur la survie des cellules isolées de coiffe de Lupinus albus. C. r. acad. sci., Paris, 204: 887-889.

243. Grossenbacher, K. A. 1938. Diurnal fluctuation in root pressure. Plant Physiol. 13: 669-676.

244. 1939. Autonomic cycle of rate of exudation of plants. Am. Jour. Bot. 26: 107-109.

245. Haberlandt, G. 1919. Zur Physiologie der Zellteilung. 3. Mitt.: Über Zellteilung nach Plasmolyse. Sitzungsber. kgl. preuss. Akad. Wiss., Berlin, 20: 322-348.

246. Hoagland, D. R., and Broyer, T. C. 1936. General nature of the process of salt accumulation by roots with description of experimental methods. Plant Physiol. 11: 471507.

247. Lund, E. J. 1931. Electric correlation between living cells in cortex and wood in the Douglas fir. Plant Physiol. 6: $631-652$.

248. MeClary, J. E. 1940. Synthesis of thiamin by exeised roots of maize. Proc. Nat. Acad. Sci., Wash., 26: 581-587.

249. Nagao, M. 1936. Studies on the growth hormones of plants. I. The production of growth substance in root tips. Sci. rep. Tôhoku univ. (Biol.) 10: 721-731. 
250. - 1937. Studies on the growth hormones of plants. III. The occurrence of growth substance in isolated roots grown under sterilized conditions. Sci. rep. Tôhoku univ. (Biol.) 12: 191-193.

251. 1938. Studies on the growth hormones of plants. IV. Further experiments on the production of growth substance in root tips. Sci. rep. Tôhoku univ. (Biol.) 13: 221-228.

252. Nobécourt, P. 1940. Synthèse de la vitamine $B_{1}$ dans des cultures de tissus végétaux. C. r. soc. biol., Paris, 133: 530-532.

253. van Overbeek, J. 1939. Is auxin produced in roots Proc. Nat. Acad. Sci., Wash., 25: 245-248.

254. - 1939. Evidence for auxin production in isolated roots growing in vitro. Bot. Gaz. 101: 450-456.

255. —, and Bonner, J. 1938. Auxin in isolated roots growing in vitro. Proc. Nat. Acad. Sci., Wash., 24: 260264.

256. Plantefol, L. 1938. Sur les échanges respiratoires des tissus végétaux en culture. C. r. acad. sei., Paris, 207: 11211123.

257. — - et Gautheret, R. 1939. La glucose et la respiration des cultures de tissus régétaux. C. r. acad. sci., Paris, 208: 927-929.

258. Robbins, W. J., and Maneval, W. E. 1924. Effect of light on growth of excised root tips under sterile conditions. Bot. Gaz. 78: 424-432.

259. Rosene, H. F. 1937. Distribution of the velocities of absorption of water in the onion root. Plant Physiol. 12: $1-19$.

260. 1941. Comparison of rates of water intake in contiguous regions of intact and isolated roots. Plant Physiol. 16: 19-38.

261. Saeger, A. 1933. Gas injury to pure cultures of Spirodela. Plant Physiol. 8: 479-480.

262. Steward, F. C., Berry, W. E., and Broyer, T. C. 1936. The absorption and accumulation of solutes by living plant cells. VIII. The effect of oxygen upon respiration and salt accumulation. Ann. Bot. $50: 345-366$. 
263. Thielman, M., u. Bérzin, L. 1927. Ueber den osmotischen Wert kultivierter Pflanzenzellen. Arch. exp. Zellforsch. 4: 273-327.

264. White, P. R. 1936. Root pressure developed in isolated tomato roots growing in vitro. (Abst.) Paper presented before Am. Soe. Plant Physiol., A.A.A.S., December, 1936.

265. - 1937. Seasonal fluctuations in growth rates of excised tomato root tips. Plant Physiol. 12: 183-190.

266. 1937. Survival of isolated tomato roots at suboptimal and supraoptimal temperatures. Plant Physiol. 12: 771-776.

267. - 1938. "Root-pressure"-an unappreciated force in sap movement. Am. Jour. Bot. 25: 223-227.

268. 1938. Root-pressure as a factor in the rise of sap. Nature 141: 581-583.

269. - 1938. "Root pressure." An unappreciated force in sap movement. Smithsonian Report 1938: 489-497.

270. Zimmerman, P. W. 1930. Oxygen requirements for root growth of cuttings in water. Am. Jour. Bot. 17: 842861.

\section{Physiology Other Than Nutrition-Animal}

271. Ebeling, A. H. 1914. The effect of the variation in the osmotic tension and of the dilution of culture media on the cell proliferation of connective tissue. Jour. Exp. Med. $20: 130-139$.

272. Warburg, O. 1923. Versuche an überlebenden Karzinomgewebe. Biochem. Ztschr. 142: 317-350.

273. 1926. Über den Stoffwechsel der Tumoren. J. Springer, Berlin.

274. - u. Kubowitz, F. 1927. Stoffwechsel wachsender Zellen (Fibroblasten, Herz, Chorion). Biochem. Ztschr. 189: 242-248.

MORPhology AND Morphogenesis-Plants-General

275. Behre, K. 1929. Physiologische und zytologische Untersuchungen über Drosera. Planta 7 : 208-306.

276. Berthelot, A., et Amoureux, G. 1937. Remarques sur l'utilisation des plantules aseptiques pour l'étude de la formation des tumeurs. C. r. acad. sei., Paris, 204: 1360-1362. 
277. Bouillenne, R., et Went, F. W. 1933. Recherches expérimentales sur la néoformation des racines dans les plantules et les boutures des plantes superieures. Ann. jard. bot. Buitenzorg 43 : 25-202.

278. Carrière, E.-A. 1875. Greffes de Cucurbitacées. Rev. hort. 1875: 14-16.

279. Dauphiné, A. 1930. Caractères histologiques de racines developpées isolément. C. r. acad. sci., Paris, 190: 13181320.

280. Delarge, L. 1938. Cultures de méristèmes radiculaires in vitro. Les variations individuelles et leur signifieation physiologiques. Bull. soc. roy. bot. belg. 71: 73-88.

281. - 1939. Cultures de méristèmes radieulaires in vitro. Les milieux réputés complets et les variations individuelles. Bull. soc. roy. bot. belg. 71: 145-162.

282. Gautheret, R. 1937. Sur la migration cellulaire dans les cultures d'organes et de tissus végétaux. C. r. soe. biol., Paris, 124: 632-634.

283. - 1938. Caractères anatomiques de fragments de tubercules de carotte cultivés in vitro. C. r. soc. biol., Paris, 127 : 259-261.

284. - 1938. Caraetères eytologiques de tranches de tubercules de carotte cultivés in vitro. C. r. soc. biol,, Paris, 127 : 609-612.

285. - 1939. Sur la mesure de la croissance des tissus de earotte cultivés in vitro. C. r. acad. sci., Paris, 208: 1340 .

286. - 1940. Recherehes sur le bourgeonnement du tissu cambial d'Ulmus campestris cultivé in vitro. C. r. acad. sei., Paris, 210: 632-634.

287. - 1940. Nouvelles reeherches sur le bourgeonnement du tissis cambial d'Ulmus campestris cultivé in vitro. C. r. aead. sei., Paris, $210: 744-746$.

288. - 1940. Recherches experimentales sur la polarité des tissus du tubereule de Carotte. C. r. acad. sci., Paris, 211: 15-18.

289. - 1940. Remarques sur la structure des tissus de carotte cultivés in vitro. C. r. soc. biol., Paris, 134: 237238. 
290. Gioelli, F. 1937. Il differenziamento citologico ed istologico dei meristemi cambiali in vitro. (Nota I.) Acead. sci. Ferrara, atti 1937, vol. 14, 2' ser.: 172-174.

291. - 1937. Influenza della temperatura e della luce sullo sviluppo dei meristemi cambiali in vitro. (Nota II.) Accad. sci. Ferrara, atti 1937, vol. 14, 2' ser.: 175-176.

292. - 1938. Morfologia, istologia, fisiologia e fisiopatologia di meristemi secondari in vitro. Accad. sei. Ferrara, atti 16: 1-87.

293. Goebel, K. 1908. Einleitung in die experimentelle Morphologie der Pflanzen. pp. 260. Teubner Verlag, Leipzig u. Berlin.

294. Haberlandt, G. 1913. Zur Physiologie der Zellteilung. Sitzungsber. kgl. preuss. Akad. Wiss., Berlin, 16: 318345 .

295. — 1914. Zur Physiologie der Zellteilung. Sitzungsber. kgl. preuss. Akad. Wiss., Berlin, 16: 1095-1111.

296. 1 1919. Zur Physiologie der Zellteilung. 4. Mitt. Sitzungsber. kgl. preuss. Akad. Wiss., Berlin, 39: 721733.

297. - 1920. Zur Physiologie der Zellteilung. 5. Mitt.: Über das Wesen des plasmolytischen Reizes bei Zellteilung nach Plasmolyse. Sitzungsber. kgl. preuss. Akad. Wiss., Berlin, 11: 323-338.

298. Jaeger, M. 1928. Untersuchungen über die Frage des Wachstums und der Entholzung verholzter Zellen. Jahrb. wiss. Bot. 68 : 345-379.

299. Klein, G., u. Kisser, J. 1924. Die sterile Kultur der hoheren Pflanzen. Bot. Abhandlng. (K. Goebel), Heft. 2: pp. 64.

300. Küster, E. 1911. Die Gallen der Pflanzen. pp. 437. Hirzel Verlag, Leipzig.

301. Lewis, K. H., and MeCoy, E. 1933. Root nodule formation on the garden bean, studied by a technique of tissue culture. Bot. Gaz. 95: 316-329.

302. Loeb, J. 1915. Rules and mechanism of inhibition and correlation in the regeneration of Bryophyllum calycinum. Bot. Gaz. 60: 249-277.

303. - 1916. Further experiments on correlation of growth in Bryophyllum calycinum. Bot. Gaz. 62: 293302. 
304.

1917. Influence of the leaf upon root formation and geotropic curvature in the stem of Bryophyllum calycinum and the possibility of a hormone theory of these processes. Bot. Gaz. 63: 25-50.

305. 1917. The chemical basis of axial polarity in regeneration. Science $46: 547-551$.

306. 1918. Chemical basis of correlation. I. Produe. tion of equal masses of shoots by equal masses of sister leaves in Bryophyllum calycinum. Bot. Gaz. 65: 150-174.

307. MaeDougal, D. T. 1926. Growth and permeability of century-old cells. Am. Nat. 60: 393-415.

308. Naylor, E. E. 1931. The morphology of regeneration of Bryophyllum calycinum. Am. Jour. Bot. 19: 32-40.

309. —, and Johnson, B. 1937. A histological study of vegetative reproduction in Saintpaulia ionantha. Am. Jour. Bot. 24: 673-678.

310. - and Sperry, J. J. 1938. Vegetative reproduction in Chlorophytum elatum. Am. Jour. Bot. 25: 695-699.

311. Nobécourt, P., et Dusseau, A. 1938. Sur la proliferation in vitro de fragments de végétaux et la formation de tumeurs aseptiques. Sciences (rev. frang.) 20: 53-56.

312. Okado, Y. 1920. Studien über die Proliferation der Markhöhlenzellen im Stengel der Vicia faba. Bot. mag., Tokyo, 34: 19-34.

313. Pearsall, W. H., and Priestley, J. H. 1923. Meristematic tissues and protein iso-electric points. New Phytol. 22: 185-191.

314. Priestley, J. H. 1928. The meristematie tissue of the plant. Biol. Rev. 3: 1-20.

315. - 1930. Studies in the physiology of cambial aetivity. III. The seasonal activity of the cambium. New Phytol. 29: 316-354.

316. - and Swingle, C. F. 1929. Vegetative propagation from the standpoint of plant anatomy. Tech. Bull. 151, U. S. Dept. Agr., Washington, D. C.

317. Riker, A. J., and Berge, T. O. 1935. Atypieal and pathological multiplication of cells approached through studies on crown gall. Am. Jour. Cancer 25: 310-357.

318. Robbins, W. J. 1941. Growtl of excised roots and heterosis in tomato. $\Lambda \mathrm{m}$. Jour. 13ot. 28: 216-225. 
319. Rosene, H. F., and Lund, E. J. 1935. Linkage between output of electric energy by polar tissues and cell oxidation. Plant Physiol. 10 : 27-47.

320. Sachs, J. 1893. Physiologische Notizen. VI. Ueber einige Beziehungen der specifischen Grösse der Pflanzen zu ihrer Organisation. Flora $77: 49-81$.

321. Schilling, E. 1915. Über hypertrophische und hyperplastische Gewebewucherungen an Sprossachsen, verursacht durch Paraffine. Jahrb. wiss. Bot. 55: 177-258.

322. - 1923. Ein Beitrag zur Physiologie der Verholzung und des Wundreizes. Jahrb. wiss. Bot. 62: 528-562.

323. Schwanitz, F. 1935. Beiträge zur Analyse der planzlichen Polarität. Beih. bot. Ztrbl. 54A : 520-530.

324. Sinnott, E. W., and Bloch, R. 1941. Division in vacuolate plant cells. Am. Jour. Bot. 28: 225-232.

325. Smith, L. H. 1907. Beobachtungen über Regeneration und Wachstum an isolierten Teilen von Pfiauzenembryonen. Diss., Halle.

326. Stingl, G. 1909. Über regenerative Neubildungen an isolierten Blättern phanerogamer Pflanzen. Flora 99: 178192.

327. Tukey, H. B. 1933. Embryo abortion in early-ripening varieties of Prunus avium. Bot. Gaz. 94: 433-468.

328. - 1938. Growth patterns of plants developed from immature embryos in artificial culture. Bot. Gaz. 99: 630-665.

329. Vöchting, H. 1878, 1884. Ueber Organbildung im Pflanzenreich. 1. u. 2. Th., Bonn.

330. —— 1892. Über Transplantation am Pflanzenkörper. Tübingen.

331. - 1894. Ueber die durch Pfropfen herbeigeführte Symbiose des Helianthus tuberosus und Helianthus annuus. Sitzungsber. kgl. preuss. Akad. Wiss., Berlin, 1894 : 705-721.

332. White, P. R. 1928. Studies on the banana. An investigation of the floral morphology and eytology of certain types of the genus Musa L. Ztsehr. Zellforseh. mik. Anat. $7: 673-733$. 
333. - 1939. Controlled differentiation in a plant tissue culture. Bull. Torrey Bot. Club 66: 507-513.

334. - 1942. "Vegetable Staticks" or Evidence concerning cell secretion, root-pressure, and gas diffusion in the functioning and morphogenesis of excised plant tissues. Am. Sci. (Sigma Xi Quart.) 30: 119-136.

335. - and Braun, A. C. 1941. Crown gall production by bacteria-free tumor tissues. Science 94 : 239-241.

336. — and 1942. A cancerous neoplasm of plants produced by autonomous, bacteria-free crown-gall tissue. Proc. Am. Phil. Soc. (In press).

337. — and 1942. A cancerous neoplasm of plants: autonomous bacteria-free erown-gall tissue. Cancer Res. 2: 597-617.

338. Wilhelm, A. 1930. Untersuchungen über das Chromogen in Vicia faba. Jahrb. wiss. Bot. 72: 203-253.

339. Winkler, H. 1902. Besprechung der Arbeit G. Haberlandt's "Culturversuche mit isolicrten Pflanzenzellen." Bot. Ztng. $60(2): 262-264$.

\section{Morphology and Morphogenesis-Plants-Growth SUBSTANCES}

340. Appleman, C. O. 1918. Special growth-promoting substances and correlation. Science 48: 319-320.

341. Avery, G. S., Burkholder, P. R., and Creighton, H. B. 1937. Production and distribution of growth hormone in shoots of Aesculus and Malus, and its probable role in stimulating eambial activity. Am. Jour. Bot. 24: 51-58.

342. Bonner, J., and English, J., Jr. 1938. A chemical and physiologieal study of traumatin, a plant wound hormone. Plant Physiol. 13: 331-348.

343. - - and Koepfli, J. B. 1939. The inhibition of root growth by auxins. Am. Jour. Bot. 26: 557-566.

344. Boysen-Jensen, P. 1910. Z̈ber die Leitung des phototropisehen Reizes in Avena Keimptlanzen. Ber. d. bot. Ges. 28: $118-120$.

345. Cooper, W. C. 1935. Ilormones in relation to root formation on stem cuttings. Plant Physiol. 10: 789-794. 
346.

1936. Transport of root-forming hormone in woody cuttings. Plant Physiol. 11: 779-793.

347. Delisle, A. F. 1937. The influence of auxin on secondary branching in two species of Aster. Am. Jour. Bot. 24: 159-167.

348. Gardner, F. E., and Marth, P. C. 1937. Parthenocarpie fruits induced by spraying with growth promoting compounds. Bot. Gaz. 99 : 184-195.

349. Goodwin, R. H. 1937. The role of auxin in leaf development in Solidago species. Am. Jour. Bot. 24: 43-51.

350. Gustafson, F. G. 1936. Inducement of fruit development by growth-promoting chemicals. Proc. Nat. Acad. Sci., Wash., 22 : 628-636.

351. - 1938. Further studies on artificial parthenocarpy. Am. Jour. Bot. 25: 237-244.

352. 1938. Induced parthenocarpy. Bot. Gaz. 99: $840-844$.

353. - 1939. The cause of natural parthenocarpy. Am. Jour. Bot. 26 : 135-138.

354. Haberlandt, G. 1921. Zur Physiologie der Zellteilung. 6. Mitt.: Über Auslösung von Zellteilung durch Wundhormone. Sitzungsber. kgl. preuss. Akad. Wiss., Berlin, 8: 221-234.

355. - 1922. Über Zellteilung-Hormone und ihre Beziehung zur Wundheilung, Befruchtung, Parthenogenese und Adventivembryonie. Biol. Ztrbl. 42: 145-172.

356. Hamner, K. C., and Bonner, J. 1938. Photoperiodism in relation to hormones as factors in floral initiation and development. Bot. Gaz. 100: 388-431.

357. Kögl, Fr., Haagen-Smit, A. J., u. Erxleben, H. 1933. Ueber ein Phytohormon der Zellstreckung. 4. Mitteilung über pflanzliche Wachstumsstoffe. Reindarstellung des Auxins aus menschlichen Harn. Ztschr. physiol. Chem. 214: 241261 .

358. - u. Haagen-Smit, A. J. 1936. Biotin und Aneurin als Phytohormone. Ztschr. physiol. Chem. 243: 209-226.

359. Le Fanu, B. 1936. Auxin aud correlative inhibition. New Phytol. 35: 205-220. 
360. Lehmann, E. 1936. Versuche zur Klärung der reziproken Verschiedenheiten von Epilobium-Bastarden. I. Der Tatbestand und die Möglichkeit seiner Klärung durch dif ferente Wuchsstoffbildung. Jahrb. Wiss. Bot. 82: 657668 .

361. Melehers, G. 1937. Die Wirkung von Genen, tiefen Temperaturen und blühenden Pfropfpartnern auf die Bluhreife von Hyoscyamus niger L. Biol. Ztrbl. 57: 568-614.

362. van Overbeek, J. 1935. The growth hormone and the dwarf type of growth in corn. Proe. Nat. Acad. Sci., Wash., 21: $292-299$.

363. - 1936. "Lazy," an a-geotropie form of maize. Jour. Hered. 27 : 93-96.

364. - 1938. Auxin production in seedlings of dwarf maize. Plant Physiol. 13: 587-598.

365. - 1938. "Laziness" in maize due to abnormal distribution of growth hormone. Jour. Hered. 29: 339341.

366. 1938. Auxin distribution in seedlings and its bearing on the problem of bud inhibition. Bot. Gaz. 100: 133-166.

367. Paál, A. 1914. Über phototropisehe Reizleitungen. Ber. d. bot. Ges. 32: 499-502.

368. - 1919. Über phototropische Reizleitung. Jahrb. wiss. Bot. 58 : $406-458$.

369. Reiche, H. 1924. Über Auslösung von Zellteilungen durch Injektion von Gewebesäften und Zelltrümmern. Ztschr. Bot. 16: 241-278.

370. Saehs, J. 1880, 1882. Stoff und Form der Pflanzenorgane. I. u. II. Arb. bot. Inst., Würzburg, 2: 452-488, 689-718.

371. 1893. Physiologisehe Notizen. VII. Ueber Waehstumsperioden und Bildungsreize. Flora 77: 217-253.

372. Snow, R. 1925. The correlative inhibition of the growth of axillary buds. Ann. Bot. $39: 841-859$.

373. - 1933. The nature of eambial stimulus. New Phytol. 32: 288-296.

374. 1935. Activation of eambial growth by pure hormones. New Phytol. 34: 347-360. 
375. Thimann, K. V. 1936. On the physiology of the formation of nodules on legume roots. Proc. Nat. Acad. Sei., Wash., $22: 511-514$.

376. — and Koepfli, J. B. 1935. Identity of the growthpromoting and root-forming substances of plants. Nature 135: 101-102.

377. - and Skoog, F. 1933. Studies on the growth hormone of plants. III. The inhibiting action of the growth substance on bud development. Proc. Nat. Acad. Sci., Wash., 19 : 714-716.

378. — - 1934. On the inhibition of bud development and other functions of growth substance in Vicia faba. Proc. Roy. Soc., London, B, 114: 317-339.

379. Went, F. W. 1928. Wuchsstoff und Wachstum. Rec. trav. bot. néerl. 25 : 1-116.

380. 1929. On a substance eausing root formation. Proc. konink. akad. Wetenschappen, Amsterdam, 32: 3539.

381. - 1932. Eine botanisehe Polaritätstheorie. Jahrb. wiss. Bot. 76 : 528-557.

382. 1 1938. Specific factors other than auxin affecting growth and root formation. Plant Physiol. 13: 55-80.

383. - 1941. Plant hormones. Publ. Am. Assoc. Adv. Sci., No. $14 ; 147-158$.

384. Zimmerman, P. W., Crocker, W., and Hitcheock, A. E. 1933. Initiation and stimulation of roots from exposure of plants to carbon monoxide gas. Contrib. Boyce Thompson Inst. 5 : 1-17.

385. — and Hitcheock, A. E. 1935. The response of roots to "root-forming" substances. Contrib. Boyce Thompson Inst. 7 : 439-445.

386. - and Wilcoxon, F. 1935. Several ehemical growth substances which cause initiation of roots and other responses in plants. Contrib. Boyce Thompson Inst. 7: 209-229.

\section{MoRPHOLOGY AND MORPHOgENESIS-ANIMAL}

387. Brachet, J. 1937. Some oxidative properties of isolated amphibian germinal vesicles. Science $86: 225$. 
388. - , and Shapiro, H. 1938. The relative oxygen consumption of dorsal and ventral regions of intaet amphibian gastrulae, ineluding observations on unfertilized eggs. Jour. Cell. \& Comp. Physiol. 10: 133-146.

389. Ebcling, A. H. 1924. Aetion de l'épithelium thyroidien en eultures pures sur la croissance des fibroblastes. C. r. soc. biol., Paris, 90 : 1449-1452.

390. - 1925. A pure strain of thyroid eells and its eharacteristies. Jour. Exp. Med. 41: 337-346.

391. —- and Fiseher, A. 1922. Mixed cultures of pure strains of fibroblasts and epithelial cells. Jour. Exp. Med. 36: 285-290.

392. Fell, H. B. 1928. The development in vitro of the isolated otoeyst of the embryonic fowl. Arch. exp. Zellforseh. 7: 69-81.

393. - 1928. Experiments on the differentiation in vitro of eartilage and bone. Part I. Areh. exp. Zellforseh. 7 : $390-412$.

394. - 1931. Osteogenesis in vitro. Arch. exp. Zellforseh. 11: $245-252$.

395. - 1931. The osteogenie eapaeity in vitro of periosteum and endosteum isolated from the limb skeleton of fowl embryos and young ehieks. Jour. Anat. 66: 157180 .

396. - 1932. Chondrogenesis in eultures of endosteum. Proe. Roy. Soc., London, B, 112: 417-427.

397. ——, and Canti, R. G. 1934. Experiments on the development in vitro of the avian knee-joint. Proe. Roy. Soc., Loudon, B, 116: 316-350.

398. — , and Landauer, W. 1935. Experiments on skeletal growth and development in vitro in relation to the problem of avian phokomelia. Proe. Roy. Soe., London, B, 118: 133-154.

399. — and Robison, R. 1929. The growth, development and phosphatase activity of embryonie avian femora and limb-buds eultivated in vitro. Biochem. Jour. 23: 767784 .

400. - 1930 . The development and phosphatase activity in vivo and in vitro of the mandibular skeletal tissue of the embryonic fowl. Biochem. Jour. 24: 1905-1921. 
401 .

1934. The development of the calcifying mechanism in avian cartilage and osteoid tissue. Biochem. Jour. 28: 2243-2253.

402. Filatow, D. 1925. Ersatz des liusenbildenden Epithels von Rana esculenta durch Bauchepithel von Bufo vulgaris. Arch. entw.-mech. Org. 105: 475-482.

403. Fischer, A. 1922. A three months old strain of epithelium. Jour. Exp. Med. 35: 367-372.

404. - 1922. A pure strain of cartilage cells in vitro. Jour. Exp. Med. 36: 379-384.

405. - 1922. Cultures of organized tissues. Jour. Exp. Med. 36: 393-397.

406. - 1925. Sur la transformation in vitro des gros leucocytes mononucléaires en fibroblastes. C. r. soc. biol., Paris, 92: 109-112.

407. - 1926. Umwandlung von Fibroblasten zu Makrophagen in vitro. Arch. exp. Zellforsch. 3: 345-352.

408. 1 1929. Ueber Charakter- und Spezifitätskonstanz der Gewebezellen. Areh. ges. Physiol. Menschen. Tiere 223: 163-170.

409. - 1930. Regeneration. Versuche an Gewebekulturen in vitro. Virchow's Arch. path. Anat. 279: 94-136.

410. - 1931. Proliferation und Differeuzierung der Gewebezellen in vitro. Protoplasma 14: 307-319.

411. ——, u. Parker, R. C. 1929. Proliferation und Differenzierung. Arch. exp. Zellforsch. 8: 297-324.

412. Gilchrist, F. G. 1928. The effect of a horizontal temperature gradient on the development of the egg of the Urodele, Triturus torosus. Physiol. Zoöl. 1: 231-268.

413. Harrison, R. G. 1904. Experimentelle Untersuchungen über die Entwicklung der Sinnesorgane der Seitenlinie bei den Amphibien. Arch. mik. Anat. 63: 35-149.

414. 1910. The outgrowth of the nerve fiber as a mode of protoplasmic norement. Jour. Exp. Zoöl. 9: $787-848$.

415. - 1912. The cultivation of tissues in extraneous media as a method of morphogenetic study. Anat. Ree. $6: 181-193$.

416. - 1933. Some difficulties of the determination problem. Am. Nat. 67: 306-321. 
417. Huxley, J. S. 1926. Modification of development by means of temperature gradients. Anat. Rec. 34: 126-127.

418. - 1927. Modification of development by means of temperature gradients. Arch. entw.-mech. Org. 112: 480516.

419. Lewis, W. H. 1935. Rat malignant cells in roller tube eultures and some results. Carnegie Inst., Wash., Publ. No. 459, Contrib. Embryol. 25: 161-172.

420. Maximow, A. 1925. Tissue cultures of young mammalian embryos. Carnegie Inst., Wash., Publ. No. 361, Contrib. Embryol. 16: 47-113.

421. Parker, R. C. 1931. Structural and functional variations of fibroblasts in pure cultures. Science 73: 401-402.

422. 1- 1932. The functional characteristics of nine races of fibroblasts. Science $76: 219-220$.

423. - 1932. The stability of functionally distinct races of fibroblasts. Science $76: 446-447$.

424. - 1932. The races that constitute the group of common fibroblasts. I. The effect of blood plasma. Jour. Exp. Med. 55: 713-734.

425. - 1933. The races that constitute the group of common fibroblasts. II. The effect of blood serum. Jour. Exp. Med. 58: 97-113.

426. 1933. The races that constitute the group of common fibroblasts. III. Differences determined by origin of explant and age of donor. Jour. Exp. Med. 58: 401-414.

427. - 1934. Studies on organogenesis. I. The ability of isolated blood cells to form organized vessels in vitro. Jour. Exp. Med. 60: 351-359.

428. - 1936. The cultivation of large quantities of adult tissue in fluid media. Science $83: 579-581$.

429. - 1936. The cultivation of tissues for prolonged periods in single flasks. Jour. Exp. Med. 64: 121-130.

430. Schotté, O. 1932. Xenoplastic inductions. (Abst.) Anat. Rec. 54 (suppl.) : 30 .

431. Spemann, H. 1936. Experimentelle Beiträge zu einer Theorie der Entwicklung. J. Springer, Berlin. 
432. - u. Geinitz, B. 1927. Ueber Weckung organisatorischer Fähigkeiten durch Verpflanzung in organisatorische Umgebung. Arch. entw.-mech. Org. 109: 129175.

433. Virchow, R. 1858. Die Cellularpathologie in ihrer Begrünung auf physiologische und pathologische Gewebelehre. Berlin.

434. Vogt, W. 1932. Einige Ergebnisse aus Versuchen mit halbseitiger Temperaturhemmung am Amphibienkeim. Rev. suisse zoöl. 39 : 309-324.

435. Weiss, P. 1935. The so-called organizer and the problem of organization in amphibian development. Physiol. Rev. 15: 639-674.

\section{PATHOLOGY-PLANT}

436. Braun, A. C., and White, P. R. 1942. Bacteriological sterility of tissues derived from secondary crown-gall tumors. Phytopath. 33: 85-100.

437. Stanley, W. M. 1938. Aucuba mosaic virus protein isolated from diseased, excised tomato roots grown in vitro. Jour. Biol. Chem. 126: 125-131.

438. White, P. R. 1934. Multiplication of the viruses of tobacco and aucuba mosaic in growing excised tomato roots. Phytopath. 24: 1003-1011.

439. 1936. The cultivation of plant disease viruses in actively growing excised plant organs in vitro. Proc. 2nd Int. Congress Microbiol., London, pp. 30-31.

\section{PATHOLOGY -ANIMAL}

440. Rivers, T. M., Haagen, E., and Muckenfuss, R. S. 1929. Development in tissue cultures of the intracellular changes characteristic of vaccinal and herpetic infections. Jour. Exp. Med. 50: 665-672.

441. — - 1929. A study of vaccinal immunity in tissue cultures. Jour. Exp. Med. 50: $673-685$.

442. - and Ward, S. M. 1935. Jennerian prophylaxis by means of intradermal injections of culture raccine virus. Jour. Exp. Med. 62: 549-560. 


\section{Miscellaneous-Plant}

443. Clark-Kennedy, A. E. 1929. Stephen Hales, D.D., F.R.S. An eighteenth century biography Cambridge Univ. Press, London.

444. Johnson, D. S. 1912. Studies of the development of the Piperaceae. II. The structure and seed development of Peperomia hispidula. Am. Jour. Bot. 1: 357-397.

445. MacDougal, D. T., and Shreve, F. 1924. Growth in trees and massive organs of plants. Carnegie Inst., Wash., Publ. No. 350 .

446. Mason, T. G., and Phillis, E. 1939. Experiments on the extraction of sap from the vacuole of the leaf of the cotton plant and their bearing on the osmotic theory of water absorption by the cell. Ann. Bot. 3: 531-544.

447. Mueller, J. H. 1935. Methionine as an impurity in natural leucine preparations. Science 81: 50-51.

448. Nobécourt, P. 1939. Sur les radicelles naissant des cultures de tissus du tubercule de carotte. C. r. soc. biol., Paris, 130: 1271-1272.

449. Palladin, V. I. 1926. Plant plysiology. (Edited by B. E. Livingston.) 3rd ed. Blakiston's, Philadelphia.

450. Pfeiffer, H. 1933. Ueber das Migrationsvermögen pflanzlicher Zellen in situ und in vitro. Arch. exp. Zellforsch. 14: $152-170$.

451. Prát, S. 1927. The toxicity of tissue juices for cells of the tissue. Am. Jour. Bot. 14: 120-125.

452. Richards, O. W. 1936. Killing organisms with chromium as from incompletely washed bichromate-sulfuric-acid cleaned glassware. Physiol. Zoöl. 9: 246-253.

453. Theophrastus. Ca. 400 B.C. Enquiry into plants. (In: Loeb classical library. G. P. Putnam's Sons, New York. 1923.)

454. Thimann, K. V., and Skoog, F. 1940. The extraction of auxin from plant tissues. Am. Jour. Bot. 27 : 951-960.

455. Wilson, J. K. 1915. Calcium-hypochlorite as a seed sterilizer. Am. Jour. Bot. 2: 420-427. 


\section{Miscellaneous-ANiMaL}

456. Ebeling, A. H. 1921. Measurement of the growth of tissues in vitro. Jour. Exp. Med. 34: 231-243.

457. Vogelaar, J. P. M., and Erlichman, E. 1939. Contributions to tissue eulture technic. Am. Jour. Cancer 35: 510-520. 



\section{INDEX}

Author names are in black face type, plant and animal names in italics. Page references in black face type indicate bibliography, while those in italics indicate illustrations.

A

Abies lasiocarpa, 55

Abies pectinata, cambium, eultures of, 127

abscission, auxin a factor in, 210

Acer pseudoplatanus, grafts in cambium enltures, 213

achenes, sterilization of, 118

acid, ascorbic, 99

acid, boric, 103, 104, 105

acid, ehromic (see potassium dichromate)

acid, humic, 56

acid, indole-acetic, effects on growth, 98, 105, 179, 18?, 186-188, 194, 202

acid, nicotinic, $97,98,100,103$, 104,105

acid, sulfuric, as nutrient, 105 (see also cleaning solution, 71)

acids, amino (see amino-acids)

Addicott, 203, 241; A. and Bonner, J., 97, 241; Bonner, J., and $\mathbf{A . ,} 34,57,93,100,131$, 185,230

adventitious embryos, origin and cultivation of, 220

adventitious roots, $50,88,120$

aeration, effect on differentiation, 194

aeration, effect on geotropic response, 192

aeration, requirements of roots, 56

Aesculus, 252

agar, 102, 104, 105 air-conditioning, of culture and transfer rooms, 74, 77

alanine, 31

alcohol, for cleaning glassware, 71

alcohol lamps for flaming instruments, 83

alcohol sterilization of tissues, 119

algae, growth in stock salt solutions, 104

Allium, 28

amino-acids, 93, 99, 100

amino-nitrogen, as measure of growtl, 156

Amoureux; Berthelot and A., 199,247

amphibian embryos, 14,15

animal tissue cultures, 21-30

Antirrhinum, cultures of seed primordia, 206

apical dominance, in roots, 55

aposporous embryos, 220

apple seeds, aseptic removal of, 118

Appleman, 211, 252

area of cultures, measurement of, 158

Arnold sterilizer, 69, 107

Arnon, $70,93,236$; A. and

Stout, 70, 93, 237; Stout and

A., 70, 93, 237; Hoagland

and A., 70,237

ascorbic acid, 99

asepsis, 117 et seq.

asparagin, 31

Aspidinm, 28

atmospheric humidity, 134 
aueuba mosaic virus, 201

autoclave, 68

autonomy of cells, 4

auxin, effects of, 210-212

Avena, 252

Avena coleoptiles, 219

Avery and La Rue, 50, 245; A., Burkholder, and Creighton, 211, 252; La Rue and A., 45, 233

Axtman; Bonner, J., and A., 98,242

\section{$B$}

bacterial digestion of fibrin, 101

bacteriological contaminations, $74,83,121$

bacteriologist's hood, for transfers, 74

Baker, 22, 90, 101, 240, 244; B. and Carrel, 22, 90, 240, 241; Carrel and B., 22, 90, 241

baker's yeast, 101

balances, 71

bark, removal for cultivation, 115,122

Barker; Bennet-Clark, Greenwood, and B., 94, 245

Bartley; Robbins and B., 35, 95, $96,97,133,157,185,239$, 243; Robbins, B., and White, V. B., 35,231 ; Robbins, White, v. B., McClary, and B., 93, 237 (see also Robbins and Schmidt [Schmidt=Bartley] $35,95,133,157,158,185$, $232,243,244$ )

bean pods, ascptic seeds from, 118

bean pods, use in testing wound subst:inces, 57, 114

becel, cambium cultures from, 123

Begonia, 28, 125

Behre, 47, 50, 247

belly epithelim of toad, 15

Bennet-Clark, Greenwood, and Barker, 94, 245
Berge; Riker and B., 199, 250

Berkefeld filters, 107

Berry; Steward, B., and Broyer, 56,246

Berthelot, 93, 104, 237; B. and Amoureux, 199, 247

Berthelot's solution, 104

Bérziñ; Thielman and B., 94, 247

Beta vulgaris, 19

biotin, 99

Blakeslee; van Overbeek, Conklin, and B., 27, 220

Bloch; Sinnott and B., 58, 126, 251

blood as a nutrient, 10

blood plasma, 21, 22, 90

Bloom, 228

Bobllioff-Preisser, 28, 234

Bocconia, 27

Bonner, D.; Bonner, J., and B., 99,242

Bonner, J., 34, 96, 97, 105, 125, $132,185,234,242$; B. and Addicott, 34, 57, 93, 131, 185, 230 ; B. and Axtman, 98, 242; B. and Bonner, D., 99, 242; B. and Buckman, 97, 245; B. and Devirian, 97, 242; B. and English, 57, 114, 126, 252; B. and Koepfli, 187, 188, 252; Addicott and B., 97, 98, 241; Hamner and B., 212, 253; van Overbeek and B., 99, 246

Börger, 28, 58, 228, 234

boric acid, 103, 104, 105

boron, 70,92

Bouillenne, M.; Bouillenne, R., and B., 212, 242

Bouillenne, R., and Boullenne, M., 212, 242; B. and Went, 210,248

Bcysen-Jensen, 210, 212，219, 252

Brachet, 218, 255; B. and Shapiro, 218, 256

branches, effect on measurements of roots, 160

lranehing habit, auxin a factor in, 211 
lirass rings, as culture chambers, 81,149

Brassica, 28

Brassica nigra, apical dominance in roots, 55

Erassica rapa, 19

Braun and White, P. R., 221, 259; White, P. R., and B., 52, 124, 221, 252

brewer's yeast, 101

“'Brewer's yeast-Harris,'” 101

bromine, as sterilizing agent, 118,119

brown sugar, 95

Broyer; Hoagland and B., 56, 245; Steward, Berry, and B., 56,246

Bryophyllum, 28, 125

Bryophyllum calycinum, 249, 250

Buckman; Bonner, J., and B., 97,245

buckwheat roots, $63,64,105$

bud cultures, 151

buffering effect of complex nutrients, 186

Bufo vulgaris, 15, 257

Burkholder; Avery, B., and Creighton, 211, 252

Burlet, 118, 228, 242; GeigerHuber and B., 98, 187, 243

Burrows, 21, 22, 35, 131, 235, 236; Carrel and B., 22, 236

\section{C}

calcium, 92, 96, 185

calcium hypochlorite, 119

calcium nitrate, 103, 104, 105

calcium sulfate, 105

callus “'blasen,", 194, 206

callus cultures, $52,53,99,105$

"calots," 66

cambial activity, initiation and control by auxin, 211

cambium cultures, $33,36,116$

cambium cultures, isolation of, $115,121,122$

cambiums, $48-50$ (see also, meristems)

Camptosorus, 48, 125 cancer, 2

Cannon, 56, 245

Canti; Fell and C., 256

carbohydrate, 57, 93, 94-96

carbon, 92

carboys, Pyrex, 69

Carrel, 21, 22, $26,35,71,75,90$, $131,183,228,236,241$; C. and Baker, 22, 90, 241; C. and Burrows, 22, 236; Baker and C., $22,90,240,241$

Carrel flasks, 80

Carrière, 13, 248

carrot, 49, 99

carrot, cultures from 105, 124

caulocaline, 212, 217

cell theory, 4,35

cellular reactions, 193-194

cellular totipotency, 4-8

celluloid rule, for measuring roots, 128,161

cereals, roots, cultivation of, 199

Chambers, 33, 131, 148, 151, 231

chemotropic response, 192

chlorides, 112

chlorine, 92

chlorine, as sterilizing agent, 119

Chlorophytum, 125

Chlorophytum elatum, 250

chromel wire loops, 82, 85

chromic acid (see potassium dichromate)

" chymical implements," 66

Citrus, fruits, aposporous embryos in, 220

"clarite," 151

Clark-Kennedy, 260

cleaning procedures, for glassware, 71,72

cleaning solutions, 69,71

clones, importance of, 132

clover roots, cultures of, 40, 105

clover roots, dominance in, 55

elover roots, root eap, 61

coagulants, 101, 102

cobalt chloride, 105

coconut milk, as a nutrient, 27

colchicine, effects on carrot cultures, 202 
coleoptile, Avena, transplantation of, 219

Colcus, 28

Coleus arifolia, 19

colony shape, 133,158

commercial sugar (see suerose) companion cells, phloem, meristematic character of, 58

Compositae, bud formation on roots, 47,51

concentration gradients, 217

Conklin; van Overbeek, C., and Blakeslee, 27

contaminations, $74,83,121$

convection currents, 74

Cooper, 210, 212, 252, 253

copper, 96

copper sulfate, 105

cortical tissues, retention of meristematic function by, 43 , 58

Corydalis solida, 6

cotton plugs, 73

cotyledons, regeneration in, 47

cover glasses, 150, 151

Crassula, 28

Creighton; Avery, Burkholder, and C., 211, 252

criteria of response to external influences, 184-194

Crocker; Zimmerman, C., and Hitchcock, 255

crocks for cleaning solution, 71 crown gall, 199, 209, 221

crown-gall tissue, cultivation of, $5.3,124,216$

(acimber mosilic virus, 200

Cucurbita, 28

"nlture conditions, 144 et seq.

culture period, length of, 142, 143

('ulture rooms, 76

culture techniques, 131 et seq.

"urvature, tropic, effect of a axin on, 212

Cuscula, 202

cuttings, derelopment of roots on, 88,121

eyclosis, 194

cystoin-1101, 105 cystoseopie seissors, 83

cytology, 202

Czech, 28, 234

Dakin solution, 119

dandelion root, polarity and bud formation, 51

Datura, 27, 220

Daucus, 28

Dauphiné, 47, 203, 234, 248

Day, 98, 242

Delarge, 133, 248

Delisle, 211, 253

Demuth; Fischer and D., 22, 90, 101, 241

developmental patterus, 210-219

deviation from norm, growth rates of eultures, 163-165

Devirian; Bonner, J., and D., $97,98,242$

dextrin, 95

dextrose, 32, 105, 107

diameter of roots, 159

diastase, digestion products as nut rients, 31

Dicranum, 98

Dietrich, 45, 233

differentiation, as affected by oxygen supply, 194, 223, 220

digests, peptic, of fibrin, 90

diphtheria bacilli, 156

disalecharides, 95

distilled water, $69,70,92$

diurnal rhythms, of water secre-

tion and of respiration, 190

dominance, 55, 136, 159

Drew, 22, 90, 237, 238

Droscra, 247

drupes, sterilization of, 118

dry woiglits, as measure of growth, 143, 157

Duhamet, 99, 187, 202, 242

Dusseall; Nobécourt and D., 34, 199,250

dwarfness, auxin a factor in, 211

\section{E.}

Ebeling, 22, 29, 90, 96, 133, 158, $240,247,256,261$; E. and Fischer, 29, 30, 256 
egg, fertilized, as meristem, 44 egg cells, cultivation of , 45, 219 Eichhornia crassipes, 20 electropotential gradient, 217 electrostatic potential, 218 elementary organism, 4,29

“'elixir proprietatis,' 66 embryo juice as mutrient, 22, 27, 90

embryogeny, 218, 219 embryological watch glasses, 81 , 130,132

embryology, experimental, 219 embryos, adventitious, 220 embryos, amphibian, 14, 15 embryos, plant, 45-47 embryos, undifferentiated, 46,47 endodermis, meristematic character of, 43

endosperm, abortive, 45, 220

endosperm, liquid, as nutrient, 27

energy sourees, 94-96

English; Bonner, J., and E., 57, $114,125,126,252$

Ephrussi, 228

epicotyl, proliferative capacity of, 48

epidermal tissue, meristematic character of, 44

epidermis, cultivation of, 28

Epilobium, 254

epithelial cells, animal, in eulture, 29

epithelium, 2, 30

epithelium, belly of toad, 15

epithelium, glandular, of kidney, 2

epithelium, of iris, 2

Erdmann, 228

erect habit, auxin as a factor in, 211

Erlichman, 90, 238; Vogelaar and $\mathbf{E}, 22,71,90,91,239,244$ errors of measurement, 162 et ser.

Erxleben; Kögl, Haagen-Smit, and $\mathbf{E . , ~ 2 1 2 , ~} 253$

Essenbeck and Suessenguth, 45, 233 ctler-alcohol, for cleaning cover glasses, 150

ethyl-methaerylate, 151

Eutettix tenellus, 245

excised roots, early cultivation of, 31-36

excision procedures, 87,88

exudate, phloem, toxicity of, 27

eye-cup, of frog, 15

\section{$\mathrm{F}$}

Fell, 131, 132, 184, 256; F. and Canti, 132, 256; F. and Landauer, 132, 256; F. and Robison, $132,256,257$

ferric chloride, 109

ferric nitrate, 109

ferrie sulfate, 103, 105, 106, 108, $109,180,181$

ferric tartrate, 105

fertilized egg cells, as material for morphogenetic study, 218219

fertilized egg cells, meristematic character of, 44

fibrin digests, as nutrients, 90 , 101

fibroblasts, apparent loss of totipoteucy in, 29,30

Fiedler, 34, 95, 99, 100, 102, 131, $159,187,192,229,231$

Fife and Frampton, 218, 245

Filatow, 15, 30, 257

fir, white, 55

Fischer, $29,30,210,229,257 ; \mathbf{F}$. and Demuth, 22, 90, 101, 241; F. and Parker, 143, 210, 257; Ebeling and F., 29, 30, 256

flaming of tubes, practice, 76,83 flasks, Carrel, 80, 81

flasks, culture, 131

flax roots, 105

floating of roots, importance of, 140

flower-forming hormones, 212

foliar leaf, differentiation of, 2 form, origin of, 1, 2, 11, 12

Frampton; Fife and F., 218, 245

Fraxinus Ornus, 19

frog tissues, 14, 15, 21 
fructose, 94

fruits, fleshy, membranaceous and woody, ascptic seeds from, 118

function, origin of, $1,2,11,12$

fungi, as parasites on tissue cultures, 199

fungoid growth of cambium eultures, 123

G

galactose, 95

Galligar, 34, 231, 239

ganglia, nerve fibers from, 209

Gardner and Marth, 211, 253

gas, toxicity of, 75,76

gas interchange as a morphogenetic factor, 192, 194

Gautheret, $33,34,36,38,49,50$, $96,99,102,104,105,116,122$, $123,127,144,148,158,184$, $203,213,221,229,231,232$, 234, 242, 245, 248; Plantefol and $\mathbf{G} ., 189,246$

Geiger-Huber, 98, 187, 243; G. and Burlet, 98, 187, 243

Geinitz; Spemann and G., 259

gelatine, 102

"'gelose,"' 104

gemmae, stipular, of Marattia, 125

gene mechanism, 30

genes, auxin in relation to, 211

genetic constitution and stability, 132

geotropic response, 192,210

Gey, G. O., 131, 146, 236; G. and Gey, M. C., 146, 236

Gey, M. C.; Gey, G. O., and G., 146,236

Gilchrist, 218, 257

Gioelli, 122, 199, 203, 249

glandular function of roots, 189 , 190

glandular hairs, eultivation of, 20

glassware, 79 et seq.

gluecuium sulfate, 105

glueose, 31,94 glycine, $31,99,103,104,105,106$

glycocoll (see glycine)

Goebel, 6, 7, 217, 249

Goodwin, 211, 253

gourds, 13

grafting, $7,13,14,15$

grafts, in vitro, 33,213

granulation of wounds, 2

grasses, meristems of, 48

Greene, 224, 225

Greenwood; Bennet-Clark, G., and Barker, 94, 245

Grossenbacher, 190, 245

growth, distribution of, in the body, 10, 11

growth, restrictions on, 10

growth habit, 57, 142

growth measurements, 154 et seq.

growth rates, 57, 141

Gruenewald scissors, 82

guard cells, loss of proliferative capacity, 44

Guilliermond, 33

Gustafson, 210, 253

Crymnosperms, sterilization of sceds, 118

\section{$\mathrm{H}$}

Haagen; Rivers, H., and Muckenfuss, 184,259

Haagen-Smit; Kögl and H., 99, 253; Kögl, H., and Erxleben, 212,253

Haberlandt, $8,9,10,16,18,20$, $21,27,28,30,31,32,33,35$, $44,100,126,184,234,245$, 249,253

hairs, glandular, stamen and stinging, cultivation of, 20

hairs, root, $6.2,63$

Hales, 66

Hamner and Bonner, J., 212, 253

hanging-drop cultures, 148, 149, 151 et seq.

hanging-drop cultures, equipment, 130,149 et seq.

Hannig, 45, 233 
Harris yeast, 101

Harrison, 9, 14, 21, 23, 30, 35, $90,131,183,209,210,219$, $229,236,257$

Heidt, 33, 231

Helianthus annuus, 251

Helianthus tuberosus, 251

heterologous grafts, 221

heterosis, 220

Heyman scissors, 82

histograms, use of, 175

histology, 202, 203

Hitchcock; Zimmerman and $\mathbf{H}$. 255; Zimmerman, Crocker, and $H ., 255$

Hoagland and Arnon, 70, 237;

H. and Broyer, 56, 245

hollow-ground slides, 130,149

homologous grafts, 221

hood, bacteriological, 74

hood, chemical, 77

hormones, 93, 96, 210-212

Hort, 42

humic acid, 56

Huxley, 218, 258

hybrid peaches, 45

hybrid tomatoes, 220

hydrogen-ion gradients, 217

hydrostatic gradients, 217

hydrostatic potential, 218

hydrostatic pressure, 190

Hyoscyamus niger, 254

hyperhydric enlargement, 206

hypocotyl, proliferative capacity of, 47

hypotheses, working, 3

I

immature ovules, cultivation of, 58

immersion heater, 83

implements, 82 et seq., 85

incompatibility, 220

increment rates, 155 et seq.

indole-acetic acid, 98, 105, 179, 182, 186-188, 194, 202

innervated cells, 209

inoculation procedures, 138 et seq.

insect galls, 126 insolation, danger from, 144

intercalary meristems, 48, 49, 124,151

intumescences, 114

iodine, 92

iodine, effects of deficiency, 188

iridectomy scissors, 82

iris, epithelium, 2

iron, 92

iron, effects on growth, 180,181

iron, optimal concentrations of, 185

iron chloride, 109

iron nitrate, 109

iron sulfate, 103, 105, 106, 109, 180,181

iron tartrate, 105

isopleth diagrams, use of, 176

isotonicity, 94

\section{J}

Jaeger, 43, 48, 249

Jensen's No. 16 virus, 202

Johnson, B.; Naylor and J., 44 125,250

Johnson, D. S., 34, 46, 4\%, 260

juvenile cells, 48

Kalancho $\ddot{e}, 28$

Kemmer, 28, 234

Kisser; Klein and K., 118, 249

Klein and Kisser, 118, 249

Knop's solution, 31, 104

Knudson, 32, 234, 239; $\mathbf{K}$. and Smith, R. S., 32, 239

Koepfli; Bonner, J., and K., 188, 252; Thimann and K., 210, 255

Kögl and Haagen-Smit, 99, 253; K., Haagen-Smit, and Erxleben, 212,253

kohl-rabi, cultivation of tissues of, 124

Kotte, 31, 32, 33, 34, 35, 36, 37, $56,94,100,101,131,192,231$

Krontowski, 229

Kubowitz; Warburg and $\mathbf{K}$., 184,247

Kunkel, 28, 234

Küster, 28, 126, 229, 249 
L

laboratory, 67 et seq.

Laibach, 210, 243

Lamium, 20

Lamprecht, 28, 234

Landauer; Fell and L., 256

La Rue, 45, 47, 233, 235; L. and Avery, 45, 233; Avery and L., $50,219,245$

lateral meristems, 48

lead, toxicity of, 92

leaf-mesophyll, cultivation of, 27,43

leaf-primordia, cultivation of, 219

Le Fanu, 210, 253

legume nodules, 199

Lehmann, 211,254

lens, origin of in amphibian eye, 15

Leonian and Lilly, 188, 243

leucine, impurities in, 100

leucocytes, 224, 225

Lewis, $\mathbf{K}$. H., and McCoy, 199, 249

Lewis, M. R., 22, 25, 34, 90, 96, 238, 240 ; L. and Lewis, W. H., $22,34,90,131,149,238$

Lewis, W. H., $22,24,74,81,90$, $147,238,258$; L. and Lewis, M. R., 22,229

lianes, 48

Liebig's meat extract, use in nutrients, $31,32,100$

Lilly; Leonian and L., 188, 243

limb-huds, vertebrate, 2

line graphs, use of, 174

linear increments, as measure of growtl, 159

Locke, 90, 238

Locke's solution, 90

Loeb, 32, 79, 229, 249, 250

Loo, S. W.; Loo, T. L., and L., $34,100,243$

Loo, T. L., and Loo, S. W., 34, $10(1,243$

loss of function, 4

Lund, 217, 245; Rosene and L., 217,251

Lupinus albus, 234, 242, 245 lymph, use as nutrient fluid, 10, 21

MacDougal, 44, 250; M. and Shreve, 44, 260

macrophage, 30

magnesium, $92,96,185$

magnesium sulfate, 103, 104, 105

maize roots, 98

malignancy, origin of, 221

maltose, 95

Malus, 252

Malyschev, 33, 95, 131, 144, 158, 231

Maneval; Robbins and M., 32, $95,144,157,232,246$

manganese, 92

manganese sulfate, 103, 104, 105

mannose, 95

manometer for measuring root pressure, 196, 19\%, 198

Marattia, 125

Marotto, 34, 231

Marth; Gardner and M., 211, 253

Mason and Phillis, 94, 260

Maximow, 81, 131, 258

Maximow embryological wateh glisss, 81

Mayer, 33, 237

McClary, 97, 245; Robbins, White, V. B., M., and Bartley, 93, 237

McCoy; Lewis, K. H., and M., 199,249

measurement, methods, 128,154 et seq.

meat extract, Licbig 's, as nutrient, 31, 32, 100

media, 90 et seq.

media room, 68 et seq.

medullary ray parenchyma, pro-

liferative calpacity of 43,48

medullary rilys, 58, 125

megaspore-mother-eell, :2

melanotic epithelium, of anphibia, 30

Melchers, 212, 254 
mercuric chloride, as disinfectant, 119

meristematic function, retention of, 58

meristematic regions, 57

meristematic tissues, 207,215

meristems, 44 et seq., 59

meristems, intercalary, 48

meristems, lateral, 48

meristems, terminal, 50

metastatic tumors, 221

methionine, as impurity in leucine, 100

mica cover glasses, 150

migration of cells, 148, 158

migration rate of viruses, 200

Moebius, 58, 125, 235

mobility of cell surfaces, 11

Molliard, 33, 47, 125, 235

monocotyledonous plants, 94

nonosaccharides, 95

morphogenesis, 3-12, 13, 14, 15, 209 et seq.

mosaic diseases, 199-202

motility of cells, 11

Muckenfuss; Rivers, Haagen, and M., 184, 259

Mueller, 100, 156, 240, 260

Musa seminifera, 45

mustard, 55

mustard roots, 105

\section{$\mathrm{N}$}

Nagao, 99, 245, 246

nasal scissors, 82

Naylor, 44, 125, 250; $\mathbf{N}$. and Johnson, B., 44, 125, 250; N. and Sperry, 44, 125, 250

necrotic lesions, 194, 201

nerve fibrils, origin of, 183, 209 neuroblast, 21

niacin (see nicotinic acid)

nickel chloride, 105

Nicotiana, callns cultures, 53, 207, 208, 214, 215, 203-206

Nicotiana glutinosa, 201

nicotinic acid, 97, 98, 100, 103, 104,105

nitrates, 112

nitrogen, 92 nitrogenous materials, 93

Nobécourt, $33,34,36,50,96,97$, $99,218,229,233,246,260$; N. and Dusseau, 34, 199, 250

nodules, bacterial, formation on legumes, 199

notebooks, 199, 168

nucleated cells, cultivation of, 44

nutrient concentrations, sensitivity to, 57,185

nutrient salts, 92,93

nutrients, 90 et seq.

\section{$\mathrm{O}$}

oak, cultivation of cambium, 123 oak, white, 55

obligate parasites, eultivation of, 194, 199

Okado, 58,250

oligodynamic organic substances, 96

omission of nutrient constituents, 110, 111

optimum concentrations, 185

optimum temperatures, 76

orehids, undifferentiated embryos of, 46

organic complexes, in nutrients, $22,90,91,100,101$

organic materials, 93 et seq.

organic nitrogen, 99

organism as a whole, 7, 29

Ornithogalum, 20

osmotic agents, 94

osmotic value, 57

ovaries, eultivation of tissues from, 57, 125

Overbeek, van, 99, 210, 211, 246, 254; O. and Bonner, J., 99, 246; O., Conklin, and Blakeslee, 27; Blakeslee and o., 220

ovules, immature, cultivation of, 58

oxygen, 92

oxygen gradients, effect on dif-

ferentiation, 194, 218

oxygen-hydrogen gradients, 217 
$\mathrm{P}$

Paál, 210, 219, 254

palisade cells, cultivation of, 20

Palladin, 104, 260

parasites, facultative and obligate, cultivation of, 194, 199202

parenchyma, cortical, medullary ray, xylem, retention of meristematic function, $43,44,58$

Parker, 29, 67, 71, 75, 119, 131, $133,143,148,149,151,152$, 158, 210, 229, 258; Fischer and $P ., 143,210,257$

pathogens, facultative and obligate, cultivation of, 194, 199202

pathology, 194 et seq.

patterus, developmental (morphogenetic), 7

pea root, 105

Fea seeds, digest of, as nutrient, 31

peacles, hybrid, 45

Pearsall and Priestley, 217, 250

Peléce; Thielman and P., 99, 244

pellicle, of animal cell, mobility of, 11

pellicle, of plant cell, rigidity of, 9

I'eperomia, 28

Peperomia hispidula, 46, 47, 260

Peperomias, undifferentiated embryos in, 46,47

pepsin, 101

peptic digests, 90,101

peptone, in nutrients, 31,101

percentages, use of 172,173

pericycle, retention of meristematic function by, 43,125

Petri-disl cultures, 132

petroleum oil, toxicity of, 92

Pfeiffer, 28, 148, 235, 260

pH, 57, 218

l.hagoeytosis, 11

phanerogamic parasites, 202

rhaseolus vulgaris, 242 phelloderm, as material for cul-

tures, 125

phellogens, 48

Phillis; Mason and P., 94, 260

phloem exudate, as nutrient, 27

phloem parenchyma, meristematic character of, 43

phloem sap, 9

phosphatase, 184

phosphates, 112

phosphorus, 92

photosynthesis, 20, 189

phototropic response, role of auxin in, 210

phyllocalines, 212

physiologically sterile plants, 45 , 220

pierced slide, $80,81,82,149$

pigmentation of amphibian embryos, 14, 15

pine, cultivation of cambium of, 123

Pisum, 28

pith, meristematic eapacity of, 43,58

pith cells, cultivation of, 20

placental tissue, cultivation of, 58

planimeter, use in measuring growth, 158

plant extracts, toxicity of, 27

Plantefol, 189, 246; P. and Gautheret, 189, 246

plasma, use as nutrient, 21, 90

plasmolytic value, 94

plasmoptysis, 182, 194

plastids, 193

plumule, rooting of, 48,50

polarity, 5-7, 217, 218

polyembryony, causes of, 220

Iolypodium, 28

poplar, cultivation of cambium, 123

Populus nigra, 19

Portulaca oleracea, cultivation of embryos, 54

potassium, 92

potassium, effect of deficiency of, 188 
potassium chloride, 103, 104, 105 potassium dichromate, 71 potassium iodide, 103, 104, 105 potassium nitrate, 103, 104, 105 potassium phosphate, acid, 105 potato tuber cultures, 124

Pothos celatocaulis, 19

Prat, 27, 28, 260

"Precision"' still, 70

preparation of nutrients, 102 et seq.

Priestley, 48, 217, 250; P. and Swingle, 48, 250; Pearsall and P., 217, 250

proboscis, insect, 218

procambial strands, technique of excision, 123

procambial tissues, 48,49

procambium, cultivation of, 49

procumbent habit, auxin a factor in, 211

protein-N, measurement of, 156 , 157

proteoses as nutrients, 101

Prunus avium, 251

Pulmonaria, 20

"'pulvis fulminans," 66

Putnam, G. P., and Sou, 42

pyridines, 97

pyridoxine, 98, 100, 103, 104

pyrimidine, 97

\section{Q}

qualitative reactions, 186 et seq. quartz cover glasses, 151

quartz still, 70

Quercus alba, 55

\section{$\mathrm{R}$}

rabbit's eye, plant callus in, 2244, 225

racks, for cover glasses, 130, 152 radish roots, 105

Rana esculenta, 15, 257

Rana palustris, 14

Rana sylvatica, 14

Razdorskii, 45, 233

Rechinger, 19, 20, 235

records, 129, 168 et seq. redox-potential, 218 regeneration, $6,19,30$

Reiche, 58, 126, 254

reimplantation of tumors, 221

replications, 165 et seq.

respiration, 189

re-utilization of nutrient constituents, 144

rhizocaline, 212

Rhoeo, 28

Richards, 71, 72, 260

Eiker and Berge, 199, 250

Ringer, 90, 239

Ringer's solution, 90

rings, brass, as culture chambers, 81,149

Bivers, Haagen, and Muckenfuss, 184, 259; R. and Ward, 184,259

Robbins, $27,32,33,34,36,50$, $56,74,82,94,98,100,101$, $105,131,143,157,185,209$, $220,231,240,243,250 ; \mathbf{R}$. and Bartley, 35, 95, 96, 97, 133, $157,185,239,243$; $\mathbf{R}$. and Maneval, 32, 95, 144, 157, 232,246 ; R. and Schmidt, 35 , $95,98,105,133,157,158,185$, $232,243,244 ; \mathbf{R}$. and White, V. B., $27,35,95,133,203,232$, 240; R., Bartley, and White, V. B., 35, 231; R., White, V. B., Mcclary, and Bartley, 93, 237

Robison; Fell and R., 256, 257

roller tube cultures, 146, 147

root eaps, 61

root eultures, 117-121

root hairs, 62,63

root nodules, auxin a factor in formation of, 211

root pressure, 172, 190, 191, 196, 197,198

root tips, cultivation of, 31,50 , 56

rooting response, 188

roots, adventitious, $50,88,120$

roots, localization of initiation, 211,212

Rosene, 190, 217, 246; R. and Lund, 217, 251 
rust infeetions, 199

Rytz; Schopfer and R., 76, 244

\section{$\mathrm{S}$}

Sachs, 220, 251, 254

Saeger, 76, 246

Saintpaulia, 28

Saintpaulia ionantha, 250

" sal volatile oleosum," 66

Salix capraea, cultures of cambium, 116, 123

Salix capraea, respiration of cambium eultures, 189

" salt-cellars"' (culture dishes), 132

salt mixtures in nutrient solutions, 90

saltations, 133

salts, 71, 92, 93

Sambucus nigra, grafts in cambium cultures, 213

sand furnaces, 66

sap, xylem, as nutrient, 27

scalariform cells, differentiation of, 194, 208

scalpels, $82,83,85$

sear tissue, 2

Scheitterer, 28, 48, 148, 151, 235

Schilling, 43, 251

Schleiden, 5, 8, 230

Schmidt; Robbins and S., 35, $95,98,105,133,157,158,185$, $232,243,244$

Schmucker, 27, 43, 91, 235

Schneider, 230

Schopfer and Rytz, 76, 244

Schotté, 30, 258

Schwanitz, 7,251

Schwann, 4, 5, 8, 230

seions, 7

scijssors, eystoseopie, 83

scissors, firuenewale, 8:

seissors, Ileyman, 82

seissors, iridectomy, 8:

scissors, nasal, 82

seasonal variations in growth, $7 \overline{7}, 78$

secondary thiekening, 159

secondary tumors, 221 seed primordia, eultivation of, $125,151,206$

seedling roots, as culture material, 117

segregation of functions, 4

segregation of tissues and cells for study, 5

Seifriz, 62

Seitz filters, 107

semi-solid culture media, 101, 102

Sempervivum, 28

serum, as nutrient, 90

serum bottles, 73

Shapiro; Brachet and S., 218, 256

shock of exeision, 48

Shreve; MacDougal and S., 44, 260

silica still, 70

silver still, 70

sink, 69

Sinnott and Bloch, 44, 58, 126, 251

Skoog; Thimann and S., 99, 210, 255,260

slides, depression (hollow ground ), 130,149

slides, piereed, $80,81,130,149$

Smith, L. H., $28,47,251$

Smith, R. S.; Knudson and S., 32,239

Snow, 210, 211, 254

soap, 71

sodium, 92

sedium acid phosphate, 103, 104, 105

sodium ehloride, 176

sodium pyrophosphate, 71

sodium sulfate, 103,104

softener, water, 70

" soft', glass eover glasses, 150

soil solution, 56

Solanum, 28

Solanum tubcrosum, 233

Solidago, 253

somatic cells, totipoteney of, 30

Spemann, 30, 219, 258; $\mathbf{S}$. and Geinitz, 219, 259 
Sperry; Naylor and S., 44, 125, 250

Spirodela, 246

squash fruit, aseptic seeds from, 118

squash stem, cultivation of procambium, 49

stamen hairs, cultivation of, 20

Stanley, 200, 259

starch, resorption of, 193

statistical analysis, $165-168$

statistical significance of results, 166

stele, 195

Stellaria media, 193, 235

stem tips, 50

sterilization of nutrients, 106, 107

sterilizer, Arnold, 69, 107

Steward, Berry, and Broyer, 56, 246

stills, 69

stinging hairs, cultivation of, 20

Stingl, 45, 58, 233, 251

stipular gemmae of Marattia, as culture material, 125

stock cultures, 113, 132

stomatal guard cells, eultivation of, 20

stone cells, 222

stone fruits, 45

Stout and Arnon, 70, 93, 237; Armon and S., 70, 93, 237

Strangeways, 230

Stukeley, 66

substrata, nutritive (see nutrients)

sucrose, 95, 96, 103, 105, 106, 185

Suessenguth; Essenbeck and S., 45,233

sugar, 71

sulfur, 70,92

sulfuric acid, 71, 105

sunflower, cultivation of callus

from, 52

sunflower roots, 105

suspensor, 219
Swingle; Priestley and S., 48, 250

Symphoricarpus, 28

$\mathrm{T}$

tap water, 70,92

T'araxacum, 220

temperature, optimal, 76, 144, 145

temperature effects, $57,76,144$, 145

temperature gradients, 218

terminal growing points, 50

terminal meristems, 50 et seq.

test-tube cultures, 131, 146, 147

Theophrastus, 42, 260

thiamin, 97, 100, 103, 104, 106, 108,185

thiazole, 97

Thielman (Tauja-Thielman), $28,95,235,239 ; \quad T$. and Bérziñ, 94, 247; T. and Peléce, $98,99,244$

Thimann, 99, 211, 244, 255; T. and Koepfli, 210, 255; T. and Skoog, 99, 210, 255, 260; T. and Went, 210, 244

Thunbergia, 28

tile, for walls, 75

“tinctura metallorum, " 66

tissue broth, as nutrient, 90

tissue culture, $9,12,35$

tissue juices, toxicity of, 27

titaninm sulfate, 105

titration of virus concentration, 200,201

tobaceo, eultivation of procambium, 49

tobaceo eallus, 105

tobaceo fruits, aseptic seeds from, 118

tomato roots, $40,69,64,98,105$, $113,179,180,181,182$

tomato seeds, 118

totipotency, 4, 8, 12, 30, 35, 44, 212

toxicity of gas, 75,76

toxins, inorganie, 202

toxins, organic, 202 
Tradescantia, 20,28

transfer room, 74-76

transplantation, 7, 8, 15, 30, 219

traumatin, 114

trays, enamel and galvanized, 72 trees, cambium, cultivation of, 49

trees, cambium, cultures of, 127 , 213

trees, cambium, excision of, 121123

trichomes, loss of meristematic function in, 44

Trifolium repens, 55

Triticum, 28

Triturus torosus, 257

tropic response, auxin as factor in, 212

tropisms, 192

Tukey, $45,58,73,125,220,233$, 235,251

tumefacient property of cells, 221

tumor metabolism, 184

tumors, 221

Tyrode, 90, 239

Tyrode's solution, 90

ty rosinase, 193, 205

tyrosine, 194, 205

\section{U}

Ćlehla, 28, 44, 101, 235

Ilmus campestris, 248

ultraviolet light, use as sterilizing agent, 118

undifferentiated tissues, eultivation of, 34,133

ungerminated embryos as culture material, 46-48

uniformity of cultures, 133

Urtica, 20

“'Uspulin,' as disinfectant, 119

V

vaccines, cultivation of, 184

van Tiegham cell, 81,149

variability, 133 et seq.

vascular strands, disorganized, 216 vascular strands, organization of in culture, 190

vascular tissue, importance for regeneration, 19

vaseline for sealing slide cultures, 151, 152

Vicia faba, 250, 252, 255

Viola, 28

Virchow, 5, 259

virus molecules, determination of shape, 79

viruses, cultivation of, 120,199 , 200

Viscum, 202

vitamin $B_{x}, 96,105$ (see thia$\min$ )

vitamin $B_{6}, 98,105,108,172$ (see pyridoxine)

vitamins, $93,96,99$

vitreous sink, 69

Vöchting, 5, 7, 8, 30, 217, 251

Vogelaar and Erlichman, 22, 71, $90,239,244,261$

Vogt, 218, 230, 259

wall color, 75

Warburg, 184, 189, 247; W. and Kubowitz, 1S4, 247

Ward; Rivers and W., 184, 259 washing of air, 75

washing glassware, 71,72

wateh glasses, Maxinuow, 81

water, distillation of, 70,92

water, filtration, 92

water, purity, $70,91,92$

water softener, 70,92

Wehnelt, 57, 125, 126, 244

weiglit vs. lengtlı (as measure of growth ), 159

Weiss, 259

Went, 210, 211, 212, 219, 220, 255; Bouillenne, R., and W., 210 , 248; Thimann and W., 210,244

Werckmeister, 45, 234

Westinghouse immersion heater, 83

wheat roots, 105

white elover, root cap, 61 
white oak, 55

White, P. R., $31,34,36,39,45$, $49,50,53,54,55,57,58,61$, $63,64,76,77,92,93,95,96$, $97,98,99,100,101,105,118$, $119,120,122,123,125,131$, $133,139,144,145,146,151$, $159,175,176,180,184,185$, $188,190,191,192,193,194$, $195,196,197,198,200,202$, 203 , 206, 20\%, 208, 209, 214, $217,218,220$, 223, 226, 230, $232,233,234,235,237,239$, $240,244,247,251,252,259$; W. and Braun, 52, 124, 221, 252; Braun and W., 221, 259 White, V. B.; Robbins and W., 27, 35, 95, 133, 203, 232, 240; Robbins, Bartley, and W., 35, 231; Robbins, W., Mcclary, and Bartley, 93, 237

Wilcoxon; Zimmerman and W., 255

Wilhelm, 58, 252

Willmer, 230

willow, cambium cultures, 105, 123

willow, polarity in, 7
Wilson, 119, 260

Winkler, 58, 252

wire racks for cover glasses, 130 , 152

wound healing, 2, 21, 43

wound hormones, 114

\section{X}

xylem fibers, loss of meristematic function by, 44

xylem parenchyma, proliferative capacity, 58

xylem sap, 9,27

\section{Y}

yeast, brewer's vs. baker's, 101 yeast, extract as nutrient, 32 , 100,105

\section{$\mathrm{Z}$}

Zimmerman, 56, 247; $Z$. and Hitchcock, 210, 255; Z. and Wilc ox on, 210,255 ; Z., Crocker, and Hitchcock, 210, 255

zinc, $70,92,96$

zine sulfate, 103, 104, 105

Zizania aquatica, 233 




\section{(1)}

\section{4}

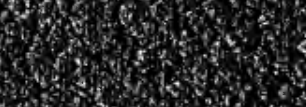

3.

tow

(3)

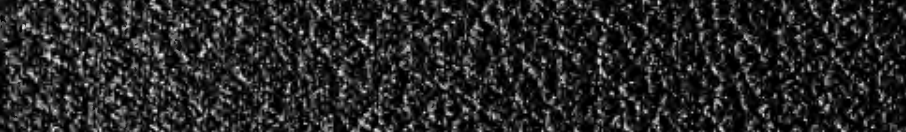

1.

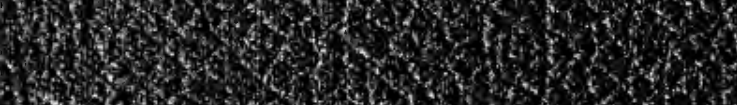

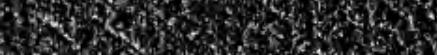

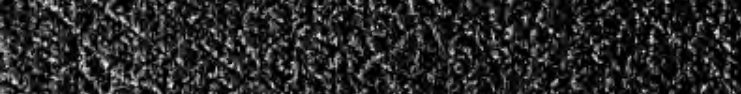

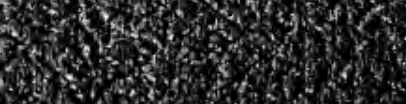

(1)

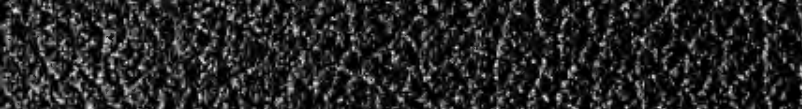

(C)

3. 4. (1)

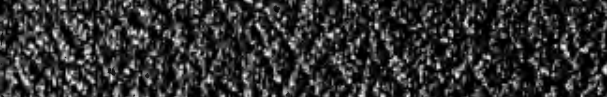
3.

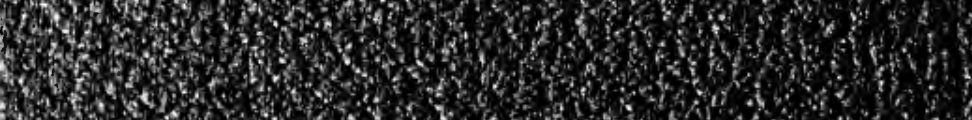
7. (3) (3)

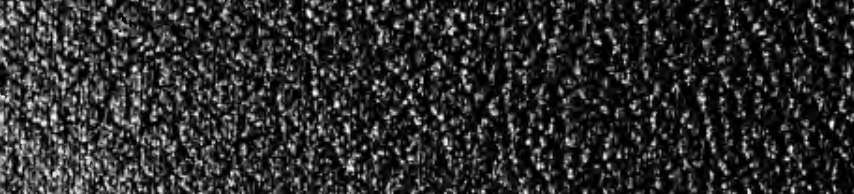

